\title{
APT Blanket System Loss-of-Coolant Accident (LOCA) Based on Initial Conceptual Design - Case 1: External HR Break Near Inlet Header
}

by

L. L. Hamm

Westinghouse Savannah River Company

Savannah River Site

Aiken, South Carolina 29808

S. Y. Lee

M. A. Shadday

F. G. Smith, III

This paper was prepared in connection with work done under the above contract number with the U. S. Department of Energy. By acceptance of this paper, the publisher and/or recipient acknowledges the U.S. Government's right to retain a nonexclusive, royalty-free license in and to any copyright covering this paper, along with the right to reproduce and to authorize others to reproduce all or part of the copyrighted paper. 


\section{DISCLAIMER}

Portions of this document may be illegible in electronic image products. Images are produced from the best available original document. 


\section{APT BLANKET SYSTEM LOSS-OF-COOLANT ACCIDENT (LOCA) BASED ON INITIAL CONCEPTUAL DESIGN -}

\section{Case 1: External HR Break Near Inlet Header}

L. Larry Hamm

Si Young Lee

M. Andy Shadday

Frank G. Smith, III

Westinghouse Savannah River Company Sávannah River Site Aiken, SC 29808

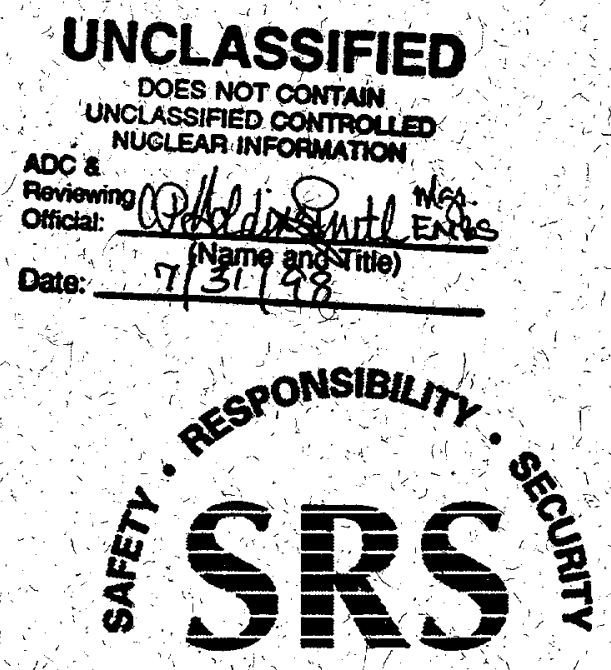




\section{DISCLAIMER}

This report was prepared as an account of work sponsored by an agency of the United States Government. Neither the United States Government nor any agency thereof, nor any of their employees, makes any warranty, express or implied, or assumes any legal liability or responsibility for the accuracy, completeness, or usefulness of any information, apparatus, product, or process disclosed, or represents that its use would not infringe privately owned rights. Reference herein to any specific commercial product, process, or service by trade name, trademark, manufacturer, or otherwise does not necessarily constitute or imply its endorsement, recommendation, or favoring by the United States Government or any agency thereof. The views and opinions of authors expressed herein do not necessarily state or reflect those of the United States Government or any agency thereof.

This report has been reproduced directly from the best available copy.

Available to DOE and DOE contractors from the Office of Scientific and Technical Information, P.O. Box 62, Oak Ridge, TN 37831; prices available from (615) 576-8401.

Available to the public from the National Technical Information Service, U.S. Department of Commerce; 5285 Port Royal Road, Springfield, VA 22161. 
KEYWORDS:

Accelerator Production of Tritium

Blanket System

Conceptual Design

TRAC Code

FLOWTRAN-TF Code

System Model

Detailed Bin Model

Safety Analysis

RETENTION - Permanent

\section{APT BLANKET SYSTEM LOSS-OF-COOLANT ACCIDENT (LOCA) BASED ON INITIAL CONCEPTUAL DESIGN -}

\section{Case 1: External HR Break Near Inlet Header}

\section{SAVANNAH RIVER TECHNOLOGY CENTER}

L. Larry Hamm

Si Young Lee

M. Andy Shadday

Frank G. Smith, III

Publication Date: July 1998

Westinghouse Savannah River Company Savannah River Site

Aiken, SC 29808

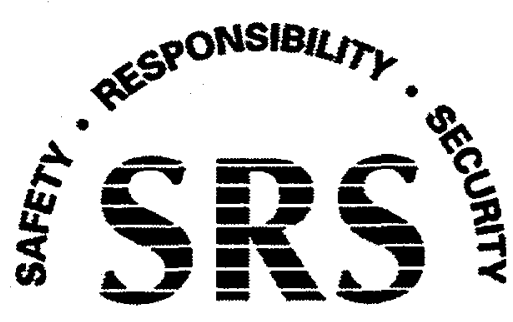

Prepared for the U.S. Department of Energy under Contract No. DE-AC09-96SR18500 
DOCUMENT: WSRC-TR-98-0059

TITLE: APT BLANKET SYSTEM LOSS-OF-COOLANT ACCIDENT (COCA) BASED ON INITIAL CONCEPTUAL DESIGN -

Case 1: External HR Break Near Inlet Header

APPROVALS

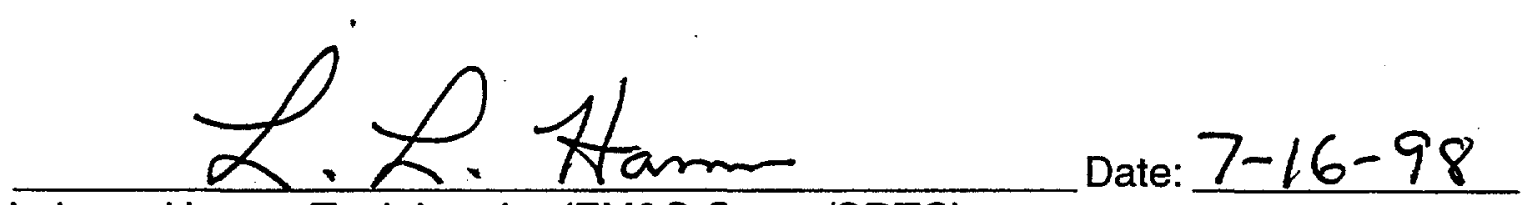

L. Larry Hamm, Task Leader (EM\&S Group/SRTC)

Date: $7-20-98$

Si Young Lee, Co-author (EM\&S Group/SRTC)

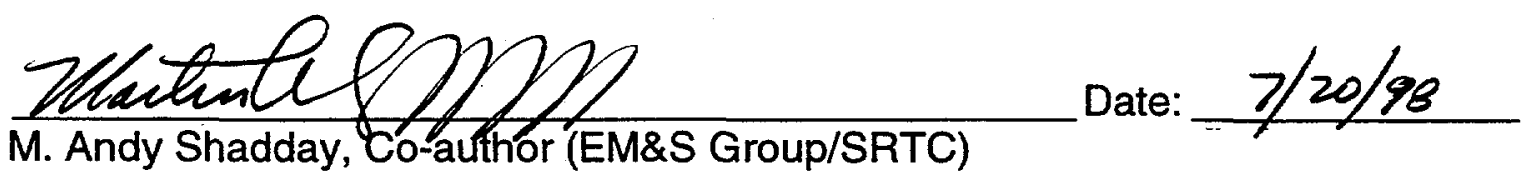

Frank is set 4

Date:

$1 / 20 / 98$

Frank G. Smith, III, Co-author (PC\&C Group/SRTC)
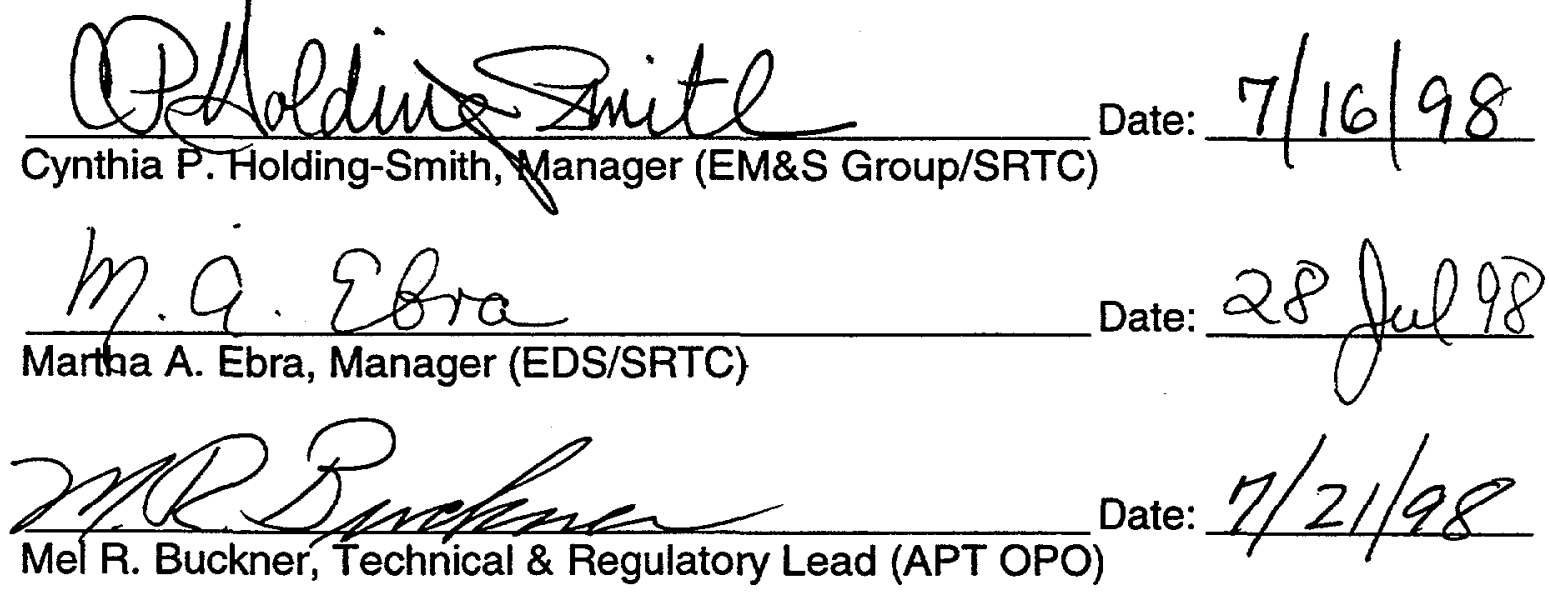

The internal technical review function is being performed at the APT project level and is coordinated through LANL.

-ii- 


\section{Table of Contents}

1 Introduction

2 TRAC 1-D System Model 3

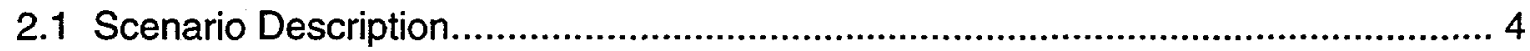

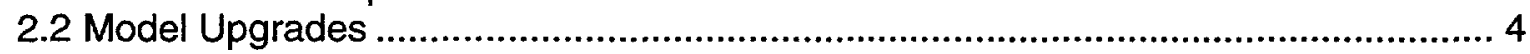

2.3 Initial Conditions ............................................................................................. 4

2.4 Transient Boundary Conditions...................................................................... 5

2.5 Trips and Controls ......................................................................................... 5

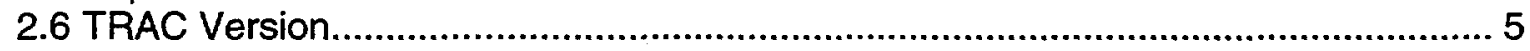

3 TRAC System Model Results $\quad 8$

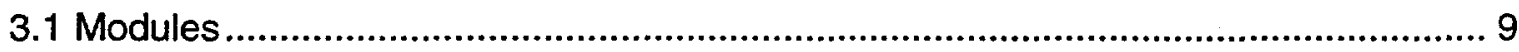

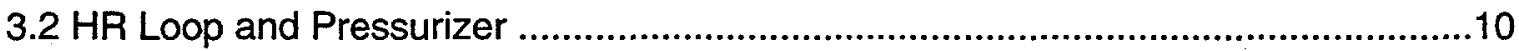

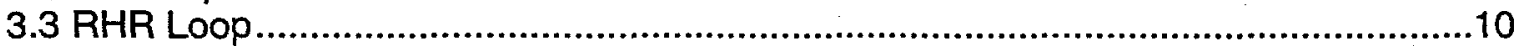

3.4 Cavity Vessel and Flood System ........................................................................10

4 FLOWTRAN-TF Detailed Bin Model

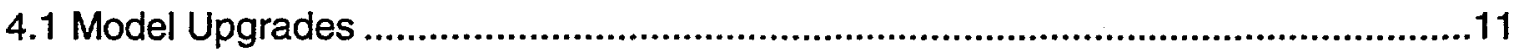

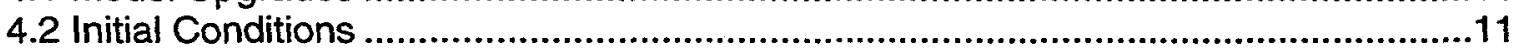

4.3 Transient Boundary Conditions.............................................................................11

5 FLOWTRAN-TF Bin Model Results 13

6 Conclusions $\quad 19$

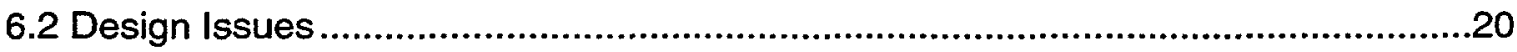

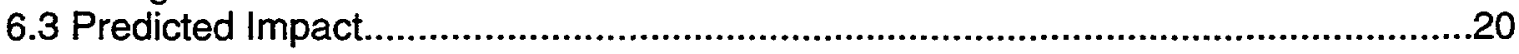

7 References $\quad 22$

Appendix A: TRAC Model Component Nomenclature

Appendix B: LOCA (Case 1) TRAC Results

Appendix C: TRAC Standard Input File for LOCA Case 1 (with Beam Shutdown and Active RHR)

Appendix D: TRAC Graphics Input File for LOCA Case 1 (with Beam Shutdown and Active RHR)

Appendix E: FLOWTRAN-TF Input File for LOCA Case 1 (with Beam Shutdown and Active RHR) 


\section{List of Figures}

Figure 1-1 Decay heat power fractions of full power for various types of blanket modules.

Figure 1-2 Break location for the external LOCA Case 1 (External HR Break Near Inlet Header) .2

Figure 2-1 Top cross-sectional face map of 6 lumped blanket system modules.........8

Figure 4-1 Finite element mesh of APT reference 1 blanket plate.

Figure 4.3-1

Inlet boundary conditions for LOCA Case 1 .

Figure 5-1 Maximum aluminum temperature for LOCA Case 1 ............................... 14

Figure 5-2 Blanket axial power shape.

Figure 5-3

Figure 5-4 Surface heat fluxes for LOCA Case 1, axial level 11, channels 1-4....... 16

Figure 5-5 Surface heat fluxes for LOCA Case 1, axial level 11, channels 5-8

\section{List of Tables}

Table 2-1 6 lumped blanket module system model used for the present PSAR analysis.

Table 2.5-1

Table 4.2-1 Trip signals used in the LOCA simulation of Case 1. 7 Initial conditions for FLOWTRAN-TF LOCA analysis. ...........................11

Table 6.1-1 FLOWTRAN-TF model results under LOCA Case 1 coñditions. 


\section{Introduction}

The APT blanket system has about $57 \mathrm{MW}$ of thermal energy deposited within the blanket region under normal operating conditions from the release of neutrons and the interaction of the high energy particles with the blanket materials. This corresponds to about $48 \%$ of total thermal energy deposited in the APT target/blanket system [1]. The deposited thermal energy under normal operation conditions is an important input parameter used in the thermal-hydraulic design and accident analysis. After the APT system shutdown, decay power drops rapidly. Figure 1-1 shows transient decay power after shutdown as a fraction of steady-state power for the $1700 \mathrm{Mev}$ APT design with 13 tungsten ladders [2]. Thus, it is necessary to provide an alternative means of cooling the blanket modules to prevent structural damage of the blanket system and the possible release of radioactive contamination and hazardous materials such as lead and mercury following severe accidents like the double-ended guillotine break (DEGB). Major components of a typical blanket heat removal system include heat exchangers, piping, and pumps. The blanket heat removal system is comprised of the primary heat removal (HR) system, the secondary heat removal system, the primary residual heat removal (RHR) system, and the secondary RHR system. These systems provide the heat removal function for all the thermal energy deposited within the blanket modules. The current blanket coolant system has one primary HR, one secondary HR, two $100 \%$ primary RHR, and two $100 \%$ secondary RHR. Five cases of external loss-of-coolant accident (LOCA) scenarios were simulated for large pipe breaks of the primary heat removal (HR) and residual heat removal (RHR) systems external to the cavity vessel in order to identify worst transient accident scenario [3]. In this report, Case 1, as one of the five cases of the external LOCA's, simulated the pipe break of the external HR system near the inlet fixed header using a one-dimensional TRAC system model with 6 lumped modules. The break location for Case 1 is shown in Fig.1-2. The model results are used to determine thermal-hydraulic safety margins. The results also provide boundary conditions for detailed FLOWTRAN-TF bin model calculations. The results of the accident Case 1 simulation are documented in this report. 


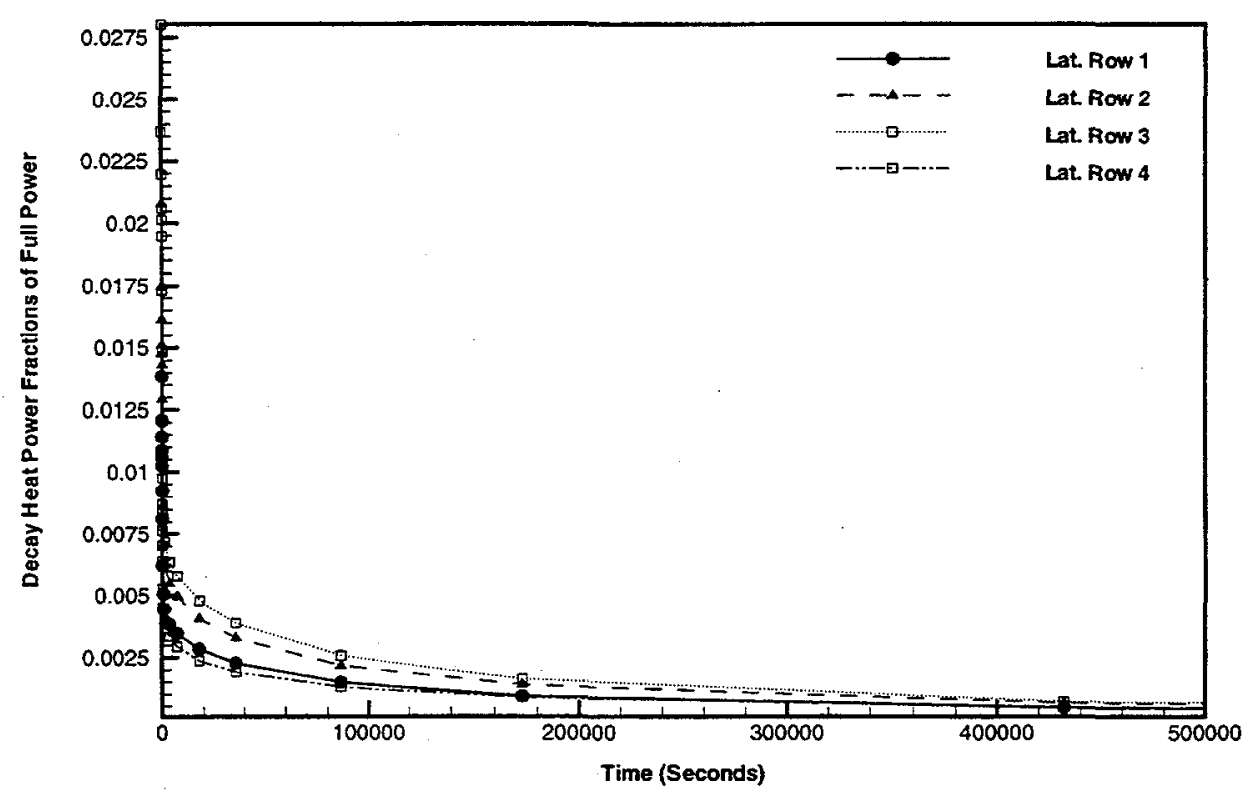

Figure 1-1 Decay heat power fractions of full power for various types of blanket modules.

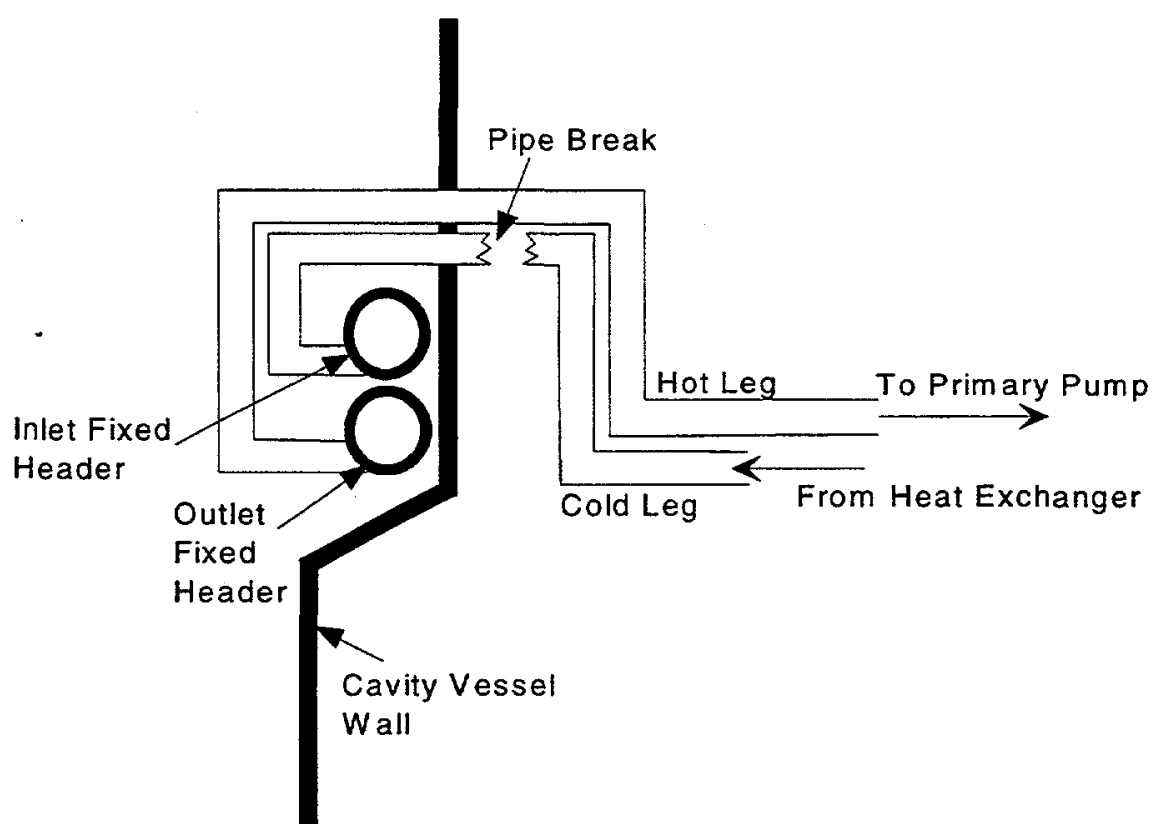

Figure 1-2 Break location for the external LOCA Case 1 (External HR Break Near Inlet Header) 


\section{TRAC 1-D System Model}

The current blanket system consists of 16 unique blanket modules based on the existing cruciform-type design components (the necessary design specifications required to develop a plate-type set of modules is currently not available but should be forthcoming in late February). Each module is separately connected to the two fixed coolant headers. A lumping strategy was developed based on module similarity, deposited power levels, and locations that resulted in a total of six separate lumped modules and reduced computational effort requirements. The six lumped modules are, respectively: the first-row lateral modules; the second-row lateral modules; the decoupler / Row 1 downstream module; the Row 1 / Row 2 downstream module; the Row 2 / Row 2 downstream module; and the remaining low-power modules, which consist of the upstream module, the four bottom modules, and the two top modules. Figure 2-1 shows a cross-sectional face map for the 6 module blanket system. Table 2-1 summarizes module description, thermal deposited power, and connection pipe size of each of the 6 blanket modules as modeled in the one-dimensional lumped approach. Figure A-1 shows the locations of all the six modules and the internal piping connections as included in the 1-D TRAC system model. The TRAC components and piping connections for the HR, pressurizer, RHR blanket coolant systems, and cavity vessel flood system are also shown in Figs. A-2 to A-6. Table A-1 lists all the blanket system components, number of cells for the components, and the component descriptions for the present one-dimensional lumped blanket system model. The present 6 lumped module blanket system model includes 170 components and 152 junctions with 10 trip control signals using for the transient LOCA accident simulations. Detailed system model descriptions are provided in Ref. [3].

\subsection{Scenario Description}

As one of design basis accidents, a cold-leg large break LOCA external to the cavity vessel was simulated by restarting steady-state normal operation results for the onedimensional 6 module blanket system model in a transient mode. Normal operation conditions for the key blanket system parameters are shown in Table A-2. Detailed description of the lumped 6 module TRAC system model is provided in Ref. [3].

The current blanket coolant system has one primary HR, one secondary HR, two $100 \%$ primary RHR, and two $100 \%$ secondary RHR. Under steady-state normal operating conditions the blanket module system is connected to a single main primary loop, with three $50 \%$ pumps in parallel. Two pumps are normally operating and the remaining pump is available for immediate startup in the event of failure of a running pump. The cooling loop has two $50 \%$ heat exchangers in parallel. The two RHR primary loops are both sized to accommodate $100 \%$ of the decay heat removal requirements. Currently, the RHR components are sized for approximately $4 \%$ of the full power flow, 1569 $\mathrm{kg} / \mathrm{sec}$. Each of the RHR primary loops has one heat exchanger and one pump. The current baseline design has the RHR systems shutdown in standby mode during normal operation to enhance the system's response to some design basis accident scenarios such as LOCA's.

A large break loss-of-coolant accident (LOCA) for Case 1 was simulated as a pipe break near the inlet fixed header of the primary HR system external to the cavity vessel. The break location for accident simulation of Case 1 is component number 65 shown in Fig. 2.1-1. When pipe component 65 is broken for the Case 1 LOCA simulation, the system 
will rapidly depressurize and the RHR pump will reach full speed in about 15 seconds after the accident. Two primary HR pumps are tripped off with time delay after the accident. Detailed control signals for the key component operations will be provided later.

\subsection{Model Upgrades}

Component action tables for the break component and check valves are updated for the Case 1 accident simulation. Component action tables for HR and RHR check valves are based on the S-shaped forcing function values. Constrained steady-state (CSS) capabilities are added to the TRAC normal operation system model. Signal variables and trip signals of the system model are also updated by using the control procedure for the Case 1 accident scenario described in Ref. [3].

\subsection{Initial Conditions}

Before simulating the accident condition, steady-state results under normal operation conditions are required to provide initial input to the transient LOCA simulation model of Case 1 (see Ref. [4]). The initial steady-state normal operation (NO) conditions of the APT blanket system were obtained by specifying maximum pump rotational speeds of the two HR pumps with desired total liquid flowrate under the constrained steady-state (CSS) controller option. The initial temperatures for the pressurizer and the RHR system components are $40 \mathrm{C}$. Table A-2 shows the initial steady-state values for the key system parameters of the blanket system.

\subsection{Transient Boundary Conditions}

The TRAC system model is documented in the report for the steady state NO calculations $[3,4]$. The steady-state NO TRAC run was restarted in transient mode to initiate the LOCA simulation of Case 1. The break component was a single-cell pipe component (component 65) located just outside the cavity vessel wall. The break location was selected to be close to the cold-leg fixed header where the pressurizer surge line is connected. For the LOCA initiation, the break component 65 was replaced two break components using transient pressure boundary conditions at the both ends of the break component to simulate a double guillotine break. The break components were set to ramp down from the NO steady-state pressure to atmospheric pressure in 0.1 second after the accident. Additionally, the pressurizer boundary condition was changed from a constant pressure break boundary to a zero fill (no flow) boundary. This is done to remove the possible pressure control of the pressurizer during the LOCA accident.

\subsection{Trips and Controls}

Power to the two HR pumps and the beam were tripped 0.2 seconds after the pressurizer surge line pressure dropped to $0.68745 \mathrm{MPa}(99.70 \mathrm{psia})$ corresponding to $95 \%$ of the pressurizer surge line pressure. The delay time chosen for the accident simulations was obtained by doubling the estimated response time for the signal transducers to actuate the component hardware. The beam trip was simulated by changing the steady-state NO power in the heat structure of each blanket module to the time dependent decay power curve. Figure 1-1 shows transient decay power curves for 
the blanket heat structures. The beam and the two HR pump power trips actually occurred about 0.21 seconds after the initiation of the transient accident. The RHR pump power signal was set to actuate without delay after a $5 \%$ reduction of the pressurizer surge line pressure. The RHR pump was modeled to attain full speed (94.35 rad/sec) within 15 seconds after the accident by using the component action table with S-shaped forcing function values. Check valves on the discharge sides of the $\mathrm{HR}$ and RHR pumps are actuated to avoid flow reversal immediately after the initiation of the LOCA accident. If flow reversal occurs during accident conditions, HR and RHR check valves are set to be closed immediately. Table 2.5-1 lists all the trip signals and controls used for the Case 1 accident simulation.

\subsection{TRAC Version}

This transient model was run using TRAC-PF1/MOD2 version 5.4.28a [10]. A modified version of TRAC to generate graphics files was employed [9]. 
Table 2-1 6 lumped blanket module system model used for the present PSAR analysis.

\begin{tabular}{|c|c|c|c|}
\hline $\begin{array}{l}6 \\
\text { Lumped } \\
\text { Modules }\end{array}$ & $\begin{array}{l}\text { Prototypic } 16 \text { Full Blanket } \\
\text { Modules }\end{array}$ & $\begin{array}{c}\text { Thermal Deposited } \\
\text { Power } \\
\text { Downflow I Upflow I } \\
\text { Total Power }\end{array}$ & $\begin{array}{l}\text { Plpe } \\
\text { Size } \\
\text { (inch) }\end{array}$ \\
\hline Module 1 & $\begin{array}{l}\text { Front } 1^{\text {st }} \text { Lateral Dec. / Row } 1 \\
\text { Module } \\
\text { Back } 1^{\text {st }} \text { Lateral Dec. / Row } 1 \\
\text { Module }\end{array}$ & $\begin{array}{l}\text { 8.222 MW / } \\
15.768 \mathrm{MW} / \\
23.990 \mathrm{MW}\end{array}$ & 7.500 \\
\hline Module 2 & $\begin{array}{l}\text { Front } 2^{\text {nd }} \text { Lateral Row } 2 / \text { Row } 3 \\
\text { Modules } \\
\text { Back } 2^{\text {nd }} \text { Lateral Row } 2 / \text { Row } 3 \\
\text { Modules }\end{array}$ & $\begin{array}{l}3.060 \mathrm{MW} / \\
7.660 \mathrm{MW} / \\
10.720 \mathrm{MW}\end{array}$ & 4.750 \\
\hline Module 3 & $\begin{array}{l}1^{\text {st }} \text { Downstream Dec. / Row } 1 \\
\text { Module }\end{array}$ & $\begin{array}{c}0.744 \mathrm{MW} / 2.812 \mathrm{MW} / \\
3.556 \mathrm{MW}\end{array}$ & 3.750 \\
\hline Module 4 & $\begin{array}{l}2^{\text {nd }} \text { Downstream Row } 1 / \text { Row } 2 \\
\text { Module }\end{array}$ & $\begin{array}{c}.924 \mathrm{MW} / 5.412 \mathrm{MW} / \\
9.336 \mathrm{MW}\end{array}$ & 5.375 \\
\hline Module 5 & $\begin{array}{c}3^{\text {rd }} \text { Downstream Row } 2 / \text { Row } 2 \\
\text { Module }\end{array}$ & $\begin{array}{c}1.355 \mathrm{MW} / 1.811 \mathrm{MW} / \\
3.167 \mathrm{MW} \\
\end{array}$ & 6.000 \\
\hline Module 6 & $\begin{array}{c}\text { Low Power Modules } \\
\text { Blanket Upstream Dec. / Row } 2 \\
\text { Module } \\
\text { Lower Front Dec. / Row } 2 \text { Module } \\
\text { Lower Front Row } 2 \text { / Row } 2 \\
\text { Module } \\
\text { Lower Back Dec. / Row } 2 \text { Module } \\
\text { Lower Back Row } 2 \text { / Row } 2 \\
\text { Module } \\
\text { Upper Front Row } 2 \text { / Row } 2 \\
\text { Module } \\
\text { Upper Back Row } 2 \text { / Row } 2 \\
\text { Module }\end{array}$ & $\begin{array}{c}\text { (Horizontal Flow) } \\
\text { o MW / } \\
5.712 \mathrm{MW} / \\
5.712 \mathrm{MW}\end{array}$ & 3.875 \\
\hline $\begin{array}{c}\text { Total } \\
\text { Deposited } \\
\text { Power }\end{array}$ & & $\begin{array}{l}17.305 \mathrm{MW} / 39.175 \\
\mathrm{MW} / 56.480 \mathrm{MW}\end{array}$ & \\
\hline
\end{tabular}


Table 2.5-1 Trip signals used in the LOCA simulation of Case 1.

\begin{tabular}{|c|c|c|c|}
\hline $\begin{array}{l}\text { Stgp } \\
\text { Signal }\end{array}$ & $\begin{array}{l}\text { Control } \\
\text { Component }\end{array}$ & $\begin{array}{c}\text { Signal Variables } \\
\text { D Number } \\
\text { (Control Variable) }\end{array}$ & Signal Values \\
\hline 101 & $\begin{array}{l}\text { Fill boundary for } \\
\text { secondary heat } \\
\text { exchanger side }\end{array}$ & 1 (time) & $1.0 \mathrm{e}-06 \mathrm{sec}$ \\
\hline 102 & $\begin{array}{l}\text { Cavity flood system } \\
\text { valve }\end{array}$ & $\begin{array}{l}10 \text { (cavity vessel } \\
\text { pressure) }\end{array}$ & valve closed \\
\hline 103 & RHR check valve & 1 (time) & $1.0 \mathrm{e}-06 \mathrm{sec}$ \\
\hline 104 & Heat structure & $\begin{array}{c}7 \text { (pressurizer pressure) } \\
\text { and time delay }\end{array}$ & $\begin{array}{l}0.2 \text { sec delay after } 5 \% \\
\text { reduction of pressurizer surge } \\
\text { line pressure }\end{array}$ \\
\hline 105 & RHR pump & $\begin{array}{c}7 \text { (pressurizer pressure) } \\
\text { and time }\end{array}$ & $\begin{array}{l}\text { full speed in } 15 \mathrm{sec} \text {. after } 5 \% \\
\text { reduction of pressurizer surge } \\
\text { line pressure }\end{array}$ \\
\hline 106 & Primary HR pump & $\begin{array}{c}7 \text { (pressurizer pressure) } \\
\text { and time delay }\end{array}$ & $\begin{array}{l}0.2 \mathrm{sec} \text { delay after } 5 \% \\
\text { reduction of pressurizer surge } \\
\text { line pressure }\end{array}$ \\
\hline 107 & $\begin{array}{l}\text { Primary } \mathrm{HR} \text { check } \\
\text { valve }\end{array}$ & $\begin{array}{c}1 \text { (time) and action table } \\
\text { (S-shaped forcing } \\
\text { function) }\end{array}$ & $1.0 \mathrm{e}-08 \mathrm{sec}$ \\
\hline 108 & $\begin{array}{c}\text { Cavity vessel check } \\
\text { valve }\end{array}$ & 1 (time) & valve closed \\
\hline 109 & $\begin{array}{l}\text { Cavity vessel check } \\
\text { valve on the HR } \\
\text { side }\end{array}$ & 1 (time) & valve closed \\
\hline 110 & $\begin{array}{l}\text { Cavity vessel vent } \\
\text { valve }\end{array}$ & 7 (pressurizer pressure) & valve closed \\
\hline
\end{tabular}




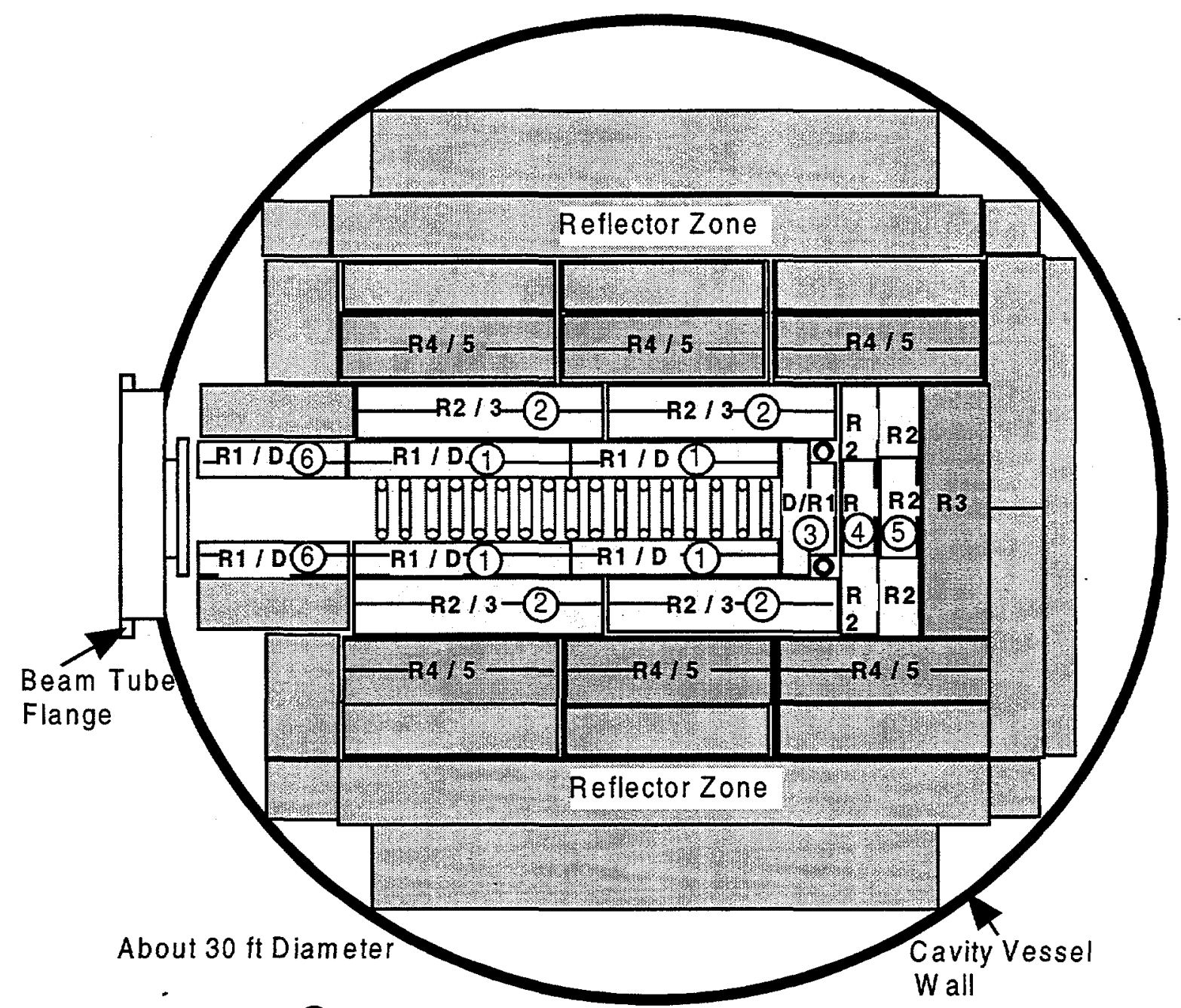

(6) Snout, 4 Bottom Modules, and 2 Top Modules

Figure 2-1 Top cross-sectional face map of 6 lumped blanket system modules.

\section{TRAC System Model Results}

The LOCA simulation model for the external cold-leg HR break near the fixed header (Case 1) was run for 600 seconds after the initiation of the accident. The simulation results show that the pressurizer and a single RHR system can mitigate this design basis accident without any damage to the blanket module system and structure. During the accident the liquid in the pressurizer was not drained completely so that gas inside the pressurizer is not entrained into the heat removal system loop. The temperature of the coolant water surrounding the blanket modules does not reach saturation temperature leading to phase change inside the blanket system under any of the LOCA accident transient times. The following subsections provide descriptions of the transient 
phenomena for the key blanket component systems observed in the accident simulation in more detail.

Results from the TRAC system model calculations are presented in graphical form in Appendix B. Appendix B1 shows output for the TRAC plenum components, Appendix B2 contains the output for pipe, pump and valve components while Appendix B3 shows output for the heat structures. A listing of the TRAC standard input file for LOCA Case 1 is in Appendix $\mathrm{C}$ and a listing of the graphics input file used to create the graphical output is given in Appendix D.

\subsection{Modules}

Figure A-1 shows the component layout of the internal blanket module system used in the TRAC system model. Transient results for coolant hydraulic parameters through the 6 blanket upward flow regions are graphically shown for the external LOCA Case 1 simulation in Figs. B2-24a through B2-24e. The results show rapid transient behavior for the flow channels of all the six blanket modules continuing up to about 100 seconds after initiation of the LOCA. During the first 20 seconds of rapid de-pressurization of the HR system, pump cavitation occurred at the pump suction sides, and then coolant flow decreased without flow reversal across the pump. At the same time, the RHR pump was actuated and RHR coolant water at $40 \mathrm{C}$ came into the internal hot blanket module system. As a result, the fluid temperatures of the six blanket modules dropped more quickly. After recovery from the HR cavitation, the RHR pump suction side cavitated around 40 seconds after the accident, but coolant flow decreased without flow reversal across the RHR pump. This caused the module fluid temperatures to rise for about 10 seconds by which time blanket system pressure was recovered. Eventually, small liquid flowrates controlled by the gravitational hydraulic head were established to the six blanket modules.

Figure B2-24e shows channel void fractions at the mid-planes of the six modules. These results show that the module 1 channel with the largest connection pipe size (7.5 inch) to the fixed header has the largest void fraction at 22 seconds of the transient time as a result of the HR pump cavitation and then this voidage was swept away quickly.

Figs. B3-26 through B3-43b show detailed graphical results for the solid structures of the six blanket modules. Maximum lead temperature was $152 \mathrm{C}$ during normal operation condition near the mid-plane of the first lateral module as shown in Fig. B3-26. Generally, solid temperatures decreased quickly up to 50 seconds and then after rising up about 2 to $3 \mathrm{C}$ for about 50 seconds the solid temperatures slowly decline following the trend of the decay heat curve shown in Fig. 1-1. Maximum aluminum cladding surface temperature was $93.5 \mathrm{C}$ during normal operation conditions at the mid-plane of the blanket module 1 and then it dropped to the minimum value (about $42 \mathrm{C}$ ) at the transient time of 50 seconds. After the HR and RHR cavitation (about 100 seconds), the aluminum surface temperatures started to approach a stabilized cooling condition.

\subsection{HR Loop and Pressurizer}

Figure A-2 shows the HR system component layout used for the one-dimensional TRAC system model. With the initiation of pipe break (component 65 ), the system pressure in the HR loop decreases rapidly. Figure B1-1a shows fixed header fluid pressures for the 
Case 1 LOCA simulation. Pressures in the hot and cold legs drop steeply following initiation of the LOCA accident. The results show that the cold-leg fixed header pressure decreased to one atmospheric pressure in 3.5 seconds and hot-leg pressure dropped to less than one atmospheric pressure within a second. After pump coastdown at about 60 seconds, the hot-leg fixed header pressure rises to near one atmospheric pressure. Pressures of both fixed headers are stabilized at about 55 seconds after the accident as shown in Fig. B1-1.

Figure A-3 shows the component layout for the pressurizer system. Figs. B2-15b to B2$15 \mathrm{e}$ show transient behaviors of the key thermal-hydraulic parameters for the pressurizer and surge line during the LOCA Case 1 accident. From these results, the liquid in the pressurizer was not drained completely during the accident so that gas inside the pressurizer is not entrained into the heat removal system loop. Void fraction in the surge line of the pressurizer was zero during the accident to satisfy the design requirement for the pressurizer component. No void was entrained into the HR loop through the surge line of the pressurizer during the entire transient time of the accident.

\subsection{RHR Loop}

Figure A-4 shows layout for the RHR system. The initial temperature for the RHR system was $40 \mathrm{C}$. Maximum RHR flowrate was about $4 \%$ of total full power liquid flowrate. The RHR system has a check valve on the RHR pump discharge to prevent flow reversal during the LOCA accident. The transient responses of the RHR system to the LOCA Case 1 scenario are shown in Figs. B2-16a to B2-16e and B2-17a to B2-17e. Figure B2-16a shows pressures for the RHR pump suction and discharge sides. Void in the RHR pump suction side was initiated at the pump suction side at about 9 seconds from the pump cavitation as shown in Fig. B2-16e. At that time the RHR check valve was activated to avoid backflow in the RHR system, and consequently the RHR flowrate was rapidly reduced. After water in the pressurizer reached the RHR pump at about 150 seconds after the accident, liquid flowrate was established in the RHR system.

Figure B2-17c shows the RHR primary heat exchanger inlet and outlet temperatures. The current Conceptual Design Report has the two 100\% RHR systems shutdown in standby mode during normal operation. Initial inlet temperature is the same as the steady-state stagnant RHR temperature of $40 \mathrm{C}$, and the RHR water temperature quickly increases as soon as the RHR pump circulates the water through the blanket modules internal to the cavity vessel.

\subsection{Cavity Vessel and Flood System}

Figure A-5 shows the TRAC component layout for the heat transfer connections between the blanket module heat structures and the cavity vessel. Figure A-6 shows the TRAC component layout for the cavity vessel and flood system. During the external LOCA Case 1 accident the cavity flood system pool is stagnant with an ambient temperature of $40 \mathrm{C}$. The cavity vessel has no liquid phase with an ambient temperature saturated at about 5 psia during the external LOCA accident. 


\section{FLOWTRAN-TF Detailed Bin Model}

The basic FLOWTRAN-TF model is described in Refs. [6,7] and was used in this version for the LOCA Case 1 analyses. The FLOWTRAN-TF model was developed to simulate the thermal-hydraulic conditions in a lateral Row 1 blanket module using the reference 1 plate-type design [5]. The areal mesh of the bin model is shown in Figure 41 along with the location and indexing used for the 12 discrete flow channels.

\subsection{Model Upgrades}

No modifications to the original model were required to for the LOCA Case 1 analysis.

\subsection{Initial Conditions}

Initial conditions for all of the flow transients are the normal operating conditions reported in Ref. [4]. The TRAC supplied initial conditions used in the FLOWTRAN-TF calculations are listed in Table 4.2-1.

\subsection{Transient Boundary Conditions}

Results from the TRAC external large-break LOCA transient were used to supply boundary conditions to the FLOWTRAN-TF code for detailed calculations of the thermal-hydraulic behavior of a single Row 1 blanket plate. The TRAC transient results used in these calculations were:

1. Total coolant flow to the lateral Row 1 blanket module taken from TRAC PIPE component 454.

2. Inlet cooling water temperature, pressure and void fraction taken from TRAC PLENUM component 350. The calculations used inlet flow as an applied boundary condition and inlet pressure was used only for physical property evaluations.

3. Outlet pressure taken from TRAC PLENUM component 330.

Inlet conditions derived from the TRAC system analysis are shown in Fig. 4.3-1 where the boundary conditions are plotted as transient values relative to the pre-incident conditions. The pre-incident flow to a single blanket plate is taken to be $1.488 \mathrm{~kg} / \mathrm{s}$. Since void fraction naturally falls between zero and one, absolute values of void fraction are plotted in the figure. For LOCA Case 1, a small amount of void fraction appears at the inlet to the coolant flow channels early in the transient. The TRAC system analysis also predicts a brief episode of flow reversal at about 80 seconds into the transient.

Table 4.2-1 Initial conditions for FLOWTRAN-TF LOCA analysis.

\begin{tabular}{|c|c|c|c|}
\hline & Pressure (MPa) & Temperature (C) & Void \\
\hline Channel Inlet & 0.686 & 53.04 & 0 \\
Channel Outlet & 0.584 & & \\
\hline
\end{tabular}




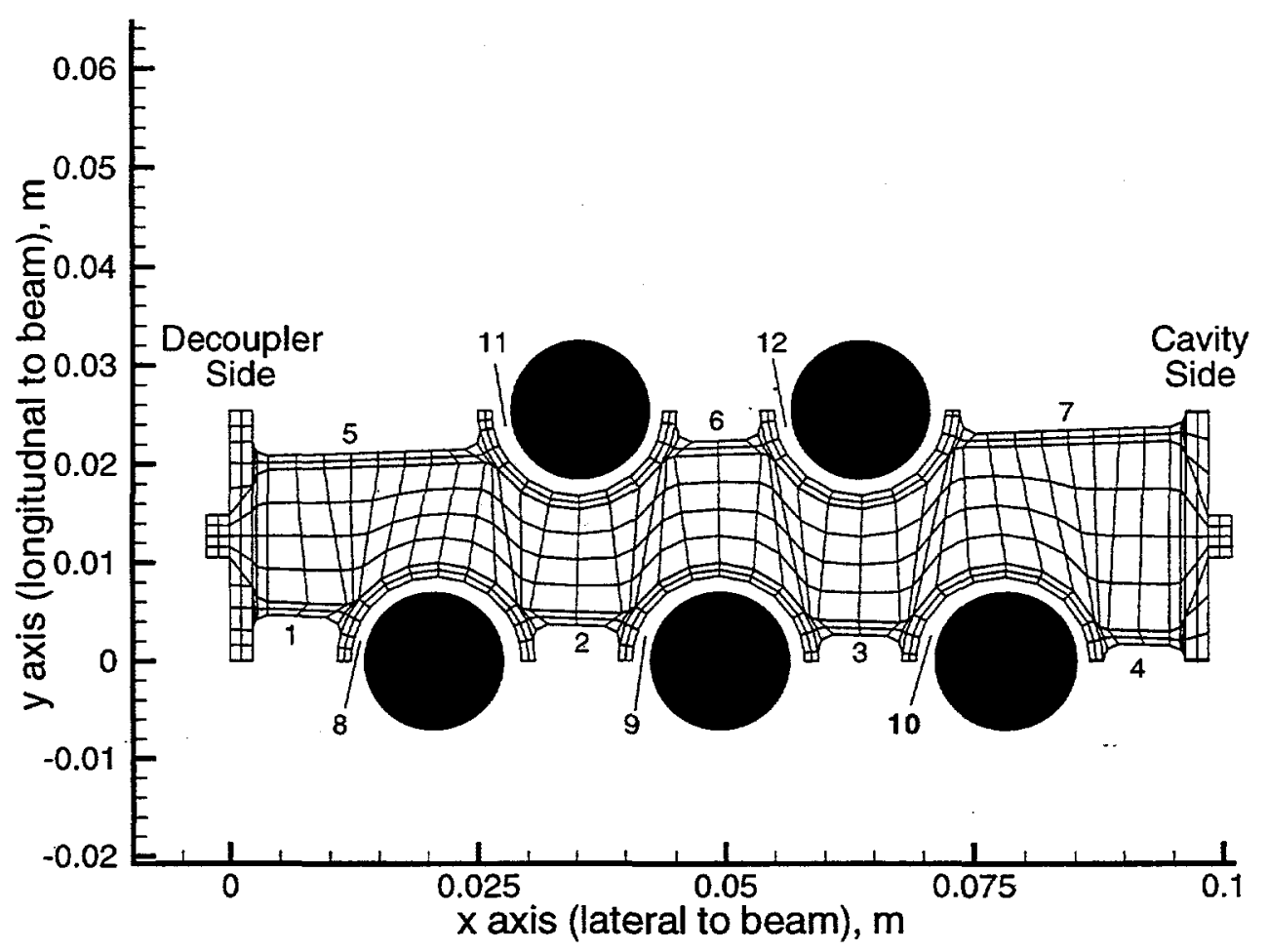

Figure 4-1 Finite element mesh of APT reference 1 blanket plate. 


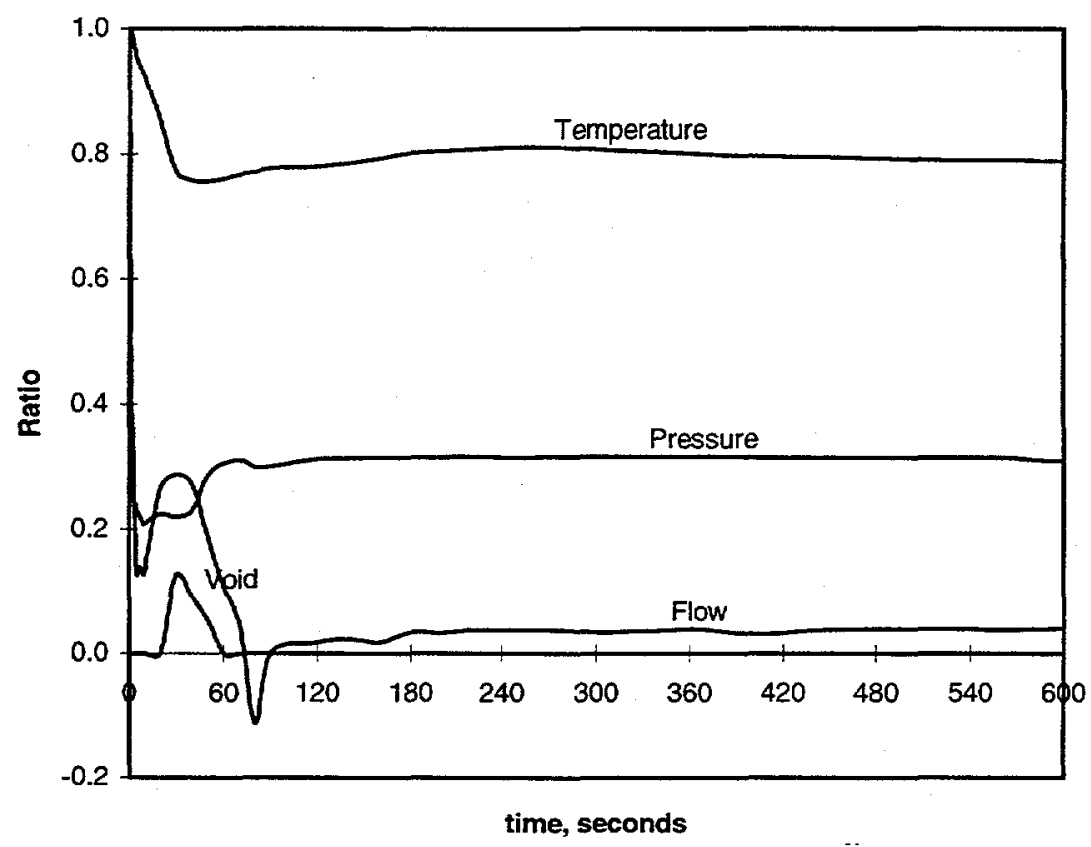

Figure 4.3-1 Inlet boundary conditions for LOCA Case 1.

\section{FLOWTRAN-TF Bin Model Results}

A listing of the input deck used for the FLOWTRAN-TF calculations of LOCA Case 1 is given in Appendix E. Some results from the FLOWTRAN-TF calculations are shown in Fig. 5-1 where the maximum aluminum temperature found anywhere in the plate cladding is plotted as a function of time into the loss-of-coolant accident transient. The initial maximum temperature of $100.0 \mathrm{C}$ is indicated on the ordinate since it is difficult to see the sudden temperature decrease that occurs within the first few seconds on the transients. Initially, the maximum aluminum temperature occurs on the side of the plate nearest the decoupler region and closest to the point of beam impact. It is assumed that the power is tripped 1.0 second after the start of the accident and that the preincident power is the nominal value $61.5 \mathrm{~kW}$.

It is clear from the metal temperatures shown in Fig. 5-1 that surface temperatures in the flow channels following beam trip are not close to local boiling conditions. To further illustrate the safety margins, operating surface heat fluxes $\left(q_{\mathrm{ohf}}\right)$ were compared to the heat fluxes predicted for onset of nucleate boiling $\left(q_{o n b}\right)$, onset of significant void formation $\left(q_{\text {osv }}\right)$ and the critical heat flux $\left(q_{\mathrm{chf}}\right)$. Since each of the 12 flow channels has 20 axial cells and at each axial level the surface is composed of from 8 to 17 surface nodes there are many (2760) surface heat fluxes at any time in the calculation. To reduce the number of data points, we have taken the approach of reporting the maximum heat flux at each axial position within each channel irrespective of the particular surface node where the maximum occurs. Further we can restrict the 
examination to the location of the peak axial heat fluxes. The axial power shape for the blanket module is shown in Fig. 5-2 along with the 20 cells that were used to discretize the axial dimension for the safety calculations. Highest operating surface heat fluxes were observed to occur in axial cells 10 through 15 .

To show some representative results, the operating surface heat flux and the calculated limits for Case 1 are shown in Figs. 5-3 through 5-5 from all of the flow channels at axial level 11. Case 1 had slightly higher metal temperatures than the other LOCA cases. Channels 1 and 5 are the rectangular flow channels nearest the decoupler side of the plate while channel 8 is the first annular flow channel on that side. This side of the plate absorbs the largest fraction of the deposited power but has a larger fraction of the coolant flow. Channels 4 and 7 are the rectangular flow channels nearest the cavity side of the plate where deposited power and coolant flow are lowest.

Results from other axial locations on the plate surface are similar demonstrating a substantial margin between the surface heat flux and the potentially limiting values. The closest approach of the operating heat flux to the limiting values typically occurs in flow channels 1 or 8 between 0 and 2 seconds into the transients. Near the top of the plate, the surface heat flux can even reverse as energy flows from the heated water back into the cooler metal. This condition was observed in the annular flow channels and in some of the low power rectangular channels.

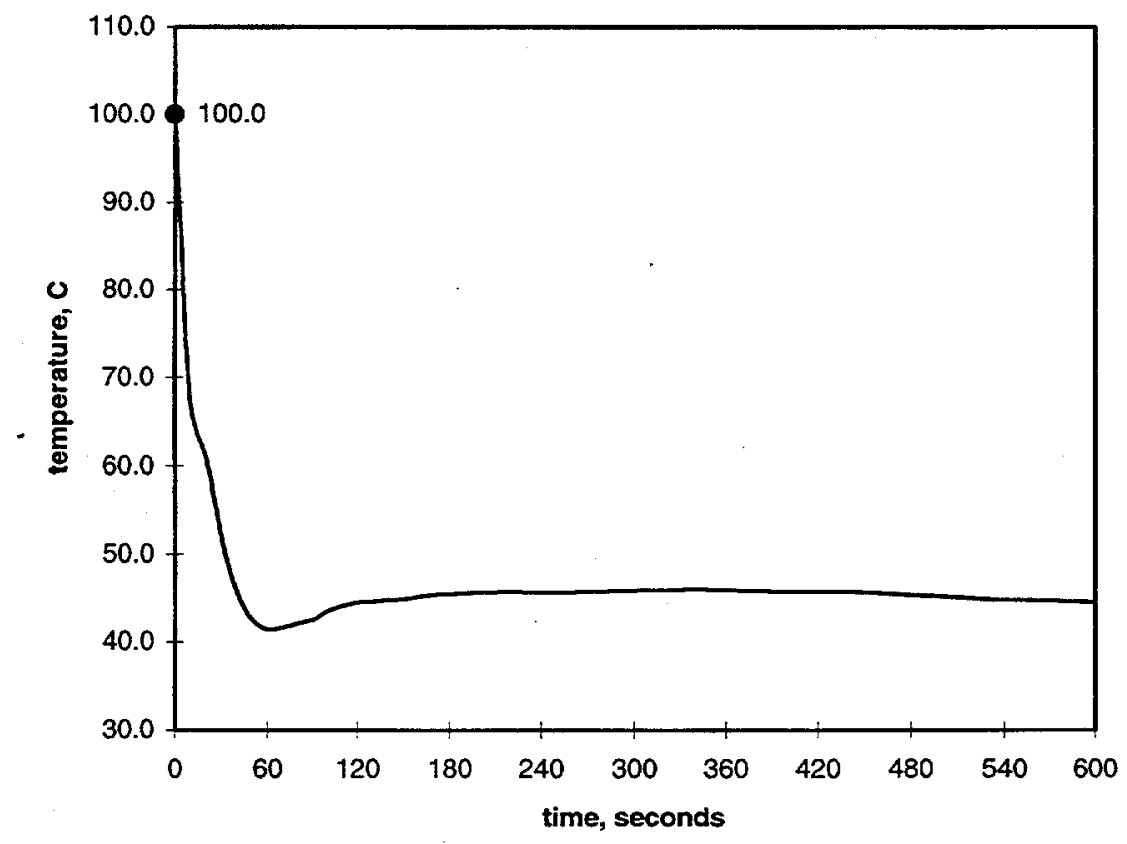

Figure 5-1 Maximum aluminum temperature for LOCA Case 1. 


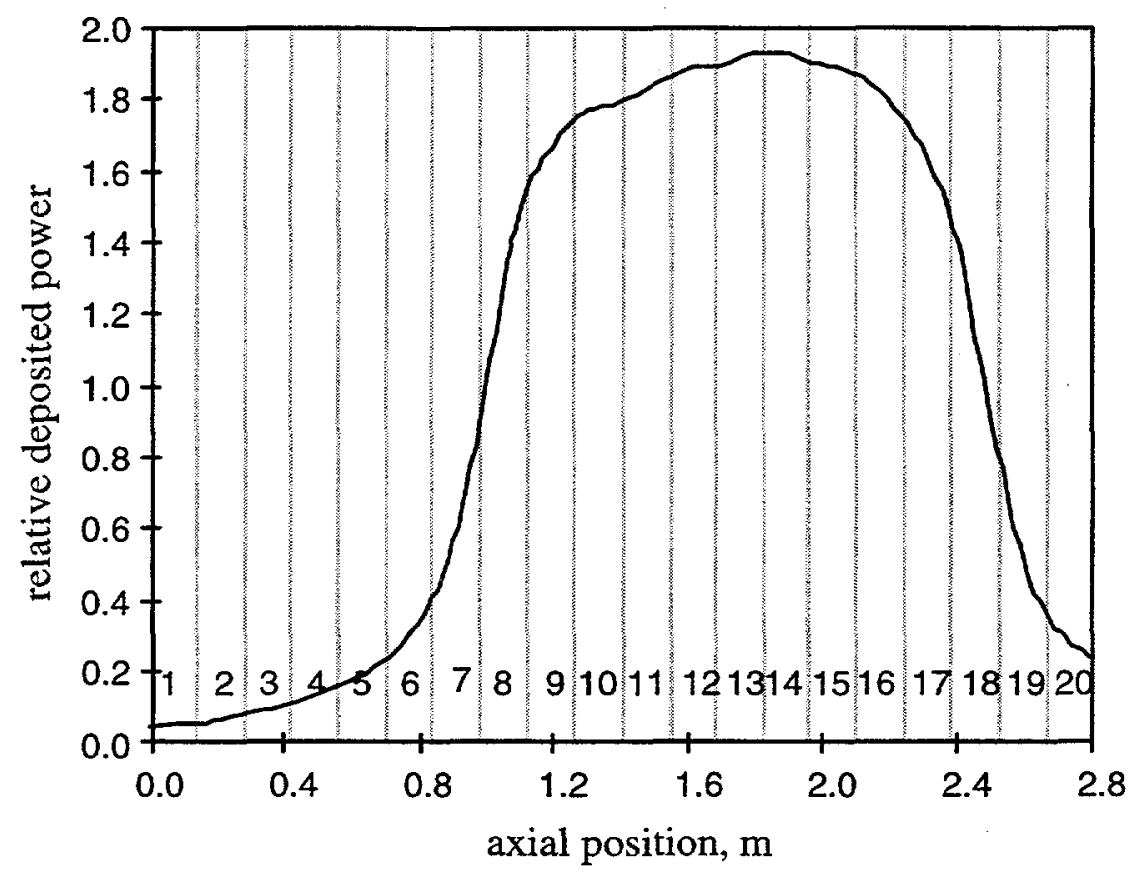

Figure 5-2 Blanket axial power shape. 

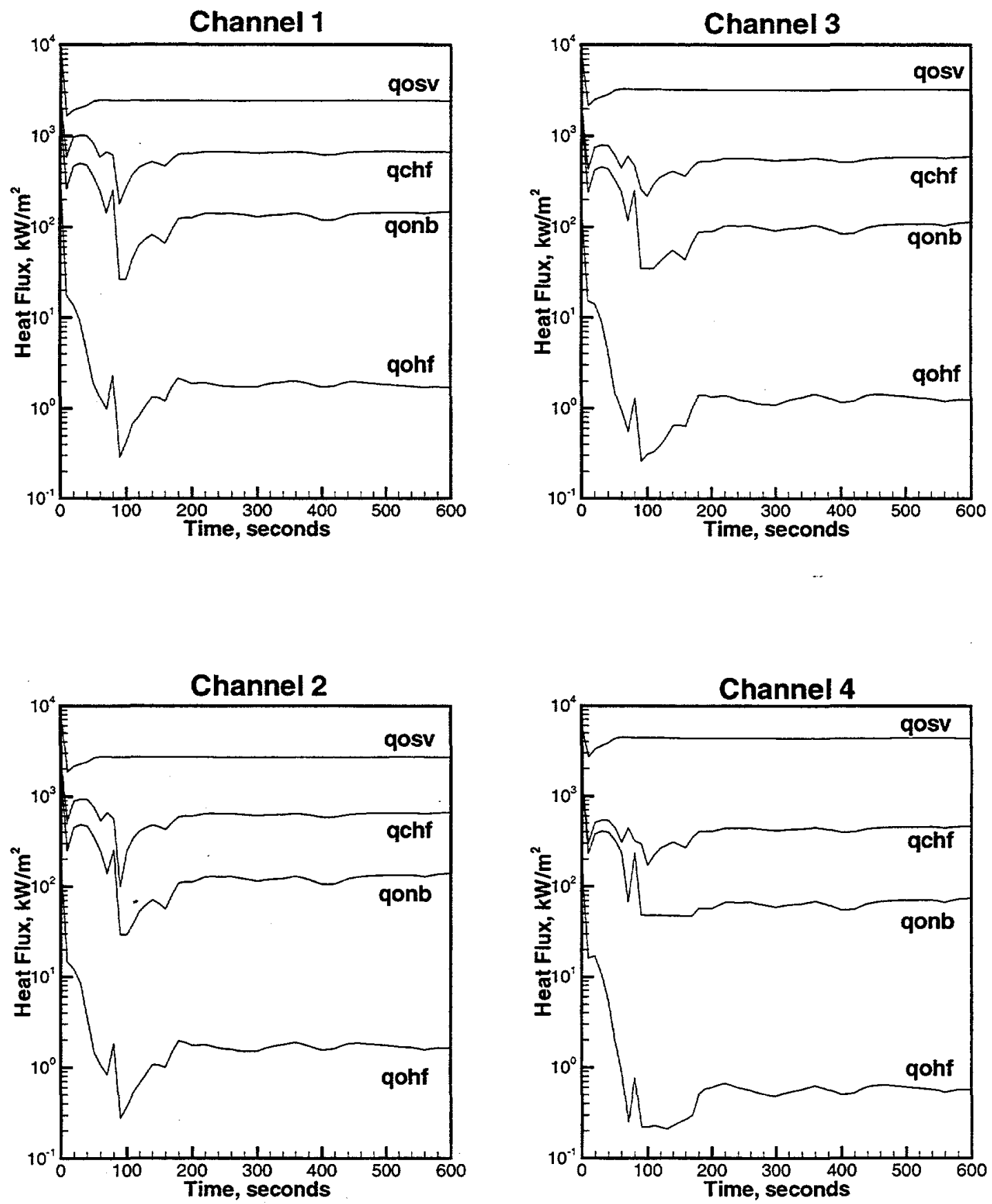

Figure 5-3 Surface heat fluxes for LOCA Case 1, axial level 11, channels 1-4. 

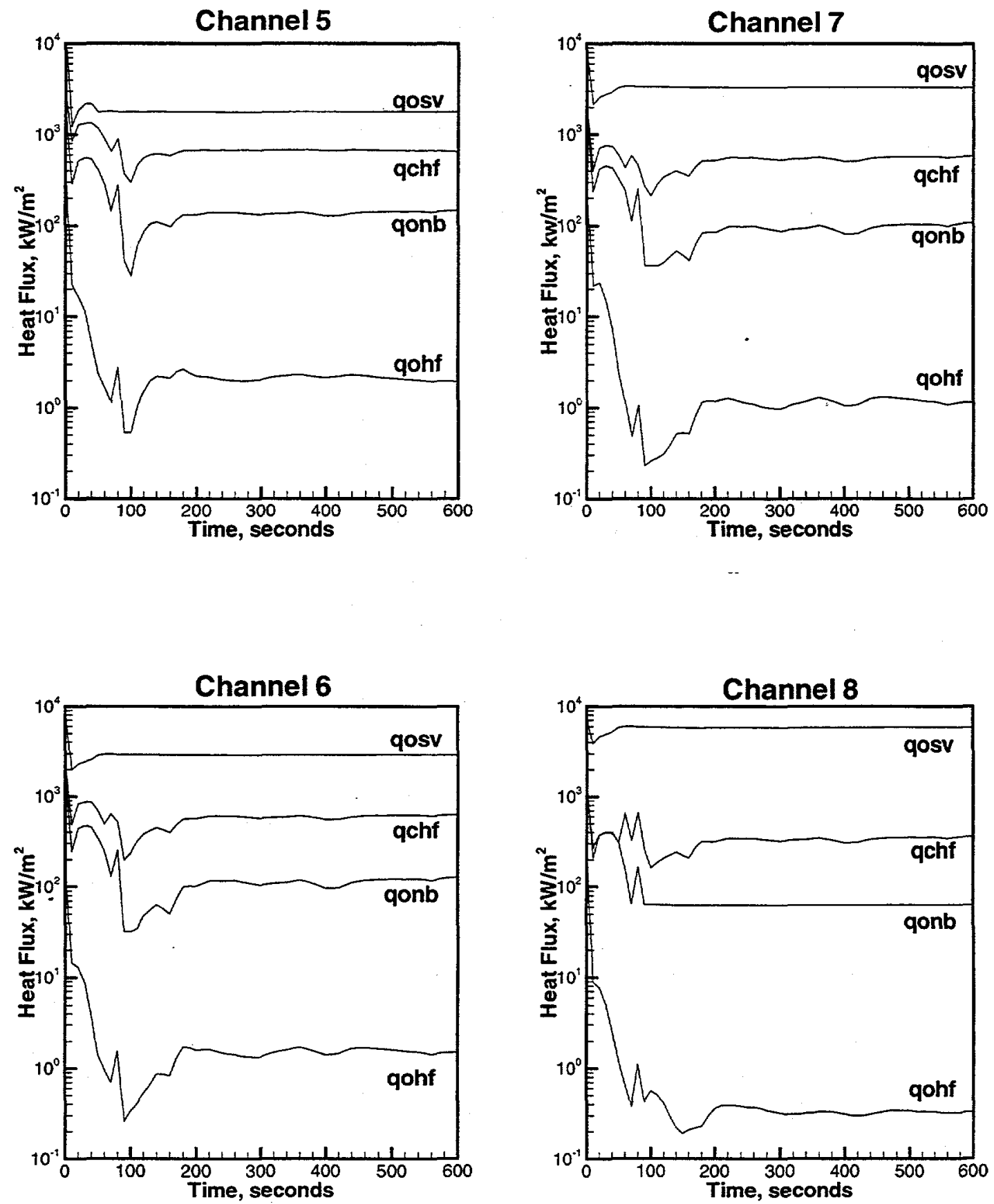

Figure 5-4 Surface heat fluxes for LOCA Case 1, axial level 11, channels 5-8. 

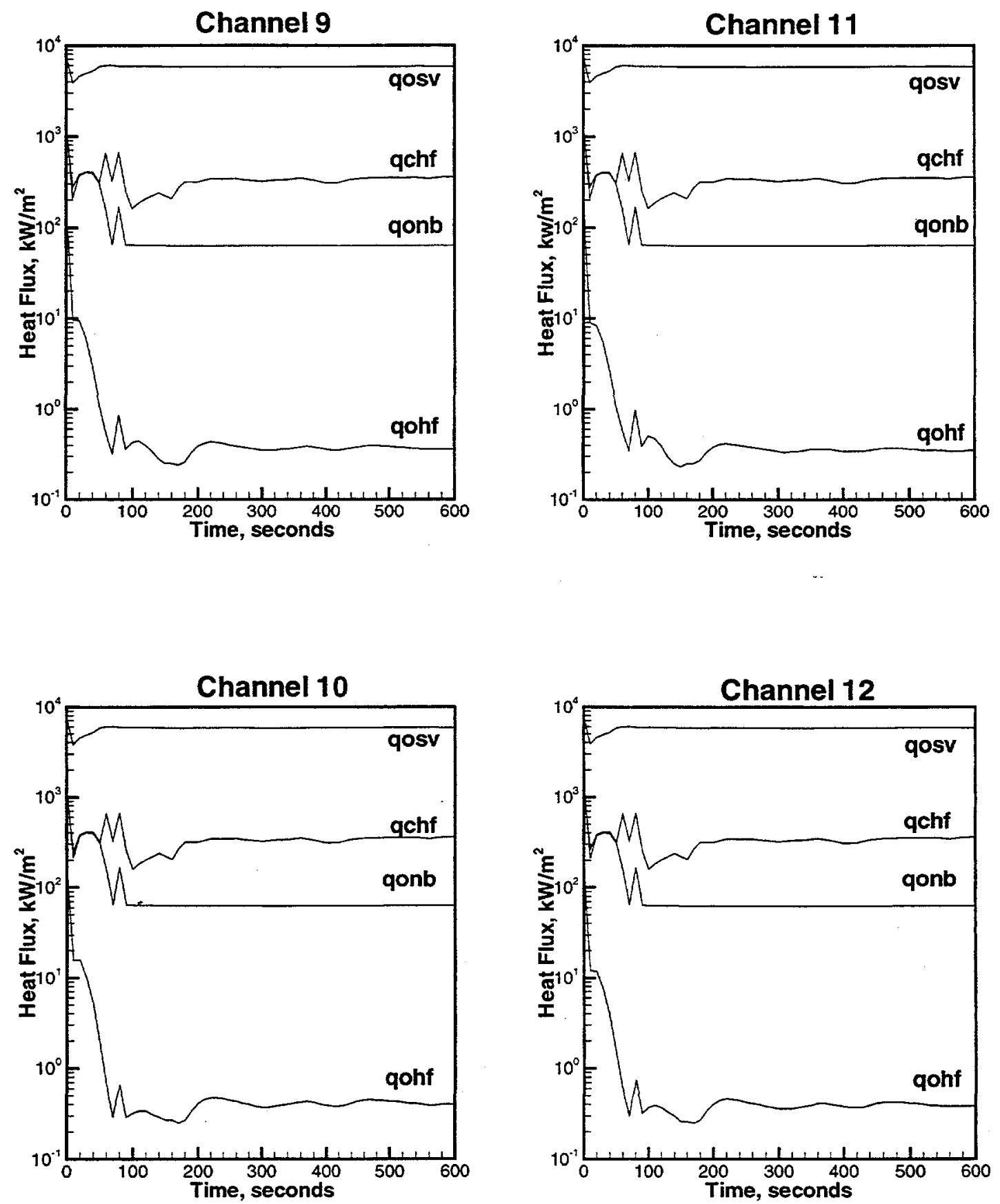

Figure 5-5 Surface heat fluxes for LOCA Case 1, axial level 11, channels 9-12. 


\section{Conclusions}

Simulations performed using the TRAC system model and the FLOWTRAN-TF detailed bin model show that the APT blanket modules maintain a coolable geometry during the LOCA Case 1 scenario. The thermal/hydraulic $(\mathrm{T} / \mathrm{H})$ design criteria, along with the basis for their development, is discussed in Refs. $[1,8]$. For LOCA the T/H onset criteria are based on meeting very strict phenomenological limits with a high degree of confidence, as follows:

- for local heated surfaces within the module components, the onset-of-significantvoids (OSV) at a three sigma confidence level; and

- for the remaining unheated piping sections of the blanket system, the onset-of-bulkboiling (OBB) at a three sigma confidence level.

Additional (steady-state derived) material design criteria are imposed on the maximum lead and aluminum (Series 6061 - Type T6) metal temperatures acceptable for the module components. The limiting values for these parameters are $327.5 \mathrm{C}$ and $115 \mathrm{C}$ for lead and aluminum, respectively. These material design criteria ensure that a coolable geometry can be maintained throughout the expected lifetime of each module unit.

On a module-by-module basis, the above steady-state material and thermal onset criteria for LOCA are compared to the FLOWTRAN-TF detailed bin model results. The bin model results for the reference 1 plate-type module are tabulated in Table 6.1-1 (note that only module 1 results are currently available since the design specifications for modules 2 through 6 do not presently exist). However, module 1 should be close to the most limiting module. Additional thermal onset criteria, which are typically considered, are also provided in Table 6.1-1. Note that these are generally more stringent than the imposed design criteria chosen.

The definitions of the criteria ratios in Table 6.1-1 are listed below, as follows:

$$
\begin{gathered}
R_{S U B}=\max \left(\frac{T_{f}-T_{i n}}{T_{s a t}-T_{i n}}\right), \text { liquid subcooling } \\
R_{S U P}=\max \left(\frac{T_{w}-T_{i n}}{T_{s a t}-T_{i n}}\right), \text { wall superheating } \\
R_{O N B}=\max \left(\frac{q_{O H F}^{\prime \prime}}{q_{O N B}^{\prime \prime}}\right), \text { ONB heat flux } \\
R_{O S V}=\max \left(\frac{q_{O H F}^{\prime \prime}}{q_{O S V}^{\prime \prime}}\right), \text { OSV heat flux }
\end{gathered}
$$




$$
R_{C H F}=\max \left(\frac{q_{O H F}^{\prime \prime}}{q_{C H F}^{\prime \prime}}\right), \text { CHF heat flux }
$$

where:

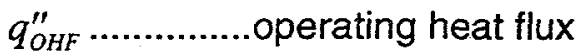

$$
\begin{aligned}
& q_{O N B}^{\prime \prime} \text {................heat flux at onset of subcooled nucleate boiling } \\
& q_{o S v}^{\prime \prime} \text {................heat flux at onset of significant void formation }
\end{aligned}
$$

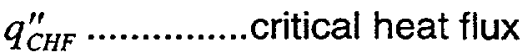

$$
\begin{aligned}
& T_{f} \text {.................fluid temperature } \\
& T_{\text {in }} \text {...................fluid temperature at inlet to flow channels, }(53.05 \mathrm{C}) \\
& T_{\text {sat }} \text {.................. local fluid saturation temperature } \\
& T_{w} \text {...................wall temperature }
\end{aligned}
$$

To evaluate these criteria, the maximum value corresponds to its limit spatially, as well as over the time period of the event sequence. The ratio of OHF-to-CHF is sometimes referred to as the departure from nucleate boiling ratio [DNBR]. Predicted thermal onset ratios should not exceed unity.

Confidence bounds are required to establish the acceptable level of probability of exceeding these criteria. The results presented in Table 6.1-1 represent primarily best estimate values (however, some parameters were set to their estimated upper bounds, such as power density). Quantification of overall uncertainties and then their corresponding confidence levels (i.e., operating and modeling uncertainties) have not yet been performed. Future efforts to perform a response surface analysis are planned. At that time quantification of safety margins will be determined.

The peak blanket metal temperature occurs in module \#1, and it is $112.8 \mathrm{C}$, as predicted by the FLOWTRAN-TF model. This occurs in the lead plate, and it is well below the lead melting point, $327.5 \mathrm{C}$. The peak aluminum temperature also occurs in module $\# 1$, and it is $100 \mathrm{C}$, below the long term temperature limit of $115 \mathrm{C}$. Since the power decay is steeper than the flow decay the reported maximum metal temperatures are essentially the pre-incident values. Actually, maximum temperatures are reached 1 second after the start of the accident when the beam trips. However, the thermal inertia of the solid is such that this brief time delay is negligible.

\subsection{Design Issues}

The TRAC system model predicts a peak lead temperature in module \#1 of $152 \mathrm{C}$ and the detailed FLOWTRAN-TF bin model predicts a peak lead temperature of $112.8 \mathrm{C}$. The cruciform design was used in the TRAC system model, and the plate design was used in the FLOWTRAN-TF model. This points out the need for consistency between the two models. The TRAC model will be upgraded in order to provide this consistency.

\subsection{Predicted Impact}

Blanket conditions during LOCA Case 1 fall within all specified thermal/hydraulic design criteria. No off-site impact to people or the environment would occur as a result of 
LOCA Case 1. The only on-site consequence would result from the release of contaminated cooling water.

Table 6.1-1 FLOWTRAN-TF model results under LOCA Case 1 conditions.

\begin{tabular}{|c|c|c|c|c|c|c|c|}
\hline $\begin{array}{c}\text { Module } \\
\#\end{array}$ & $\begin{array}{l}\text { Max } \\
\text { Pb } \\
\text { Temp } \\
\text { (C) }\end{array}$ & $\begin{array}{l}\text { Max } \\
\text { AI } \\
\text { Temp } \\
(C)\end{array}$ & $\begin{array}{c}\text { Max } \\
\text { Subcooling } \\
\text { Ratio }\end{array}$ & $\begin{array}{l}\text { Max } \\
\text { Supertheat } \\
\text { Ratio }\end{array}$ & $\begin{array}{l}\text { Max } \\
\text { ONB } \\
\text { Ratio }\end{array}$ & $\begin{array}{l}\text { Max } \\
\text { Osv } \\
\text { Ratio }\end{array}$ & $\begin{array}{l}\text { Max } \\
\text { CHR } \\
\text { Ratio }\end{array}$ \\
\hline 1 & 112.8 & 100.0 & 0.348 & 0.597 & 0.315 & 0.099 & 0.309 \\
\hline 2 & TBD & TBD & TBD & TBD & TBD & TBD & TBD \\
\hline 3 & TBD & TBD & TBD & TBD & TBD & TBD & TBD \\
\hline 4 & TBD & TBD & TBD & TBD & TBD & TBD & TBD \\
\hline 5 & TBD & TBD & TBD & TBD & TBD & TBD & TBD \\
\hline 6 & TBD & TBD & TBD & TBD & TBD & TBD & TBD \\
\hline
\end{tabular}




\section{References}

1. "APT Conceptual Design Report," Los Alamos National Laboratory report, LA-UR97-1329 (April 1997).

2. G. Willcutt, "Decay Power Fractions for $1700 \mathrm{MeV}$ Design", e-mail memo from Los Alamos National Laboratory, March 20, 1997.

3. L. L. Hamm, S. Y. Lee, M. A. Shadday, and F. G. Smith, III, "APT Blanket System Model Based on Initial Conceptual Design - Integrated 1-D TRAC System Model," Westinghouse Savannah River Company, WSRC-TR-98-0053 (July 1998).

4. L. L. Hamm, S. Y. Lee, M. A. Shadday, and F. G. Smith, III, "Normal operation (NO) of APT Blanket System and Its Components Based on Initial Conceptual Design", Westinghouse Savannah River Company, WSRC-TR-98-0057 (July 1998).

5. R. Kapernick, "Blanket Reference 1 Plate-Type Design for Lateral Row 1 Module", e-mail memo from Los Alamos National Laboratory, Oct. 11, 1997.

6. L. L. Hamm, S. Y. Lee, M. A. Shadday, and F. G. Smith, III, "APT Blanket Detailed Bin Model Based on Initial Plate-Type Design - 3D FLOWTRAN-TF Model", Westinghouse Savannah River Company, WSRC-TR-98-0055 (July 1998).

7. L. L. Hamm, S. Y. Lee, M. A. Shadday, and F. G. Smith, III, "FLOWTRAN-TF Code Modifications made for APT Blanket Safety Analyses", Westinghouse Savannah River Company, WSRC-TR-98-0056 (July 1998).

8. L. L. Hamm, S. Y. Lee, M. A. Shadday, and F. G. Smith, III, "APT Blanket System Safety Analysis Methodology," Westinghouse Savannah River Company, Westinghouse Savannah River Company, WSRC-TR-98-0052 (May 1998).

9. L. L. Hamm, S. Y. Lee, M. A. Shadday, and F. G. Smith, III, "TRAC Code Modifications made for APT Blanket Safety Analysis," Westinghouse Savannah River Company, WSRC-TR-98-0054 (July 1998).

10. Safety Code Development Group, "TRAC-PF1/MOD2: An Advanced Best Estimate Computer Program for Pressurized Water Reactor Thermal-Hydraulic Analysis," Los Alamos National Laboratory report LA-12031-M, Vol. 1 (NUREG/CR-5673), (July 21, 1993).

11. L. L. Hamm, S. Y. Lee, M. A. Shadday, and F. G. Smith, III, "APT Blanket System Loss-of-Flow Accident (LOFA) Analyses Based on Initial Conceptual Design Case 1: with Beam Shutdown and Active RHR," Westinghouse Savannah River Company, WSRC-TR-98-0058 (July 1998). 


\section{Appendix A: TRAC Model Component Nomenclature}

Table A-1 Blanket System Component Descriptions in TRAC Model.

\begin{tabular}{|c|c|c|c|c|}
\hline System & Component Type & Comp & $\begin{array}{l}\text { No of } \\
\text { Cells }\end{array}$ & Descriptions \\
\hline \multirow[t]{25}{*}{$\mathrm{HR}$} & Fixed Header $(\mathrm{FH})$ & 380 & 1 & coolant Supply FH \\
\hline & & 340 & 1 & coolant Return FH \\
\hline & Pressurizer (Pzr) & 760 & 1 & Pzr surge line 1 connected to Supply FH 380 \\
\hline & & 761 & 2 & Pzr surge line 2 \\
\hline & & 762 & 1 & Pzr surge line 3 \\
\hline & & 763 & 1 & Pzr surge line 4 \\
\hline & & 764 & 1 & Pzr surge line 5 \\
\hline & & 765 & 13 & Pzr surge line 6 \\
\hline & & 766 & 9 & primary Pzr \\
\hline & Hot Leg Loop & 20 & 1 & pipe connected to Return $\mathrm{FH} 340$ \\
\hline & & 21 & 1 & plenum for potential break loc. \\
\hline & & 22 & 7 & pipe connection to external loop \\
\hline & & 23 & 1 & pipe connect. for potential break \\
\hline & & 24 & 13 & connection pipe \\
\hline & & 25 & 1 & connection pipe \\
\hline & & 26 & 2 & pipe connected to two pumps \\
\hline & & 27 & 1 & plenum for two pump connection \\
\hline & & 28 & 2 & pump\#1 suction pipe \\
\hline & & 29 & 7 & pump\#2 suction pipe \\
\hline & & 30 & 2 & pump located at cell face 2 \\
\hline & & 31 & 2 & pump located at cell face 2 \\
\hline & & 32 & 3 & check valve located at pump\#1 discharge \\
\hline & & 33 & 3 & check valve located at pump\#2 discharge \\
\hline & & 34 & 1 & pump outlet plenum \\
\hline & & 36 & 1 & connect. pipe between pump and pipe \\
\hline \multirow[t]{17}{*}{-} & & 37 & 1 & HX connect. pipe for potential break \\
\hline & & 38 & 1 & pipe connect. to two HX's inlet plenum \\
\hline & & 40 & 1 & plenum \\
\hline & $\mathrm{HX}$ & 48 & 3 & $\mathrm{HX \# 1}$ inlet pipe \\
\hline & & 50 & 4 & $\mathrm{HX} \# 11^{\text {st }}$ pass \\
\hline & & 52 & 3 & $\mathrm{HX} \# 1$ middle header \\
\hline & & 54 & 4 & $H X \# 12^{\text {nd }}$ pass \\
\hline & & 49 & 3 & $\mathrm{HX} \# 2$ inlet pipe \\
\hline & & 51 & 4 & 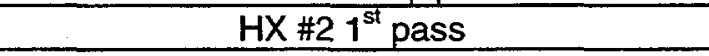 \\
\hline & & 53 & 3 & $\mathrm{HX} \# 2$ middle header \\
\hline & & 55 & 4 & $H X \# 22^{\text {nd }}$ pass \\
\hline & & 710 & 1 & HX\#1 secondary side fill \\
\hline & & 711 & 4 & $\mathrm{HX} \# 12^{\text {nd }}$ pass secondary side \\
\hline & & 712 & 3 & HX \#1 middle header secondary side \\
\hline & & 713 & 4 & $H X \# 11^{\text {st }}$ pass secondary side \\
\hline & & 714 & 1 & HX \#1 secondary side break BC \\
\hline & & 730 & 1 & $\mathrm{HX} \# 2$ secondary side fill $\mathrm{BC}$ \\
\hline
\end{tabular}


Table A-1 Blanket System Component Descriptions in TRAC Model (continued).

\begin{tabular}{|c|c|c|c|c|}
\hline System. & Component Type & Comp & $\begin{array}{l}\text { No } \\
\text { of } \\
\text { Cells }\end{array}$ & Descriptions \\
\hline & & 731 & 4 & HX \#2 $2^{\text {nd }}$ pass secondary side \\
\hline & & 732 & 3 & HX \#2 middle header secondary side \\
\hline & & 733 & 4 & $\mathrm{HX} \# 21^{\text {st }}$ pass secondary side \\
\hline & & 734 & 1 & $\mathrm{HX} \# 2$ secondary side break $\mathrm{BC}$ \\
\hline \multirow[t]{12}{*}{ HR } & Cold Leg Loop & 56 & 3 & HX \#1 outlet pipe \\
\hline & & 57 & 6 & HX \#2 outlet pipe \\
\hline & & 60 & 3 & HX outlet plenum merged after two HX's \\
\hline & & 62 & 1 & cold leg pipe \\
\hline & & 63 & 1 & cold leg pipe \\
\hline & & 64 & 13 & cold leg pipe located outside cavity wall \\
\hline & & 65 & 1 & pipe for cold leg pipe break \\
\hline & & 66 & 1 & horizontal cold leg pipe penetration \\
\hline & & 67 & 1 & plenum for internal break on HR loop \\
\hline & & 854 & 2 & HR isolation valve for internal break \\
\hline & & 69 & 1 & plenum for internal LOCA simulation \\
\hline & & 68 & 5 & pipe connect. to FH 340 inside cavity \\
\hline \multirow[t]{9}{*}{$\begin{array}{l}\text { Cavity } \\
\text { Vessel } \\
\end{array}$} & Cold Leg Loop & 850 & 2 & valve located bet. cavity vessel and HR \\
\hline & & 852 & 2 & valve located bet. cavity vessel and $H R$ \\
\hline & & & 1 & plenum for cavity vessel connection \\
\hline & & 828 & 3 & cavity vent valve \\
\hline & & 802 & 1 & break component for cavity vent pressure BC \\
\hline & & 823 & 11 & pipe for cavity lower section simulation \\
\hline & & 824 & 1 & plenum for cavity connection \\
\hline & & 840 & 2 & valve to connect cavity line to Module 1 \\
\hline & & 825 & 4 & pipe for cavity middle section simulation \\
\hline \multirow[t]{8}{*}{$\begin{array}{l}\text { Cavity } \\
\text { Pool }\end{array}$} & Cavity Flood Line & 820 & 13 & $\begin{array}{l}\text { pipe for cavity pool connection to cavity } \\
\text { vessel }\end{array}$ \\
\hline & & 821 & 2 & cavity flood line valve \\
\hline & & 822 & 1 & flood line pipe inside cavity vessel \\
\hline & Cavity Flood Pool & 801 & 1 & break component for cavity pool BC \\
\hline & & 810 & 10 & pipe for top cavity pool section \\
\hline & & 811 & 1 & plenum for middle cavity pool section \\
\hline & & 812 & 7 & pipe for lower cavity pool section \\
\hline & & 813 & 1 & plenum for cavity pool bottom \\
\hline \multirow[t]{10}{*}{ RHR } & RHR Loop & 621 & 1 & pipe located to return $\mathrm{FH}$ \\
\hline & & 623 & 10 & pipe located inside the cavity vessel \\
\hline & & 624 & 1 & pipe located outside the cavity vessel \\
\hline & & 625 & 18 & pipe bet. RHR pump and pipe comp. \#624 \\
\hline & & 630 & 2 & RHR pump located at face 2 \\
\hline & & 640 & 3 & check valve located at pump discharge \\
\hline & & 652 & 4 & HX tubes \\
\hline & & 660 & 16 & pipe at the cold leg side \\
\hline & & 661 & 1 & pipe located before cavity vessel \\
\hline & & 662 & 8 & cold leg pipe inside cavity vessel \\
\hline
\end{tabular}


WESTINGHOUSE SAVANNAH RIVER COMPANY

BLANKET SAFETY ANALYSES FOR LOCA

(CASE 1: EXTERNAL HR BREAK NEAR INLET HEADER)
Report:

Section:

Date:

Page:
WSRC-TR-98-0059

Appendix A

07/13/98

3 of 12

Table A-1 Blanket System Component Descriptions in TRAC Model (continued).

\begin{tabular}{|c|c|c|c|c|}
\hline System & Component Type & $\operatorname{comp}$ & $\begin{array}{l}\text { No } \\
\text { of } \\
\text { Cells }\end{array}$ & Descriptions \\
\hline & & 663 & 1 & cold leg pipe connected to supply FH \\
\hline & & 672 & 1 & fill for $\mathrm{HX}$ secondary side $\mathrm{BC}$ \\
\hline & & 671 & 4 & HX secondary shell side \\
\hline & & 673 & 1 & break comp. for $\mathrm{HX}$ secondary side $\mathrm{BC}$ \\
\hline \multirow[t]{18}{*}{ Module } & Module 1 Flow & 454 & 7 & pipe connected to supply $\mathrm{FH}$ \\
\hline & & 80 & 1 & $\begin{array}{l}\text { plenum for potential internal break simulation } \\
\text { at Module } 1\end{array}$ \\
\hline & & 375 & 5 & $\begin{array}{l}\text { pipe connection bet. Suuply FH and Module } \\
1 \text { upper plenum }\end{array}$ \\
\hline & & 370 & 1 & upper plenum for Module 1 downcomer \\
\hline & & 360 & 5 & Module 1 downflow region \\
\hline & & 350 & 1 & $\begin{array}{c}\text { middle plenum bet. Module } 1 \text { downflow and } \\
\text { upflow regions }\end{array}$ \\
\hline & & 300 & 5 & Module 1 upflow region \\
\hline & & 330 & 1 & upper plenum for module 1 upflow region \\
\hline & & 335 & 5 & $\begin{array}{c}\text { connection pipe after Module } 1 \text { upper } \\
\text { plenum }\end{array}$ \\
\hline & & 429 & 4 & pipe connected to return FH \\
\hline & Module 2 Flow & 173 & 7 & pipe coonected to supply FH \\
\hline & & 81 & 1 & $\begin{array}{l}\text { plenum for potential internal break simulation } \\
\text { at Module } 2\end{array}$ \\
\hline & & 82 & 3 & pipe connection \\
\hline & & 172 & 1 & upper plenum for Module 2 downcomer \\
\hline & & 158 & 6 & Module 2 downflow region \\
\hline & & 147 & 1 & $\begin{array}{l}\text { middle plenum bet. Module } 2 \text { downflow and } \\
\text { upflow regions }\end{array}$ \\
\hline & & 102 & 6 & Module 2 upflow region \\
\hline & & 133 & 1 & upper plenum for module 2 upflow region \\
\hline \multirow[t]{14}{*}{$=$} & & 136 & 7 & pipe connected to return $\mathrm{FH}$ \\
\hline & Module 3 Flow & 415 & 7 & pipe connected to supply FH \\
\hline & & 85 & 1 & $\begin{array}{l}\text { plenum for potential internal break simulation } \\
\text { at Module } 3\end{array}$ \\
\hline & & 86 & 3 & pipe connection \\
\hline & & 479 & 1 & upper plenum for Module 3 downcomer \\
\hline & & 478 & 5 & Module 3 downflow region \\
\hline & & 418 & 1 & $\begin{array}{c}\text { middle plenum bet. Module } 3 \text { downflow and } \\
\text { upflow regions }\end{array}$ \\
\hline & & 409 & 5 & Module 3 upflow region \\
\hline & & 423 & 1 & upper plenum for module 3 upflow region \\
\hline & & 417 & 7 & pipe connected to return $\mathrm{FH}$ \\
\hline & Module 4 Flow & 485 & 7 & pipe connected to supply FH \\
\hline & & 87 & 1 & $\begin{array}{l}\text { plenum for potential internal break simulation } \\
\text { at Module } 4\end{array}$ \\
\hline & & 88 & 3 & pipe connection \\
\hline & & 489 & 1 & upper plenum for Module 4 downcomer \\
\hline
\end{tabular}


Table A-1 Blanket System Component Descriptions in TRAC Model (continued).

\begin{tabular}{|c|c|c|c|c|}
\hline System. & Component Type & $\underset{\#}{\text { Comp }}$ & $\begin{array}{l}\text { No of } \\
\text { Cells }\end{array}$ & Descriptions \\
\hline & & 480 & 6 & Module 4 downflow region \\
\hline & & 419 & 1 & $\begin{array}{l}\text { middle plenum bet. Module } 4 \text { downflow and } \\
\text { upflow regions }\end{array}$ \\
\hline & & 412 & 6 & Module 4 upflow region \\
\hline & & 483 & 1 & upper plenum for module 4 upflow region \\
\hline & & 484 & 7 & pipe connected to return $\mathrm{FH}$ \\
\hline Module & Module 5 Flow & 513 & 7 & pipe connected to supply FH \\
\hline & & 89 & 1 & $\begin{array}{c}\text { plenum for potential internal break } \\
\text { simulation at Module } 5\end{array}$ \\
\hline & & 90 & 3 & pipe connection \\
\hline & & 510 & 1 & upper plenum for Module 5 downcomer \\
\hline & & 507 & 6 & Module 5 downflow region \\
\hline & & 503 & 1 & $\begin{array}{c}\text { middle plenum bet. Module } 4 \text { downflow and } \\
\text { upflow regions }\end{array}$ \\
\hline & & 500 & 6 & Module 5 upflow region \\
\hline & & 508 & 1 & upper plenum for Module 5 upflow region \\
\hline & & 511 & 7 & pipe connected to return $\mathrm{FH}$ \\
\hline & Module 6 Flow & 541 & 7 & pipe connected to supply FH \\
\hline & & 83 & 1 & $\begin{array}{c}\text { plenum for potential internal break } \\
\text { simulation at Module } 6\end{array}$ \\
\hline & & 84 & 1 & pipe connection \\
\hline & & 538 & 1 & upper plenum for Module 6 decoupler \\
\hline & & 535 & 5 & Module 6 downcomer region \\
\hline & & 531 & 1 & $\begin{array}{l}\text { middle plenum bet. Module } 6 \text { decoupler and } \\
\text { main heated regions }\end{array}$ \\
\hline & & 528 & 5 & Module 6 main heated region \\
\hline & & 536 & 1 & $\begin{array}{c}\text { upper plenum for module } 6 \text { main heated } \\
\text { region }\end{array}$ \\
\hline & & 539 & 12 & pipe connected to return $\mathrm{FH}$ \\
\hline & $\begin{array}{l}\text { Module } 1 \text { Heater } \\
\text { Structure }\end{array}$ & 901 & 5 & Al tube structure in Row 1 \\
\hline & & 951 & 5 & Lead zone with Al cladding in Row 1 \\
\hline & & 984 & 5 & Al tube structure in decoupler \\
\hline & $\begin{array}{l}\text { Module } 2 \text { Heater } \\
\text { Structure }\end{array}$ & 905 & 6 & Al tube structure in Row 2 \\
\hline & & 955 & 6 & Lead zone with Al cladding in Row 2 \\
\hline & & 916 & 6 & Al tube structure in Row 3 \\
\hline & & 966 & 6 & Lead zone with Al cladding in Row 3 \\
\hline & $\begin{array}{c}\text { Module } 3 \text { Heater } \\
\text { Structure }\end{array}$ & 911 & 5 & Al tube structure in Row 1 \\
\hline & & 961 & 5 & Lead zone with Al cladding in Row 1 \\
\hline & & 988 & 5 & Al tube structure in decoupler \\
\hline & $\begin{array}{l}\text { Module } 4 \text { Heater } \\
\text { Structure }\end{array}$ & 912 & 6 & Al tube structure in Row 1 \\
\hline & & 962 & 6 & Lead zone with Al cladding in Row 1 \\
\hline & & 931 & 6 & Al tube structure in Row 2 \\
\hline
\end{tabular}


Table A-1 Blanket System Component Descriptions in TRAC Model (continued).

\begin{tabular}{|c|c|c|c|c|}
\hline System & Component Type & $\begin{array}{c}\text { Comp } \\
\text { \# }\end{array}$ & $\begin{array}{c}\text { No } \\
\text { of } \\
\text { Cells }\end{array}$ & \\
\hline & $\begin{array}{c}\text { Module 5 Heater } \\
\text { Structure }\end{array}$ & 978 & 6 & Lead zone with Al cladding in Row 2 \\
\hline & & 963 & 6 & Lescriptions \\
\hline & & 932 & 6 & Lead zone with Al cladding in Row 2 \\
\hline & & 979 & 6 & Lead zone with Al cladding in Row 2 \\
\hline & $\begin{array}{c}\text { Module 6 Heater } \\
\text { Structure }\end{array}$ & 915 & 5 & Al tube structure in Row 2 \\
\hline & & 965 & 5 & Lead zone with Al cladding in Row 2 \\
\hline
\end{tabular}

Table A-2 Steady State Conditions.

\begin{tabular}{|c|c|c|}
\hline Parameter & Units & $\begin{array}{c}\text { Calculated } \\
\text { Values }\end{array}$ \\
\hline Total power deposited in blanket modules & $\mathrm{MW}$ & 56.5 \\
\hline Total flow rate & $\mathrm{kg} / \mathrm{sec}$ & 1569 \\
& $\mathrm{gpm}$ & 25252 \\
\hline Pressure in cold-leg fixed header & $\mathrm{MPa}$ & 0.7325 \\
& $\mathrm{psia}$ & 106.24 \\
\hline Pressure in hot-leg fixed header & $\mathrm{MPa}$ & 0.4563 \\
& $\mathrm{psia}$ & 66.180 \\
\hline Pressurizer (cell \#1) pressure & $\mathrm{MPa}$ & 0.7311 \\
& $\mathrm{psia}$ & 106.03 \\
\hline Pump \#1 suction pressure & $\mathrm{MPa}$ & 0.2751 \\
& $\mathrm{psia}$ & 39.90 \\
\hline Pump \#1 discharge pressure & $\mathrm{MPa}$ & 1.0356 \\
& $\mathrm{psia}$ & 150.20 \\
\hline Pump \#2 suction pressure & $\mathrm{MPa}$ & 0.2958 \\
& $\mathrm{psia}$ & 42.91 \\
\hline Pump \#2 discharge pressure & $\mathrm{MPa}$ & 1.0409 \\
& $\mathrm{psia}$ & 150.97 \\
\hline Temperature in cold-leg fixed header & $\mathrm{C}$ & 49.43 \\
& $\mathrm{~F}$ & 121.0 \\
\hline Temperature in hot-leg fixed header & $\mathrm{C}$ & 58.03 \\
& $\mathrm{~F}$ & 136.5 \\
\hline Max. fluid temperature of the hottest & $\mathrm{C}$ & 71.95 \\
module & $\mathrm{F}$ & 161.5 \\
\hline
\end{tabular}




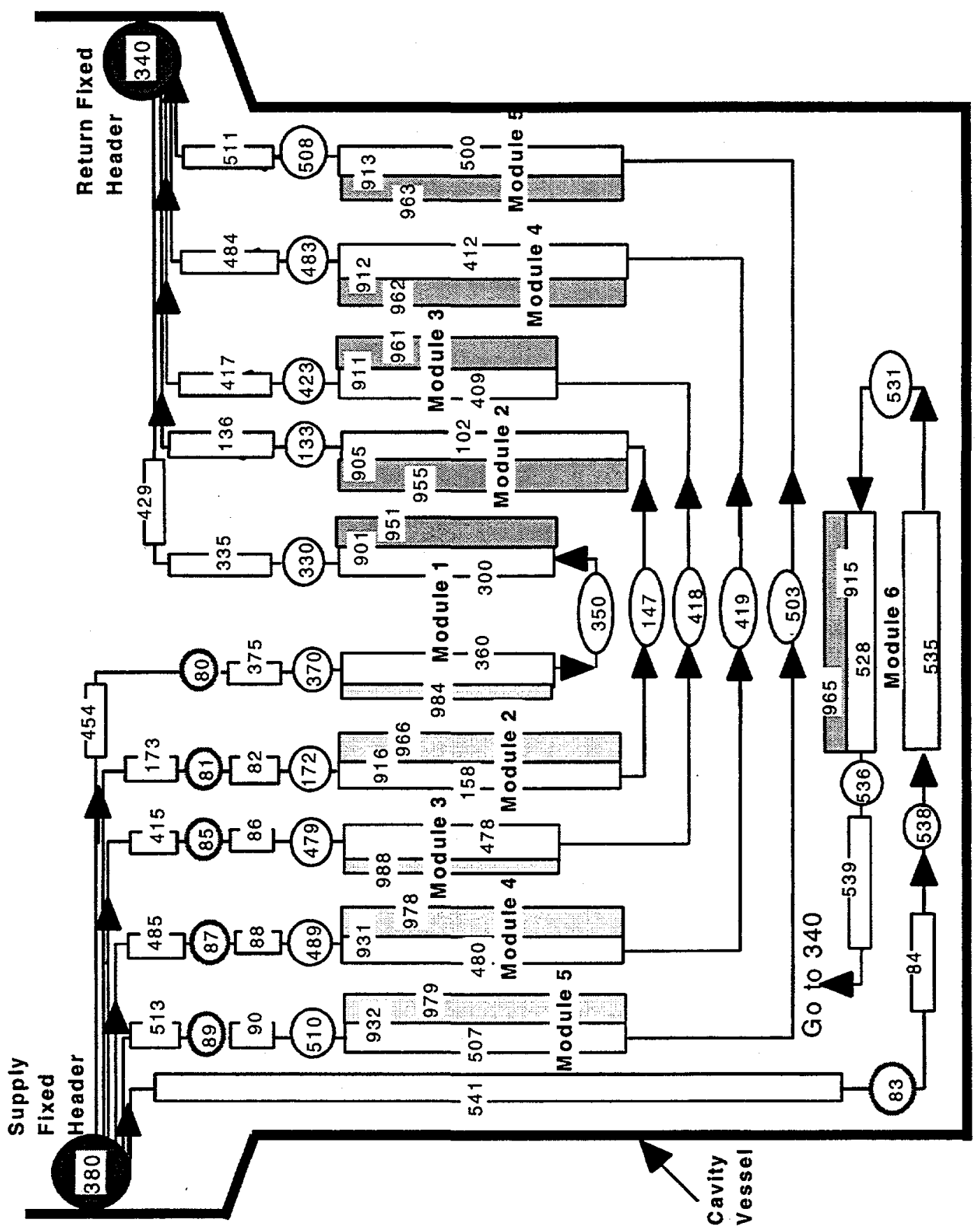

Figure A-1 6 blanket module layout for safety analysis. 
WESTINGHOUSE SAVANNAH RIVER COMPANY

BLANKET SAFETY ANALYSES FOR LOCA

(CASE 1: EXTERNAL HR BREAK NEAR INLET HEADER)
Report: WSRC-TR-98-0059

Section:

Date:

Page:
Appendix A

$07 / 13 / 98$

7 of 12

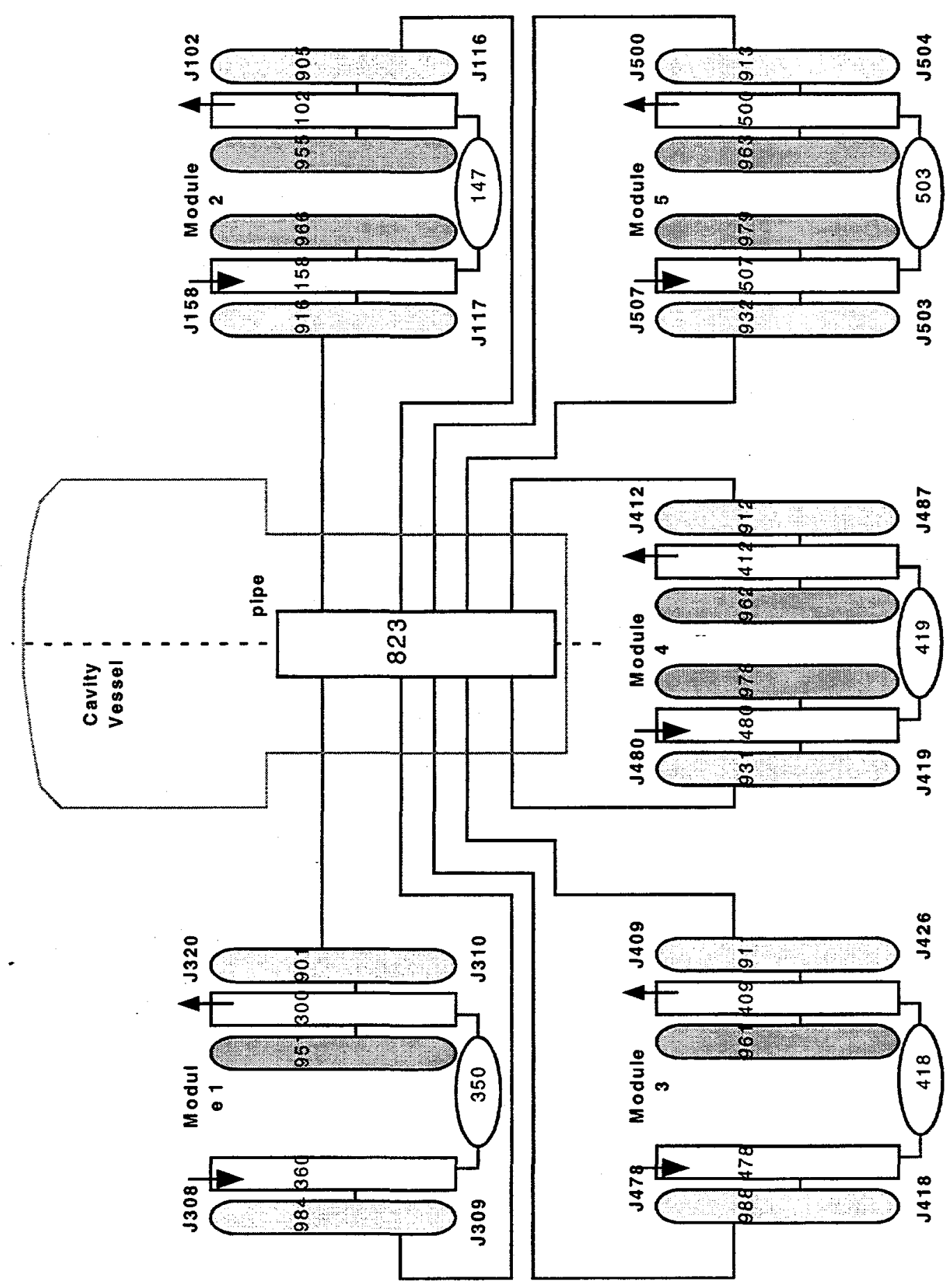

Figure A-2 TRAC component layout for the cavity vessel and blanket module heat structures. 
Report:

Section:

Date:

Page:
WSRC-TR-98-0059

Appendix A

$07 / 13 / 98$

8 of 12

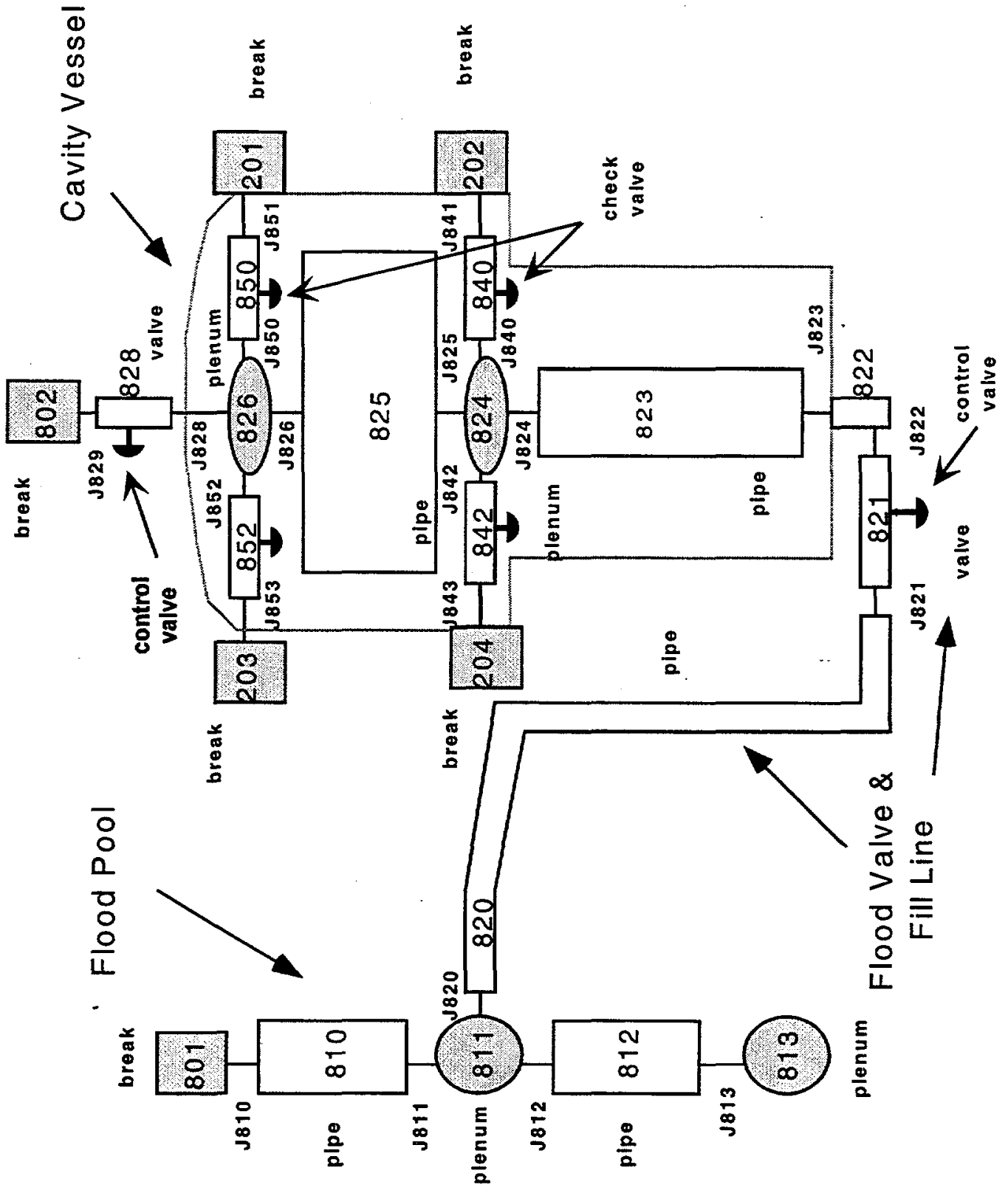

Figure A-3 TRAC component layout for the cavity vessel and cavity flood system. 


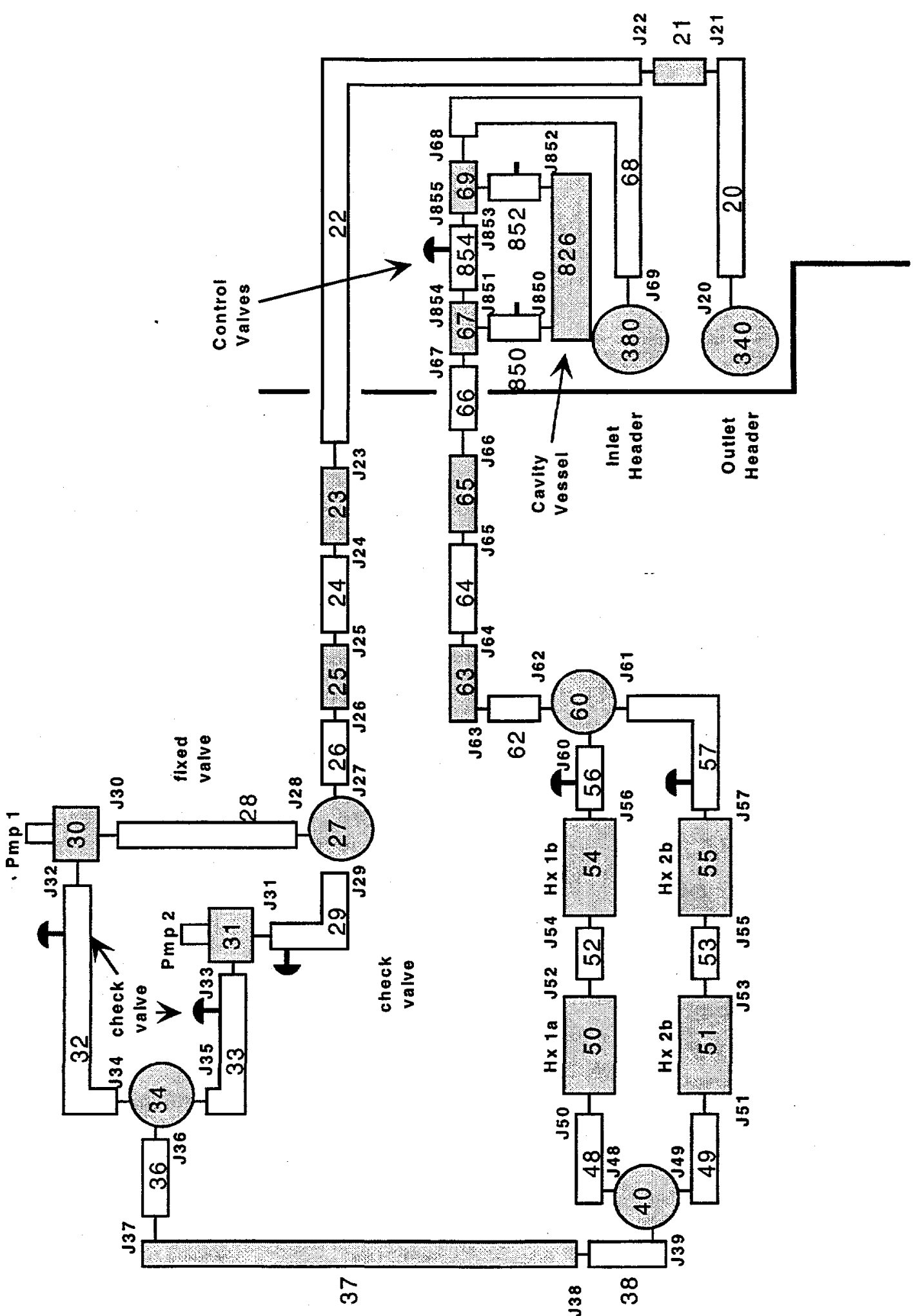

Figure A-4 TRAC component layout for blanket primary HR coolant loop. 


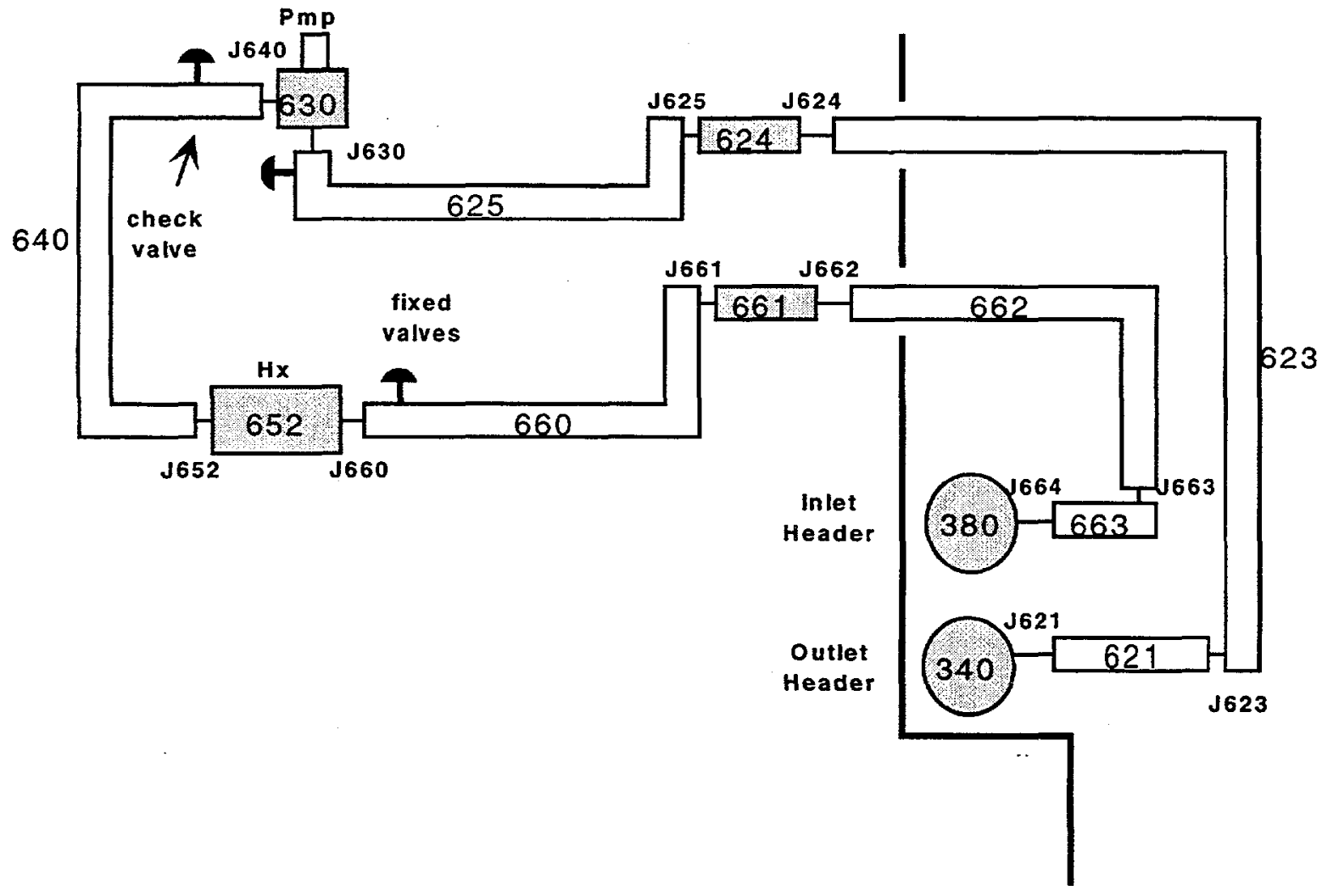

Figure A-5 TRAC component layout for blanket primary RHR coolant loop. 


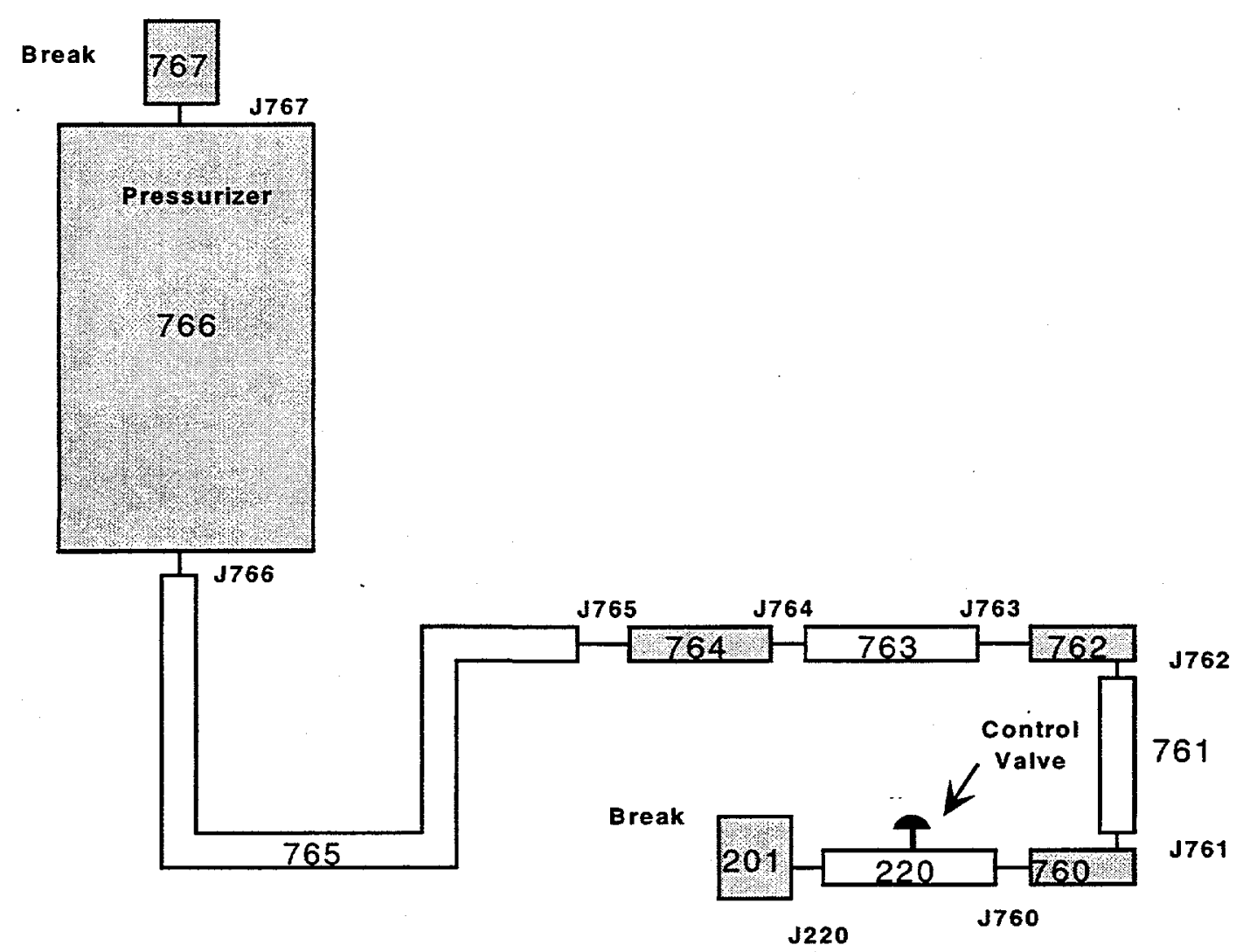

Figure A-6 TRAC component layout for blanket primary pressurizer and surge line. 


\section{Appendix B: LOCA (Case 1) TRAC Results}

\section{Appendix B1 LOCA (Case 1) TRAC Plenum Component Figures}

The following figures are from a TRAC simulation for Case 1 of a LOCA (external HR break near inlet header):

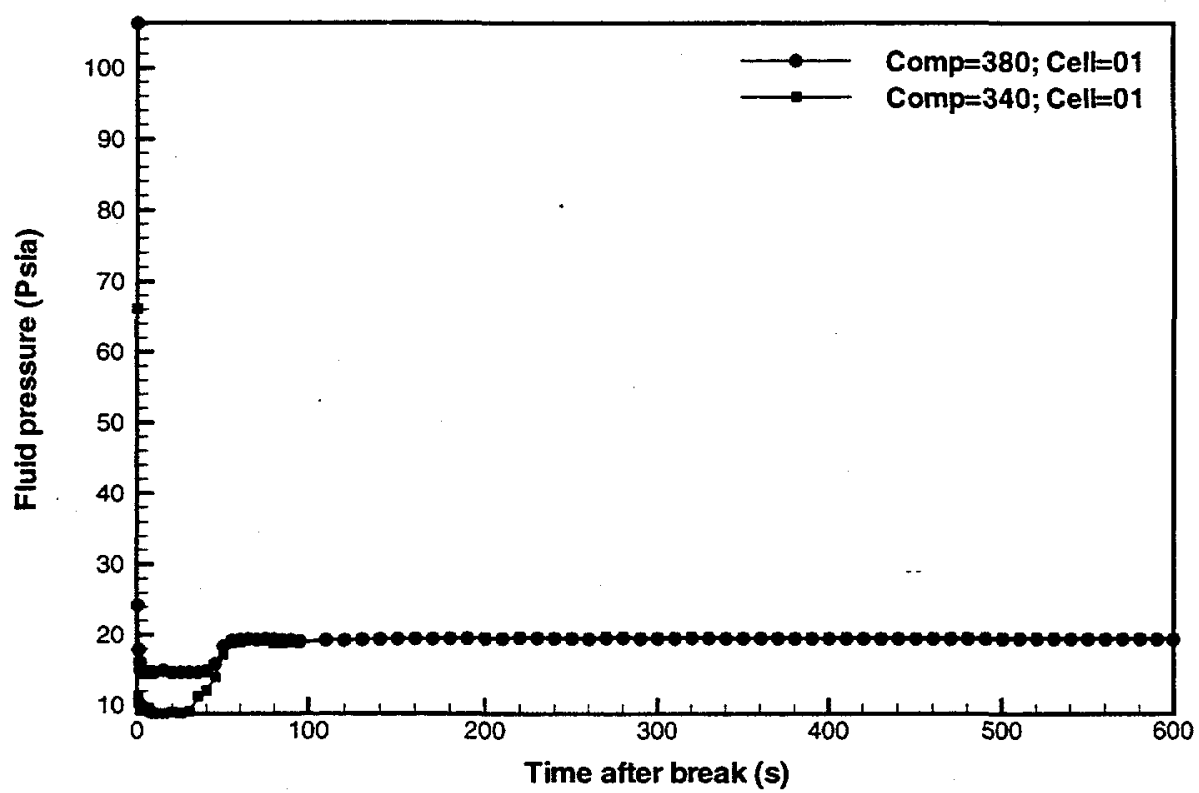

Figure B-1a Fixed header fluid pressures for a LOCA (Case 1: external HR break near inlet header). 


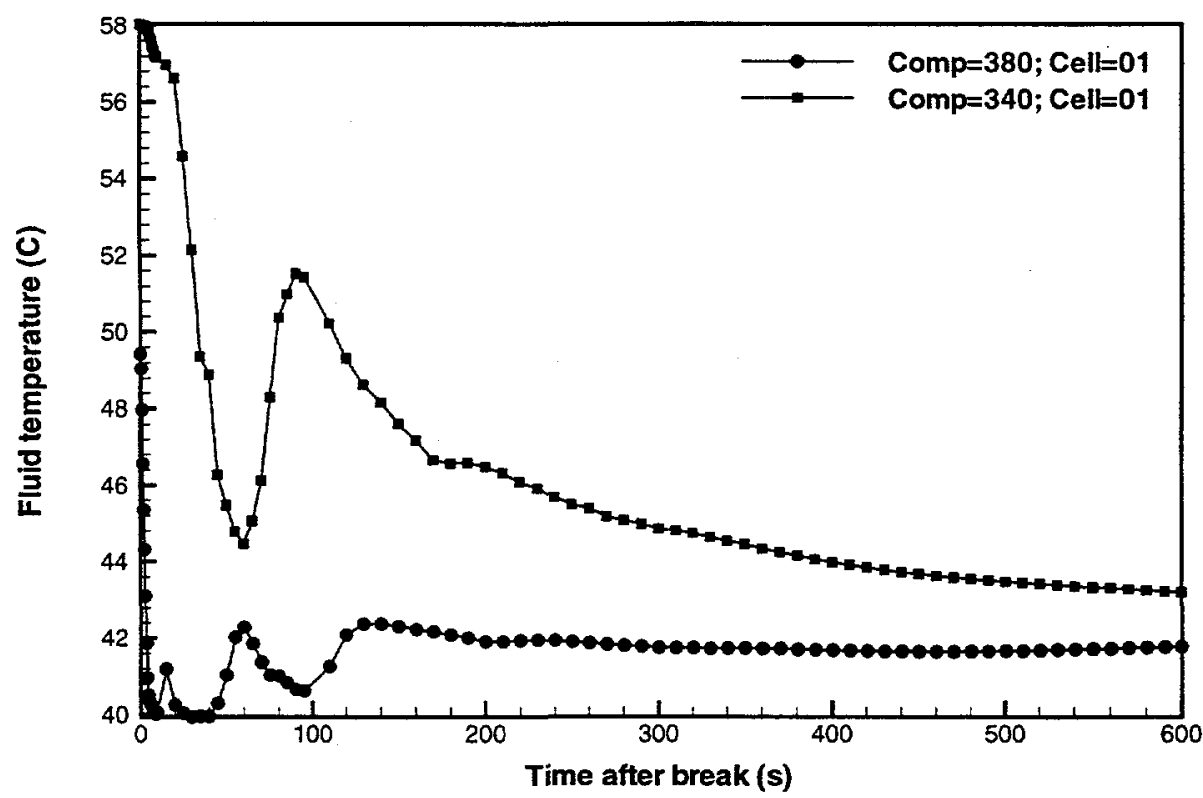

Figure B-1b Fixed header fluid temperatures for a LOCA (Case 1: external HR break near inlet header).

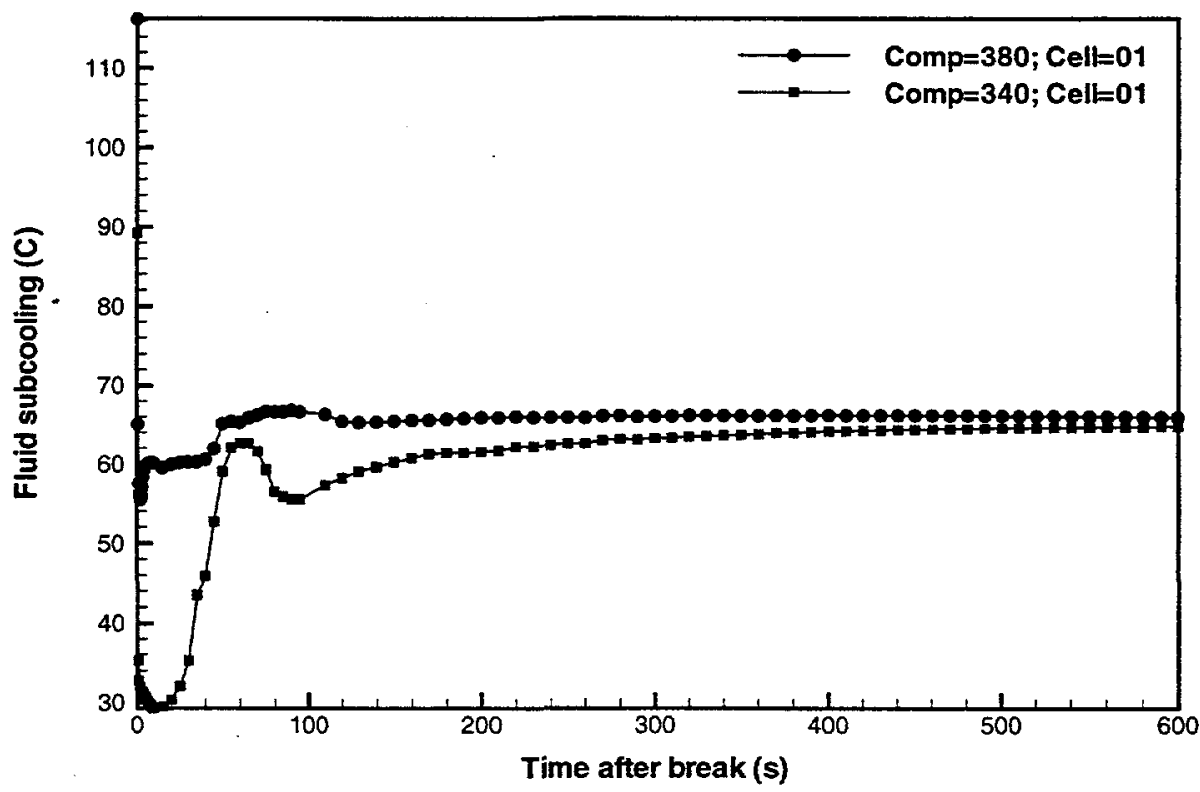

Figure B-1c Fixed header fluid subcoolings for a LOCA (Case 1: external HR break near inlet header). 


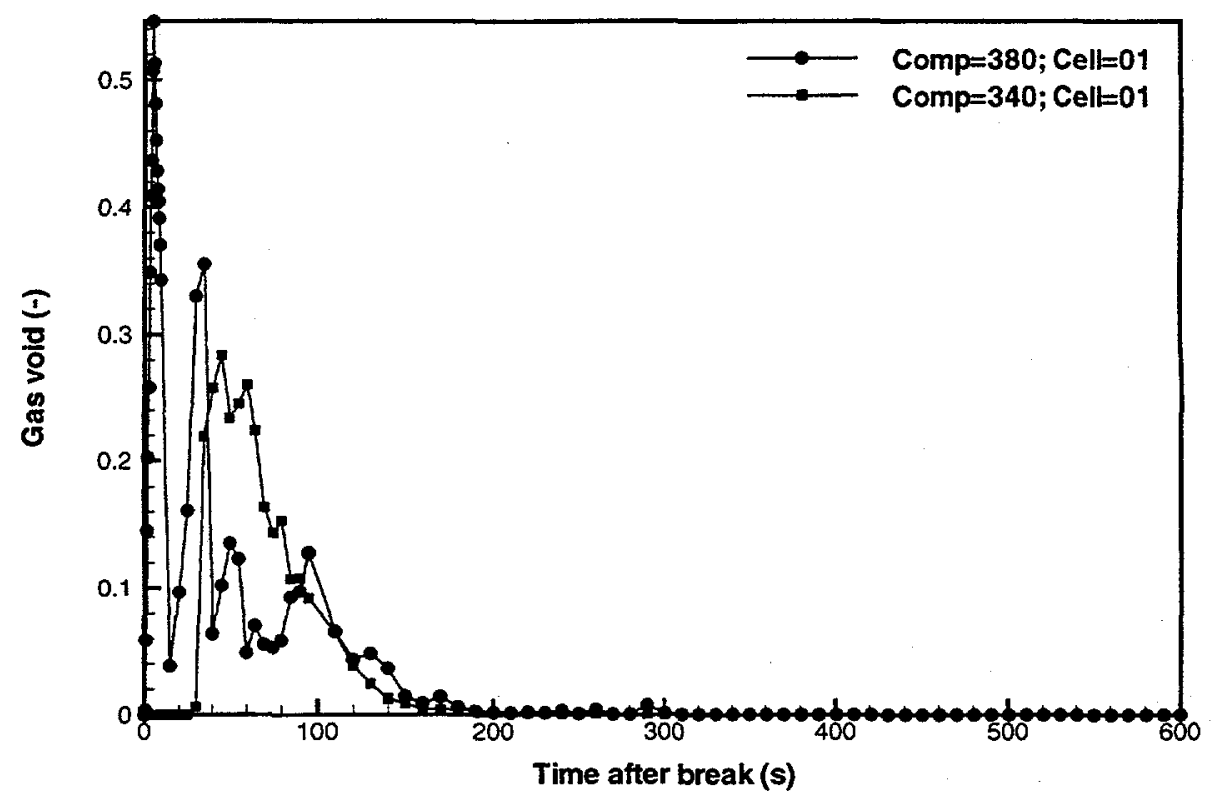

Figure B-1d Fixed header void fractions for a LOCA (Case 1: external HR break near inlet header).

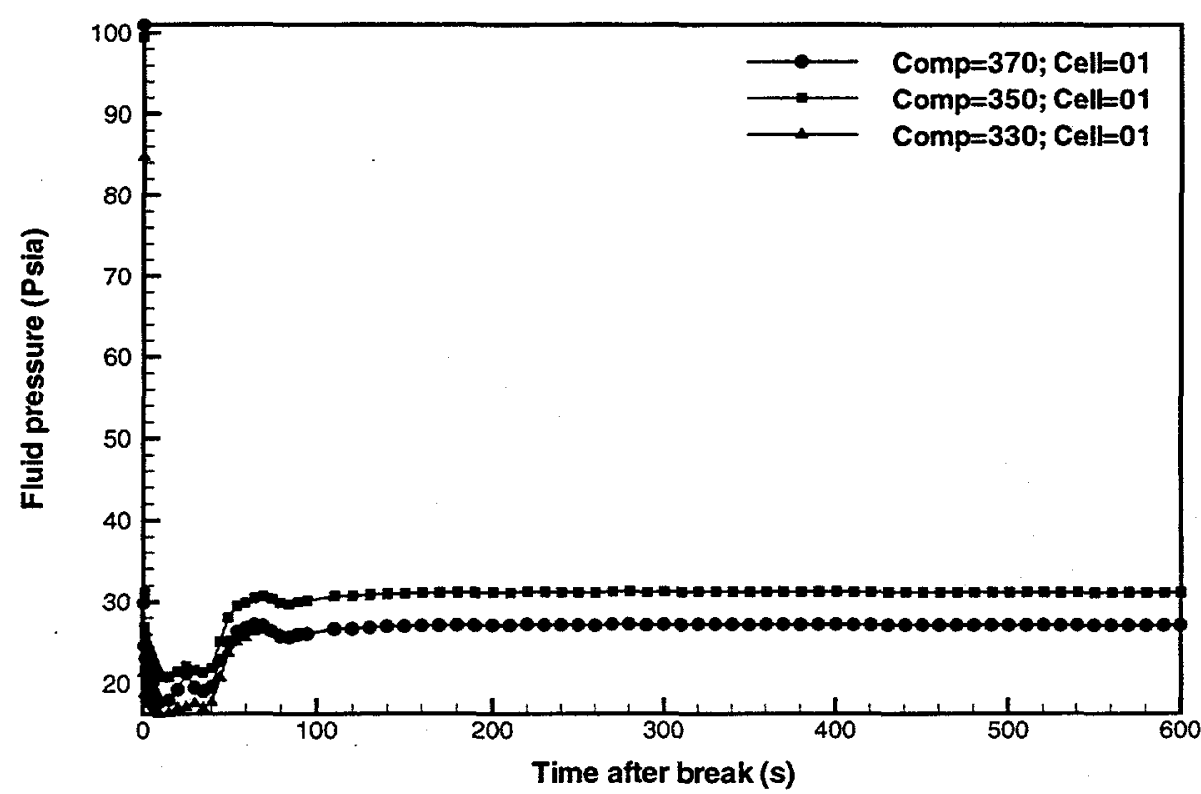

Figure B-2a Module 1 plenum fluid pressures for a LOCA (Case 1: external HR break near inlet header). 


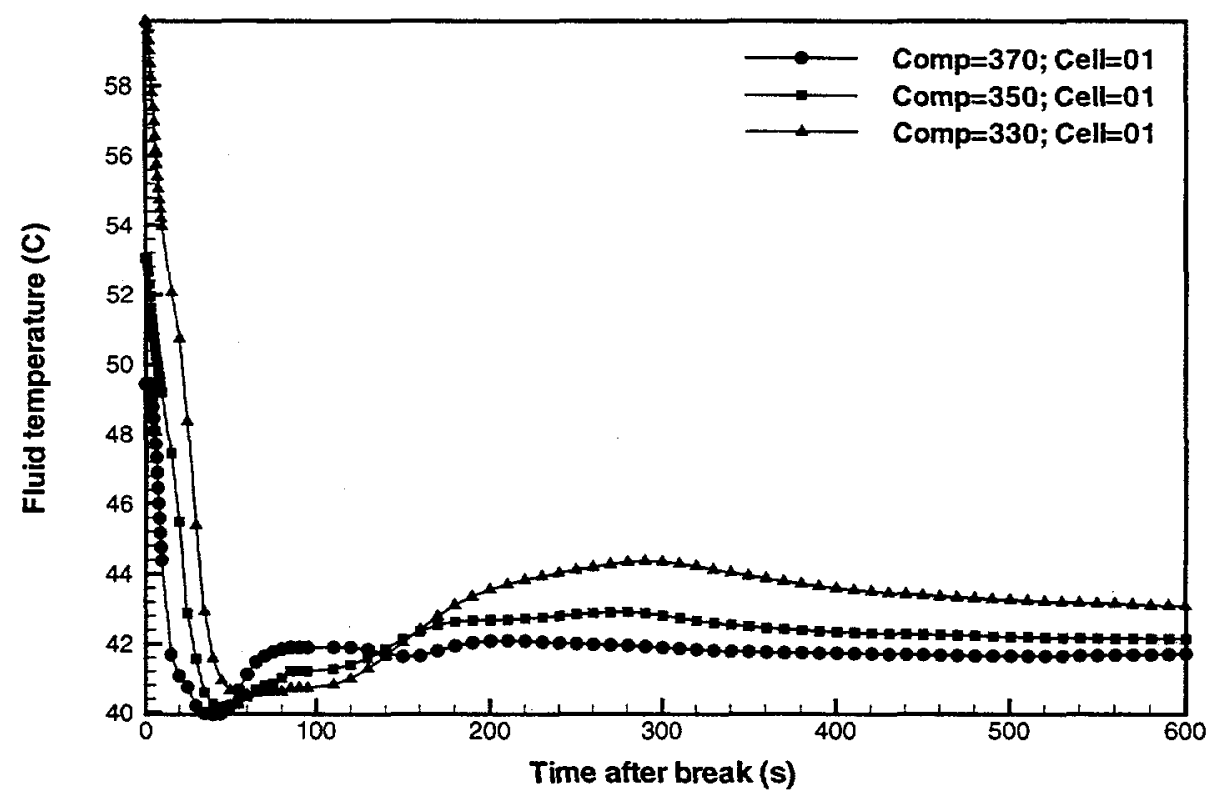

Figure B-2b Module 1 plenum fluid temperatures for a LOCA (Case 1: external HR break near inlet header).

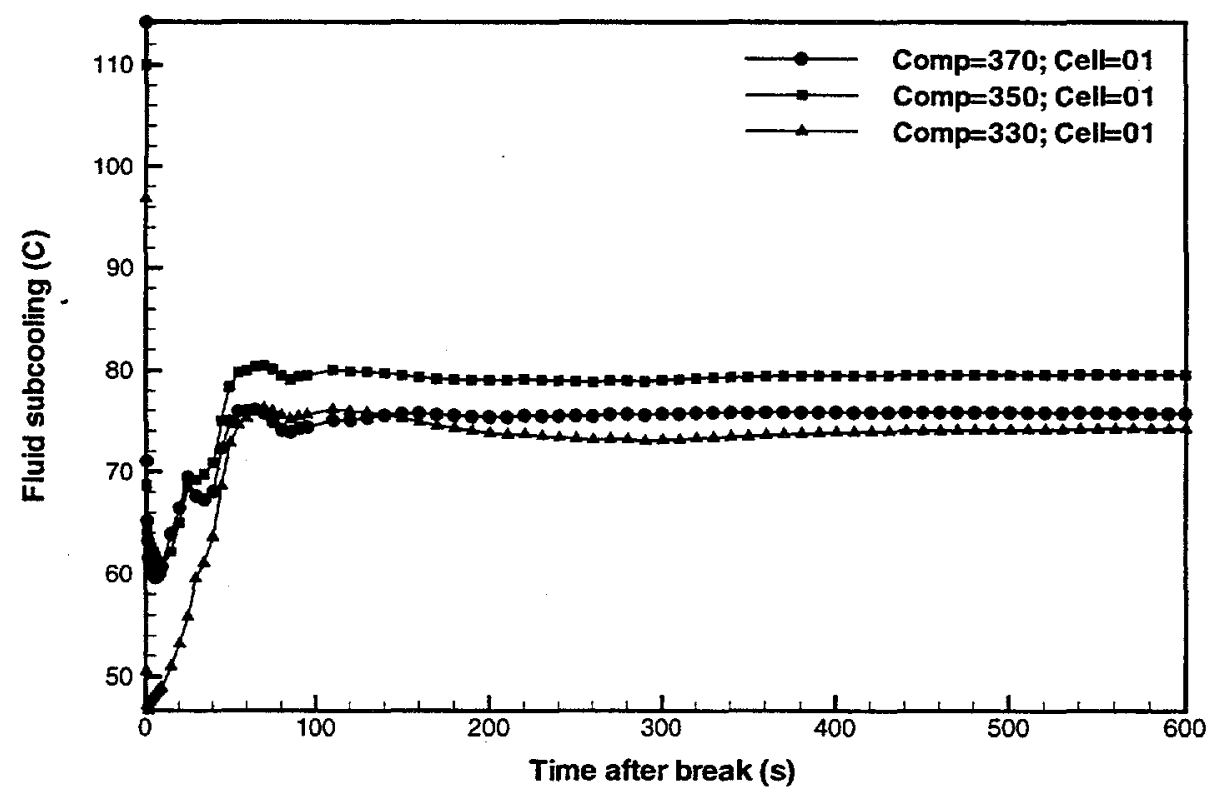

Figure B-2c Module 1 plenum fluid subcoolings for a LOCA (Case 1: external HR break near inlet header). 


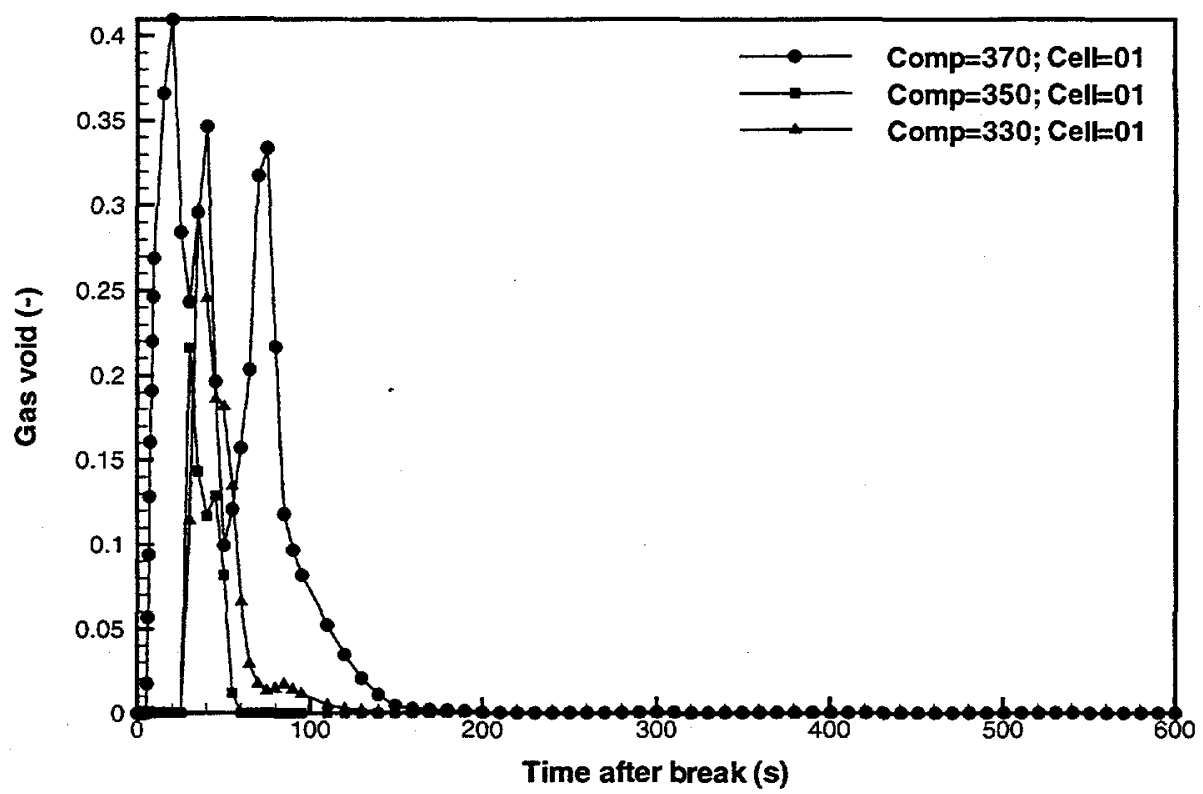

Figure B-2d Module 1 plenum void fractions for a LOCA (Case 1: external HR break near inlet header).

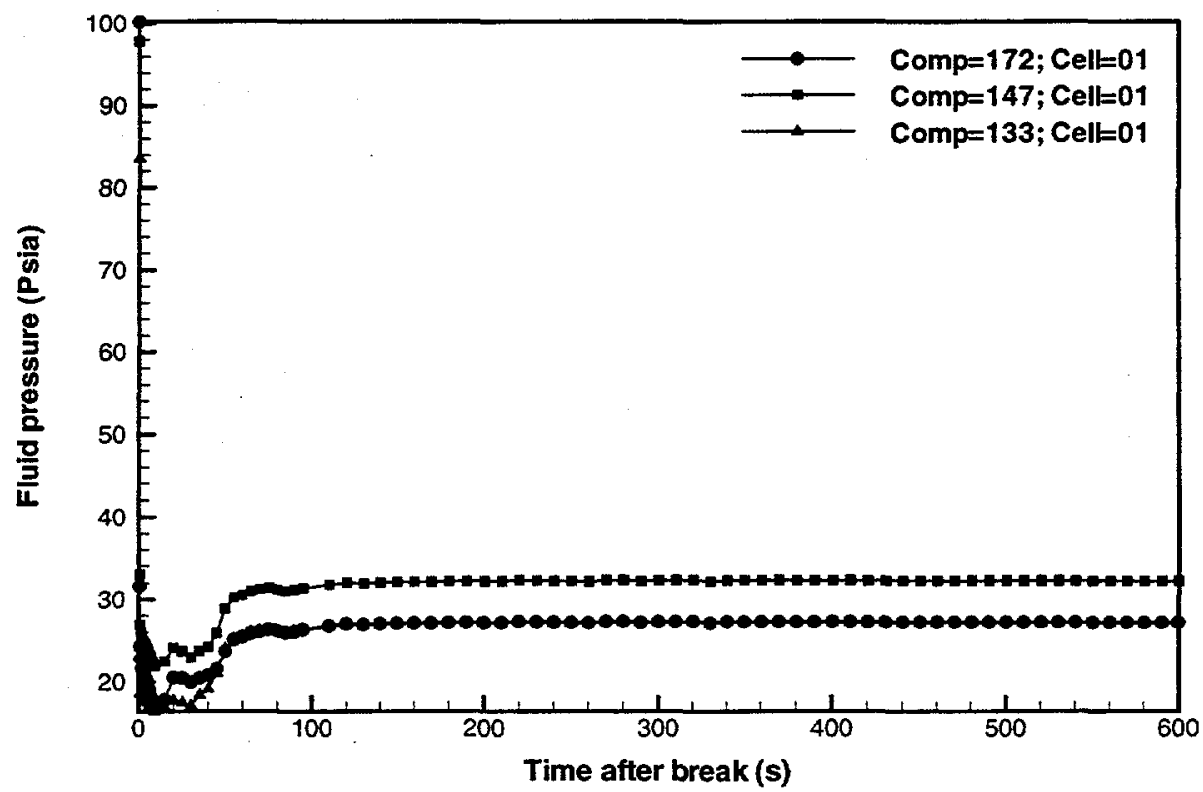

Figure B-3a Module 2 plenum fluid pressures for a LOCA (Case 1: external HR break near inlet header). 


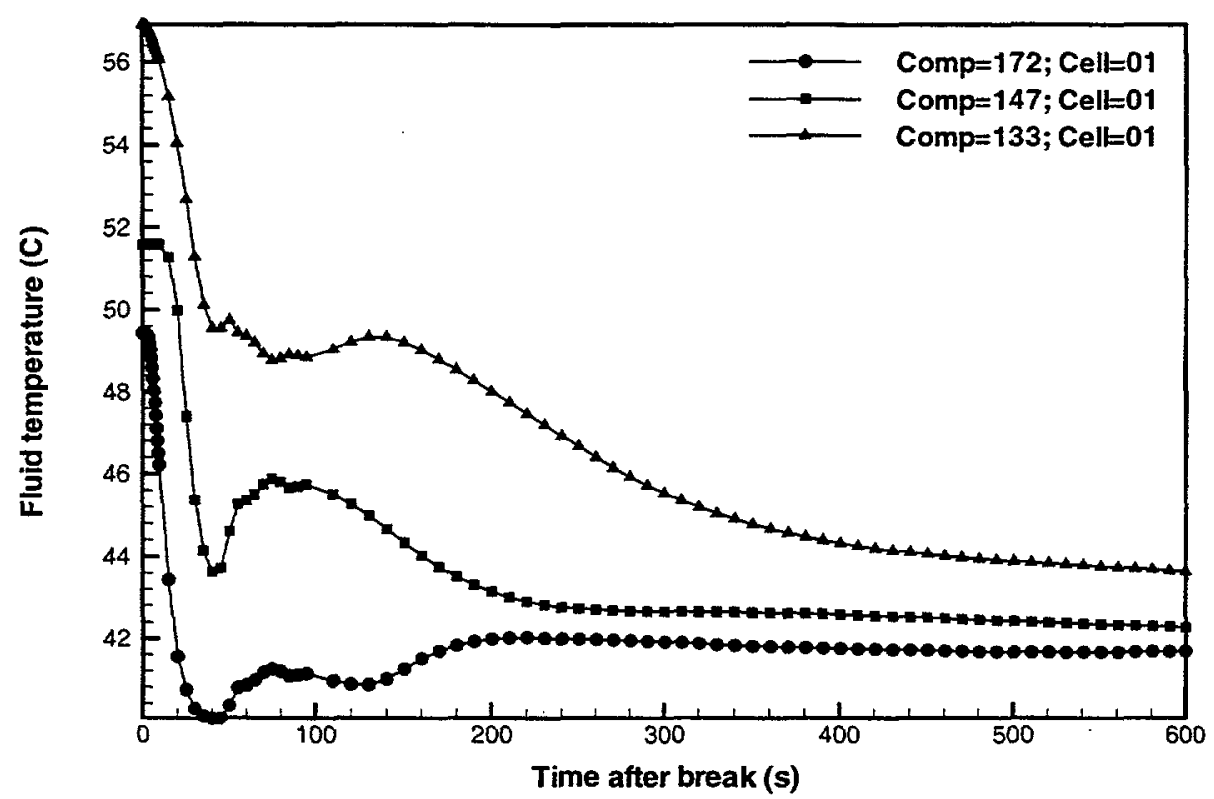

Figure B-3b Module 2 plenum fluid temperatures for a LOCA (Case 1: external HR break near inlet header).

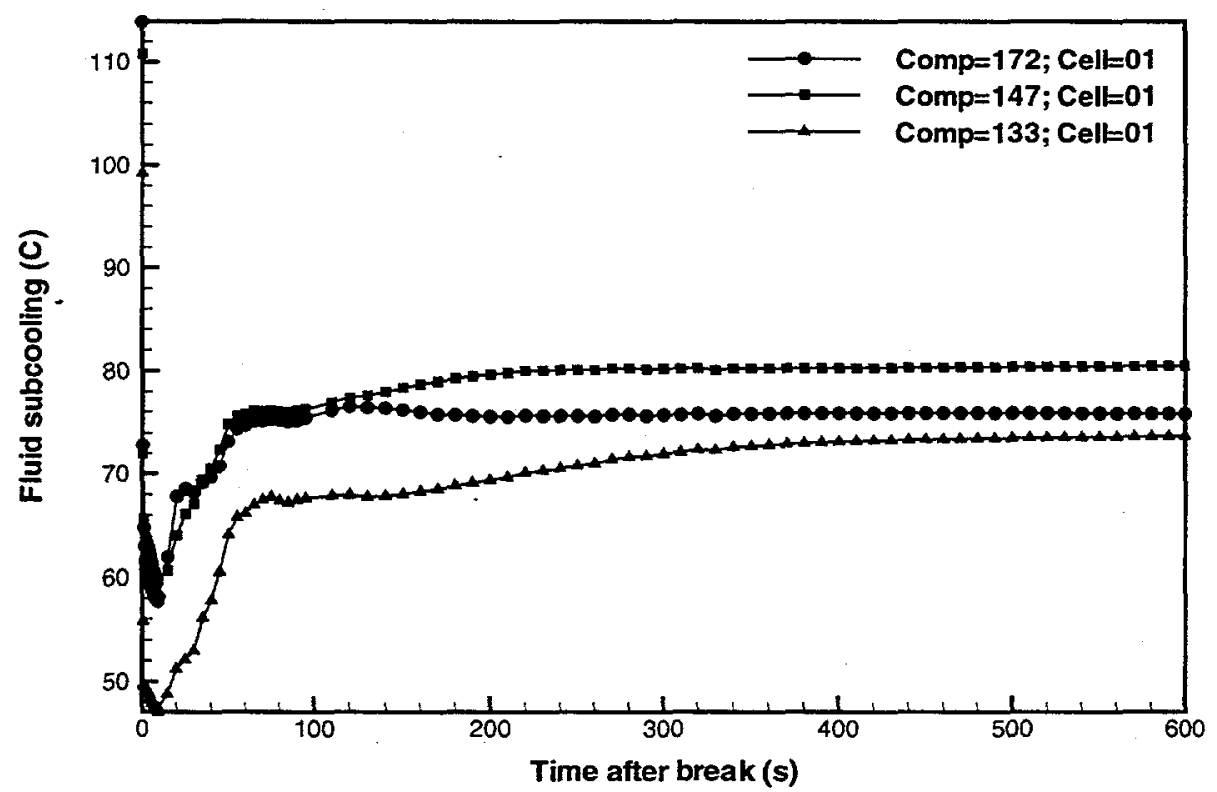

Figure B-3c Module 2 plenum fluid subcoolings for a LOCA (Case 1: external HR break near inlet header). 


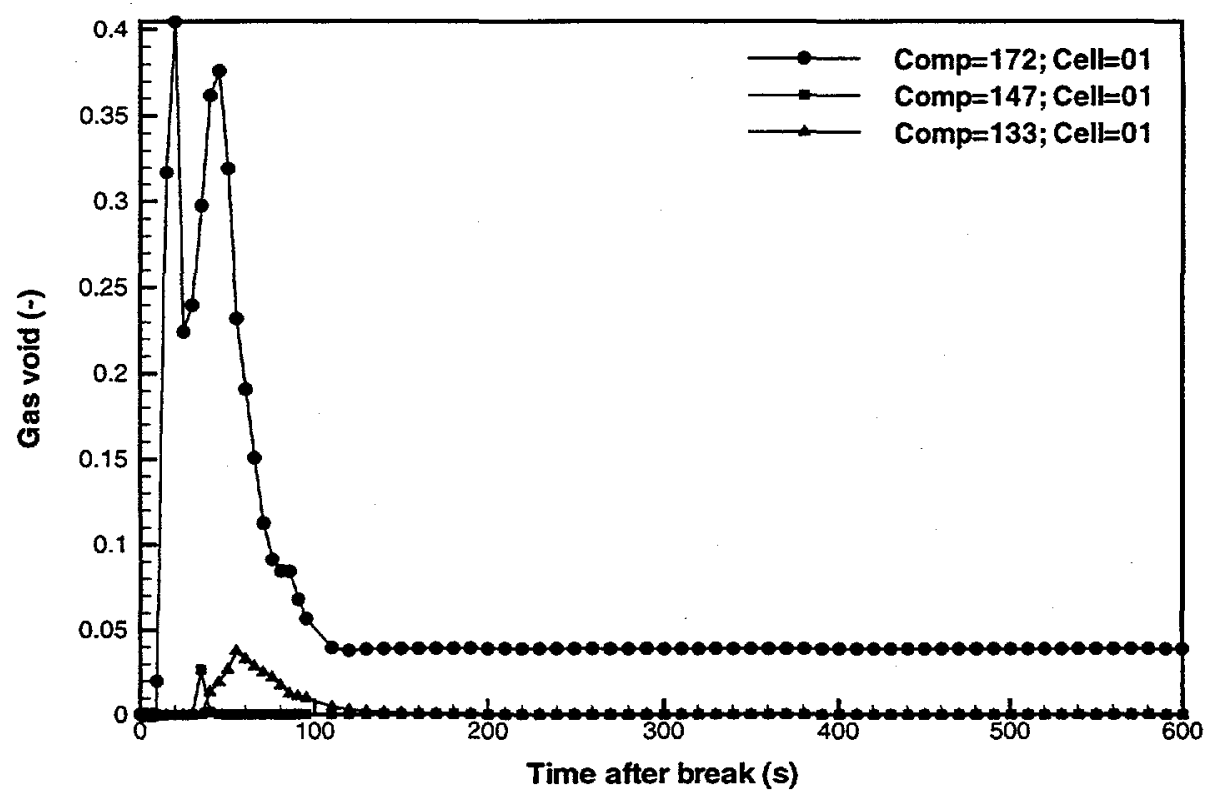

Figure B-3d Module 2 plenum void fractions for a LOCA (Case 1: external HR break near inlet header).

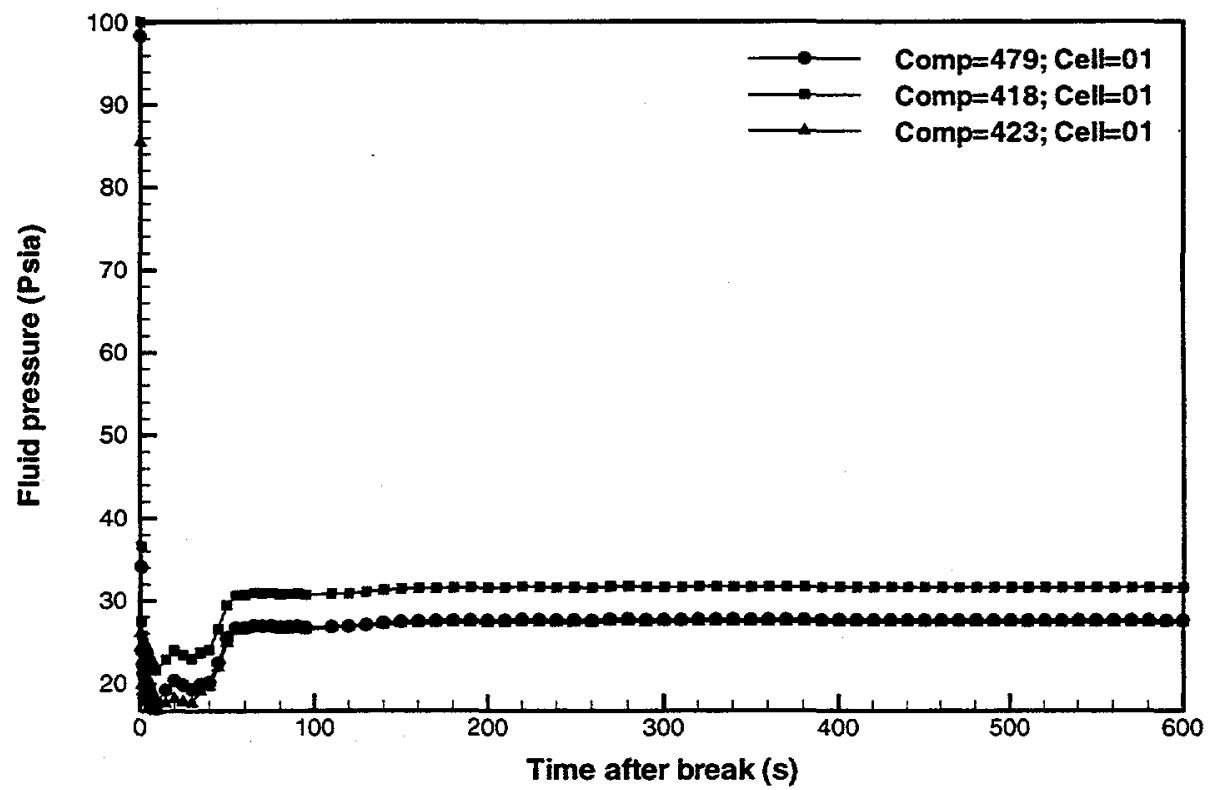

Figure B-4a Module 3 plenum fluid pressures for a LOCA (Case 1: external HR break near inlet header). 


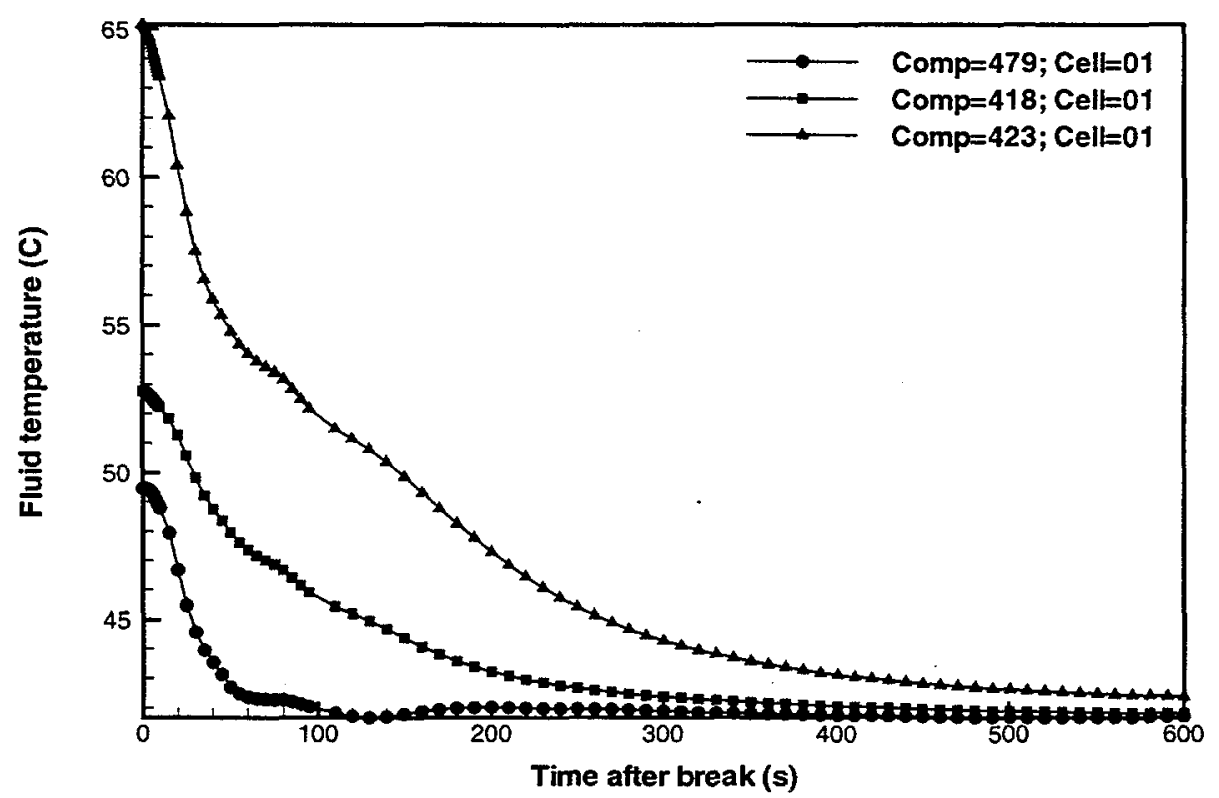

Figure B-4b Module 3 plenum fluid temperatures for a LOCA (Case-1: external HR break near inlet header).

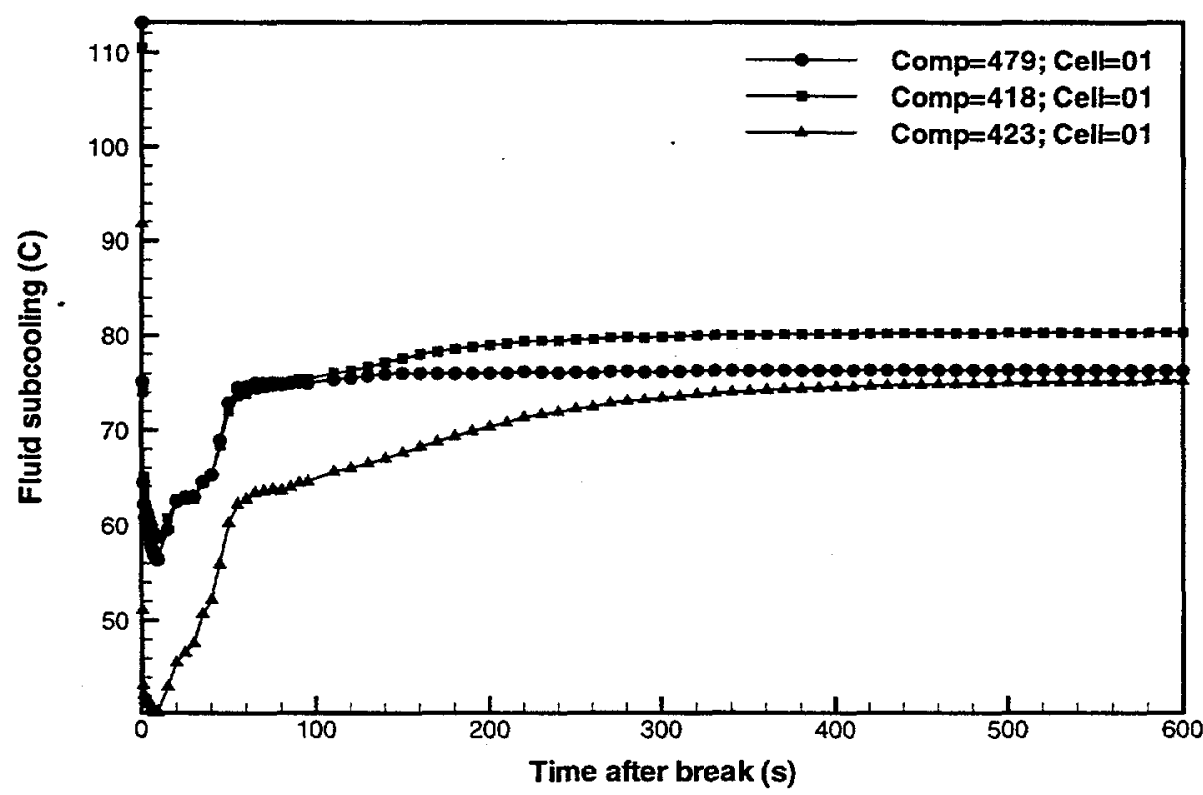

Figure B-4c Module 3 plenum fluid subcoolings for a LOCA (Case 1: external HR break near inlet header). 


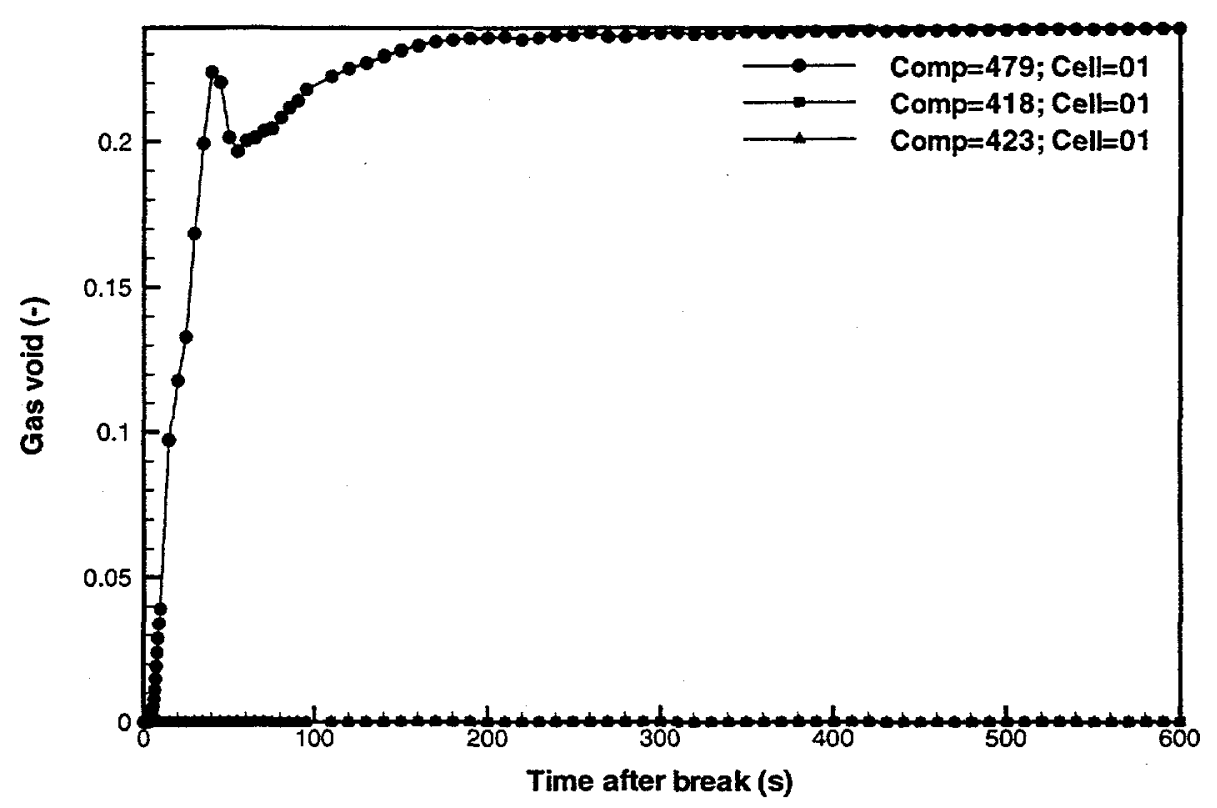

Figure B-4d Module 3 plenum void fractions for a LOCA (Case 1: external HR break near inlet header).

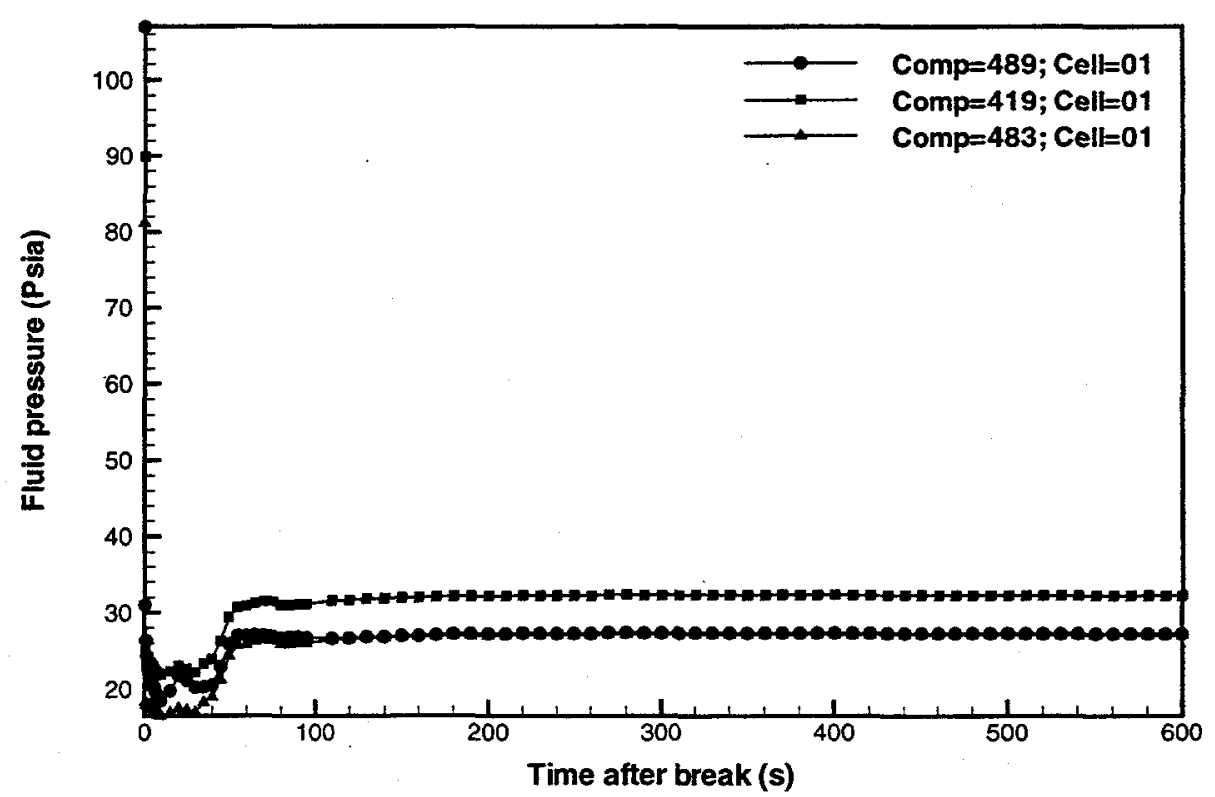

Figure B-5a Module 4 plenum fluid pressures for a LOCA (Case 1: external HR break near inlet header). 


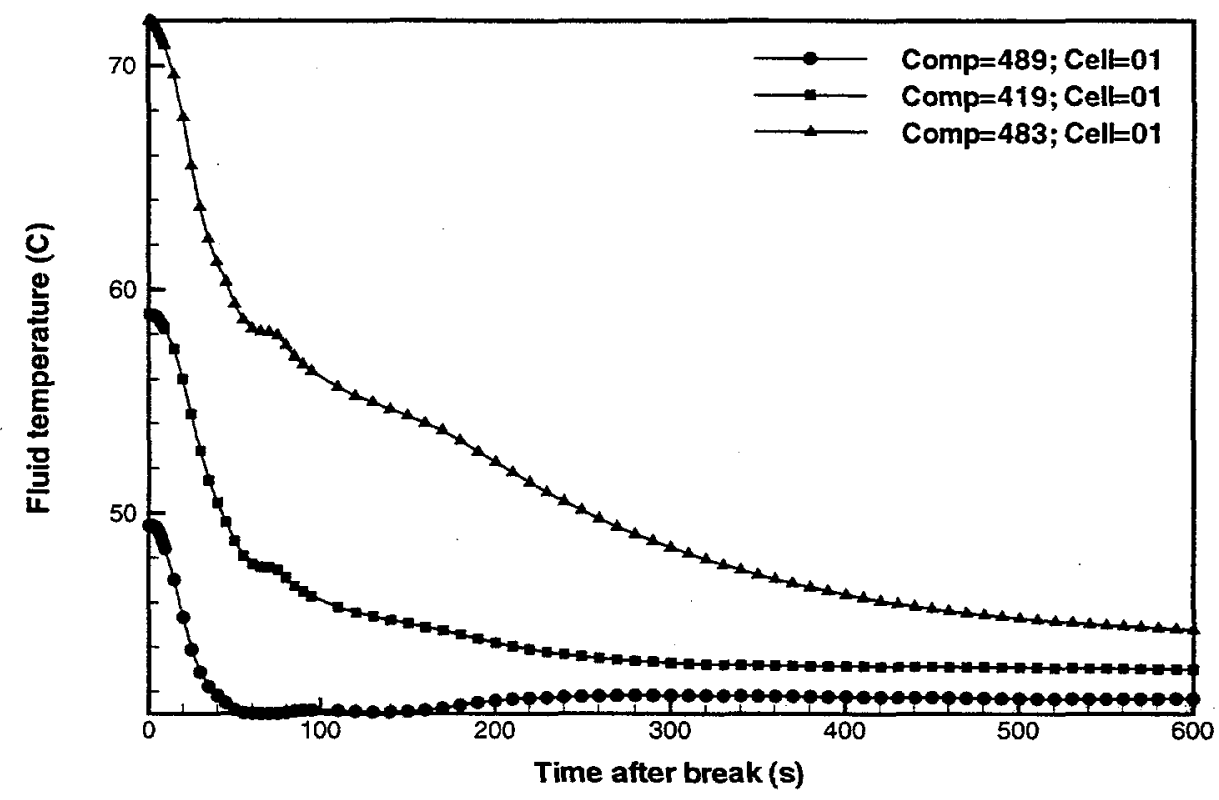

Figure B-5b Module 4 plenum fluid temperatures for a LOCA (Case 1: external HR break near inlet header).

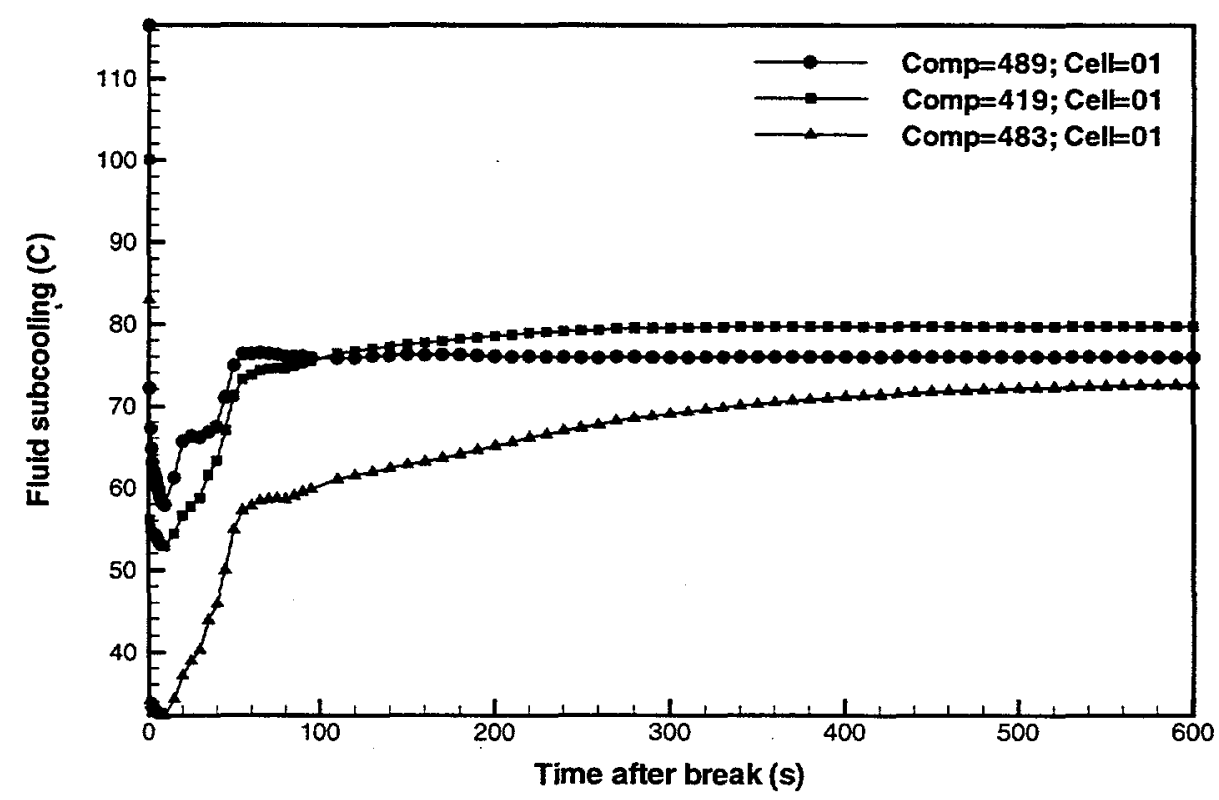

Figure B-5c Module 4 plenum fluid subcoolings for a LOCA (Case 1: external HR break near inlet header). 


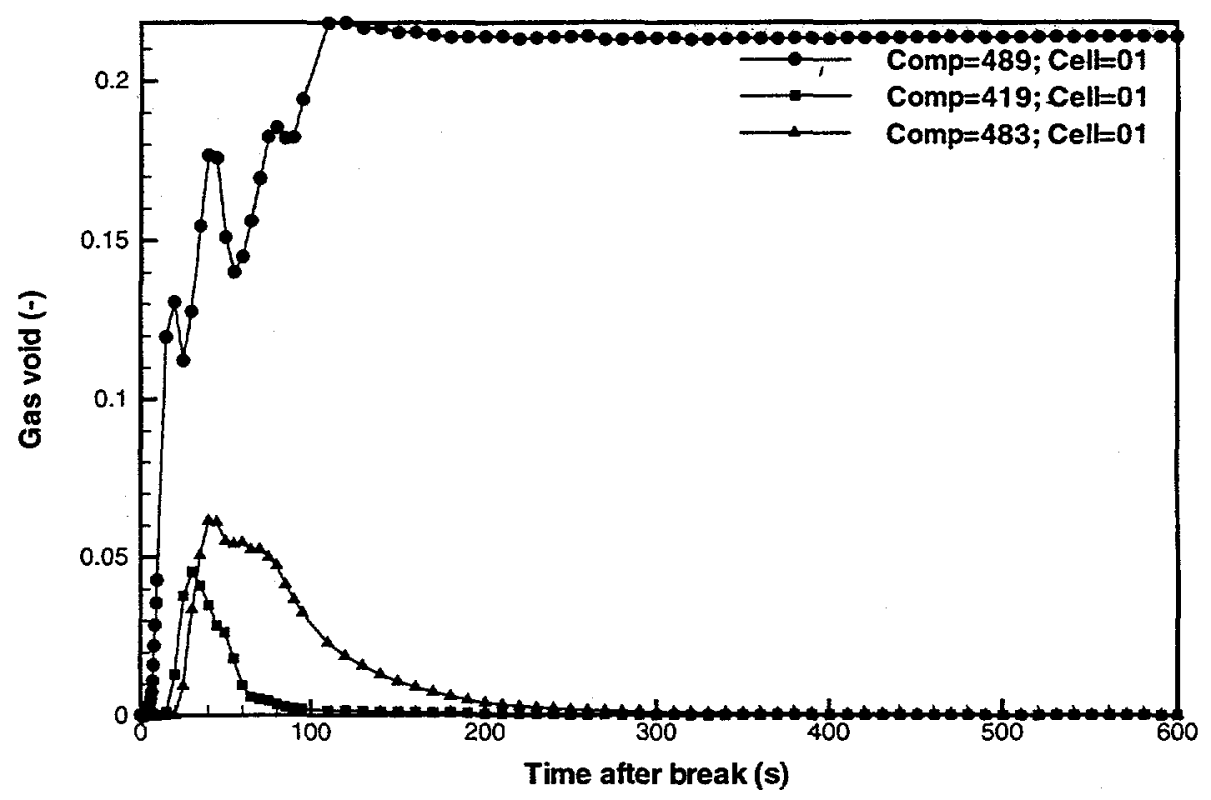

Figure B-5d Module 4 plenum void fractions for a LOCA (Case 1: external HR break near inlet header).

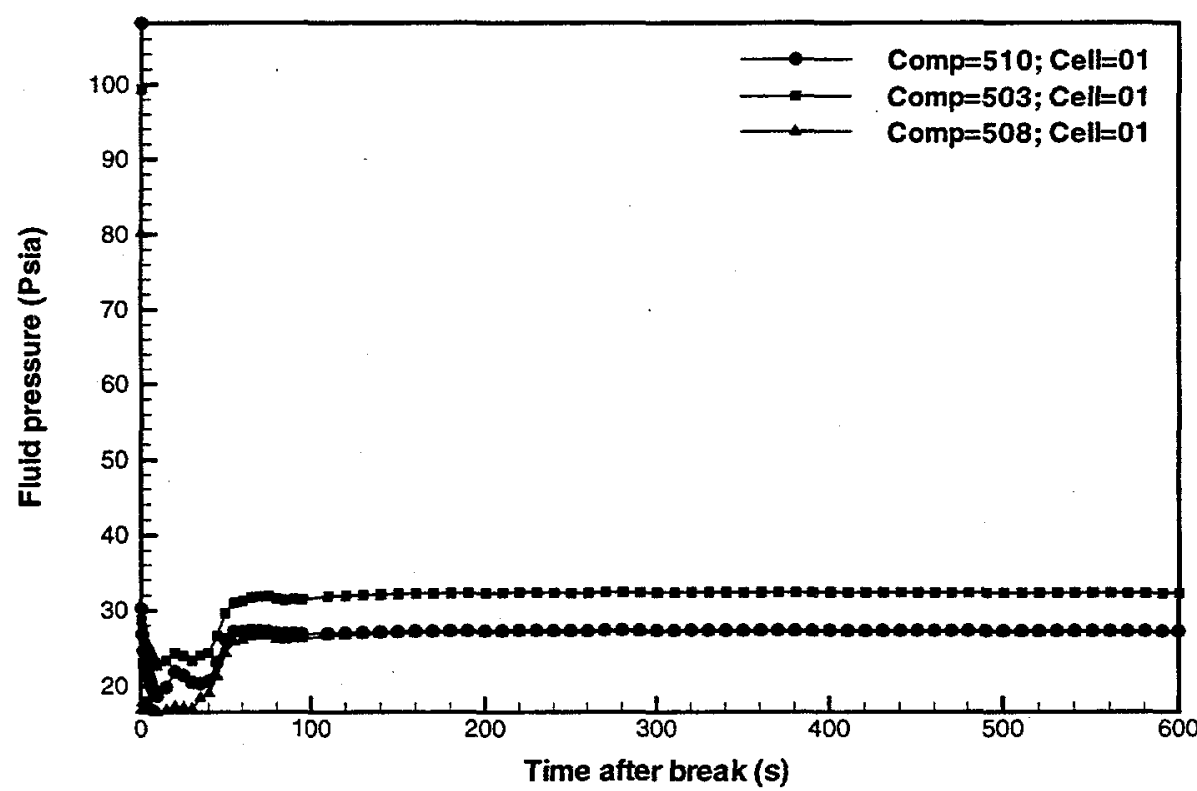

Figure B-6a Module 5 plenum fluid pressures for a LOCA (Case 1: external HR break near inlet header). 


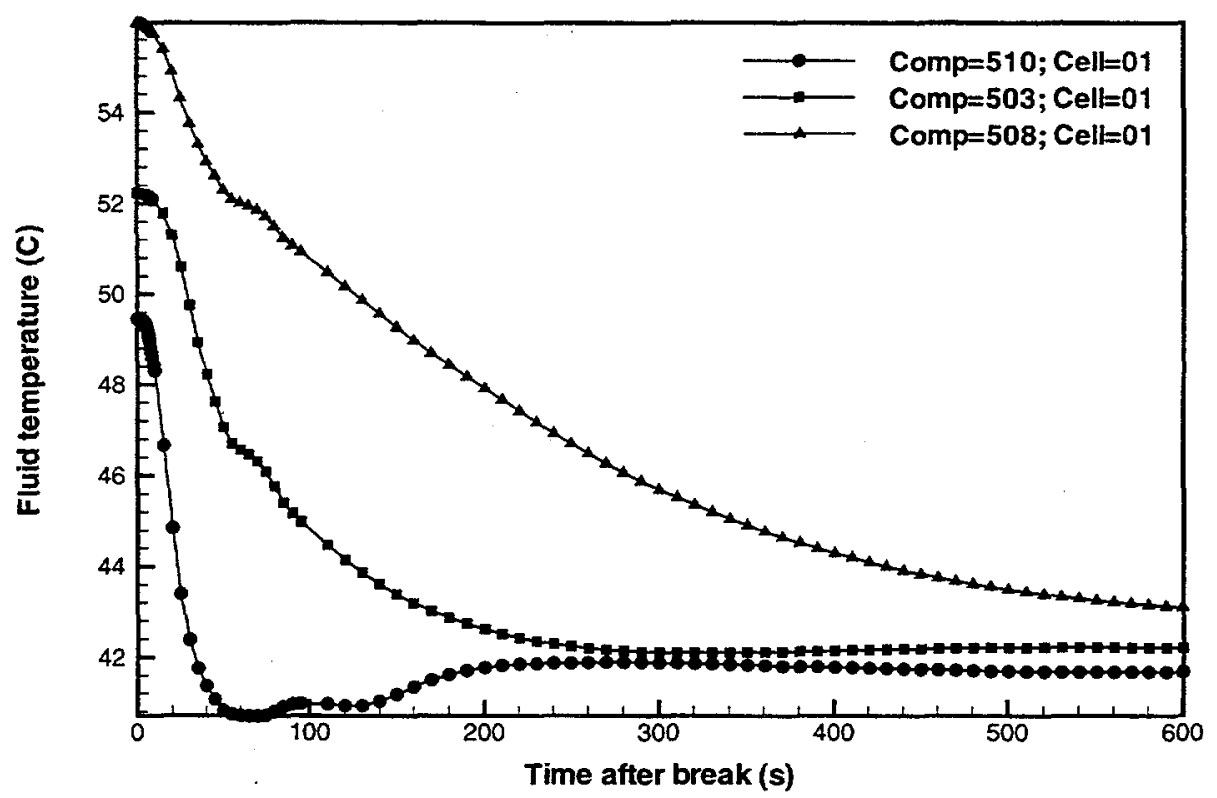

Figure B-6b Module 5 plenum fluid temperatures for a LOCA (Case 1: external HR break near inlet header).

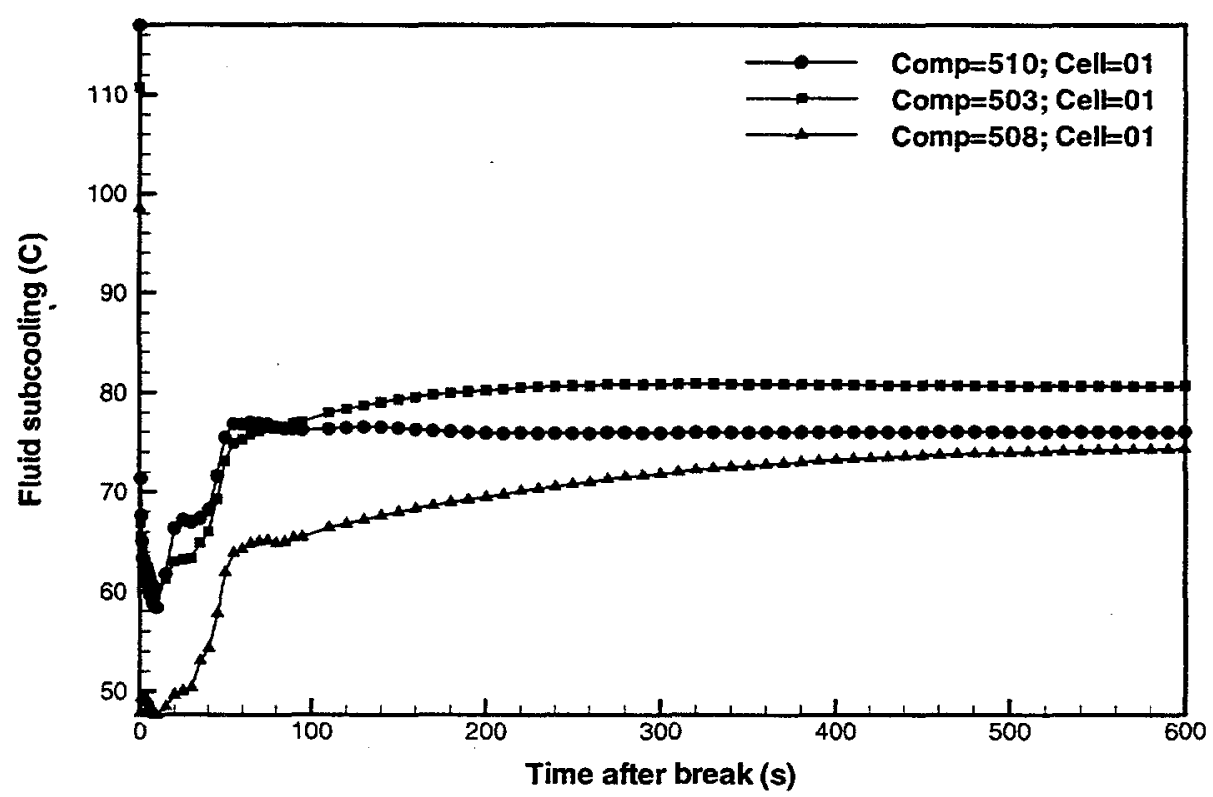

Figure B-6c Module 5 plenum fluid subcoolings for a LOCA (Case 1: external HR break near inlet header). 


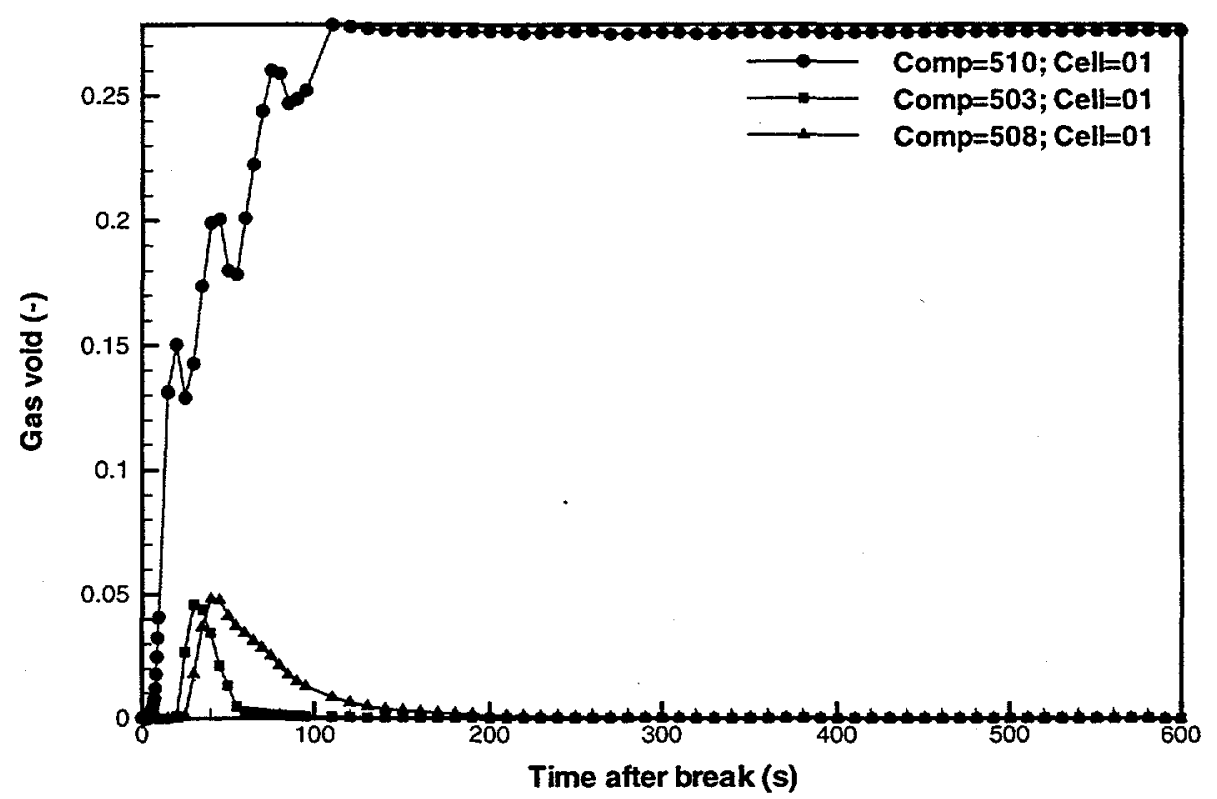

Figure B-6d Module 5 plenum void fractions for a LOCA (Case 1: external HR break near inlet header).

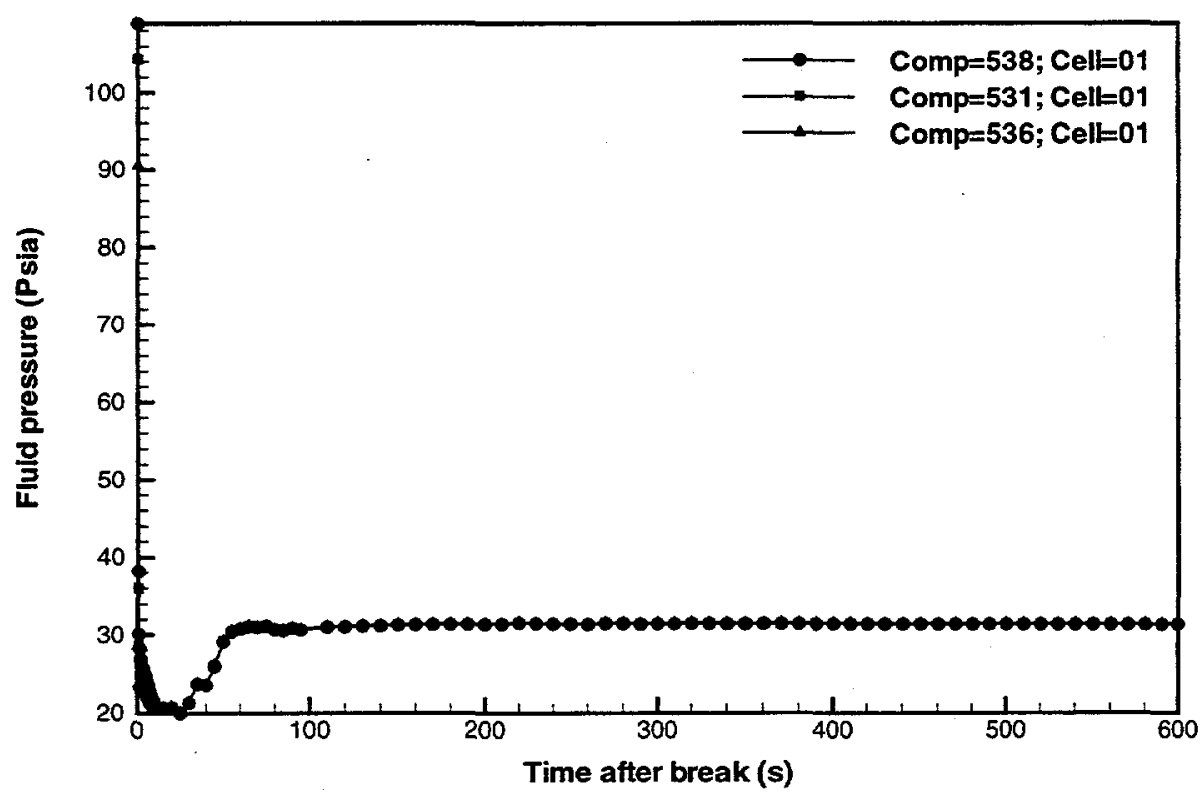

Figure B-7a Module 6 plenum fluid pressures for a LOCA (Case 1: external HR break near inlet header). 


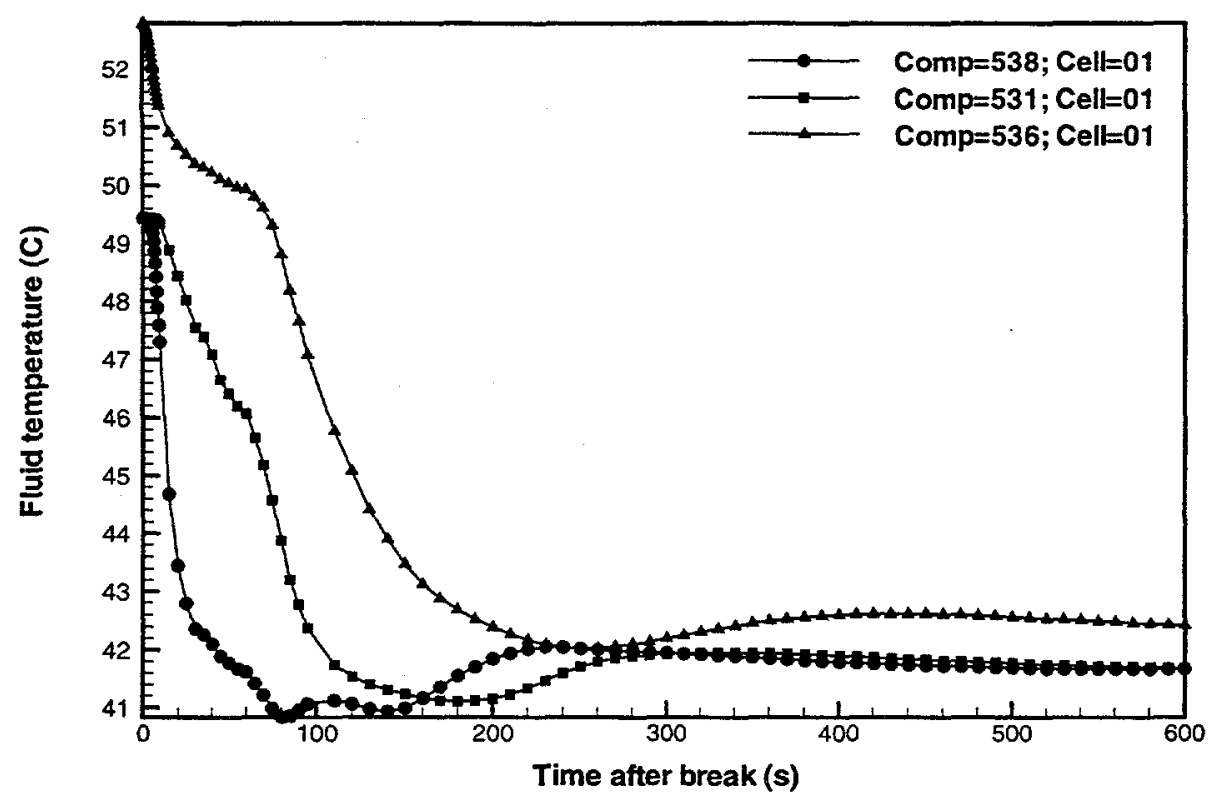

Figure B-7b Module 6 plenum fluid temperatures for a LOCA (Case 1: external HR break near inlet header).

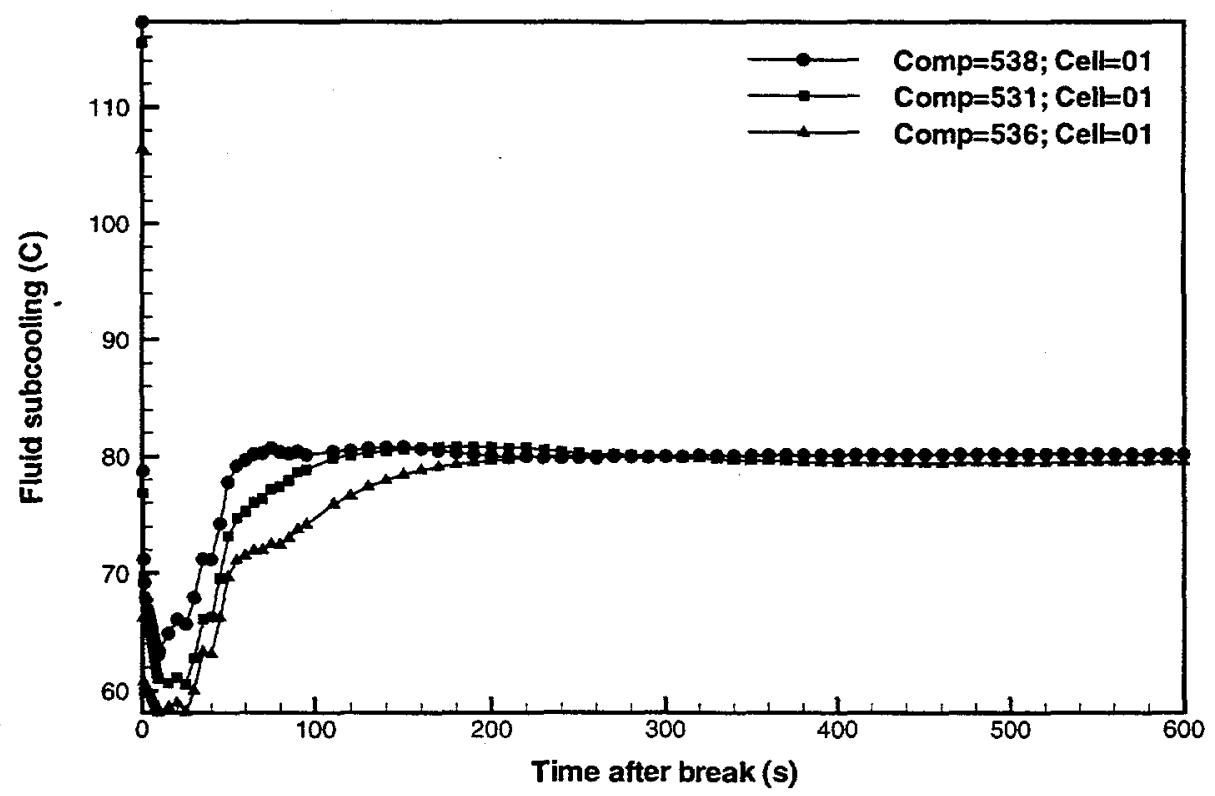

Figure B-7c Module 6 plenum fluid subcoolings for a LOCA (Case 1: external HR break near inlet header). 


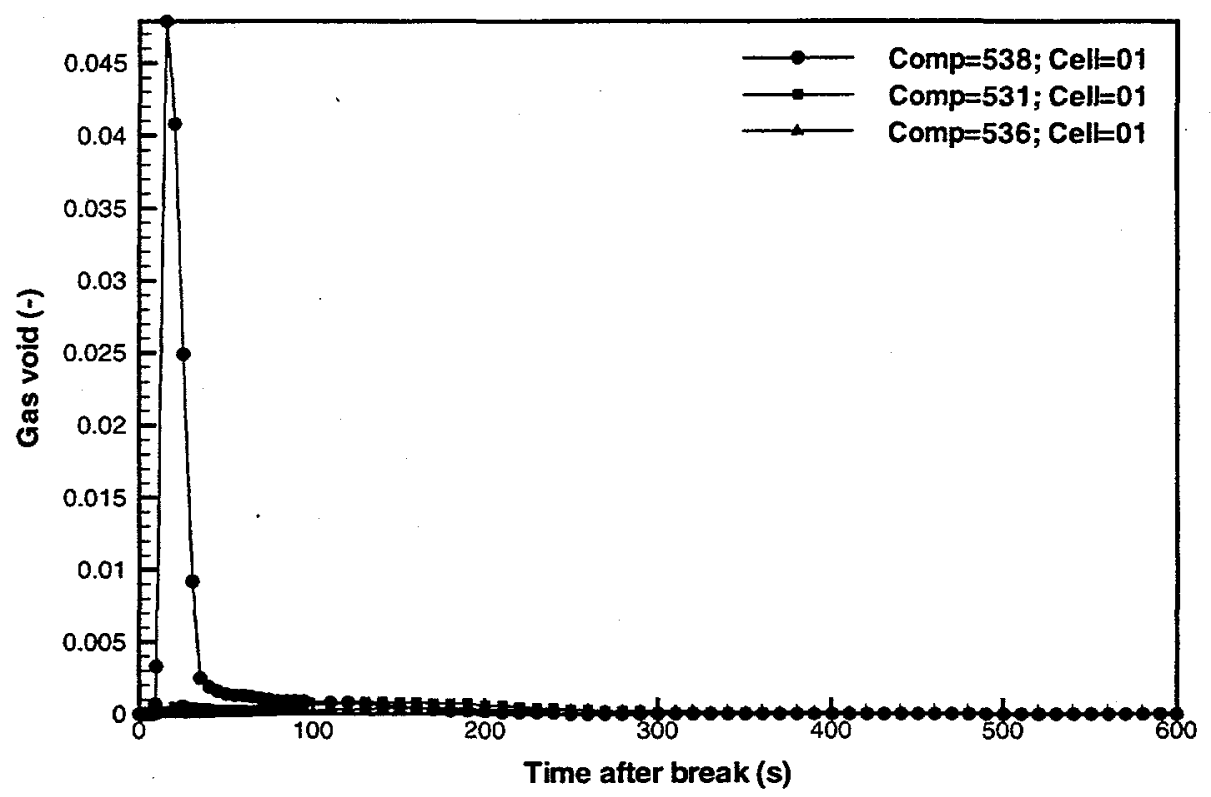

Figure B-7d Module 6 plenum void fractions for a LOCA (Case 1: external HR break near inlet header). 


\section{Appendix B2 LOCA (Case 1) TRAC Pipe, Pump, and Valve Component} Figures

The following figures are from a TRAC simulation for Case 1 of a LOCA (external HR break near inlet header):

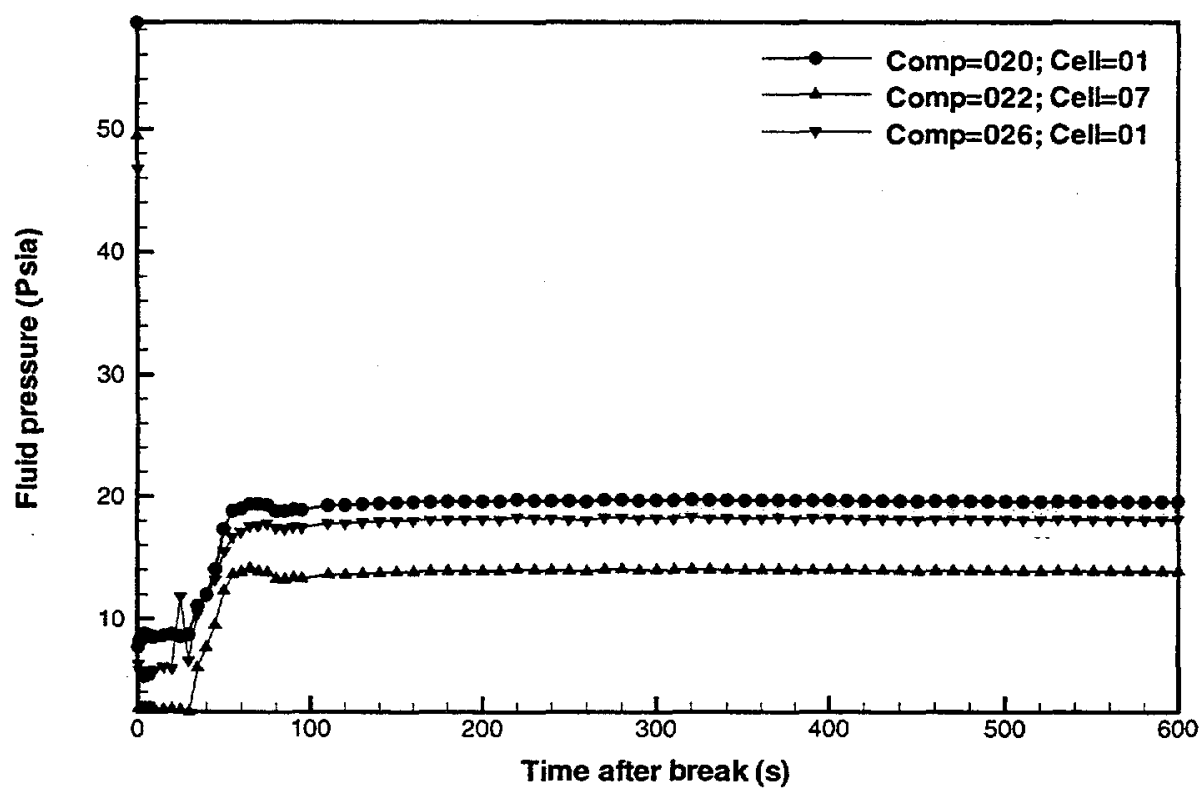

Figure B-8a Primary HR hot-leg piping fluid pressures for a LOCA (Case 1: external HR break near inlet header). 


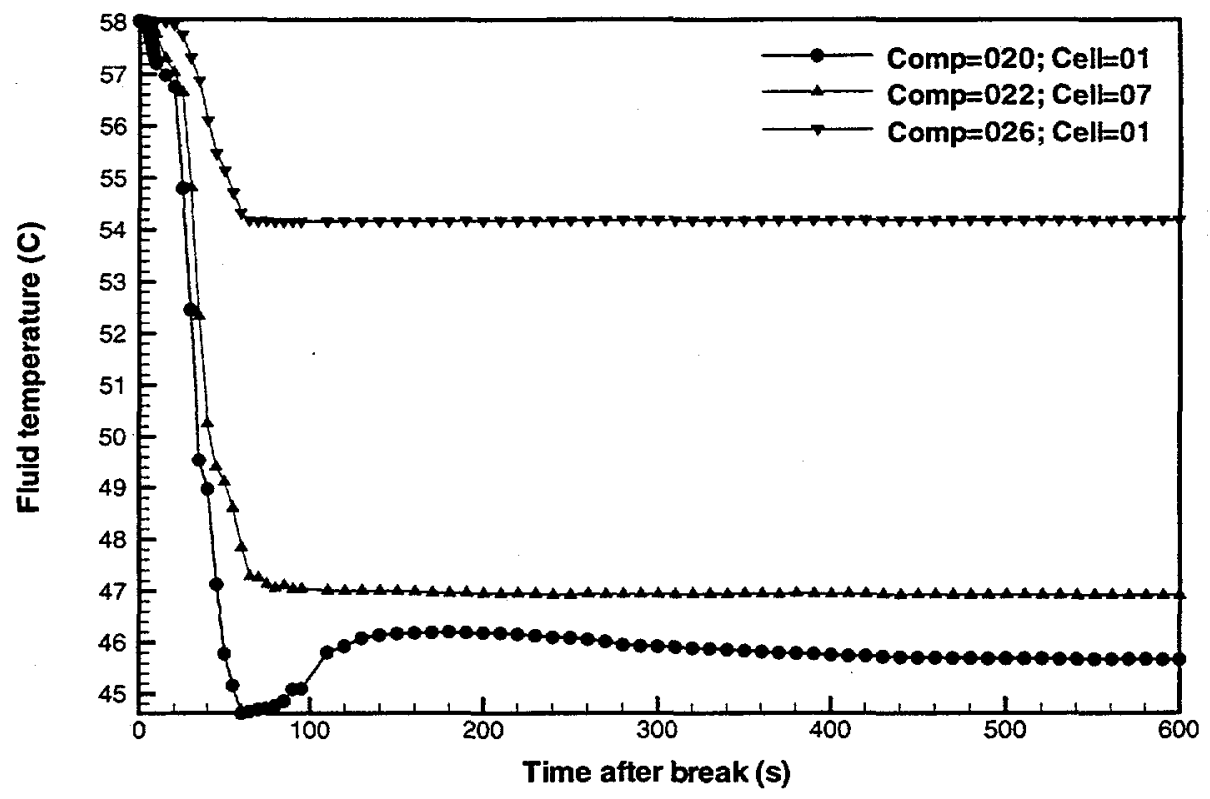

Figure B-8b Primary HR hot-leg piping fluid temperatures for a LOCA (Case 1: external HR break near inlet header).

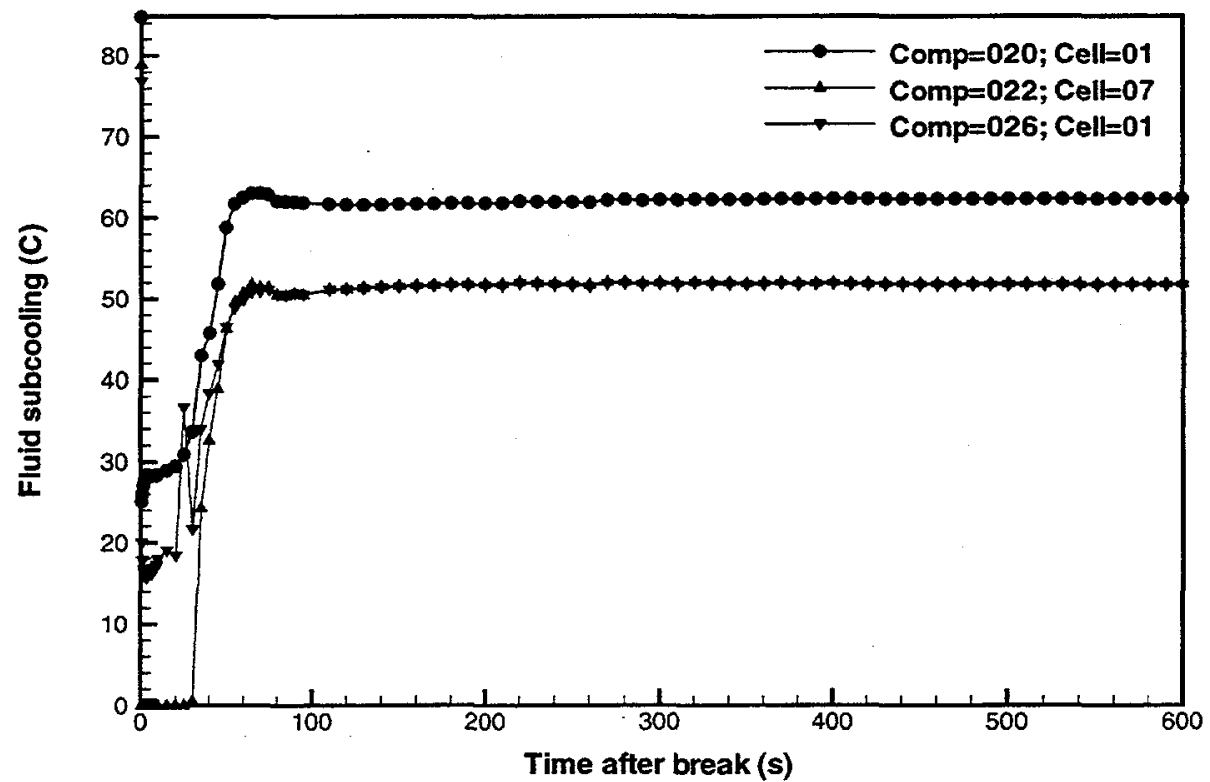

Figure B-8c Primary HR hot-leg piping fluid subcoolings for a LOCA (Case 1: external HR break near inlet header). 


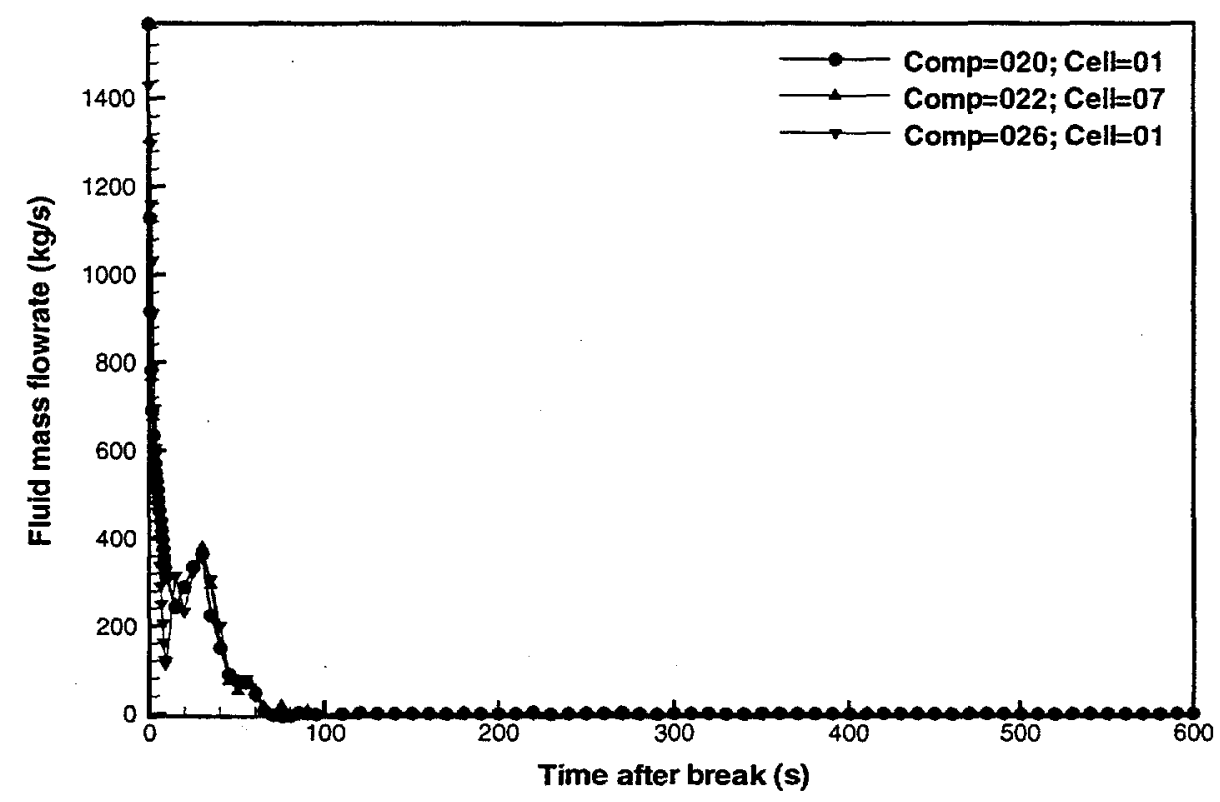

Figure B-8d Primary HR hot-leg piping liquid mass flowrates for a-LOCA (Case 1: external HR break near inlet header).

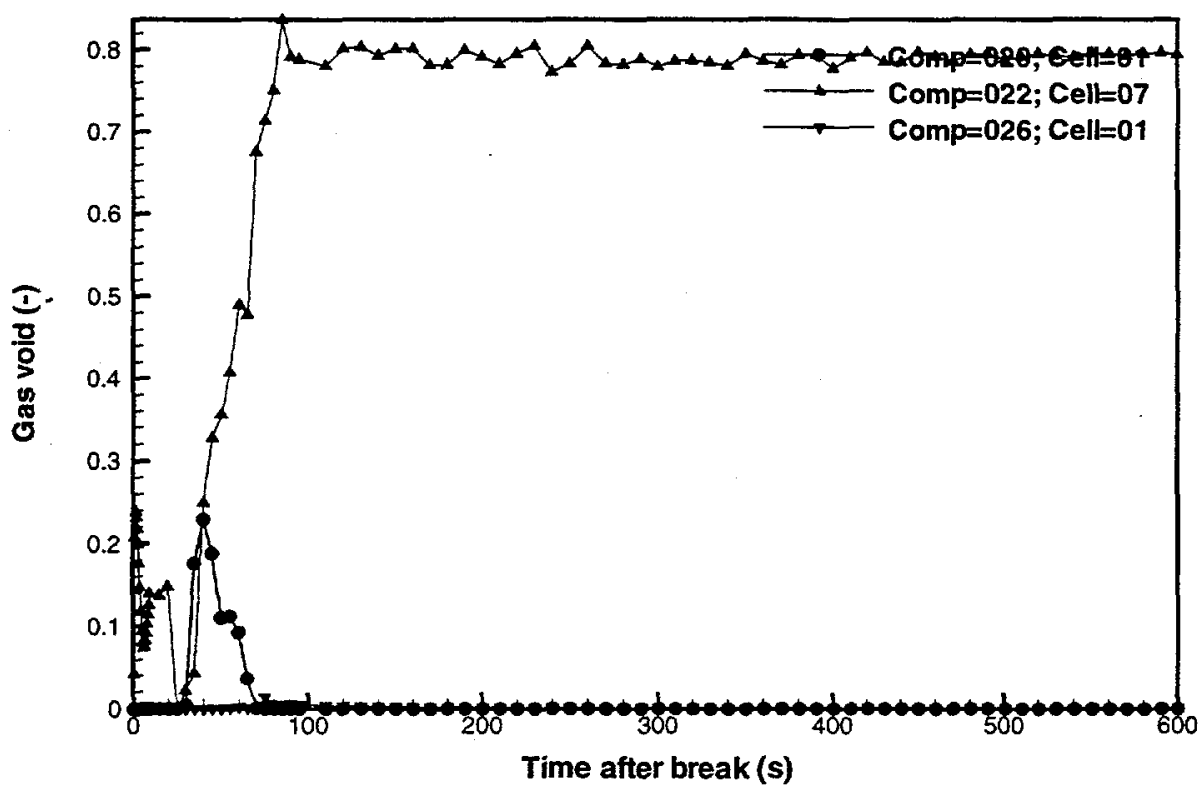

Figure B-8e Primary HR hot-leg piping void fractions for a LOCA (Case 1: external HR break near inlet header). 


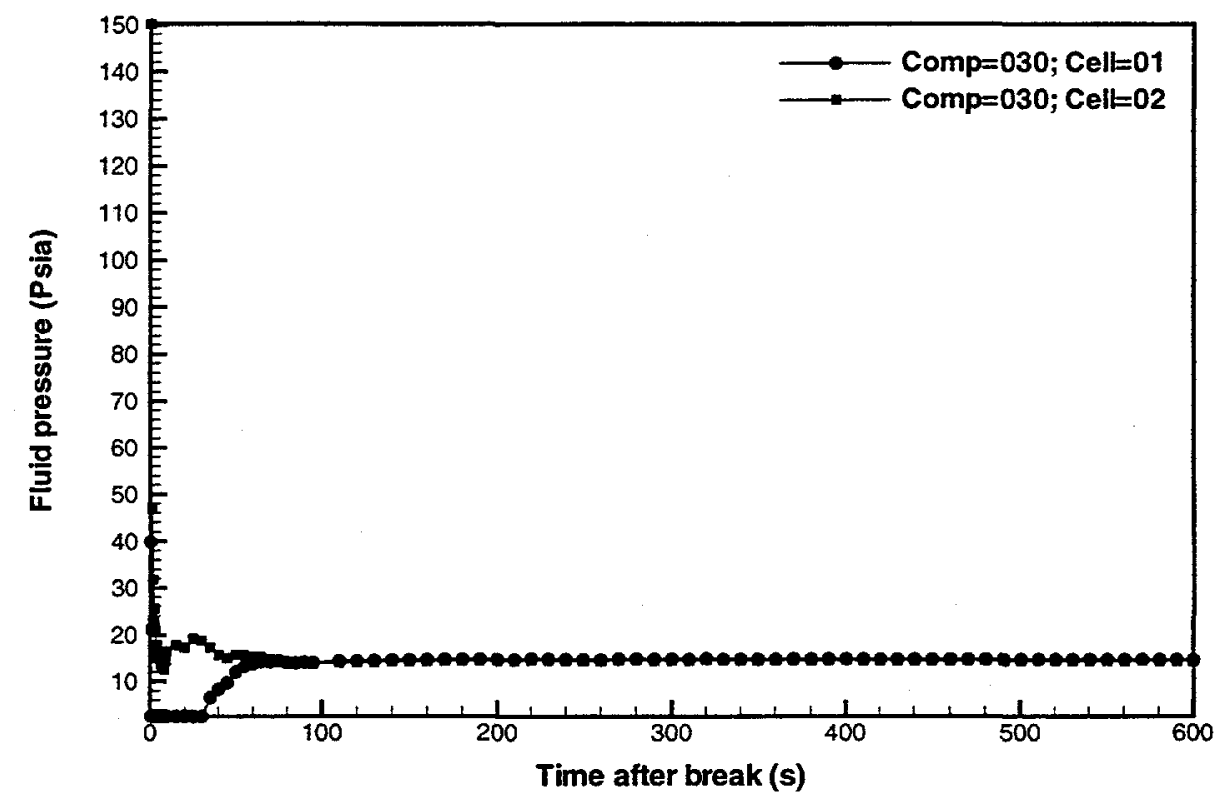

Figure B-9a Primary HR pump 1 fluid pressures for a LOCA (Case 1: external HR break near inlet header).

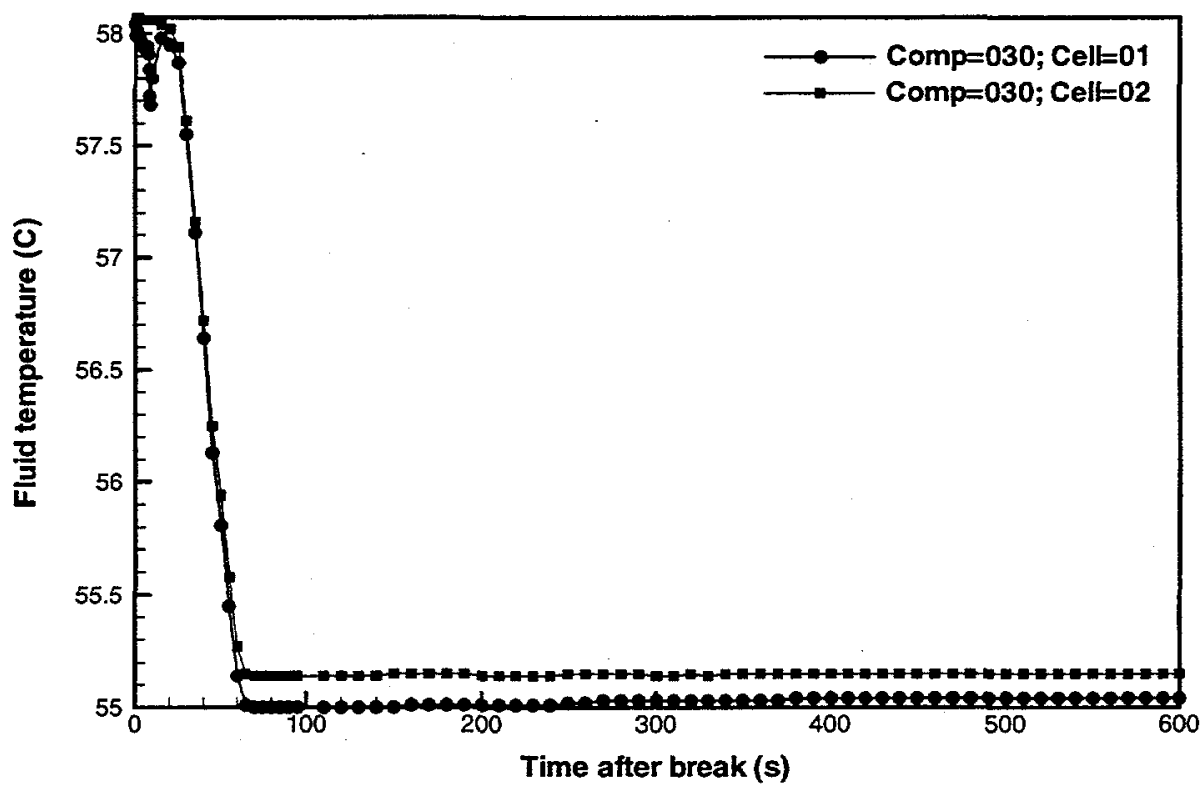

Figure B-9b Primary HR pump 1 fluid temperatures for a LOCA (Case 1: external HR break near inlet header). 


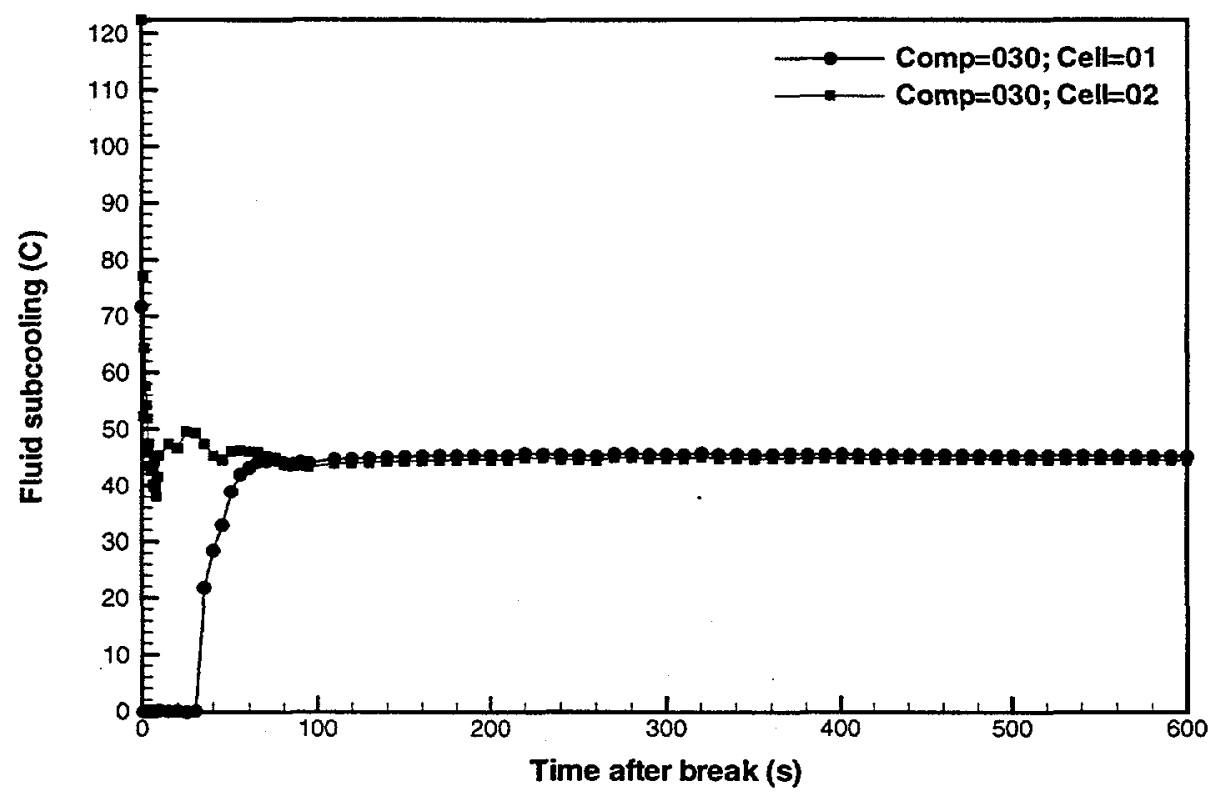

Figure B-9c Primary HR pump 1 fluid subcoolings for a LOCA (Case 1: external HR break near inlet header).

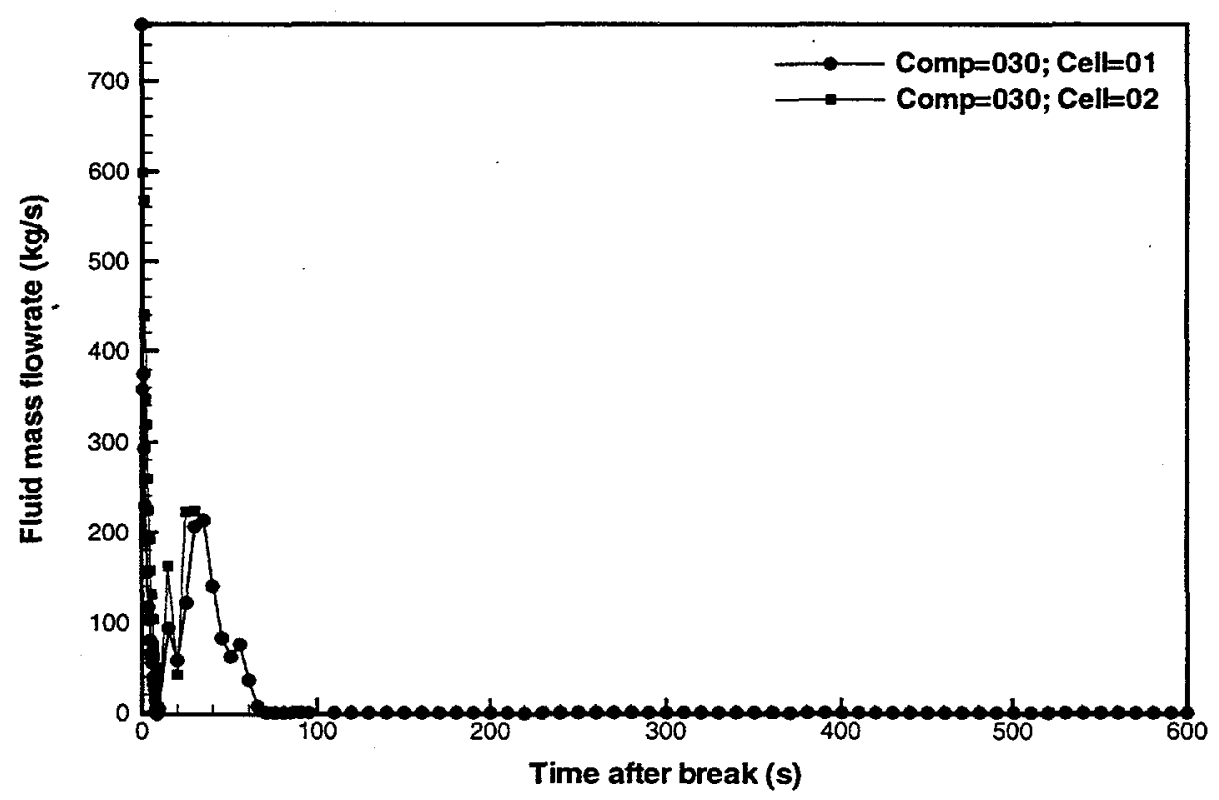

Figure B-9d Primary HR pump 1 liquid mass flowrates for a LOCA (Case 1: external HR break near inlet header). 


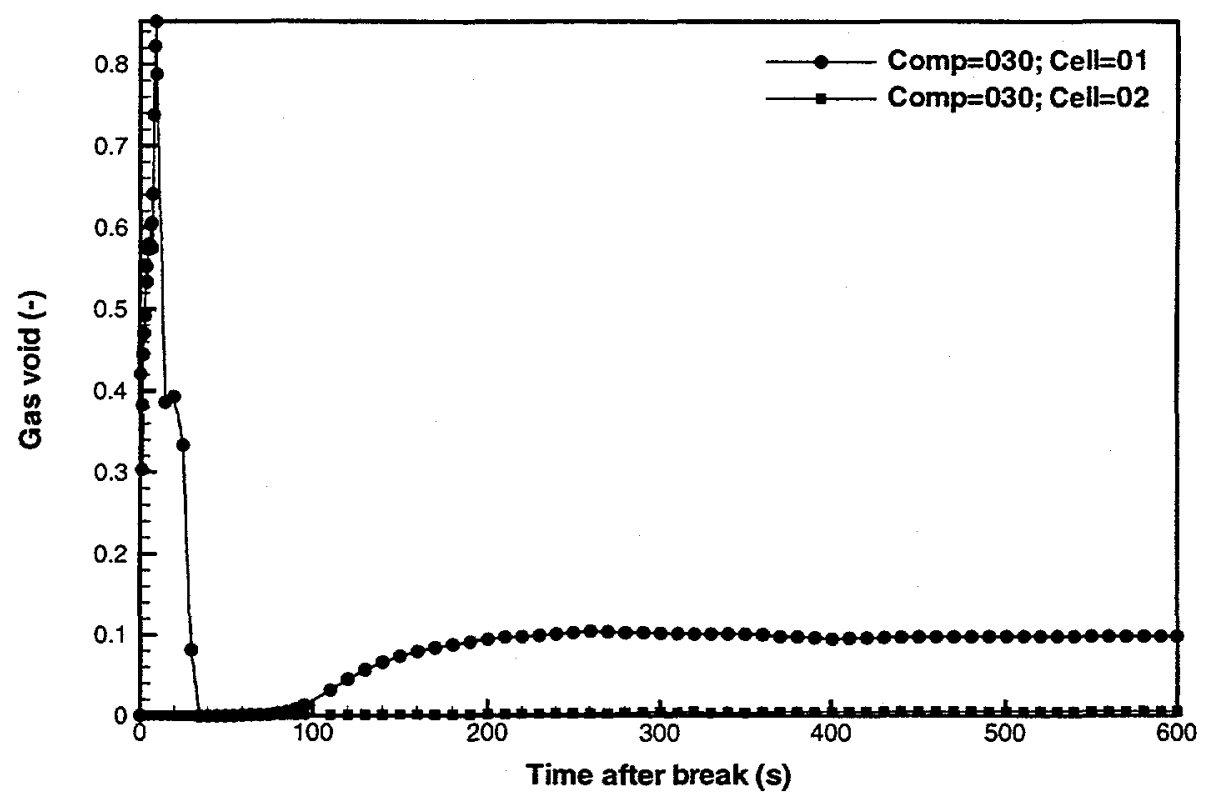

Figure B-9e Primary HR pump 1 void fractions for a LOCA (Case 1: external HR break near inlet header).

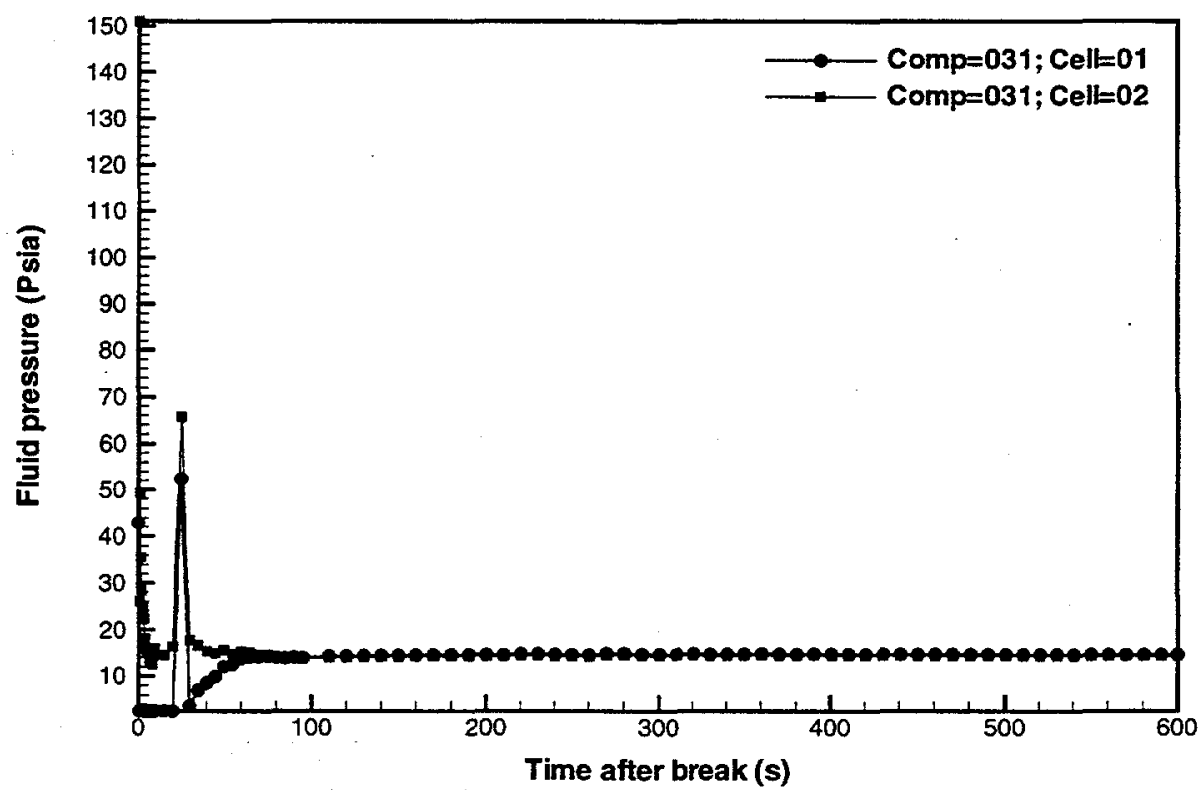

Figure B-10a Primary HR pump 2 fluid pressures for a LOCA (Case 1: external HR break near inlet header). 


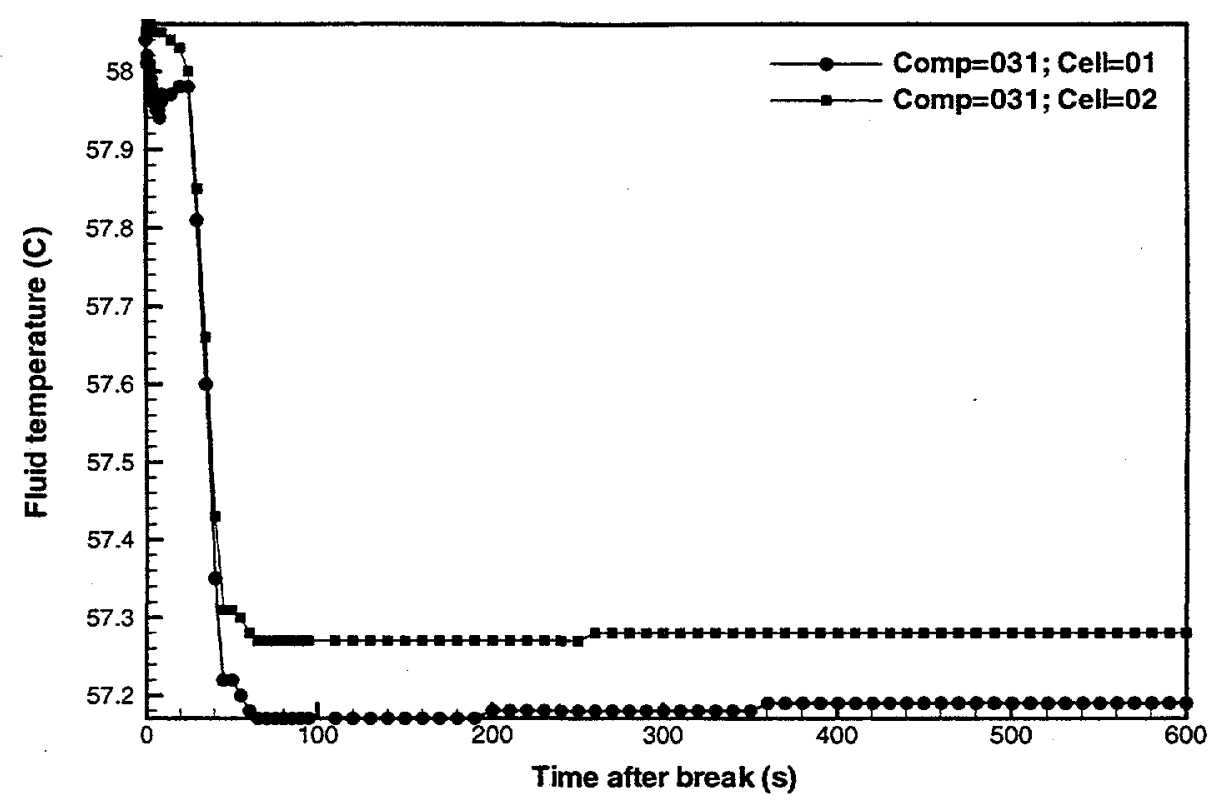

Figure B-10b Primary HR pump 2 fluid temperatures for a LOCA (Case 1: external HR break near inlet header).

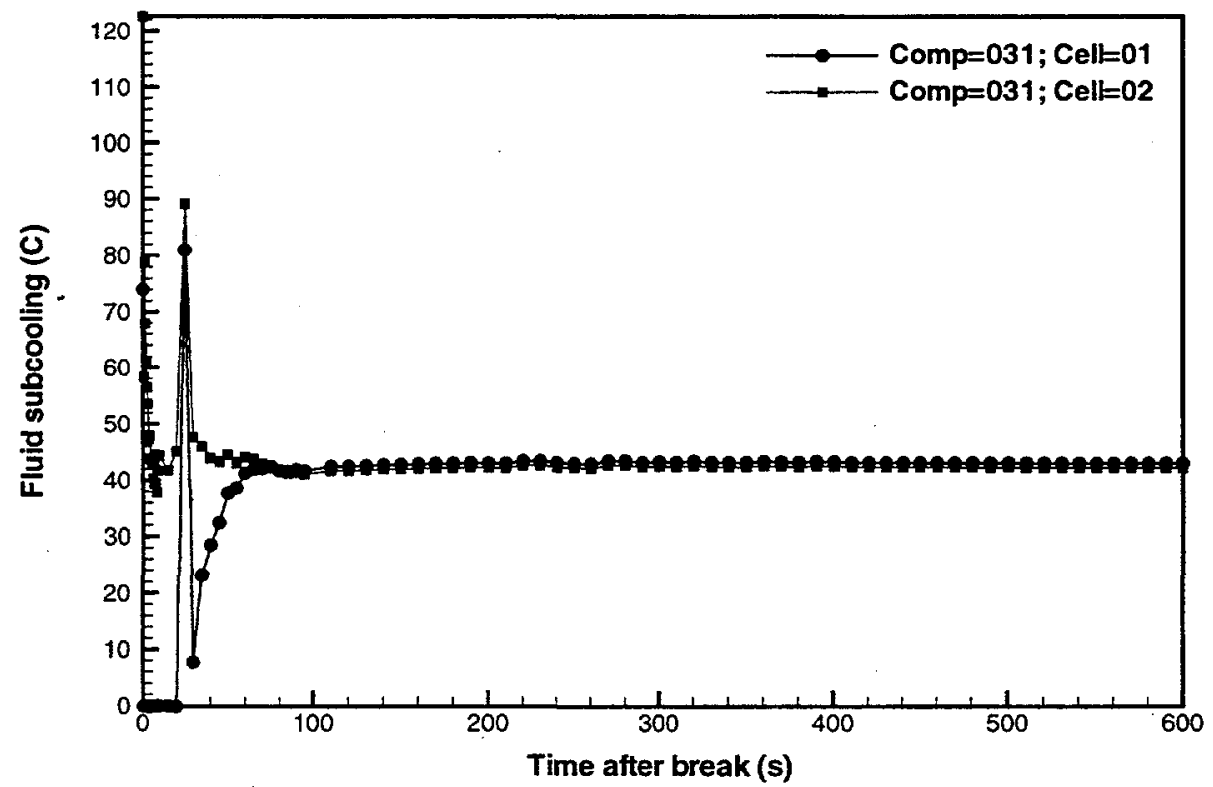

Figure B-10c Primary HR pump 2 fluid subcoolings for a LOCA (Case 1: external HR break near inlet header). 
Report:

Section:

BLANKET SAFETY ANALYSES FOR LOCA

(CASE 1: EXTERNAL HR BREAK NEAR INLET HEADER)
Date:

Page:
WSRC-TR-98-0059

Appendix B

07/13/98

23 of 72

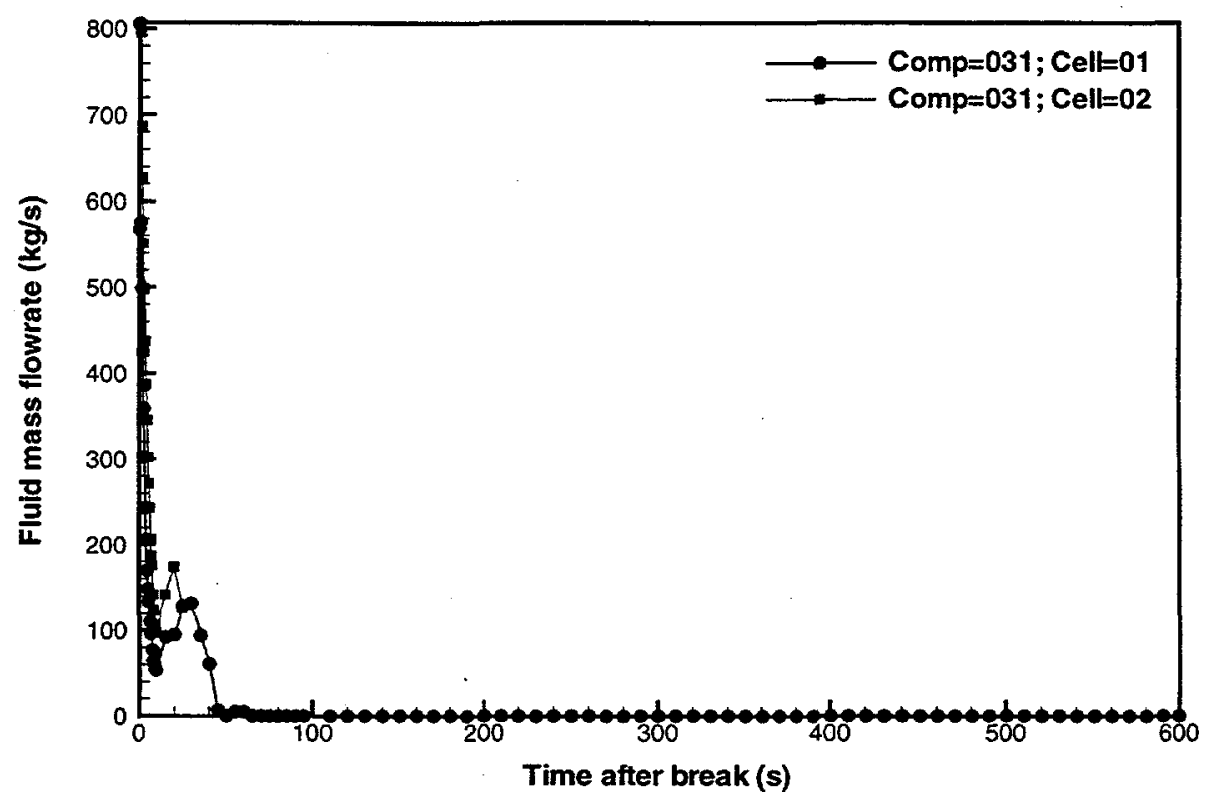

Figure B-10d Primary HR pump 2 liquid mass flowrates for a LOCA (Case 1: external HR break near inlet header).

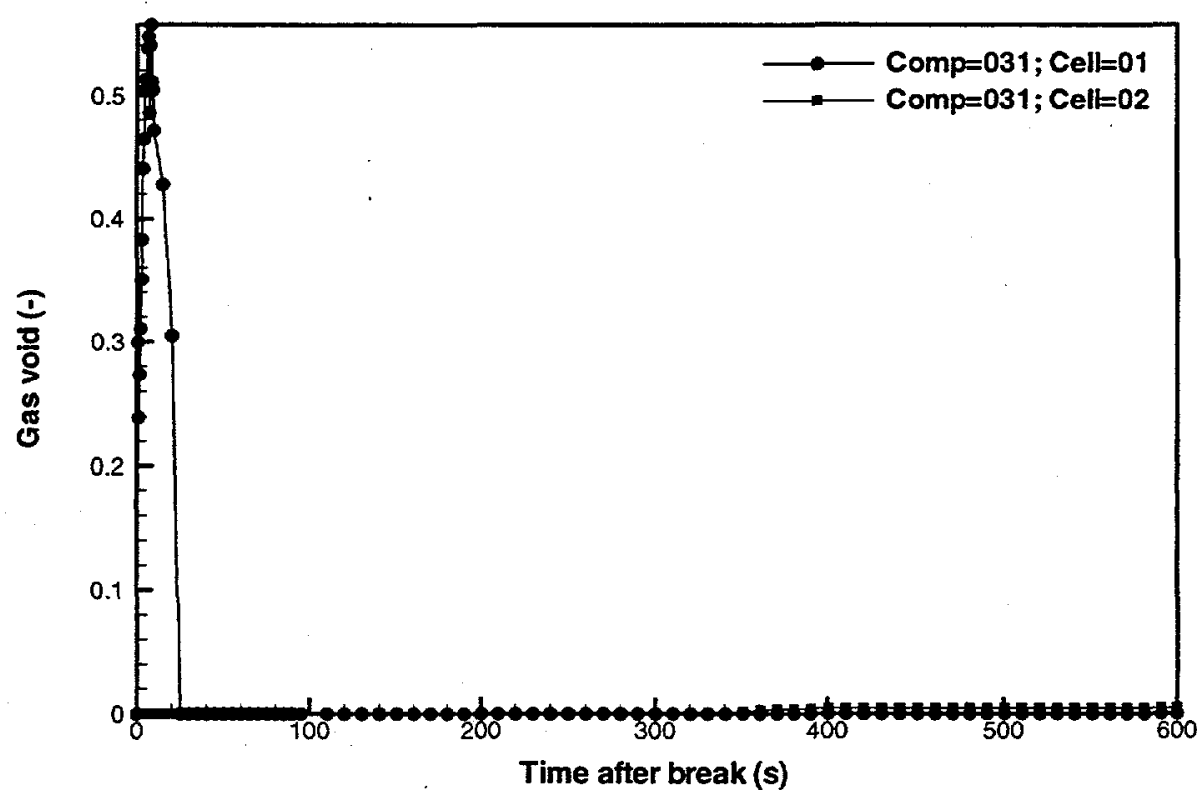

Figure B-10e Primary HR pump 2 void fractions for a LOCA (Case 1: external HR break near inlet header). 


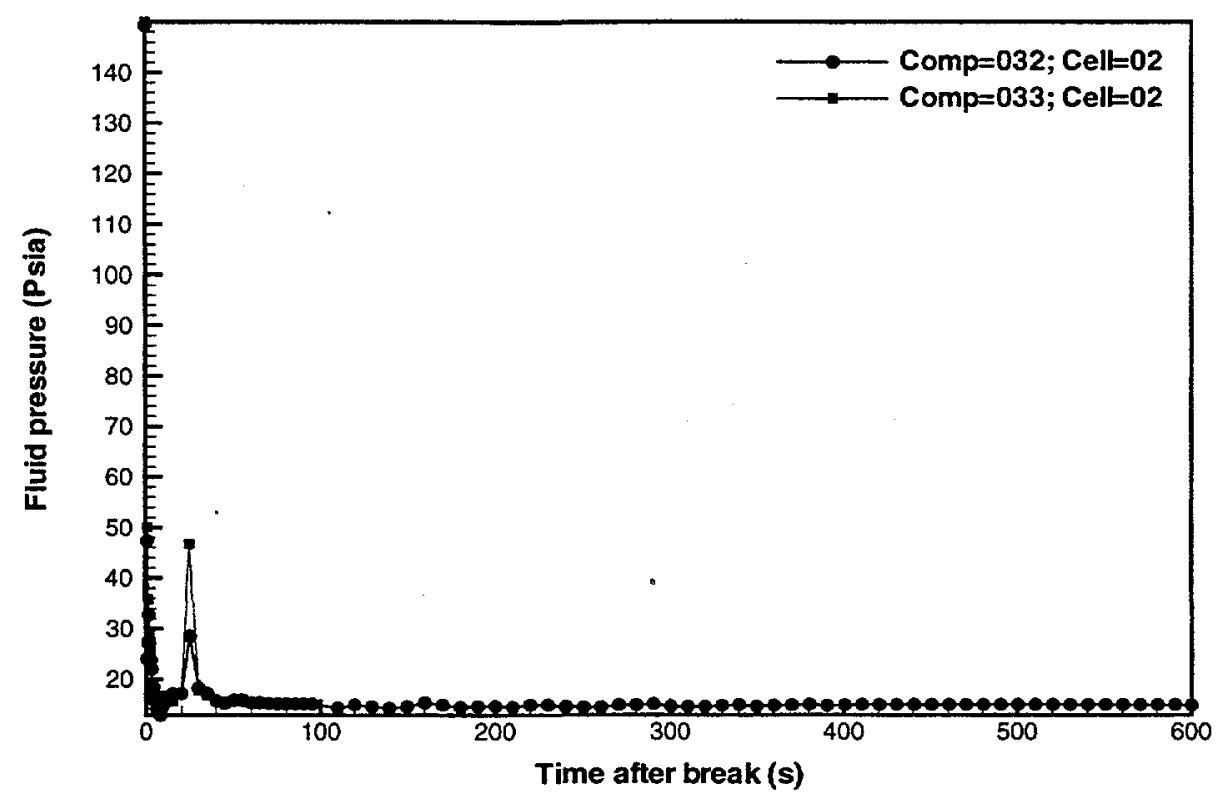

Figure B-11a Primary HR pump discharge piping fluid pressures for a LOCA (Case 1: external HR break near inlet header).

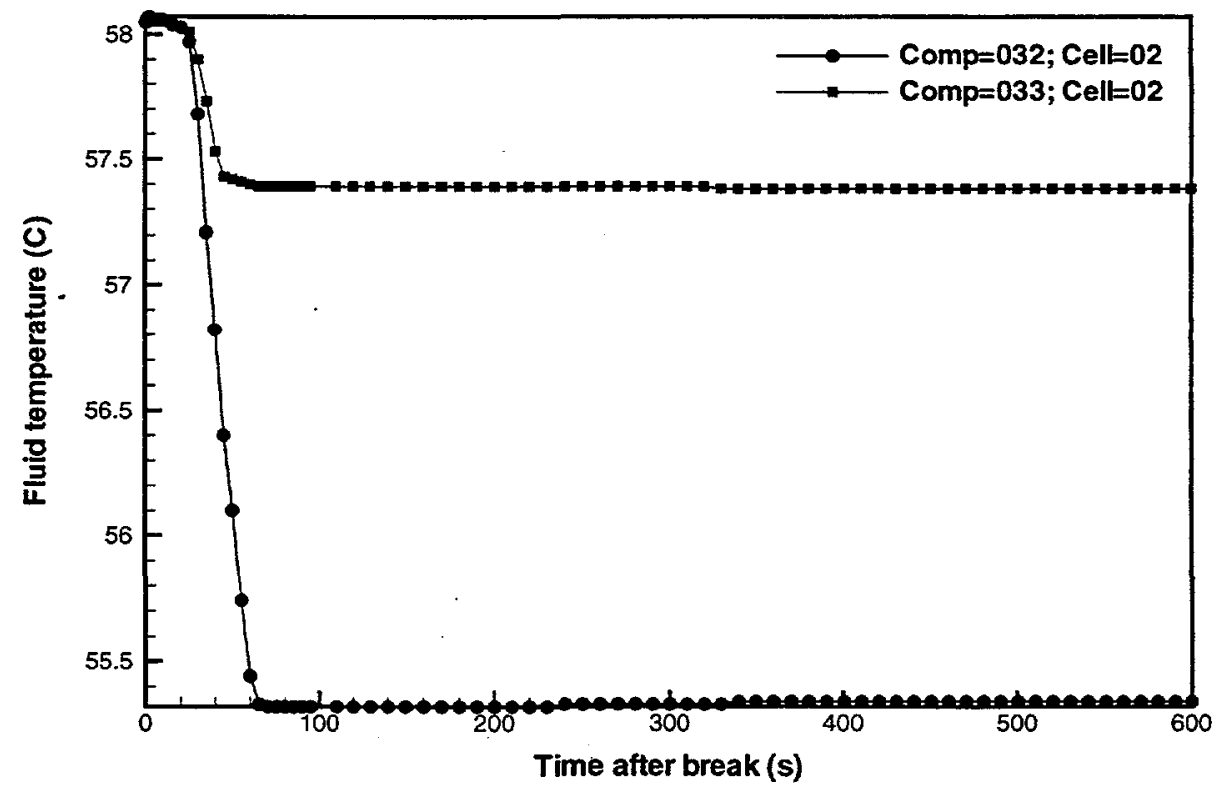

Figure B-11b Primary HR pump discharge piping fluid temperatures for a LOCA (Case 1: external HR break near inlet header). 


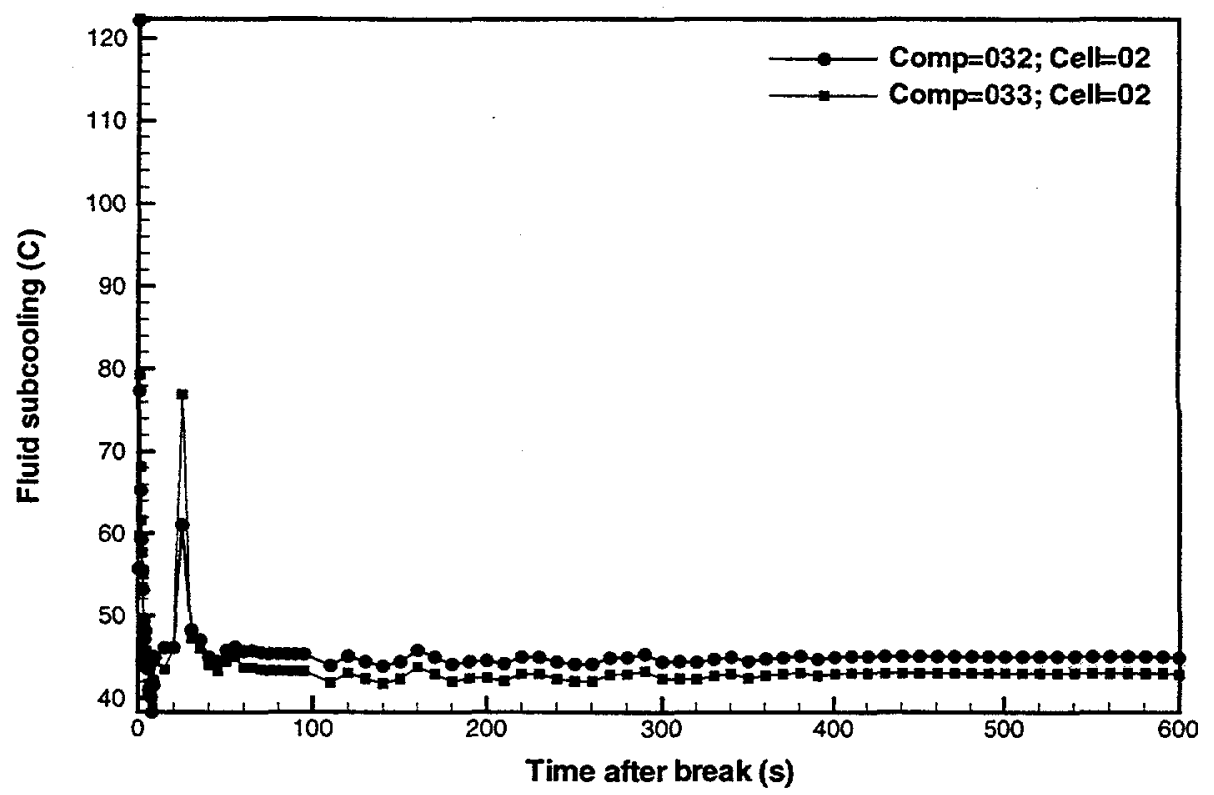

Figure B-11c Primary HR pump discharge piping fluid subcoolings for a LOCA (Case 1: external HR break near inlet header).

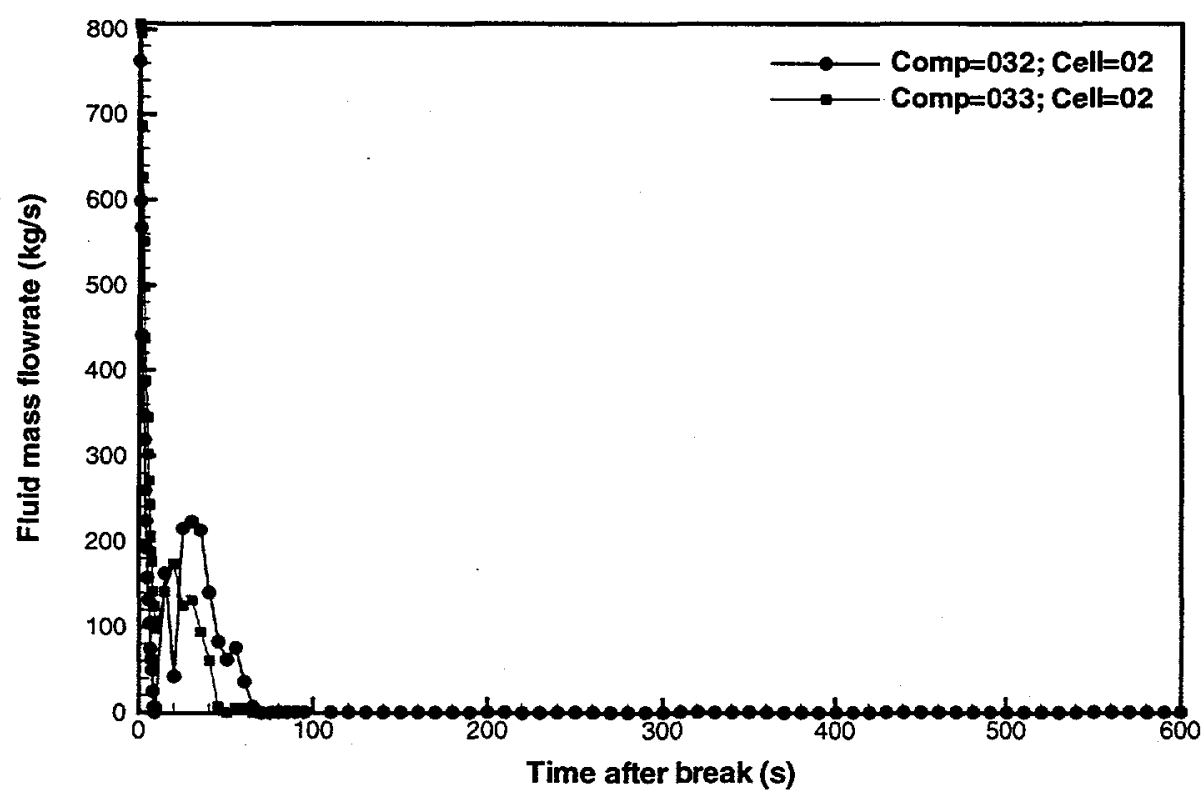

Figure B-11d Primary HR pump discharge piping liquid mass flowrates for a LOCA (Case 1: external HR break near inlet header). 


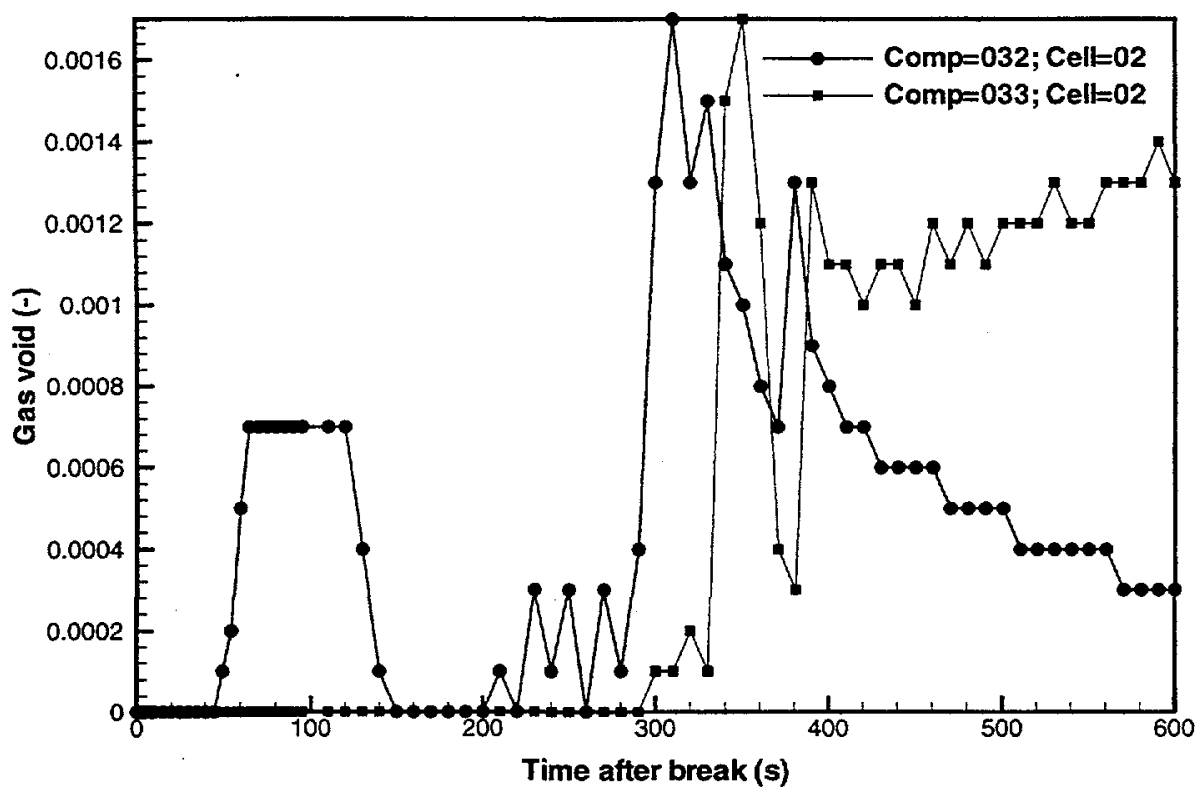

Figure B-11e Primary HR pump discharge piping void fractions for a LOCA (Case 1: external HR break near inlet header).

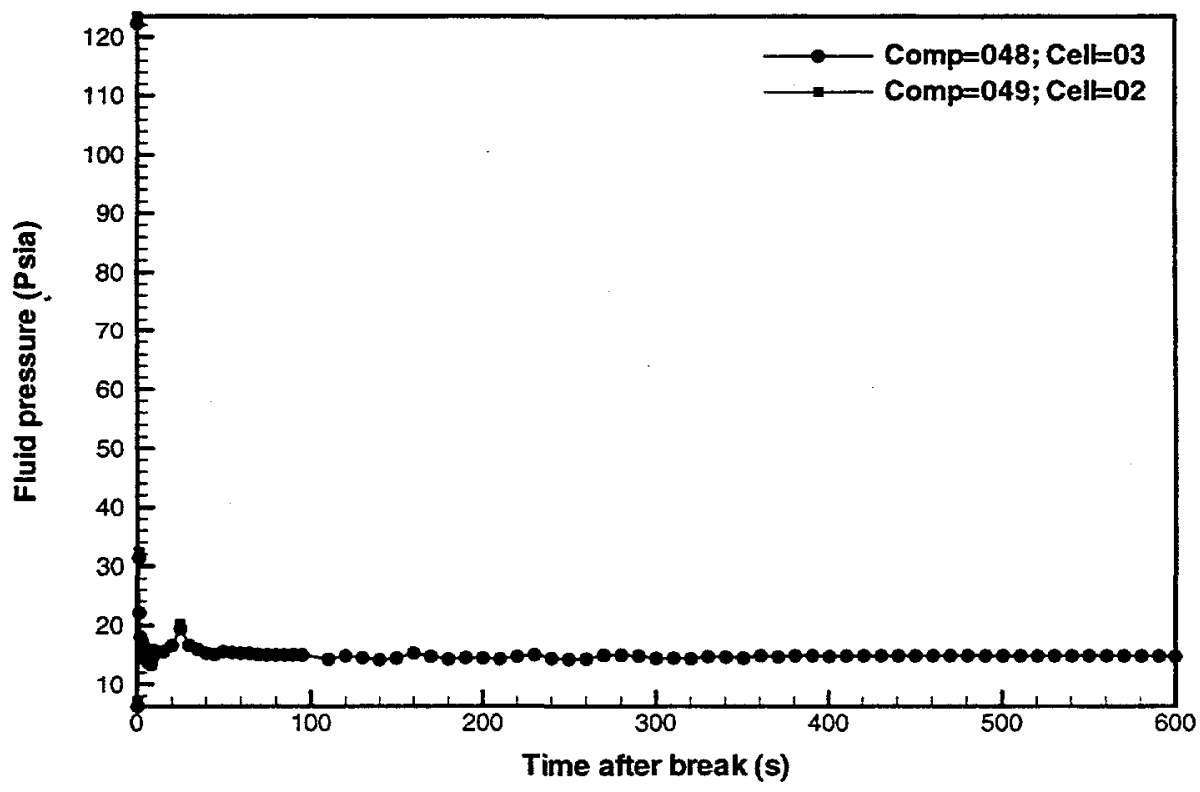

Figure B-12a Primary HR heat exchanger inlet piping fluid pressures for a LOCA (Case 1: external HR break near inlet header). 


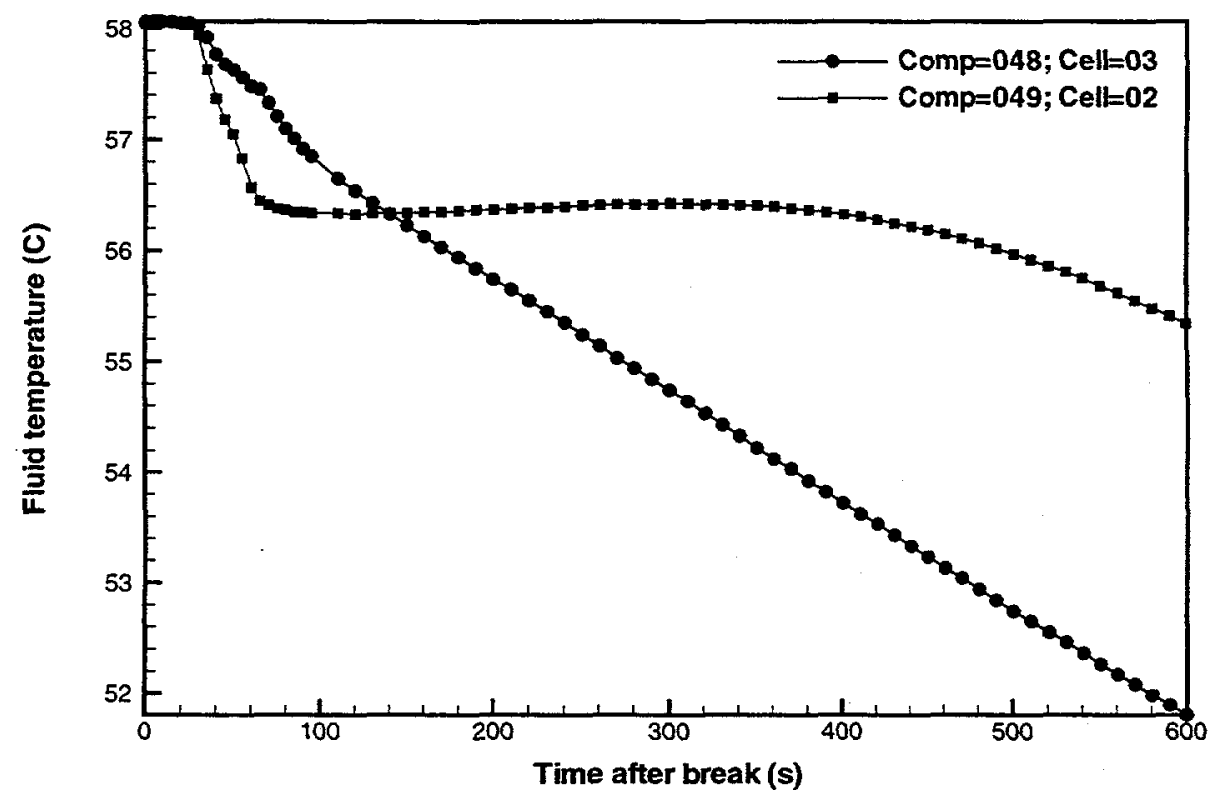

Figure B-12b Primary HR heat exchanger inlet piping fluid temperatures for a LOCA (Case 1: external HR break near inlet header).

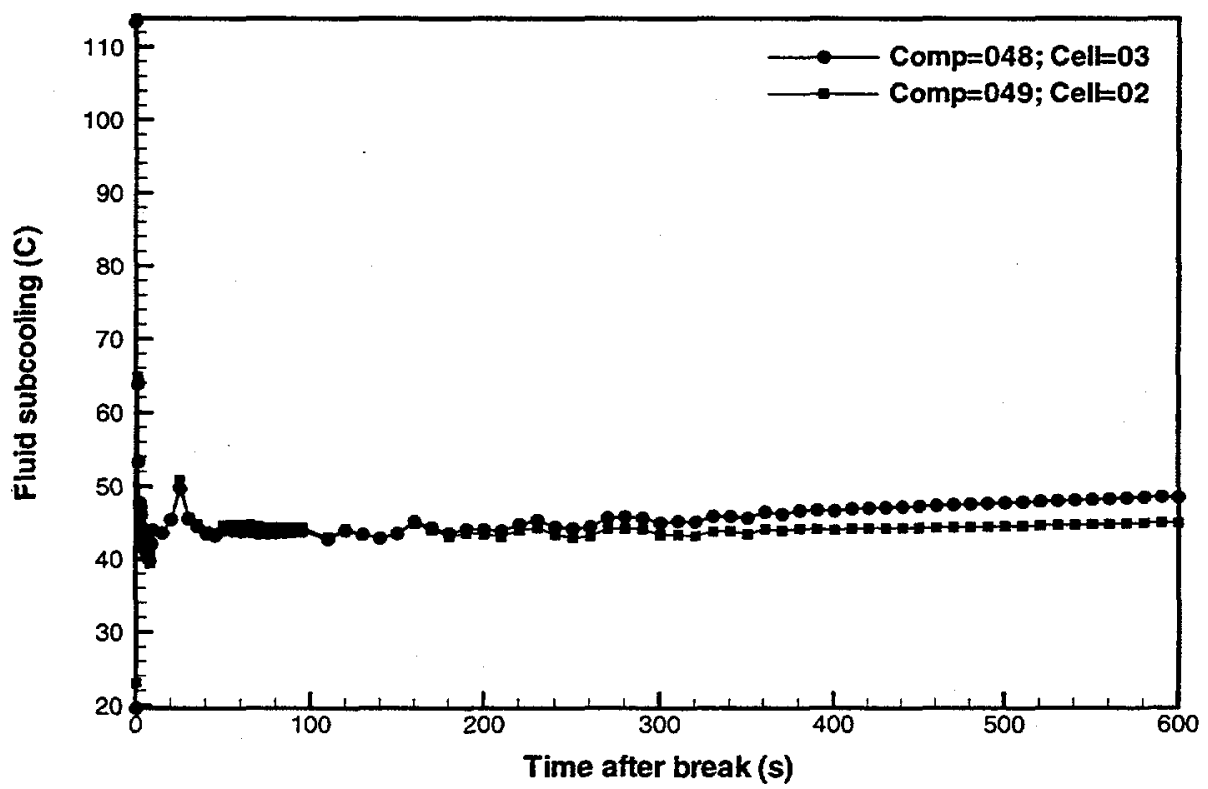

Figure B-12c Primary HR heat exchanger inlet piping fluid subcoolings for a LOCA (Case 1: external HR break near inlet header). 


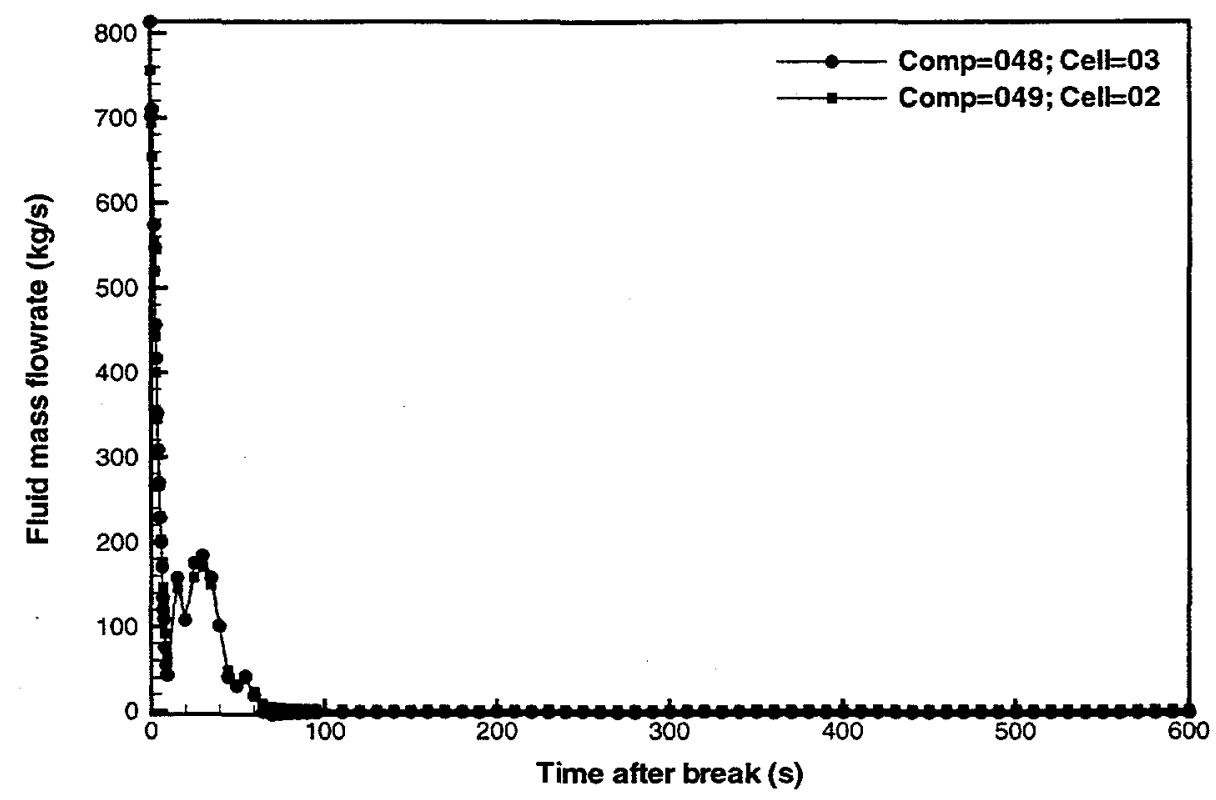

Figure B-12d Primary HR heat exchanger inlet piping liquid mass flowrates for a LOCA (Case 1: external HR break near inlet header).

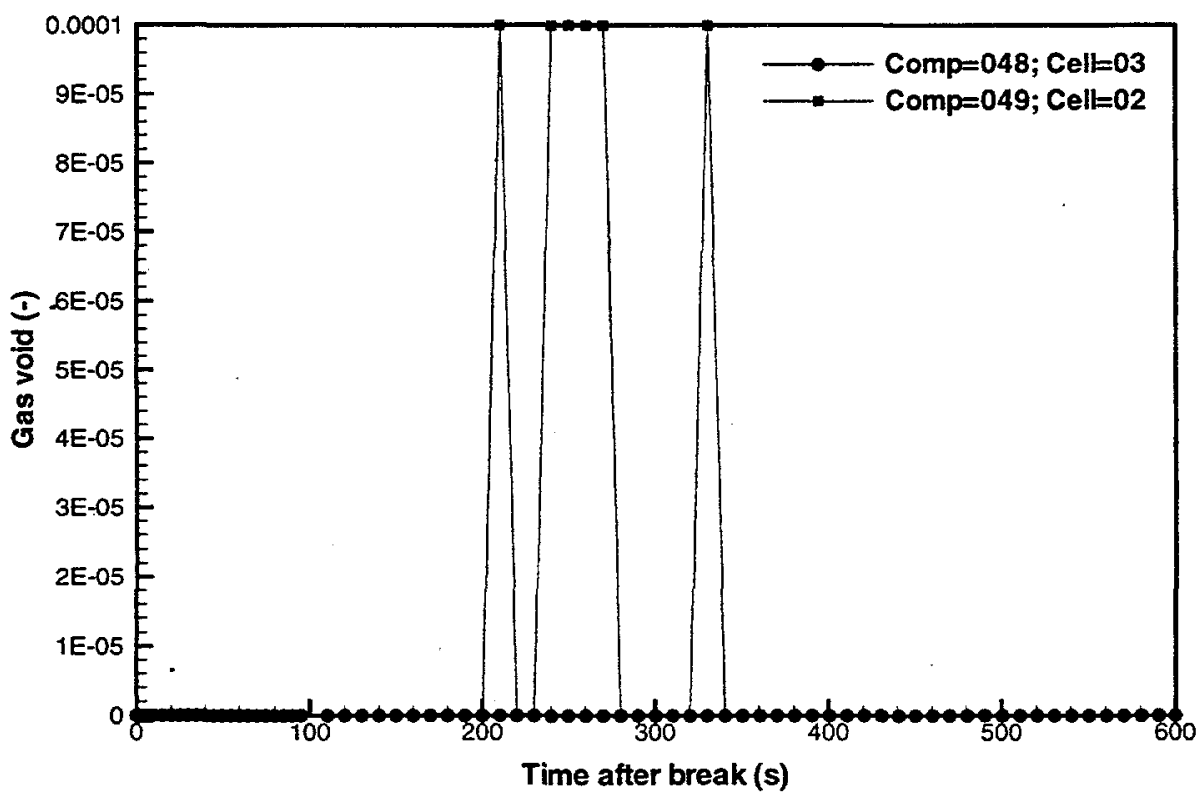

Figure B-12e Primary HR heat exchanger inlet piping void fractions for a LOCA (Case 1: external HR break near inlet header). 


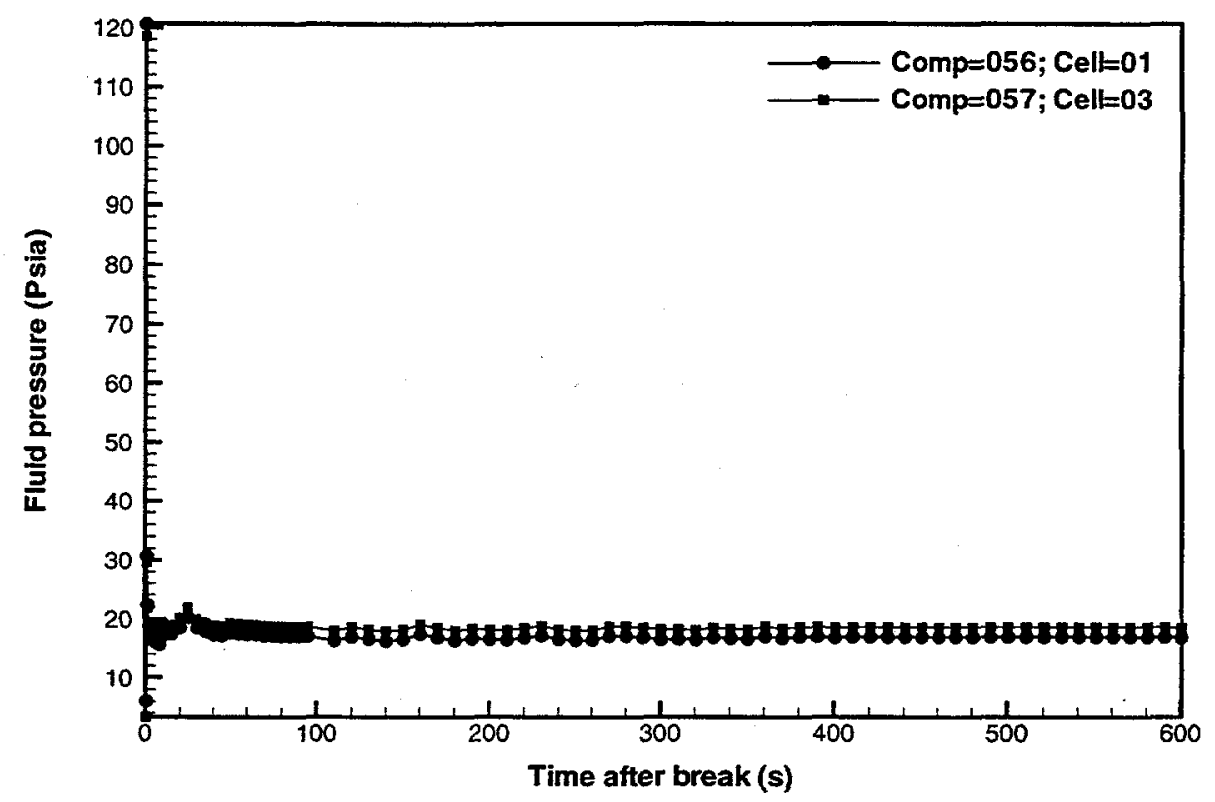

Figure B-13a Primary HR heat exchanger outlet piping fluid pressures for a LOCA (Case 1: external HR break near inlet header).

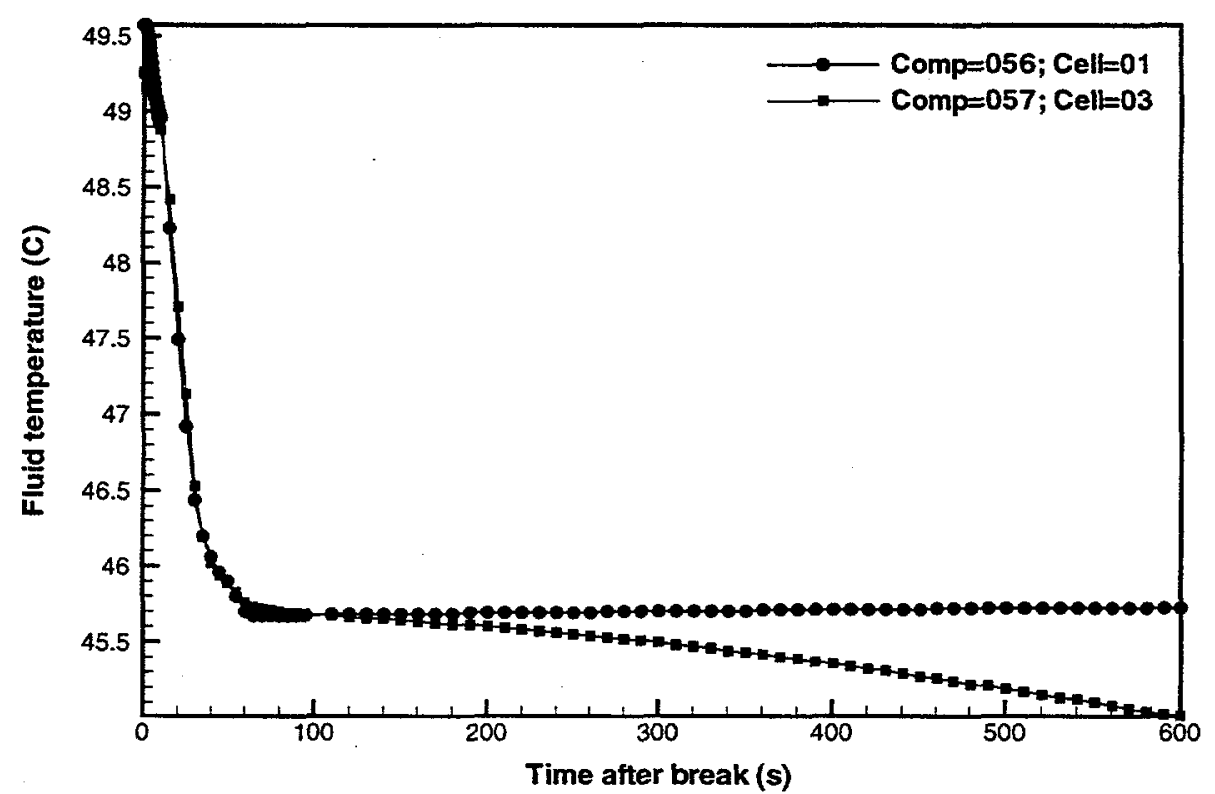

Figure B-13b Primary HR heat exchanger outlet piping fluid temperatures for a LOCA (Case 1: external HR break near inlet header). 


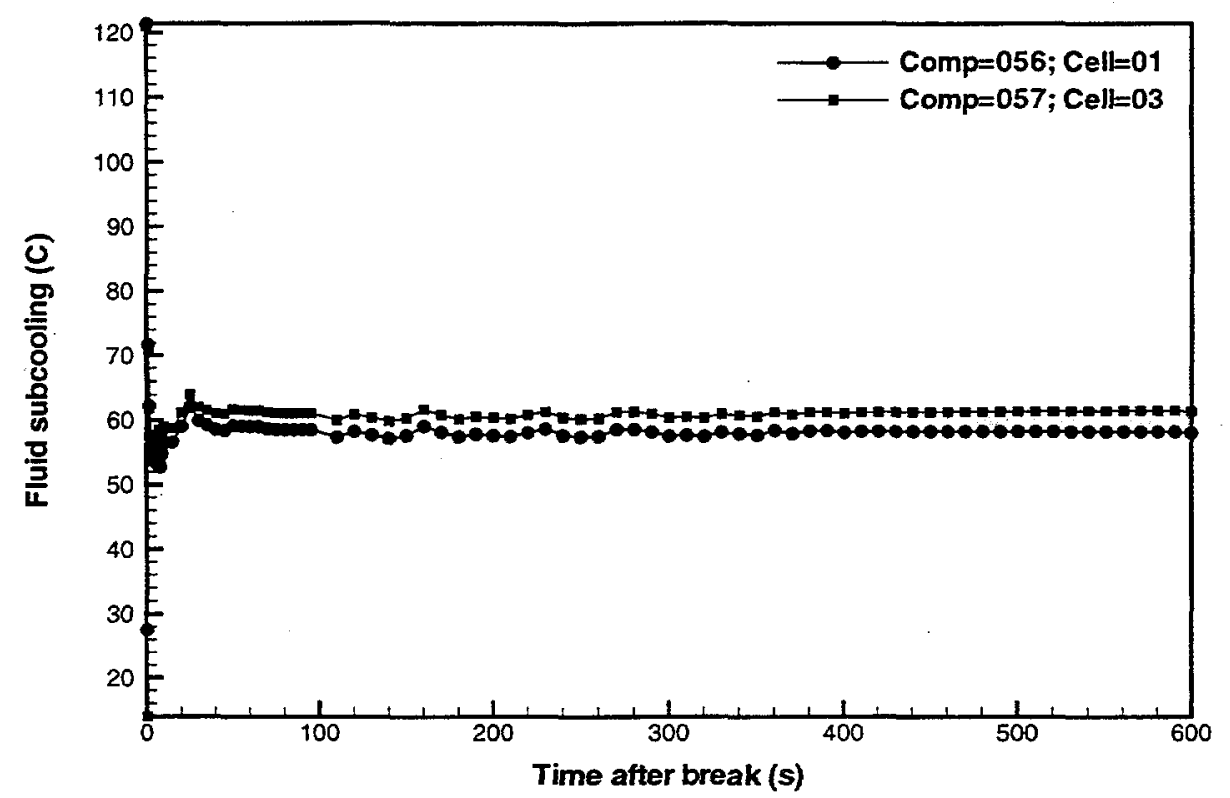

Figure B-13c Primary HR heat exchanger outlet piping fluid subcoolings for a LOCA (Case 1: external HR break near inlet header).

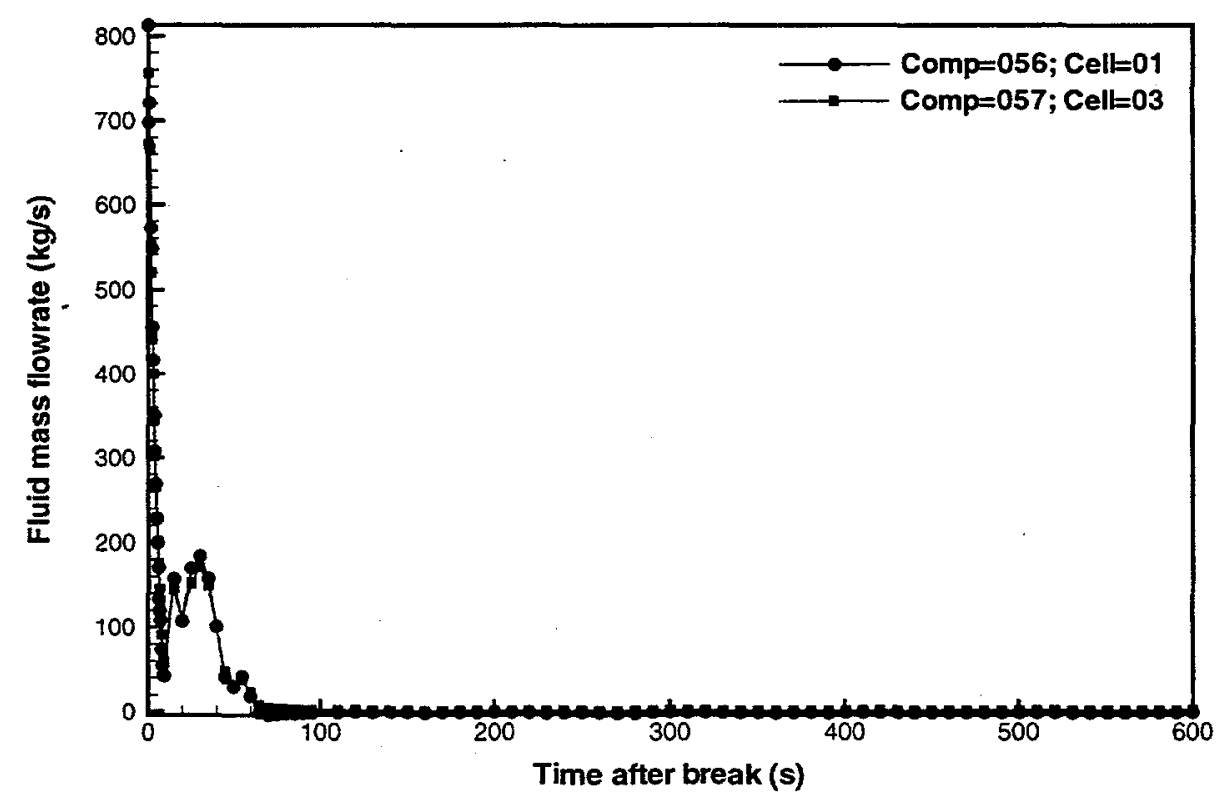

Figure B-13d Primary HR heat exchanger outlet piping liquid mass flowrates for a LOCA (Case 1: external HR break near inlet header). 


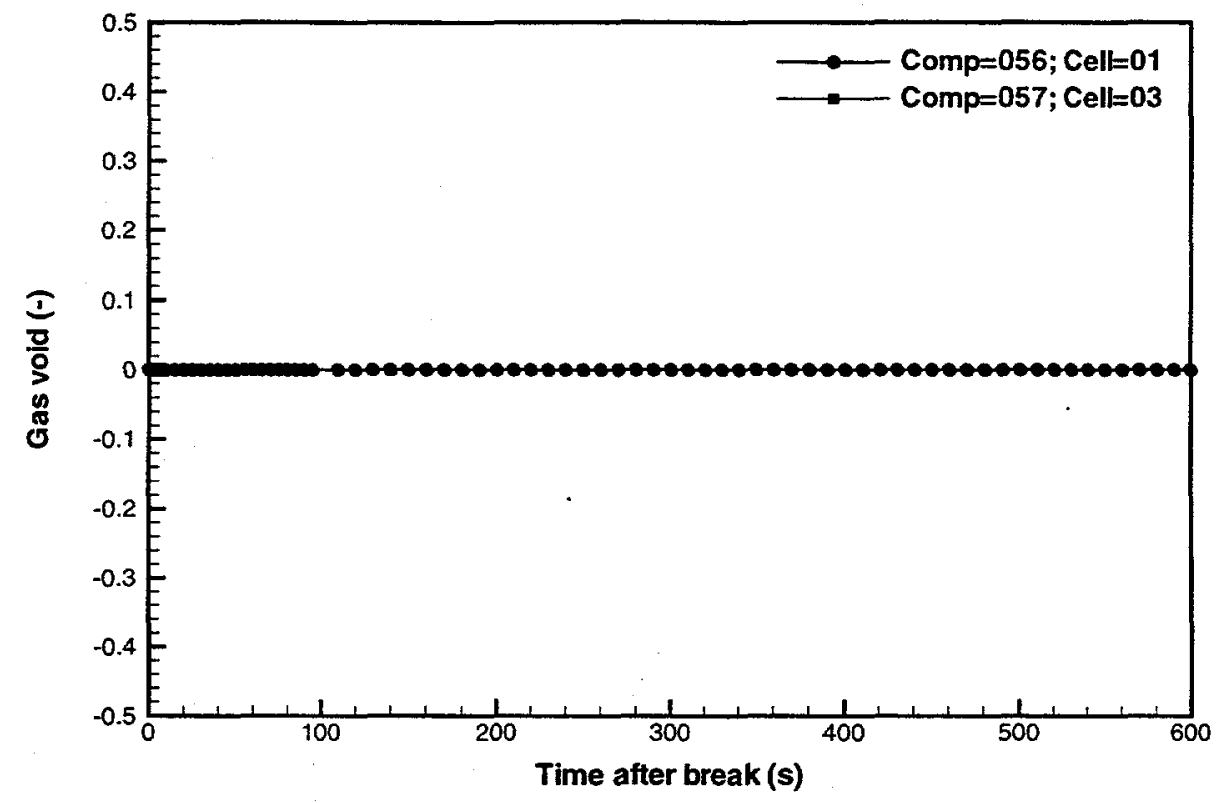

Figure B-13e Primary HR heat exchanger outlet piping void fractions for a LOCA (Case 1: external HR break near inlet header).

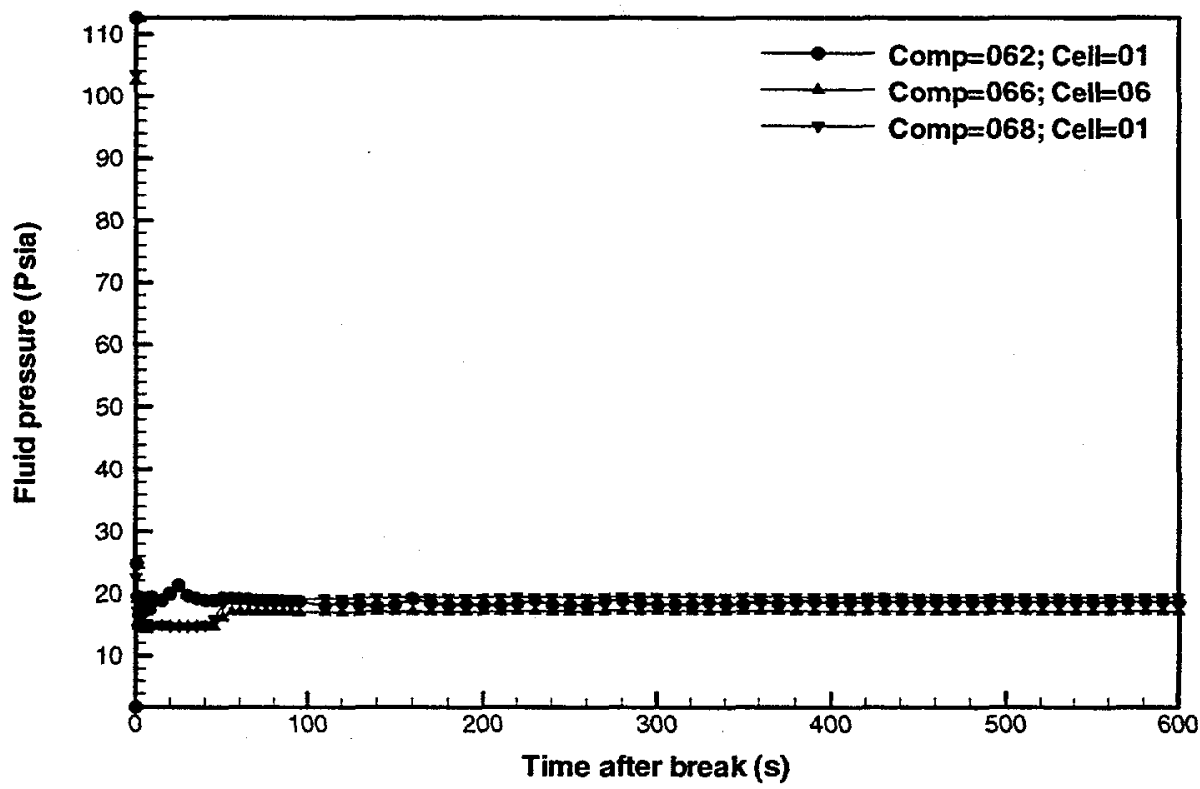

Figure B-14a Primary HR cold-leg piping fluid pressures for a LOCA (Case 1: external HR break near inlet header). 
Figure B-14b Primary HR cold-leg piping fluid temperatures for a LOCA (Case 1: external HR break near inlet header).

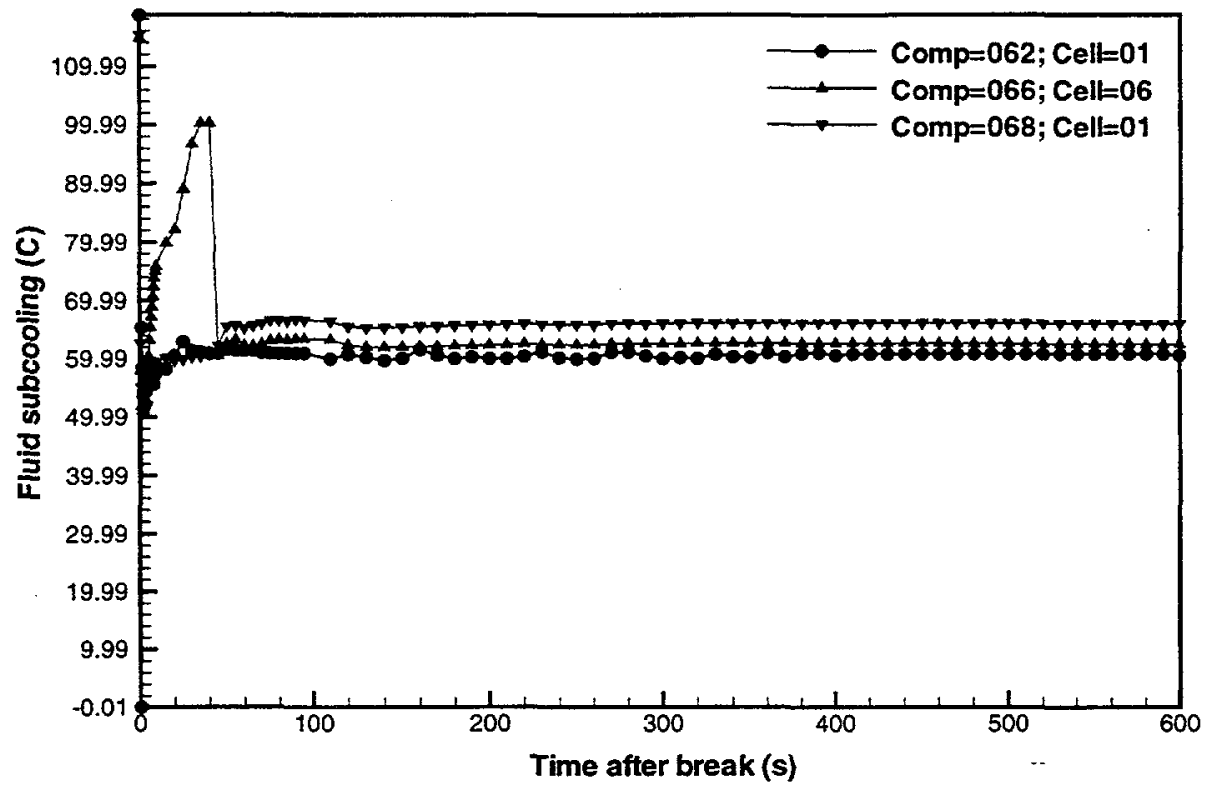

Figure B-14c Primary HR cold-leg piping fluid subcoolings for a LOCA (Case 1: external HR break near inlet header). 


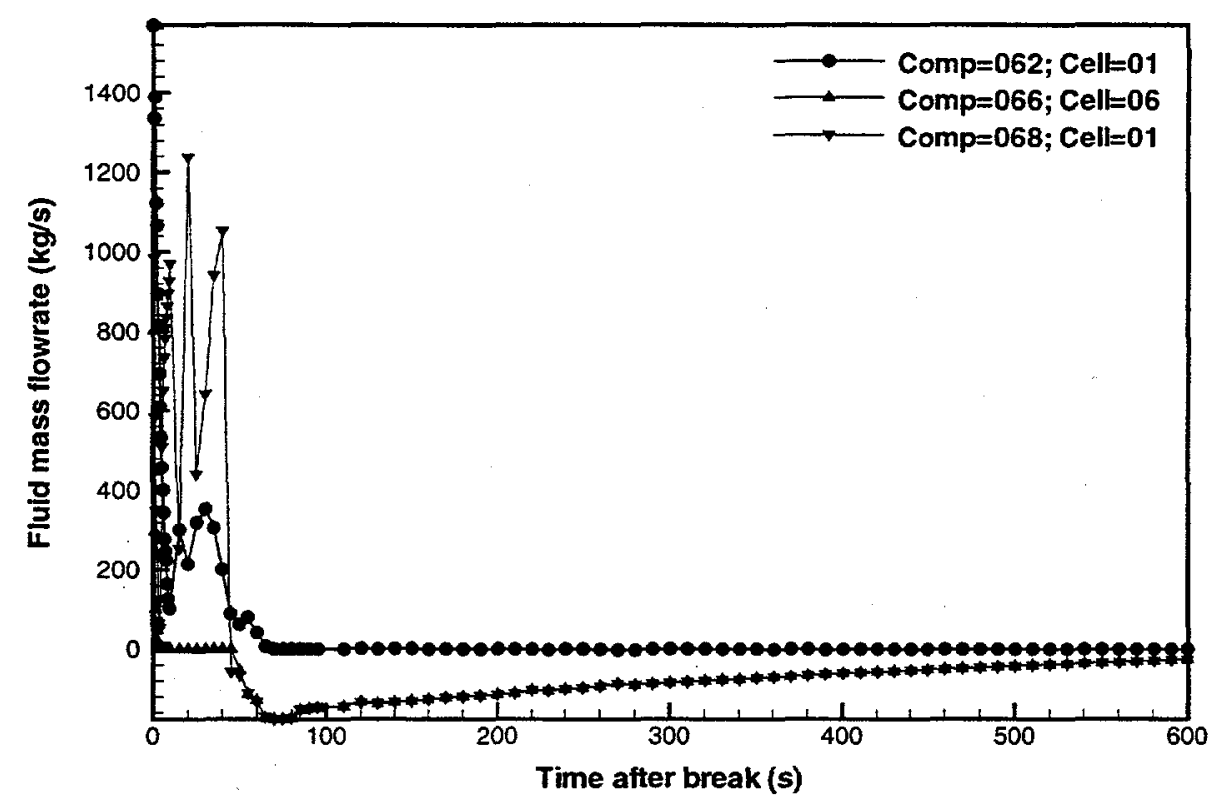

Figure B-14d Primary HR cold-leg piping liquid mass flowrates for a LOCA (Case 1: external HR break near inlet header).

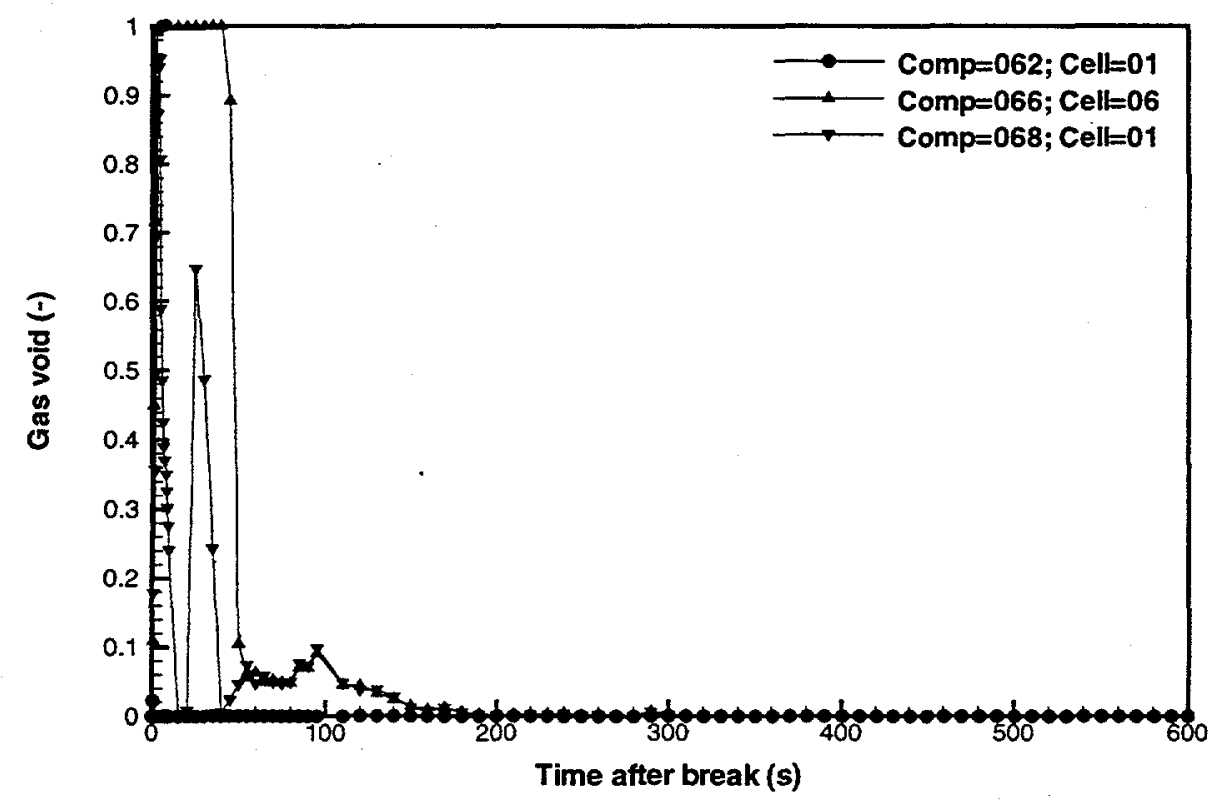

Figure B-14e Primary HR cold-leg piping void fractions for a LOCA (Case 1: external HR break near inlet header). 


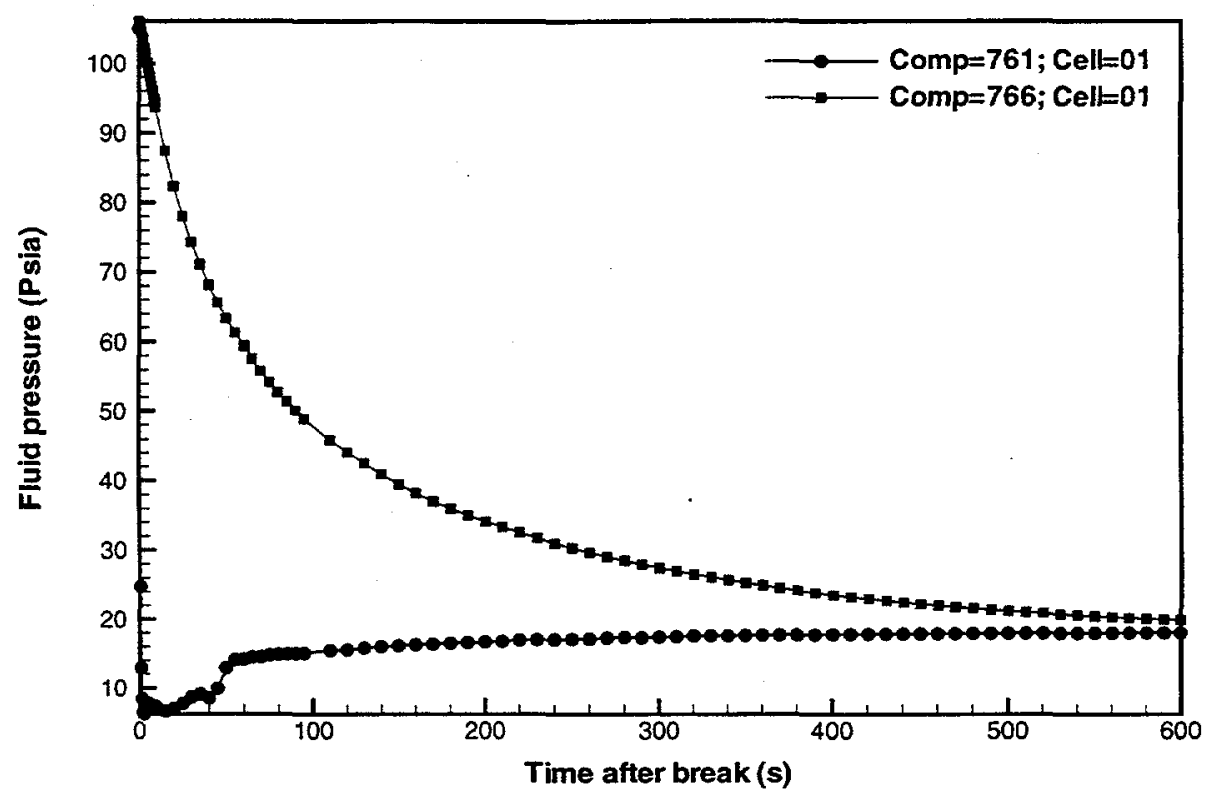

Figure B-15a Primary HR pressurizer and surge line fluid pressures for a LOCA (Case 1: external HR break near inlet header).

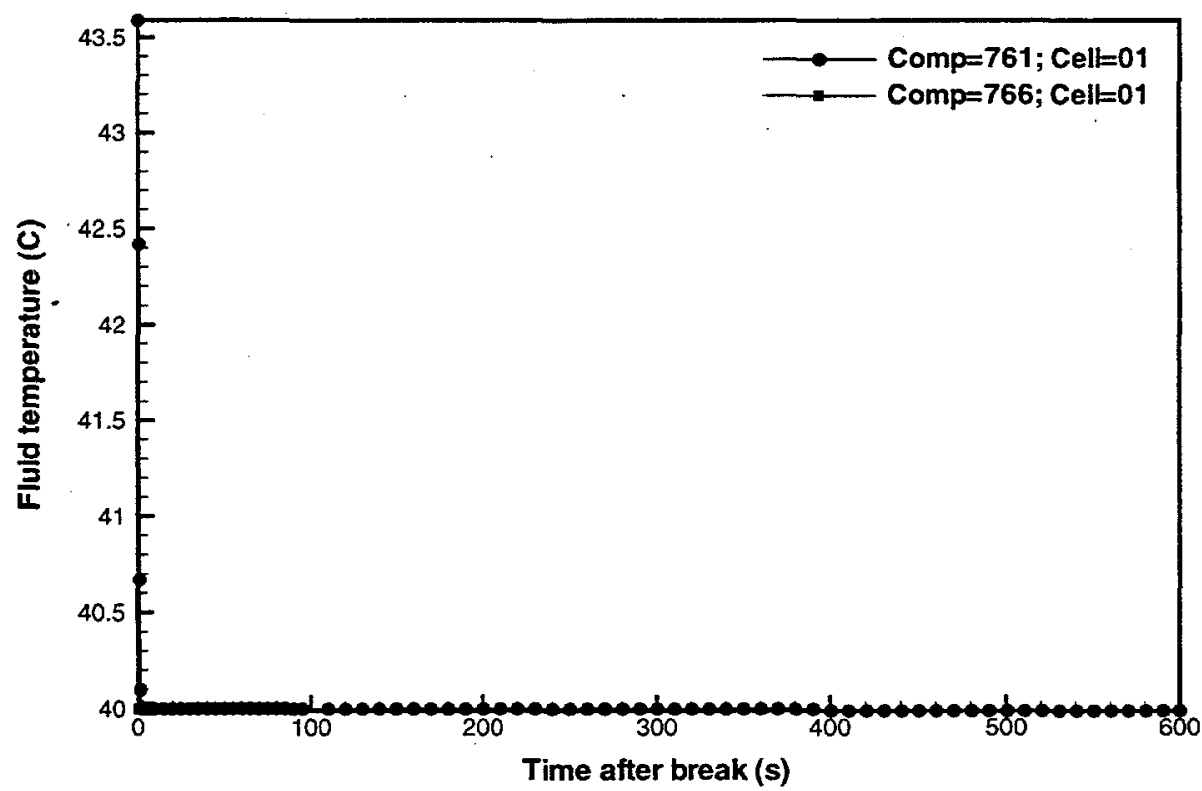

Figure B-15b Primary HR pressurizer and surge line fluid temperatures for a LOCA (Case 1: external HR break near inlet header). 


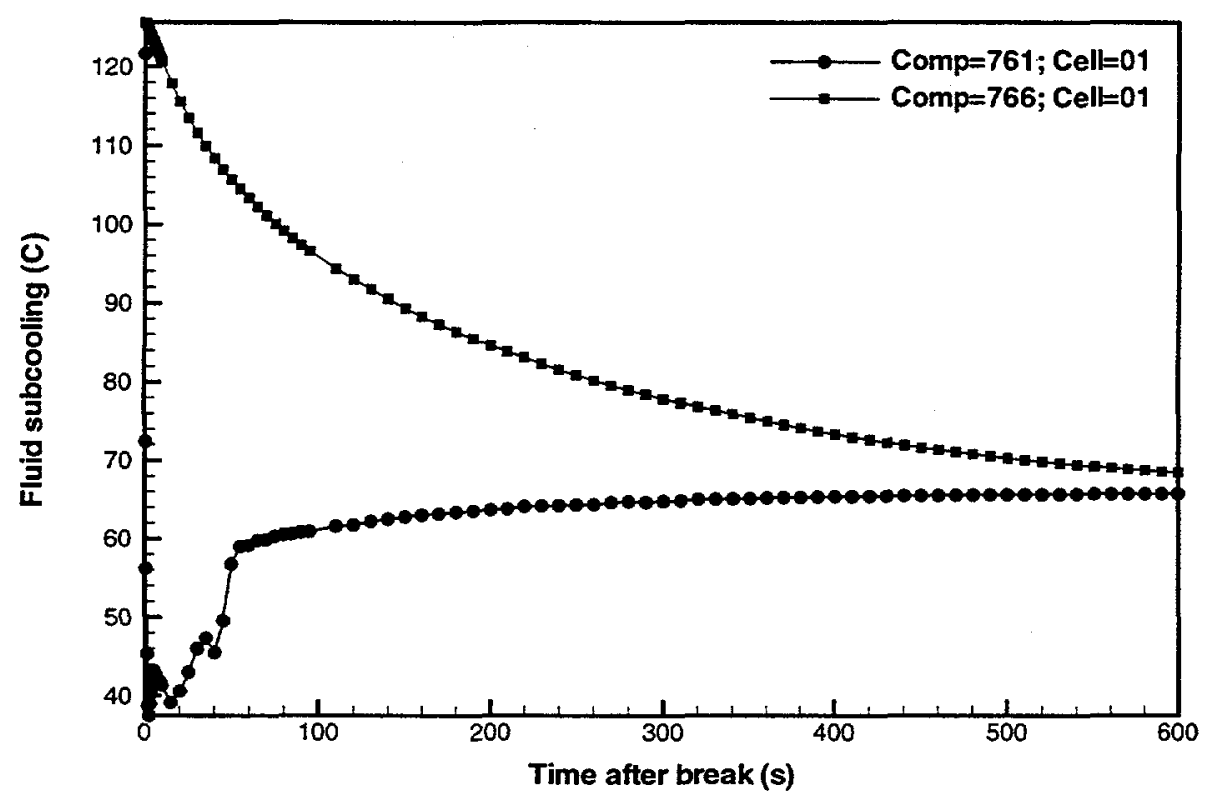

Figure B-15c Primary HR pressurizer and surge line fluid subcoolings for a LOCA (Case 1: external HR break near inlet header).

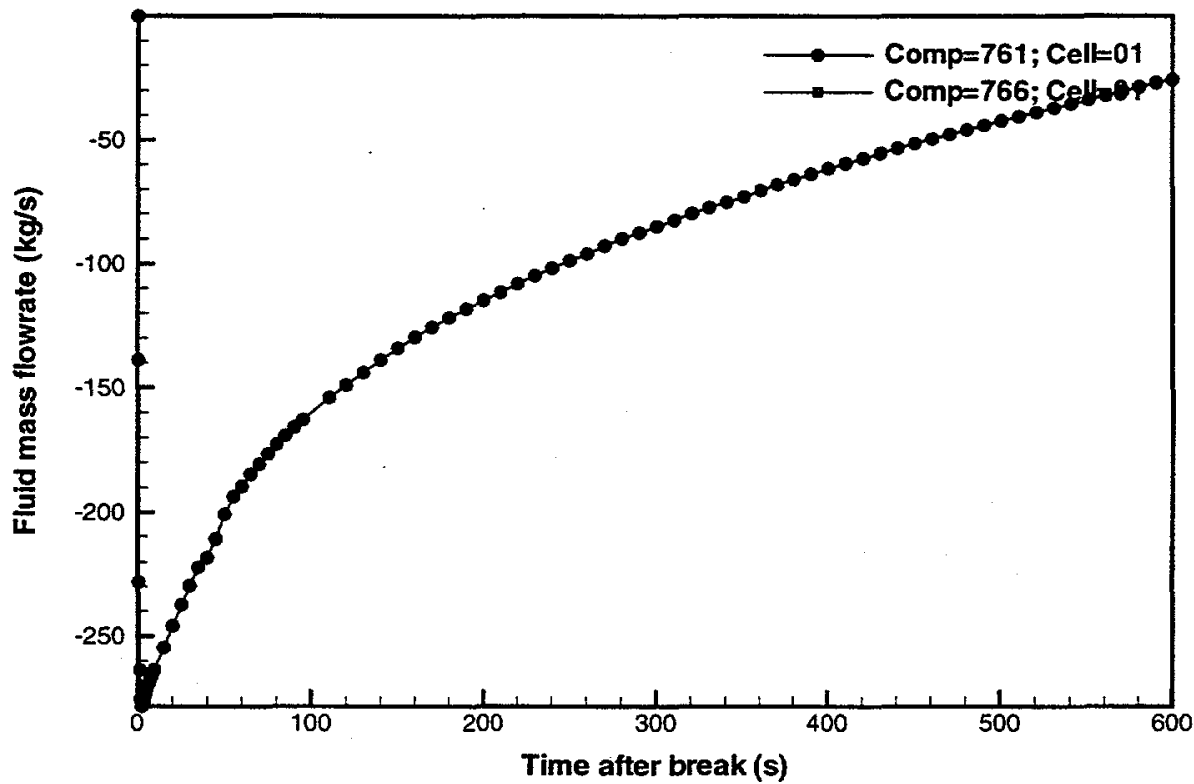

Figure B-15d Primary HR pressurizer and surge line liquid mass flowrates for a LOCA (Case 1: external HR break near inlet header). 


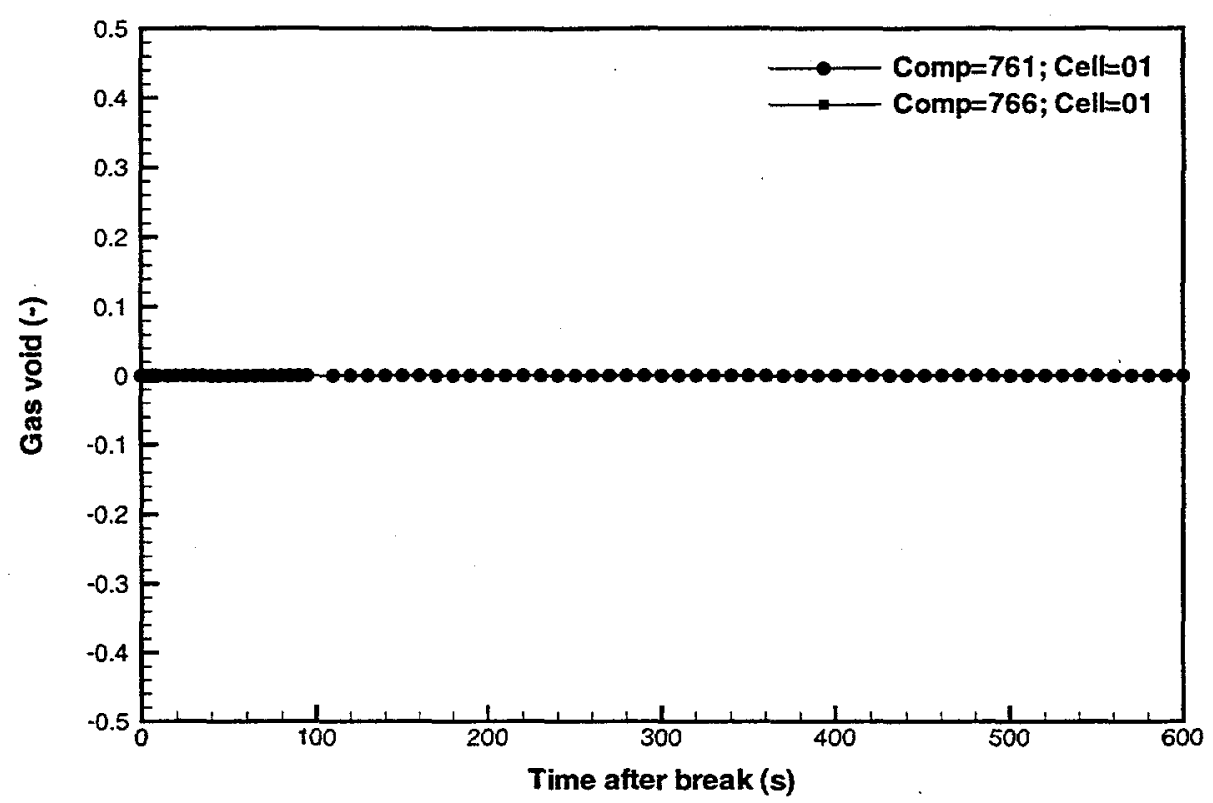

Figure B-15e Primary HR pressurizer and surge line void fractions for a LOCA (Case 1: external HR break near inlet header).

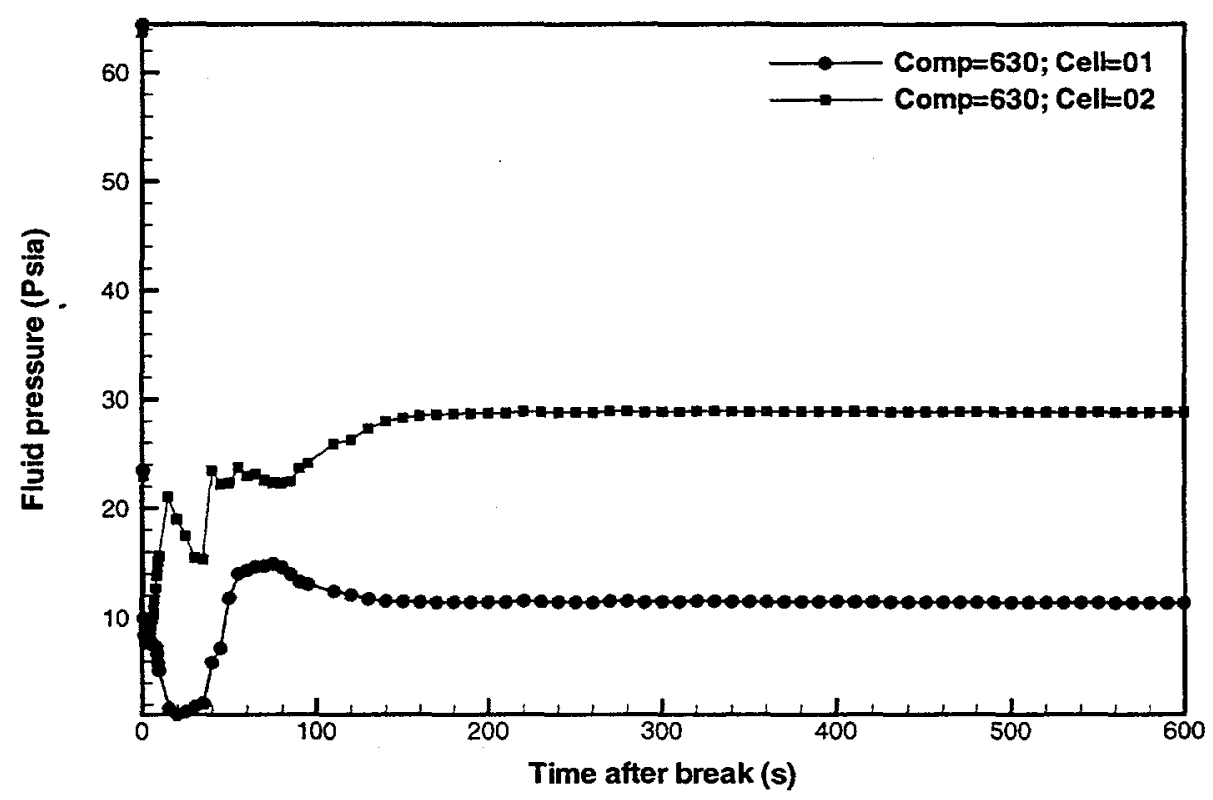

Figure B-16a Primary RHR pump fluid pressures for a LOCA (Case 1: external HR break near inlet header). 


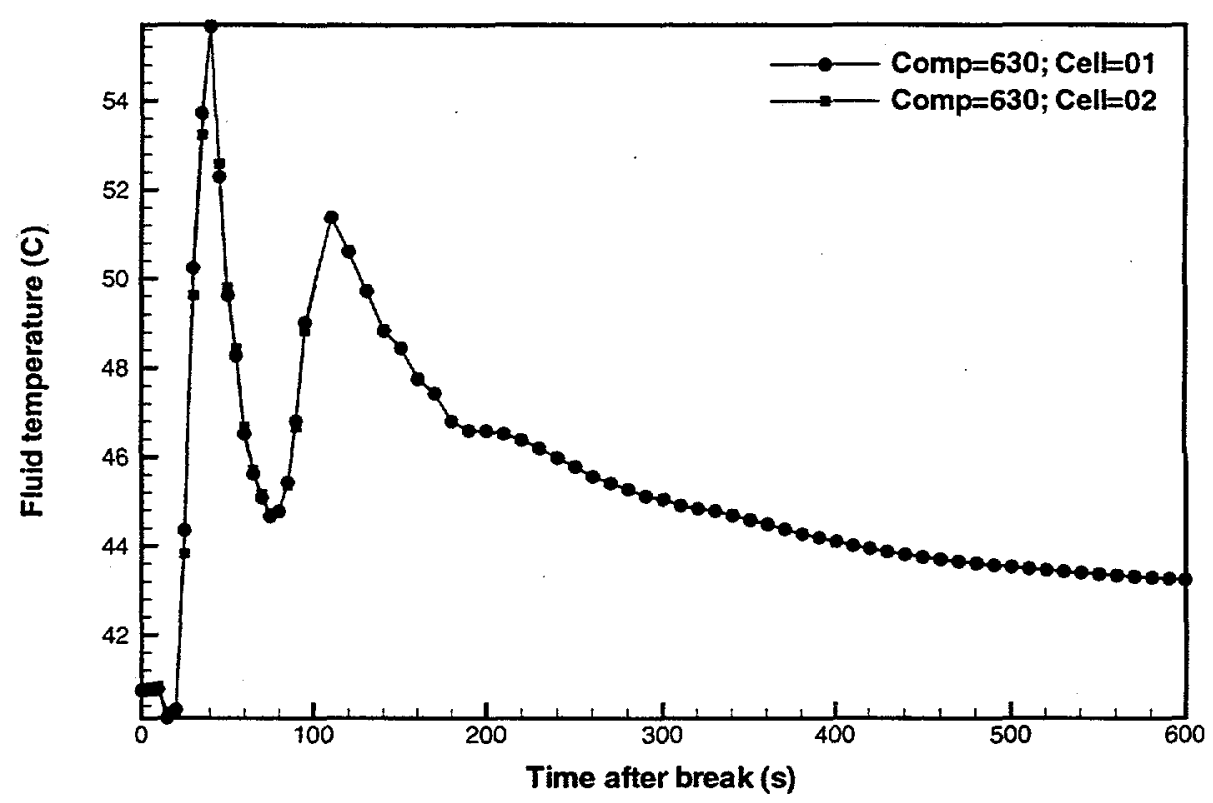

Figure B-16b Primary RHR pump fluid temperatures for a LOCA (Case 1: external HR break near inlet header).

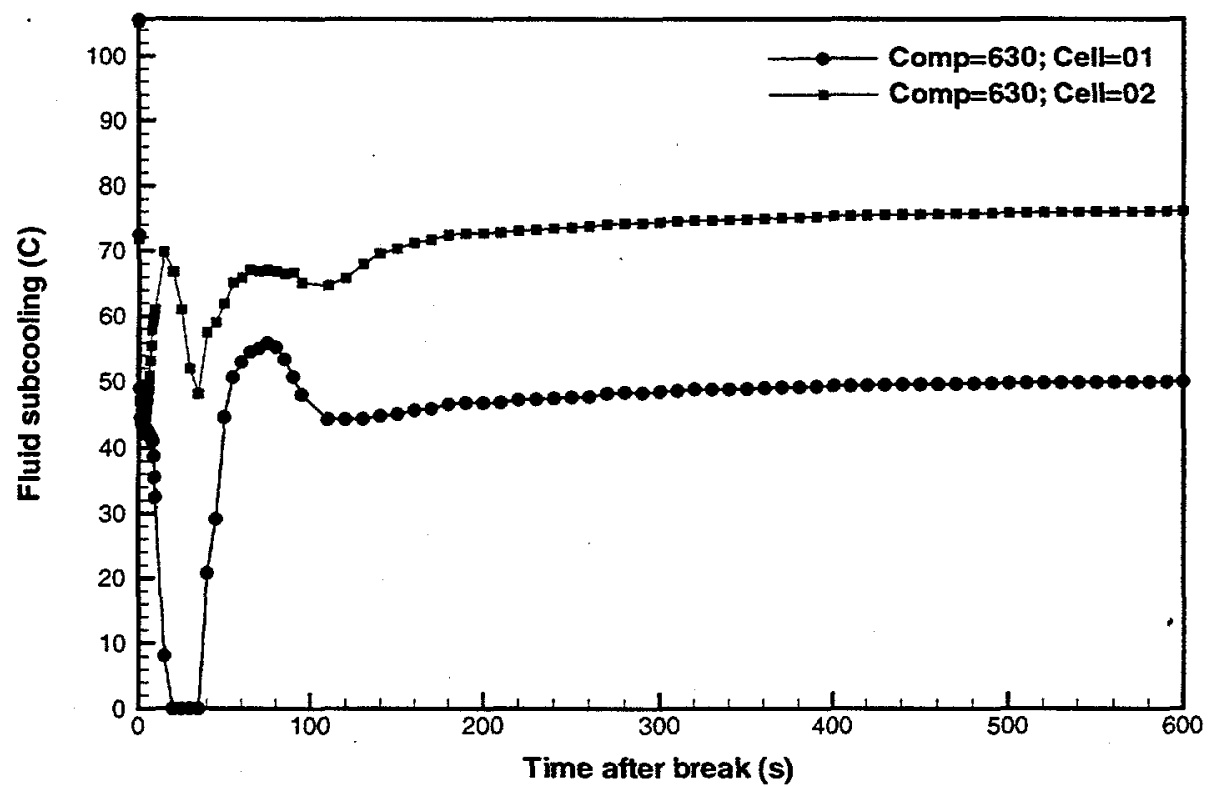

Figure B-16c Primary RHR pump fluid subcoolings for a LOCA (Case 1: external HR break near inlet header). 


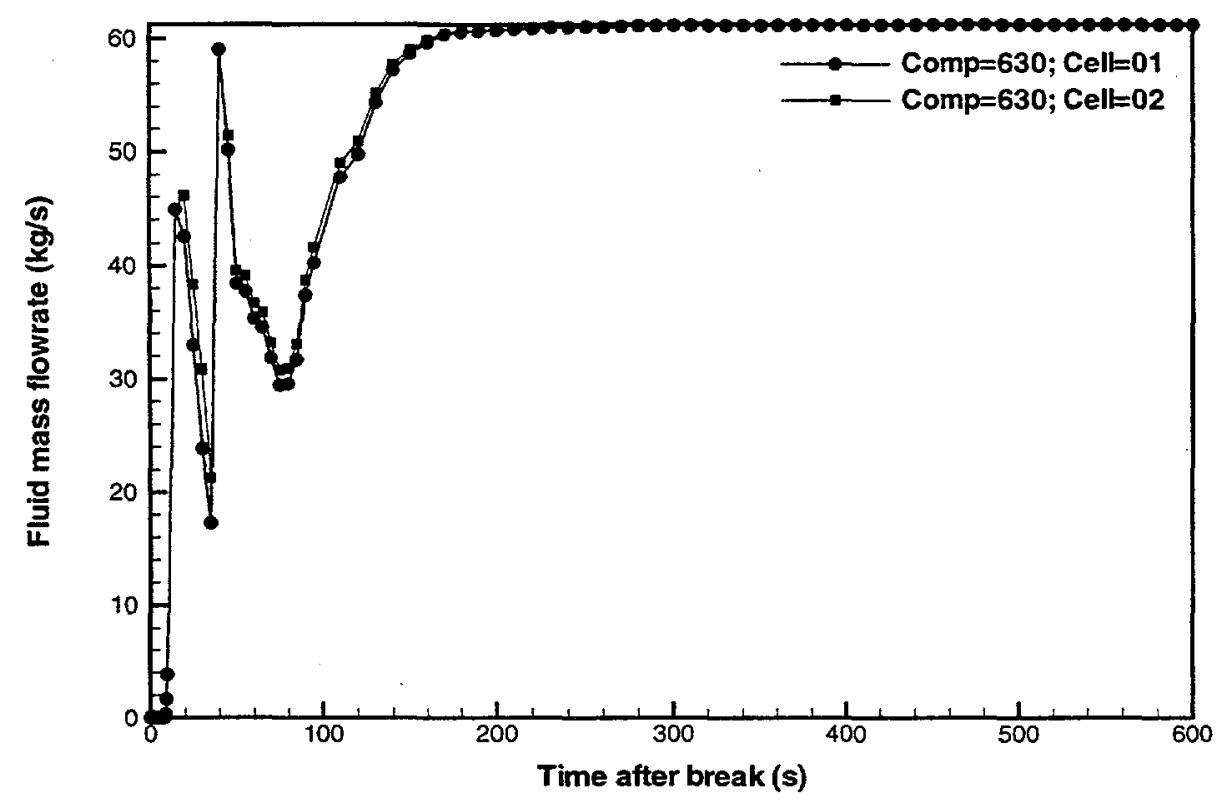

Figure B-16d Primary RHR pump liquid mass flowrates for a LOCA (Case 1: external HR break near inlet header).

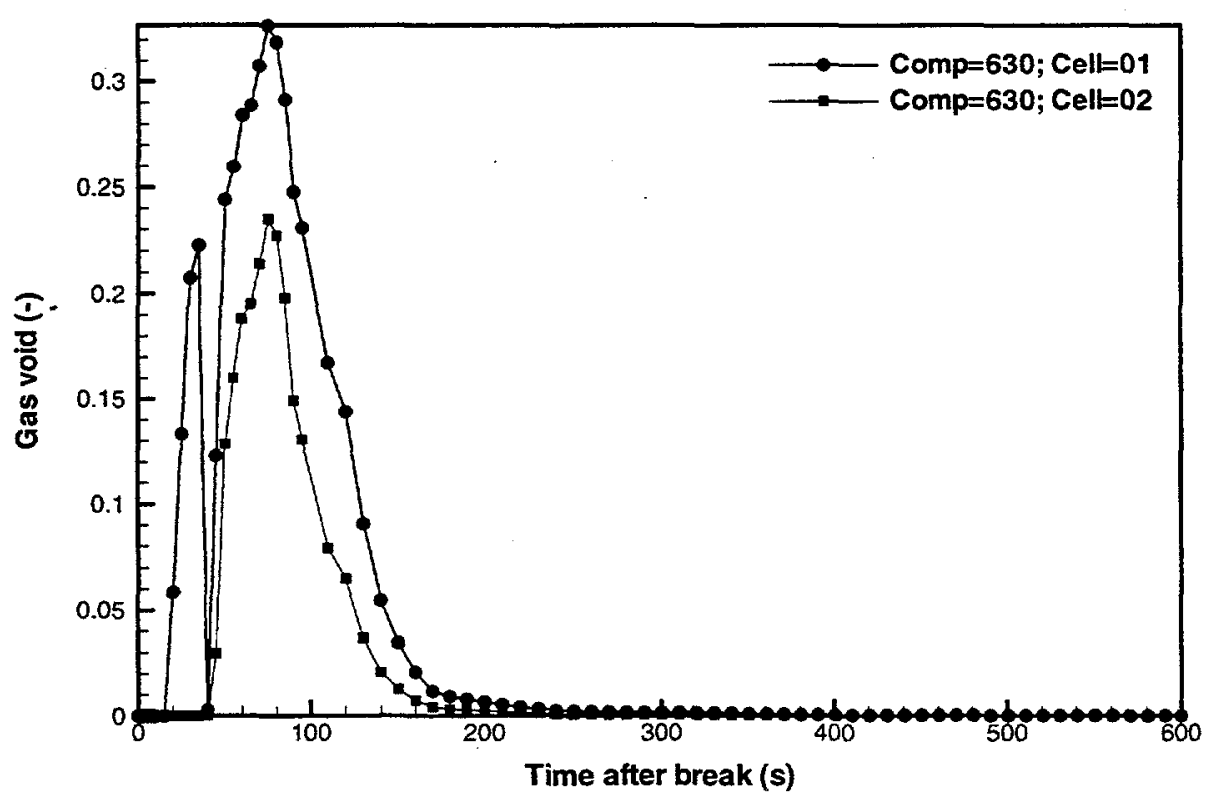

Figure B-16e Primary RHR pump void fractions for a LOCA (Case 1: external HR break near inlet header). 


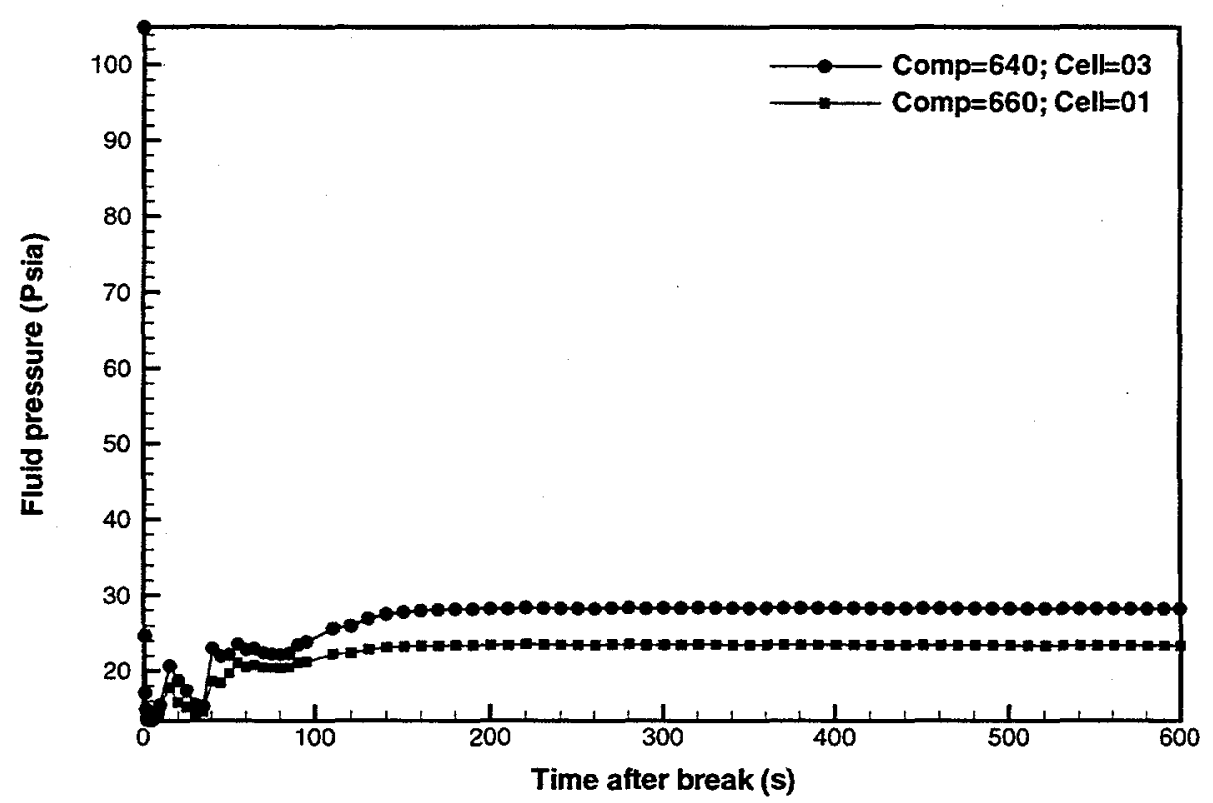

Figure B-17a Primary RHR heat exchanger fluid pressures for a LOCA (Case 1: external HR break near inlet header).

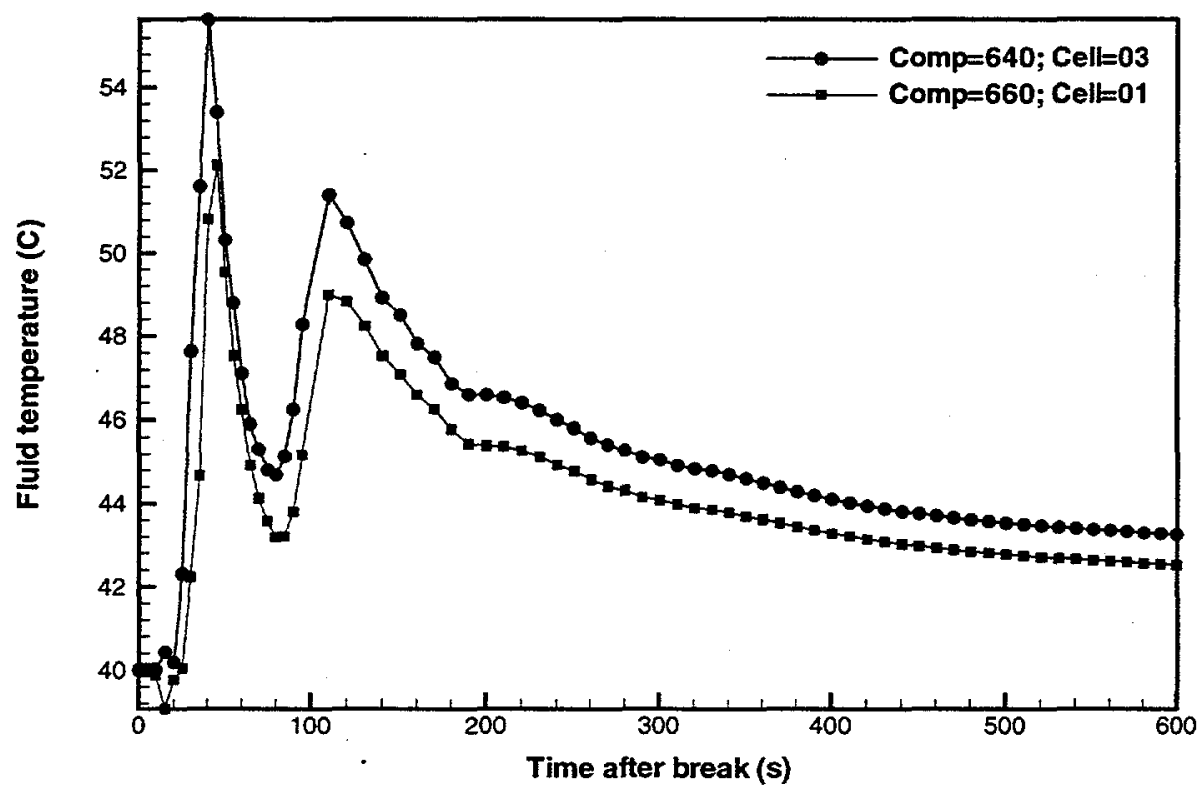

Figure B-17b Primary RHR heat exchanger fluid temperatures for a LOCA (Case 1: external HR break near inlet header). 


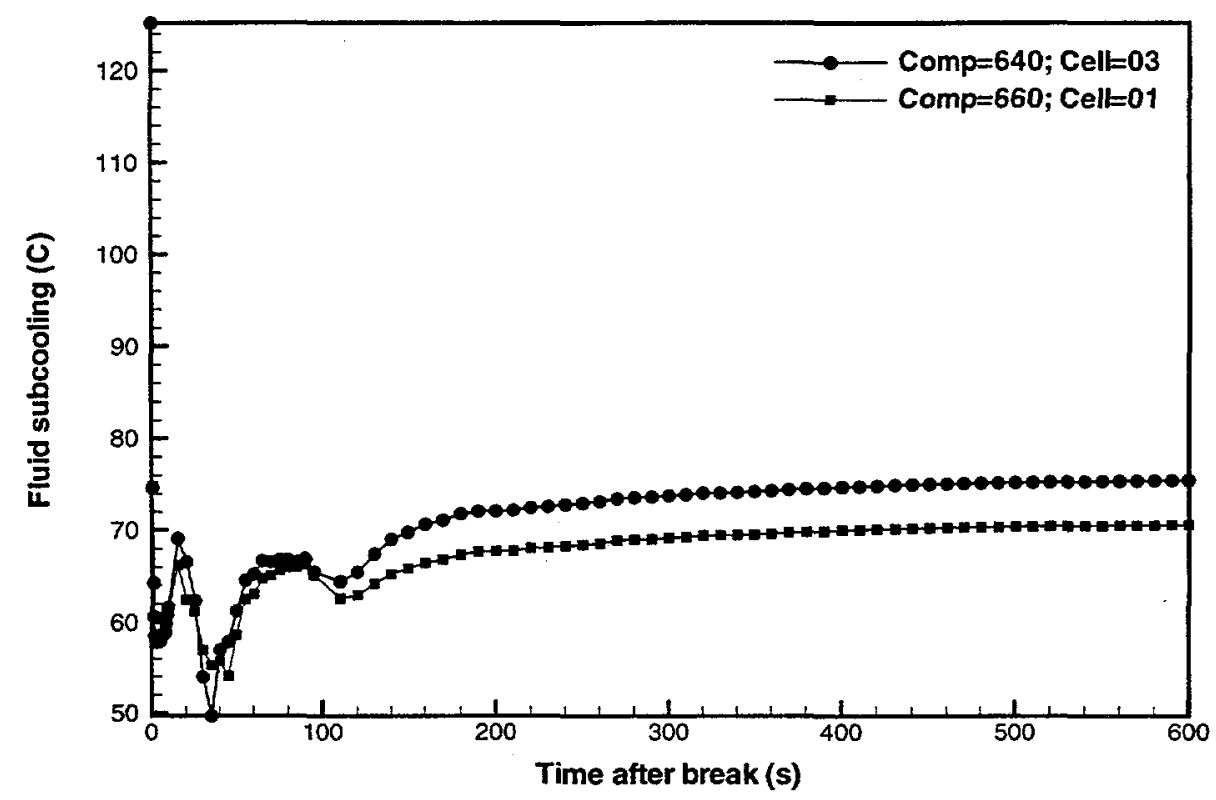

Figure B-17c Primary RHR heat exchanger fluid subcoolings for a LOCA (Case 1: external HR break near inlet header).

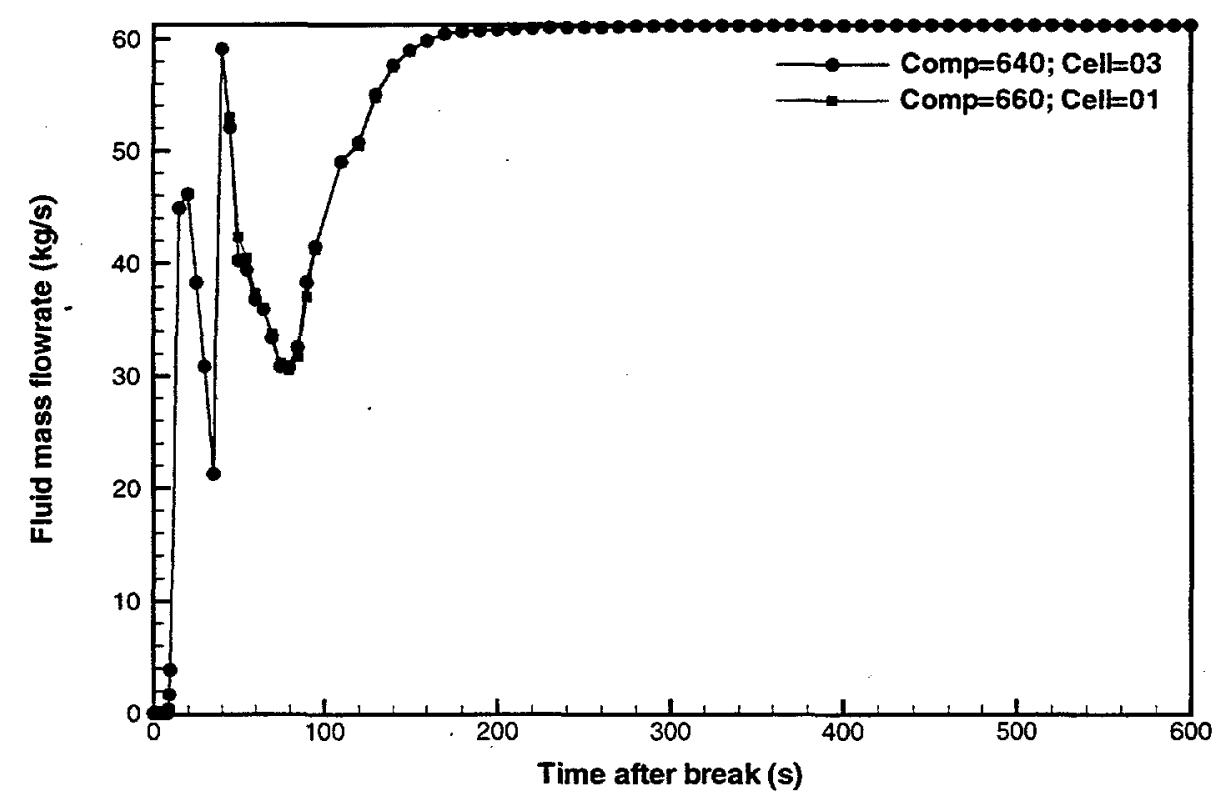

Figure B-17d Primary RHR heat exchanger liquid mass flowrates for a LOCA (Case 1: external HR break near inlet header). 


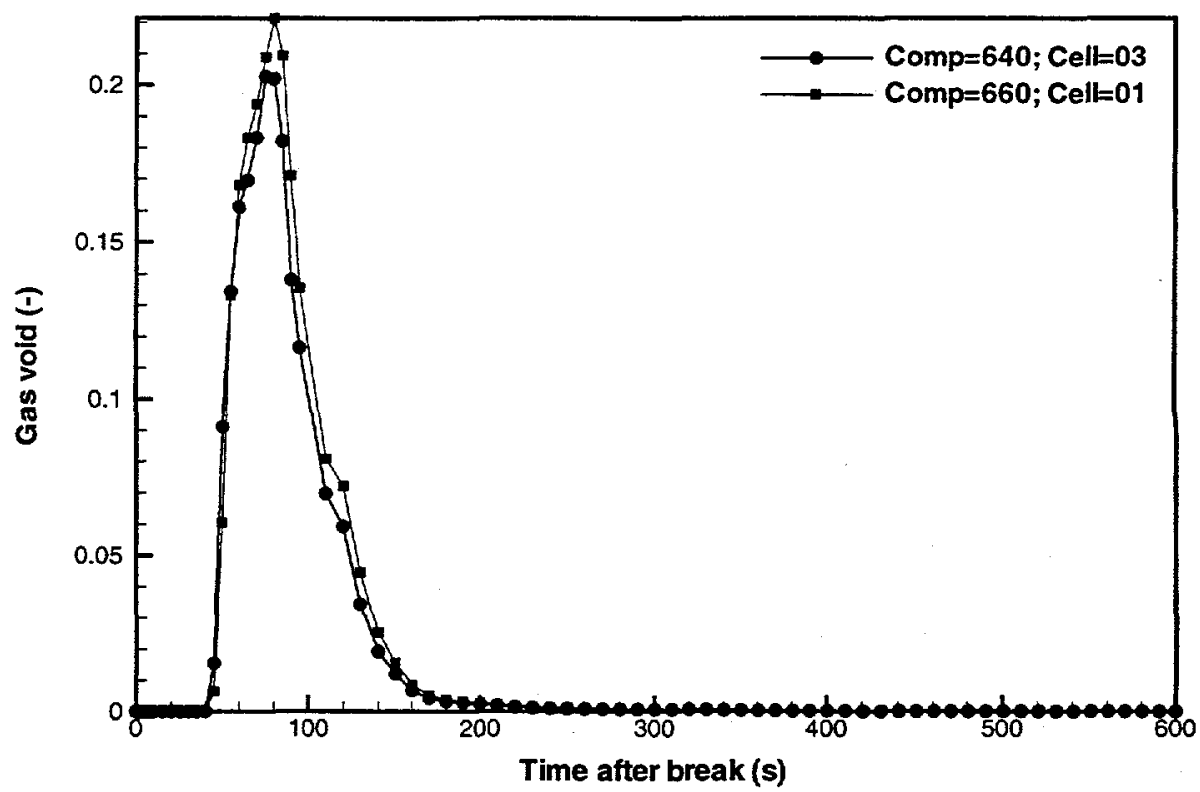

Figure B-17e Primary RHR heat exchanger void fractions for a LOCA (Case 1: external HR break near inlet header).

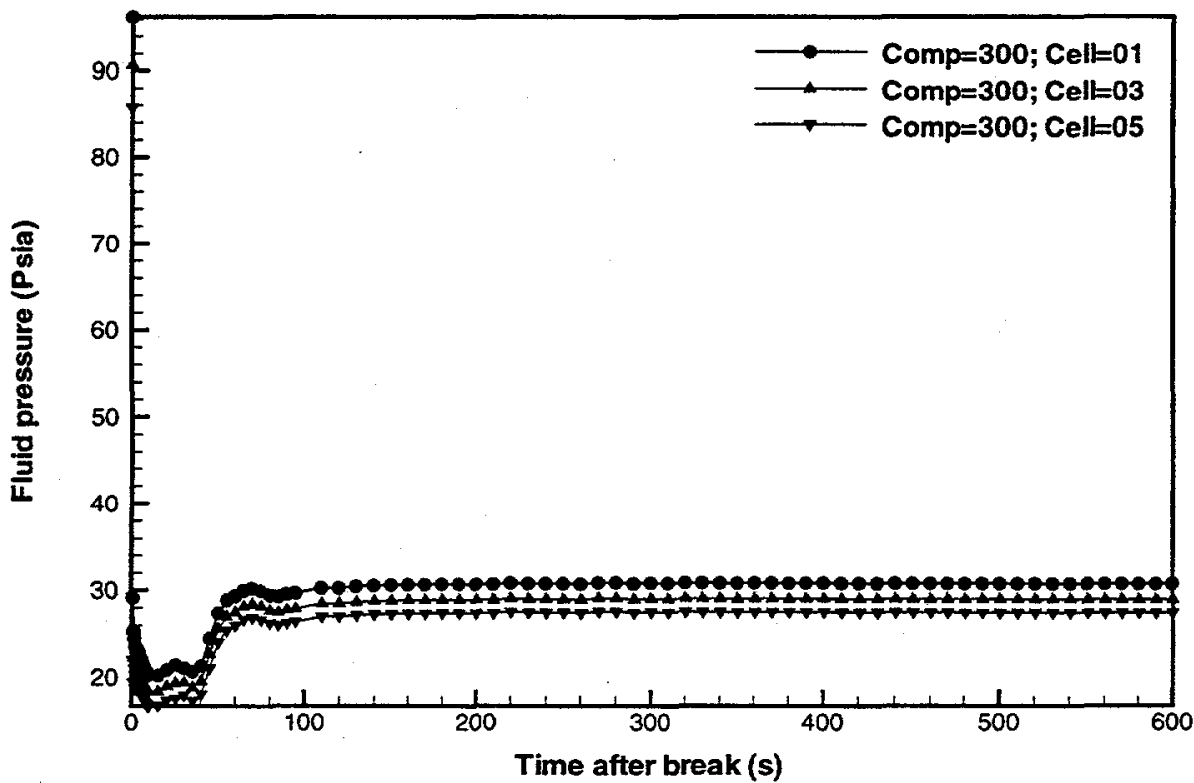

Figure B-18a Module 1 channel fluid pressures for a LOCA (Case 1: external HR break near inlet header). 


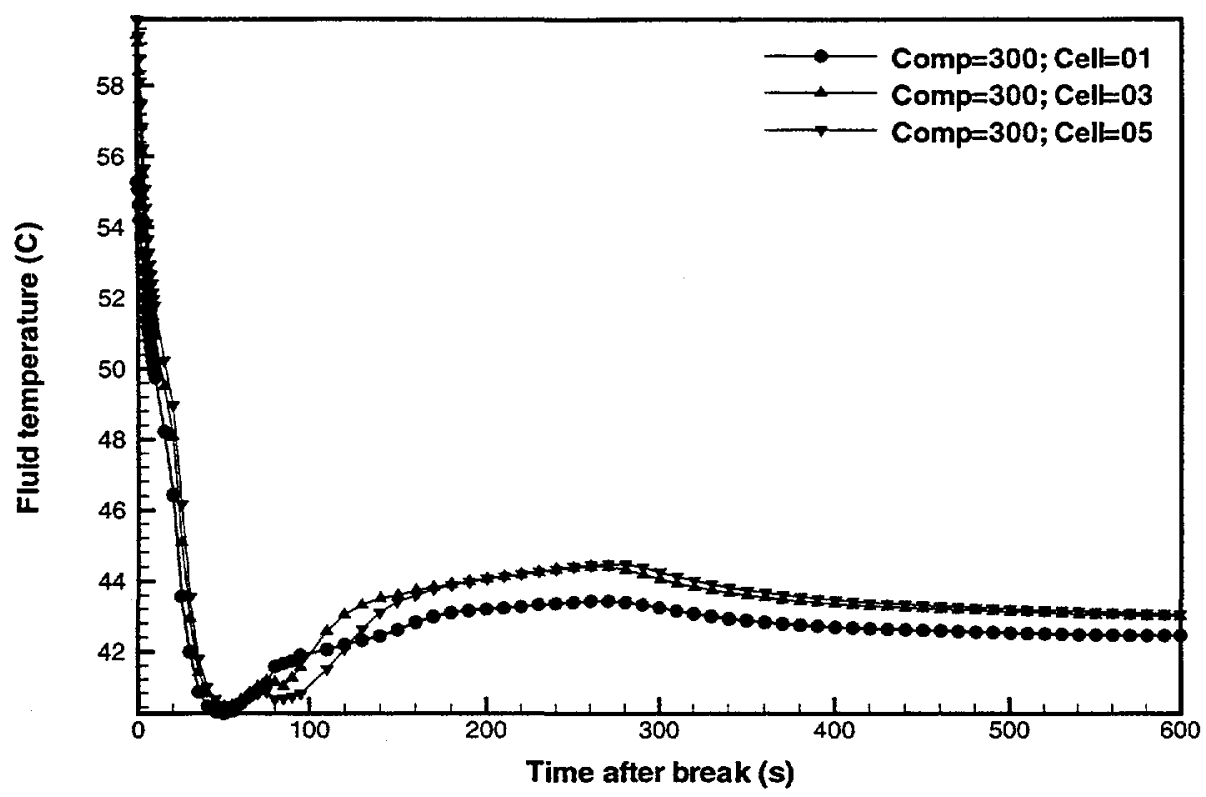

Figure B-18b Module 1 channel fluid temperatures for a LOCA (Case 1: external HR break near inlet header).

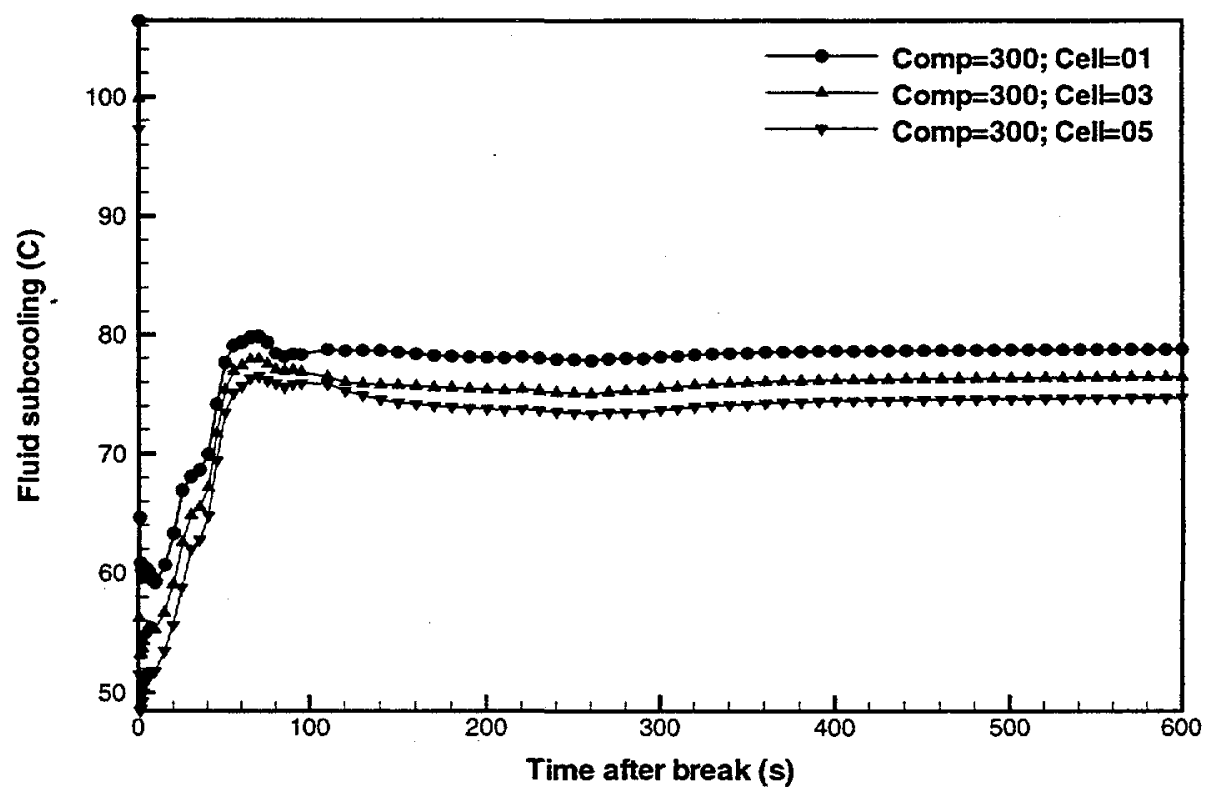

Figure B-18c Module 1 channel fluid subcoolings for a LOCA (Case 1: external HR break near inlet header). 


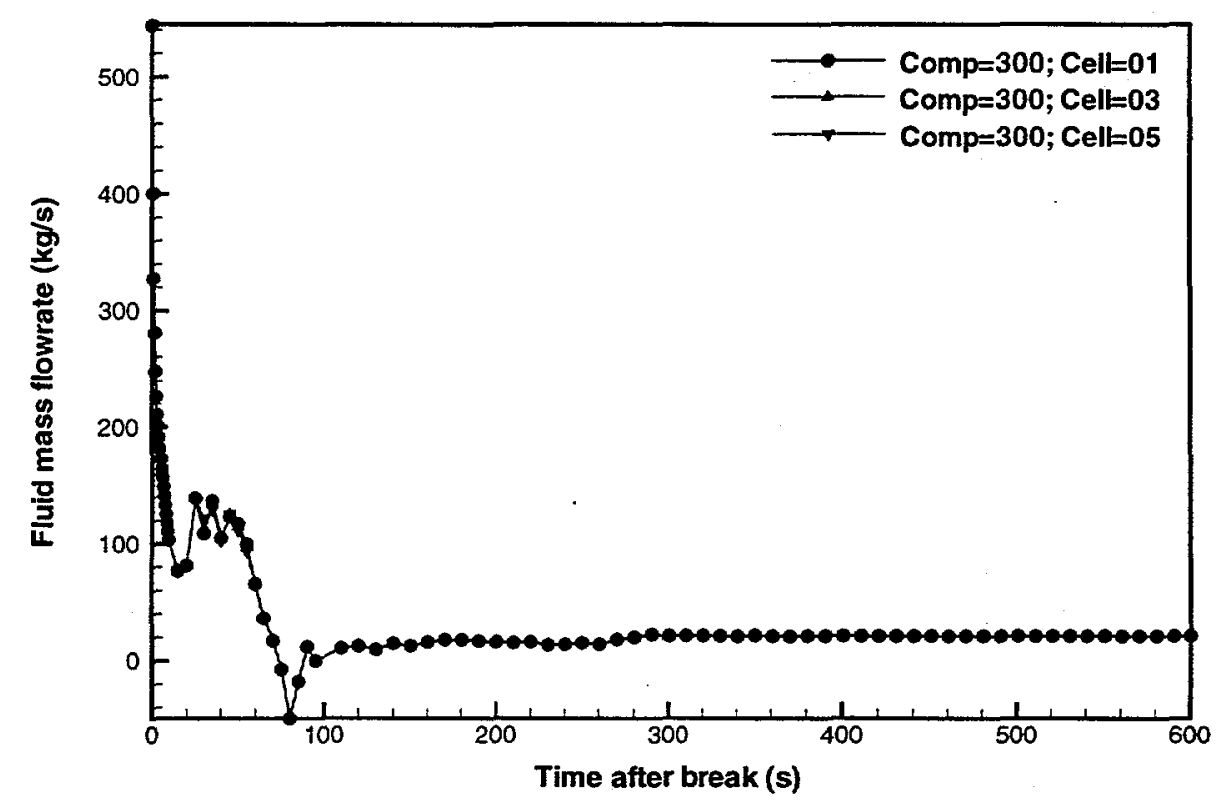

Figure B-18d Module 1 channel liquid mass flowrates for a LOCA (Case 1: external HR break near inlet header).

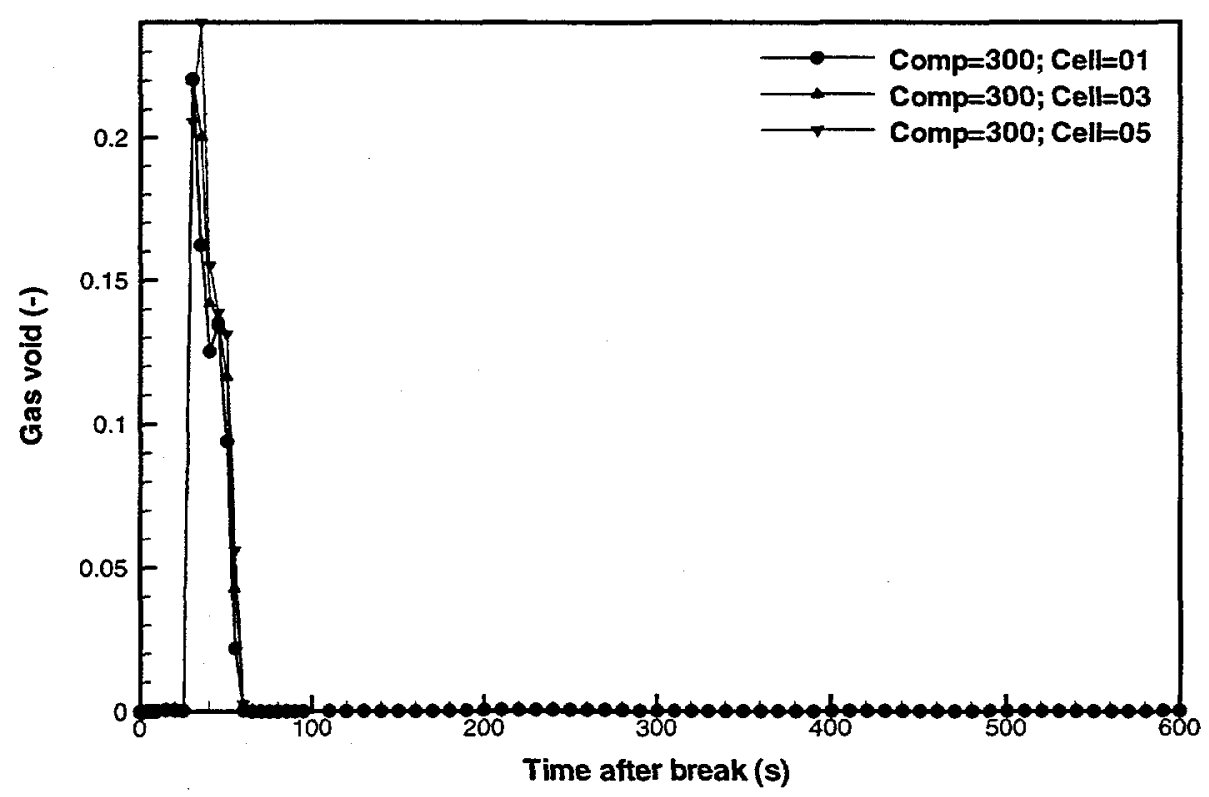

Figure B-8e Module 1 channel void fractions for a LOCA (Case 1: external HR break near inlet header). 


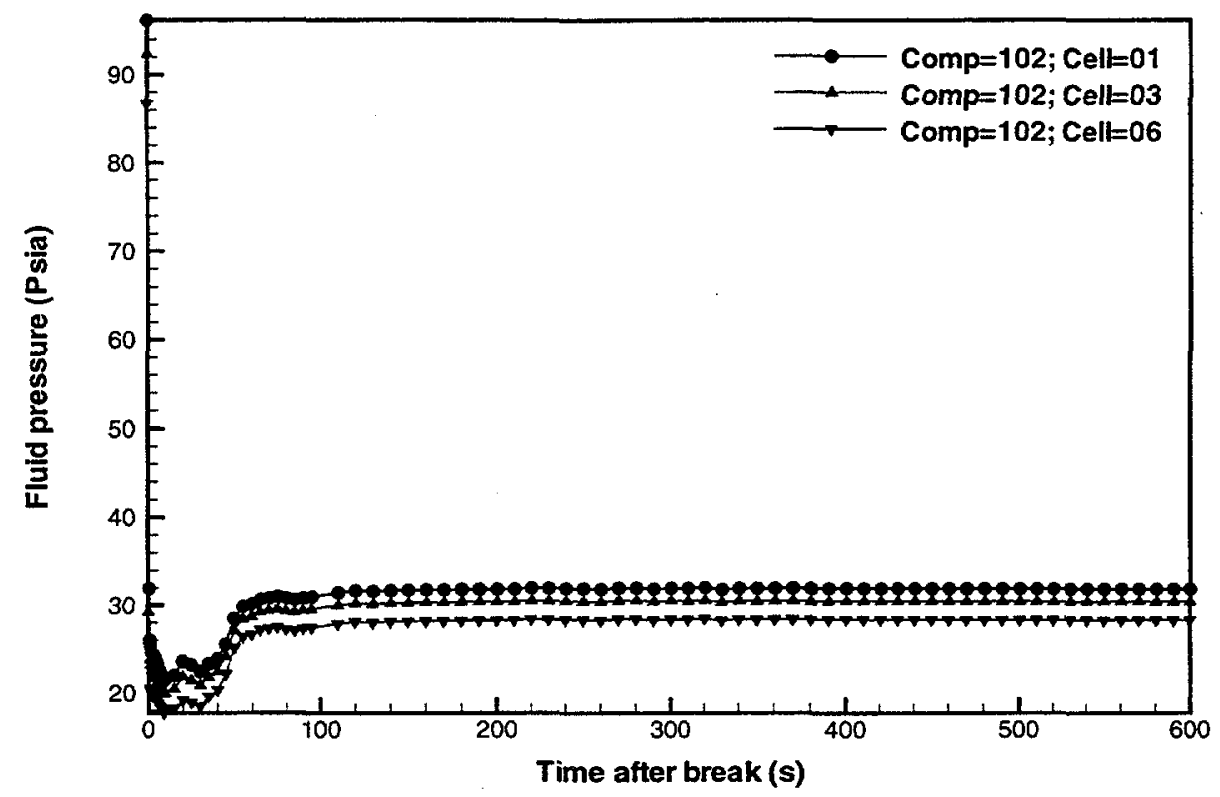

Figure B-19a Module 2 channel fluid pressures for a LOCA (Case 1: external HR break near inlet header).

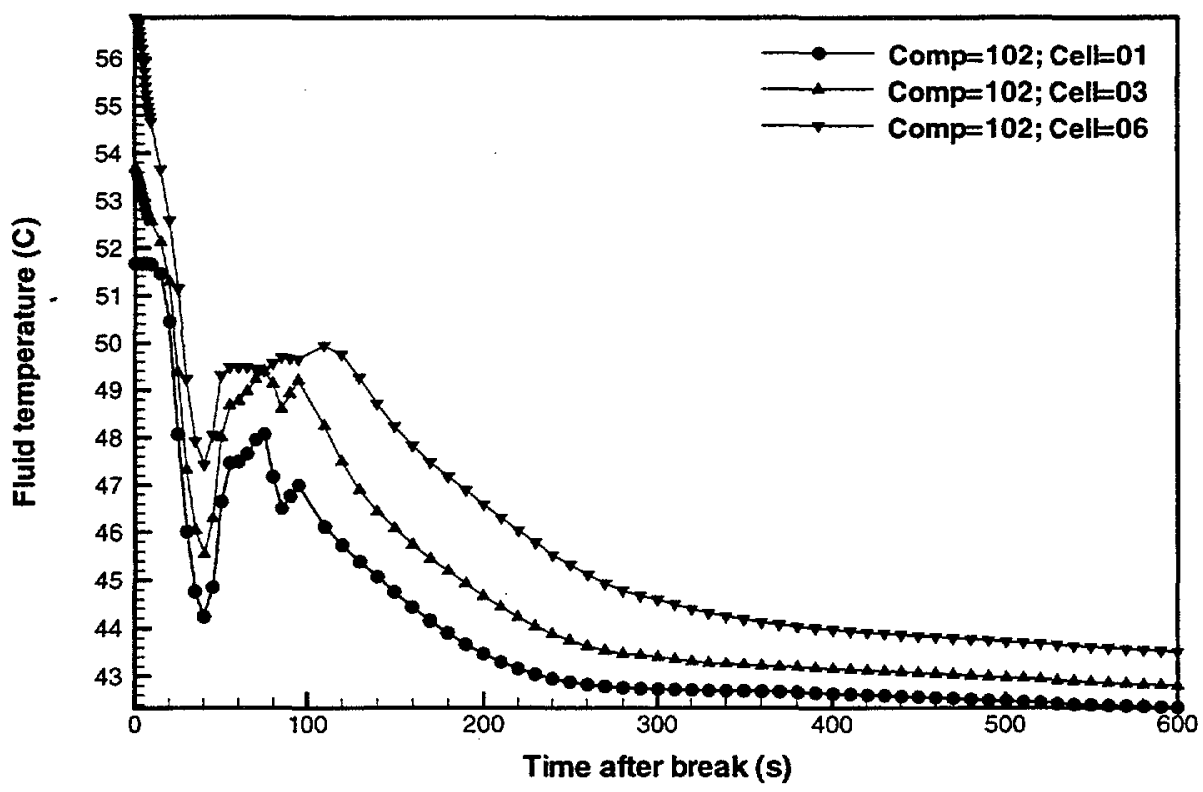

Figure B-19b Module 2 channel fluid temperatures for a LOCA (Case 1: external HR break near inlet header). 


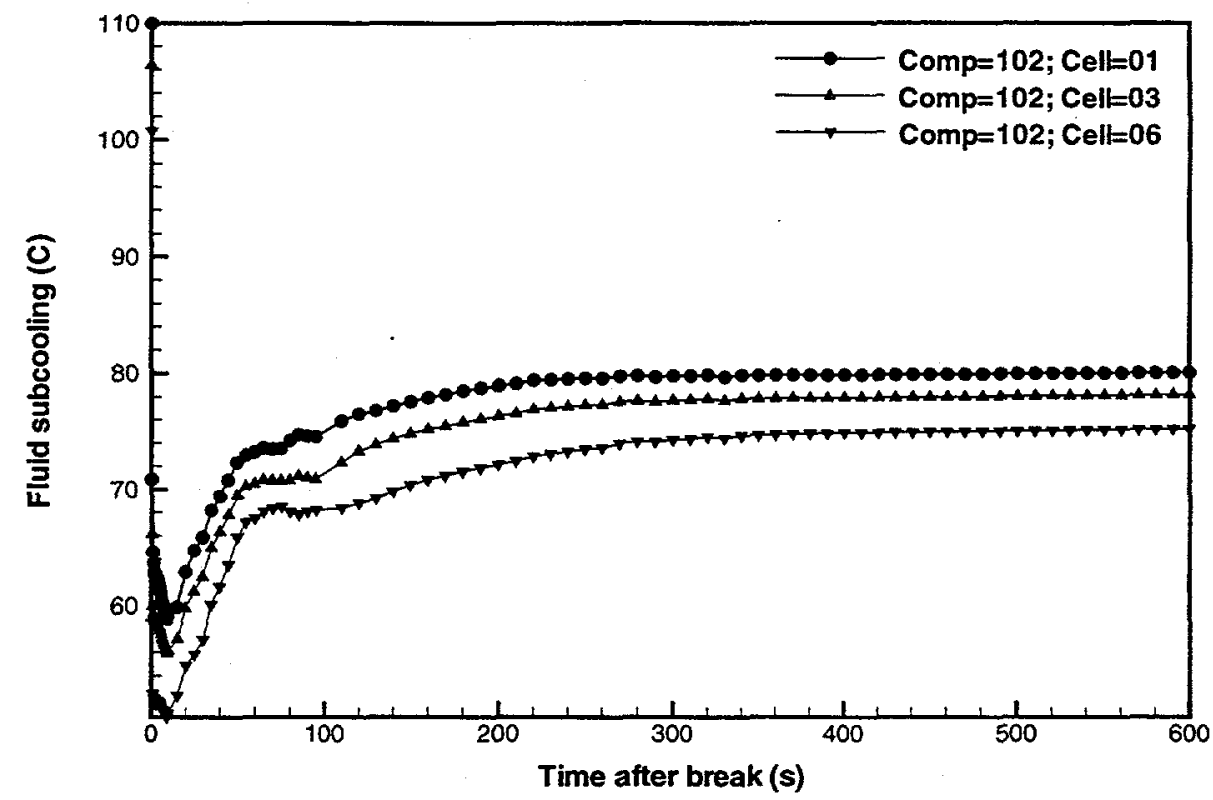

Figure B-19c Module 2 channel fluid subcoolings for a LOCA (Case 1: external HR break near inlet header).

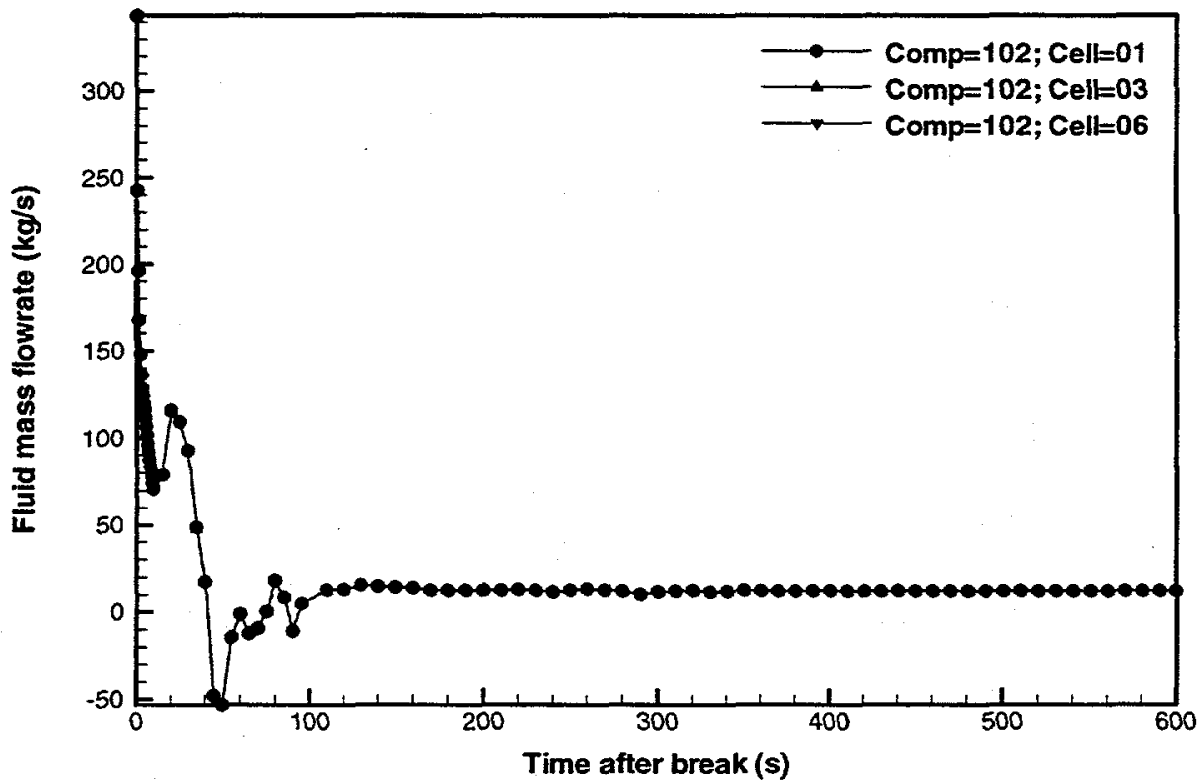

Figure B-19d Module 2 channel liquid mass flowrates for a LOCA (Case 1: external HR break near inlet header). 


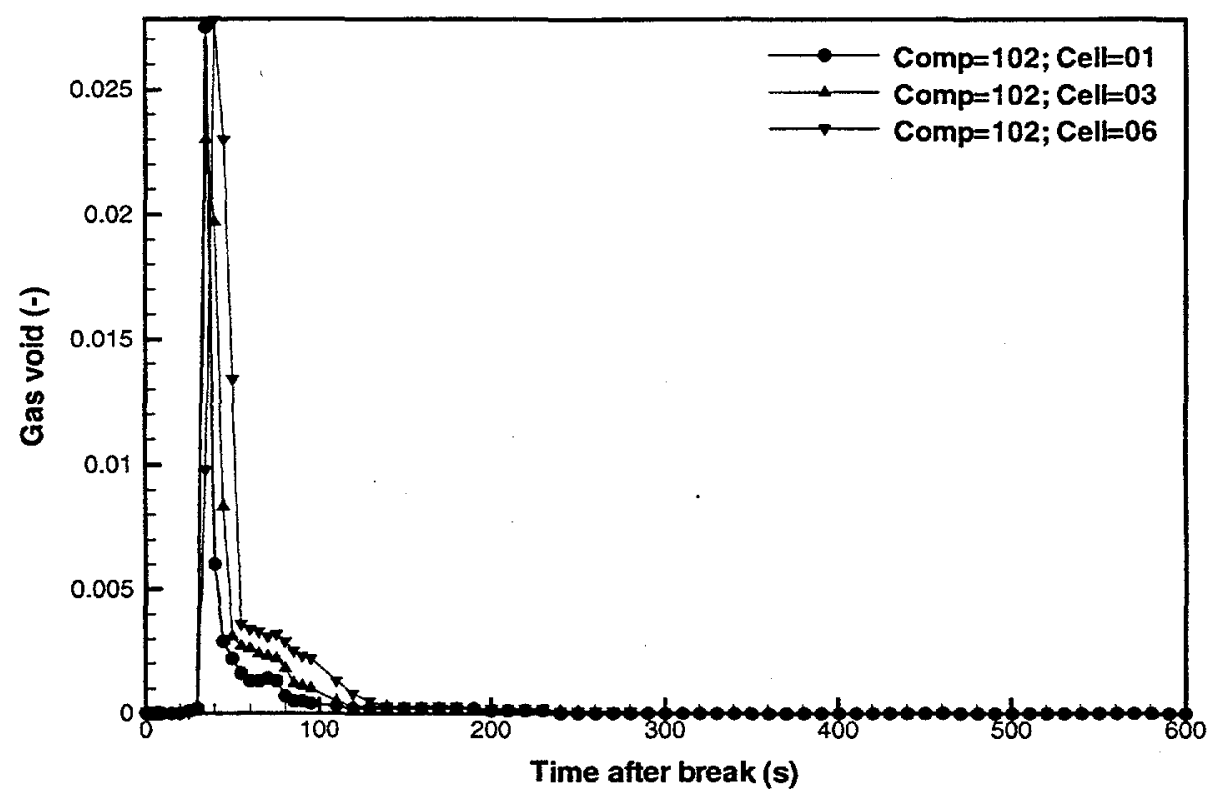

Figure B-19e Module 2 channel Module 2 channel void fractions for a LOCA (Case 1: external HR break near inlet header).

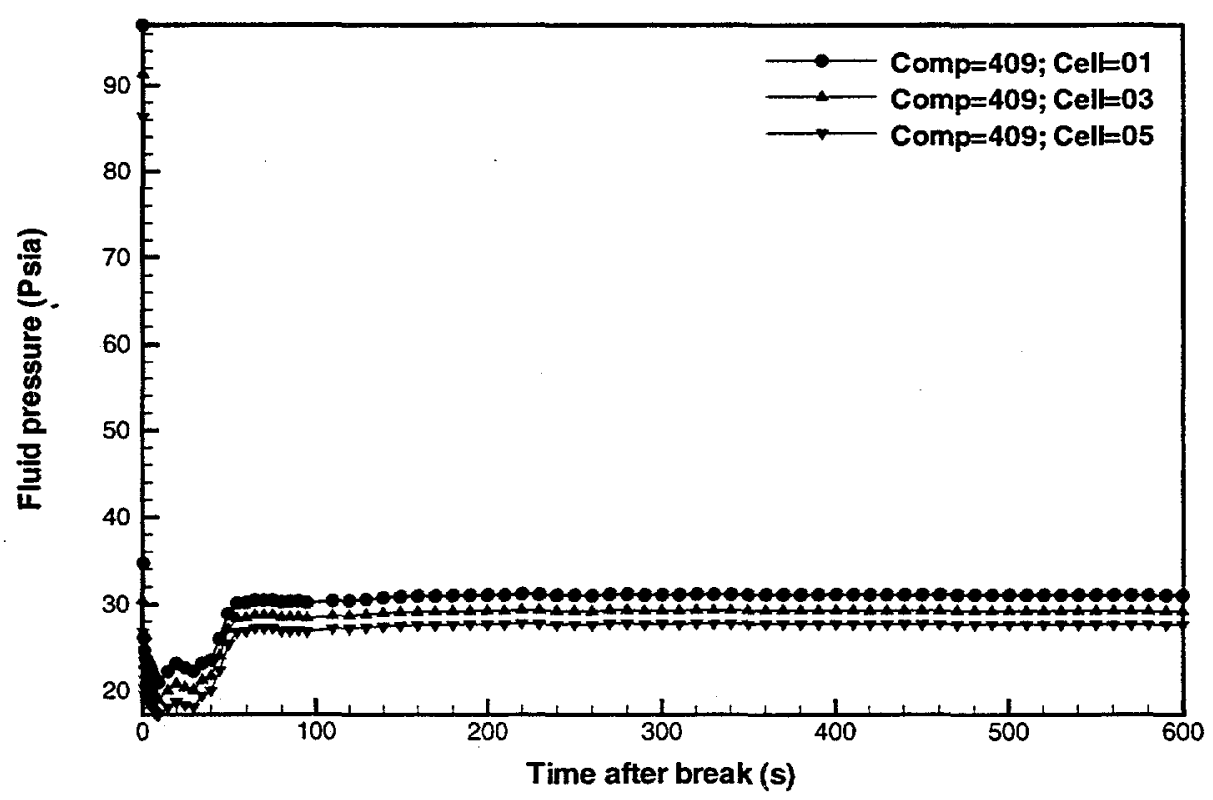

Figure B-20a Module 3 channel fluid pressures for a LOCA (Case 1: external HR break near inlet header). 


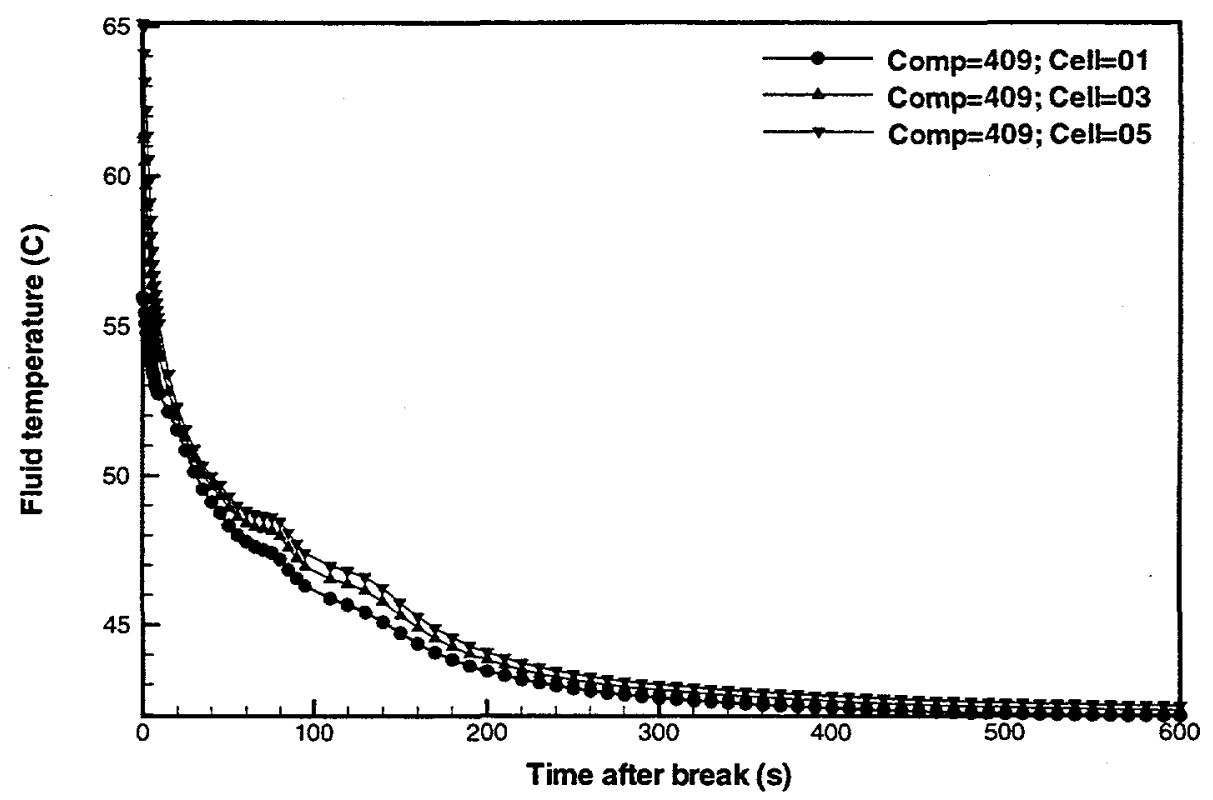

Figure B-20b Module 3 channel Module 3 channel fluid temperatures for a LOCA (Case 1: external HR break near inlet header).

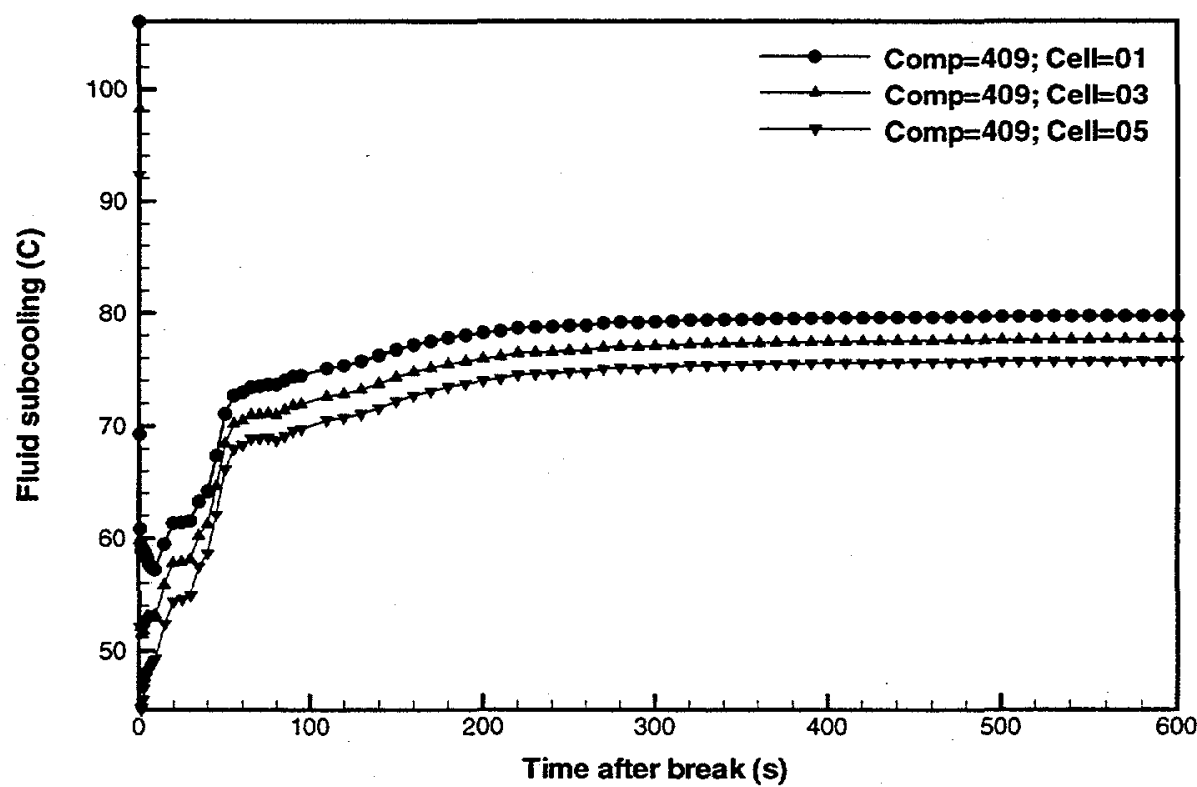

Figure B-20c Module 3 channel fluid subcoolings for a LOCA (Case 1: external HR break near inlet header). 


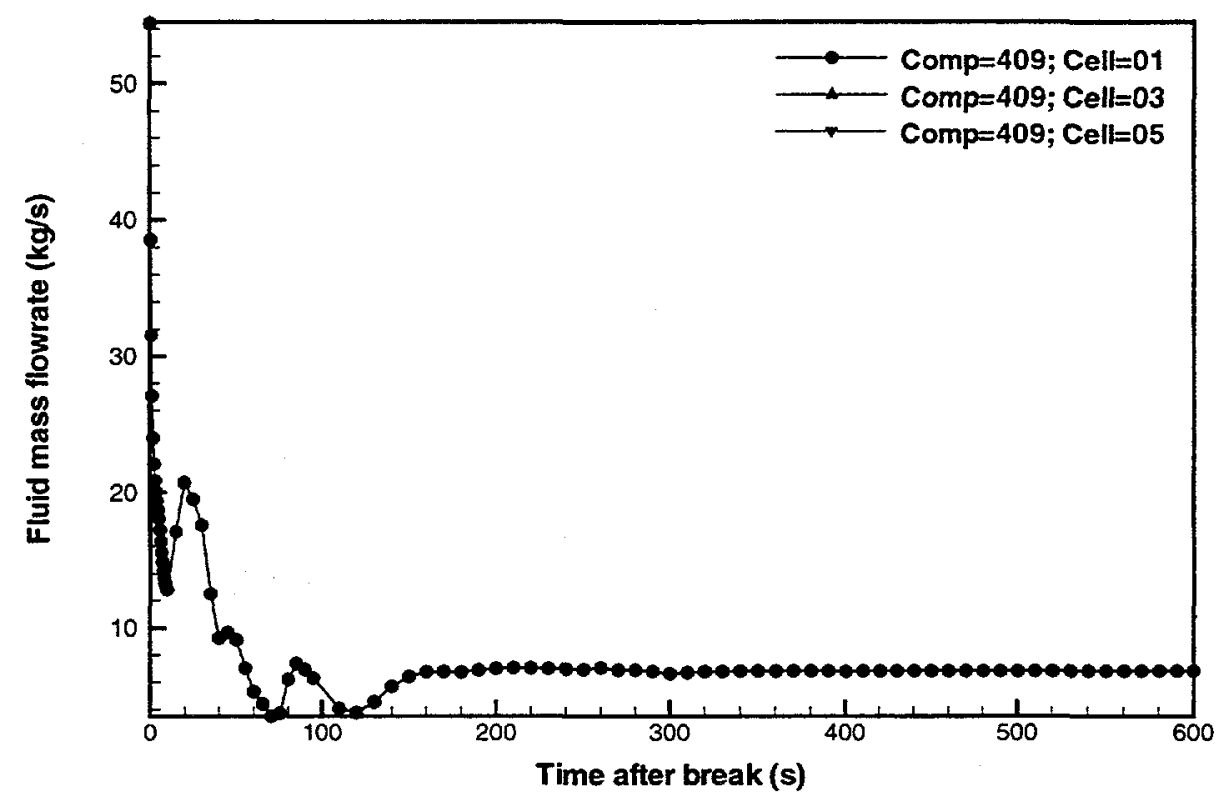

Figure B-20d Module 3 channel liquid mass flowrates for a LOCA (Case 1: external HR break near inlet header).

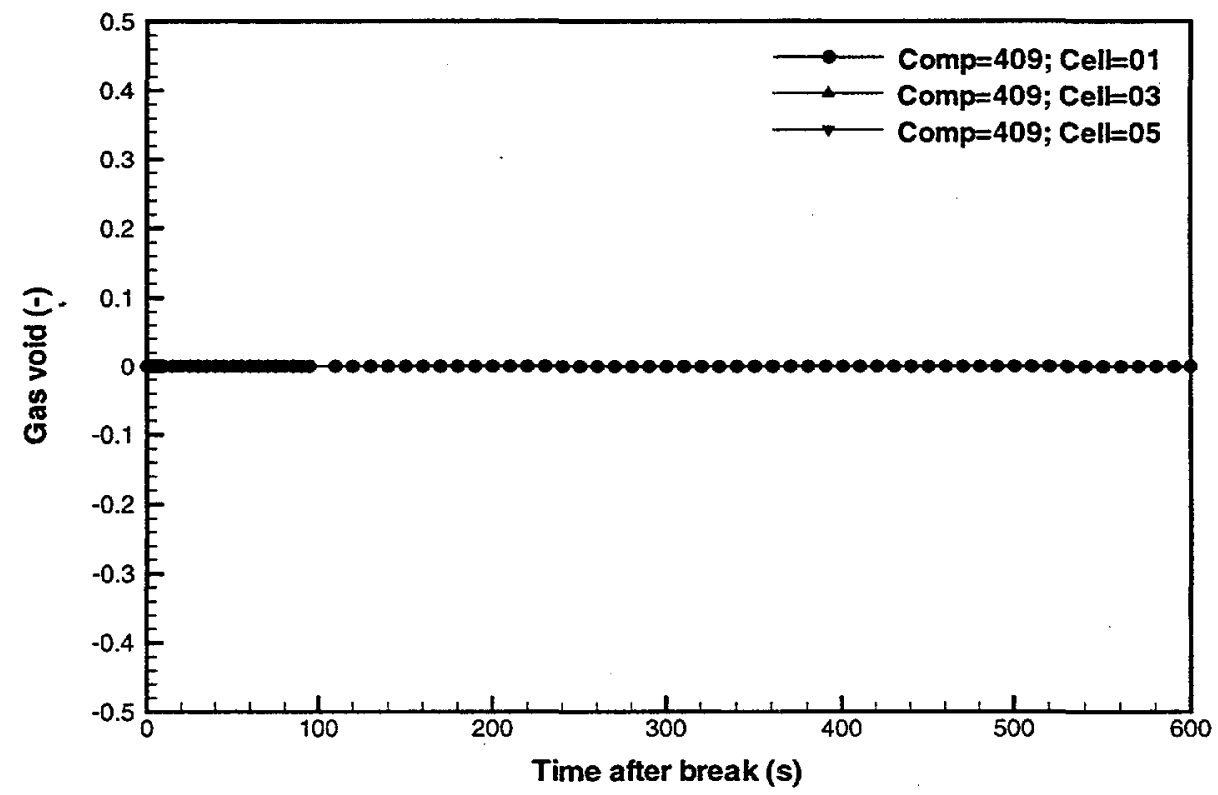

Figure B-20e Module 3 channel void fractions for a LOCA (Case 1: external HR break near inlet header). 


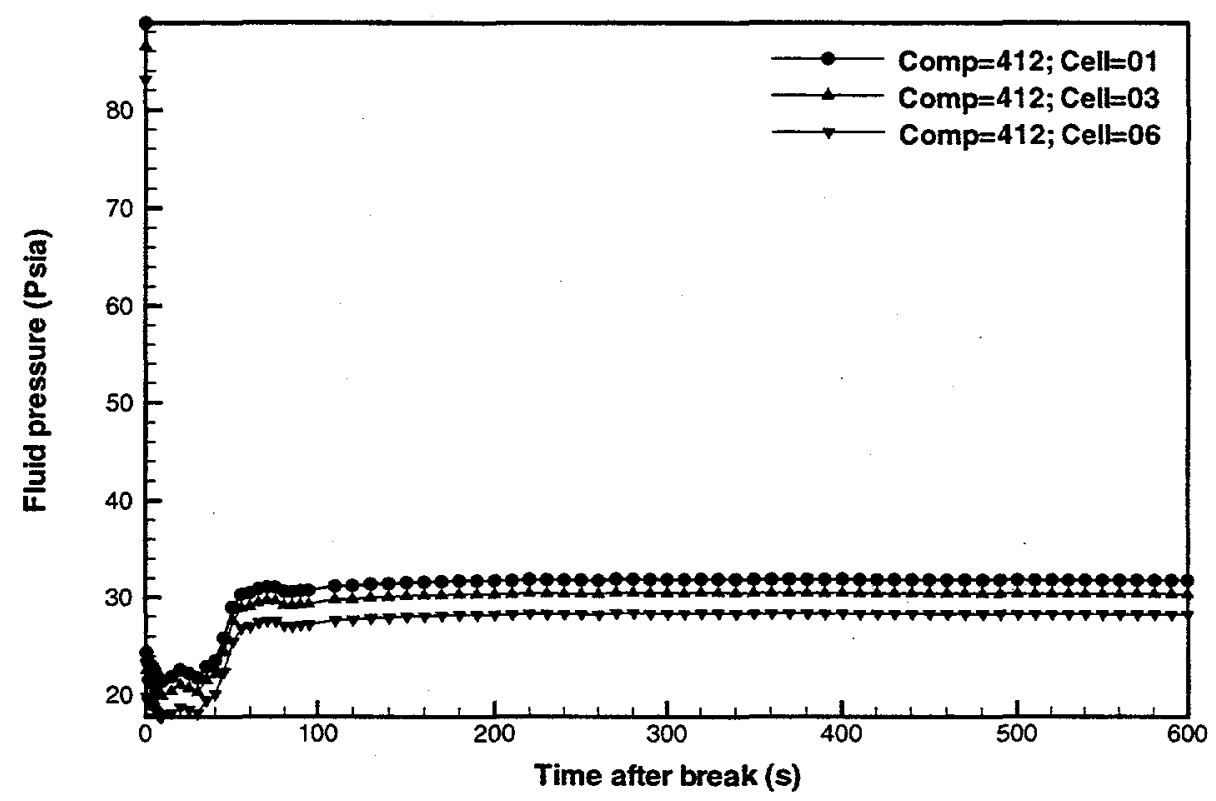

Figure B-21a Module 4 channel fluid pressures for a LOCA (Case 1: external HR break near inlet header).

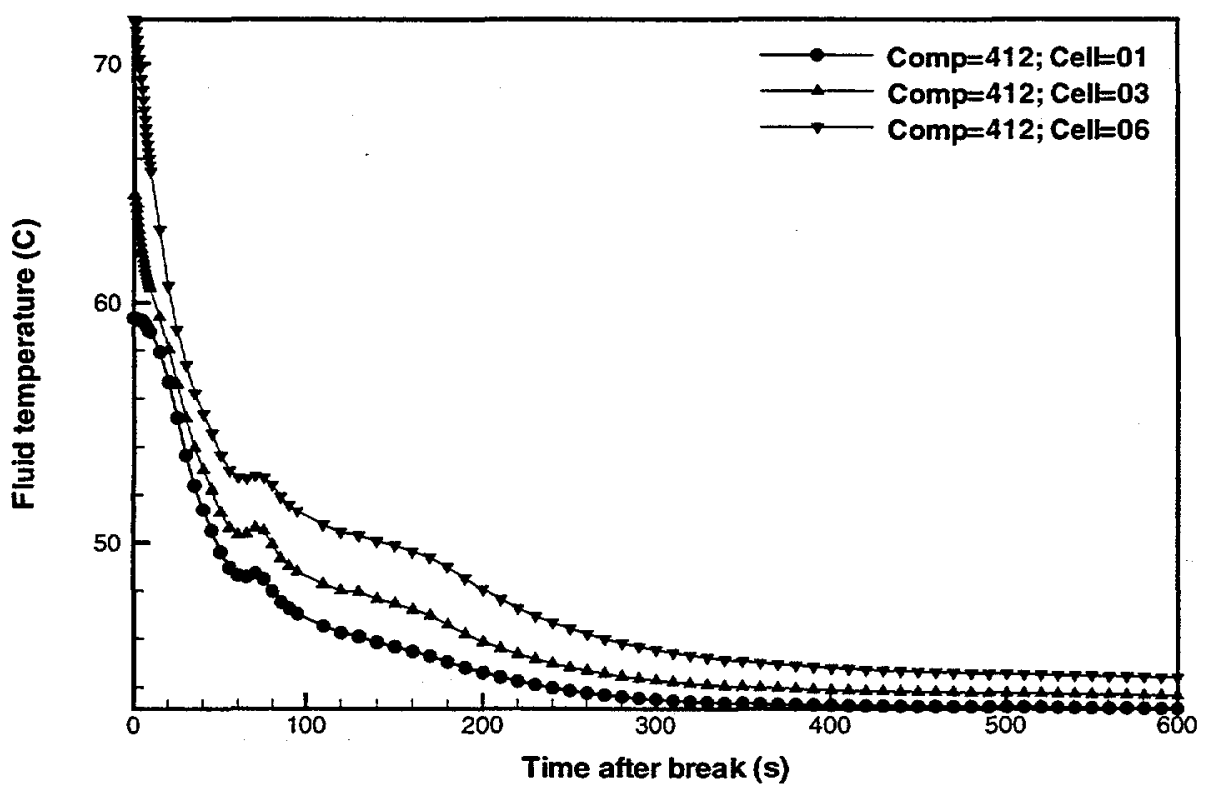

Figure B-21b Module 4 channel fluid temperatures for a LOCA (Case 1: external HR break near inlet header). 


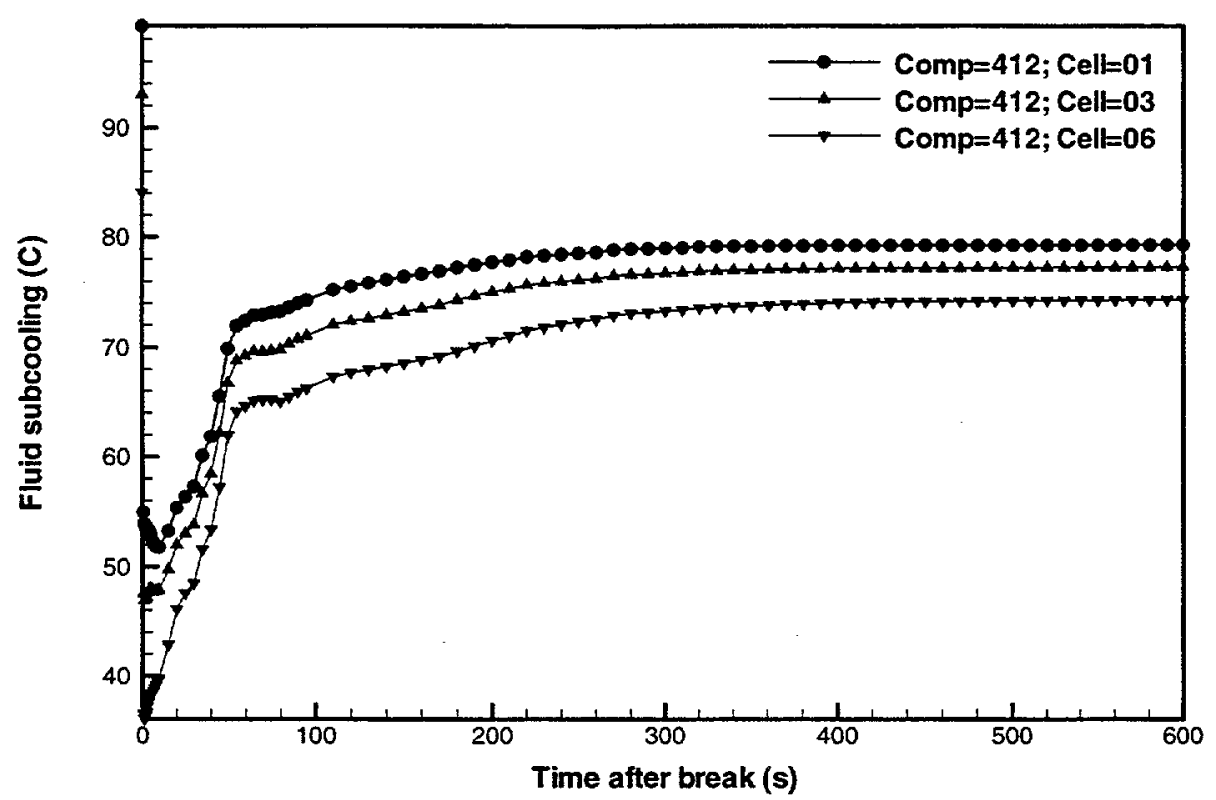

Figure B-21c Module 4 channel fluid subcoolings for a LOCA (Case 1: external HR break near inlet header).

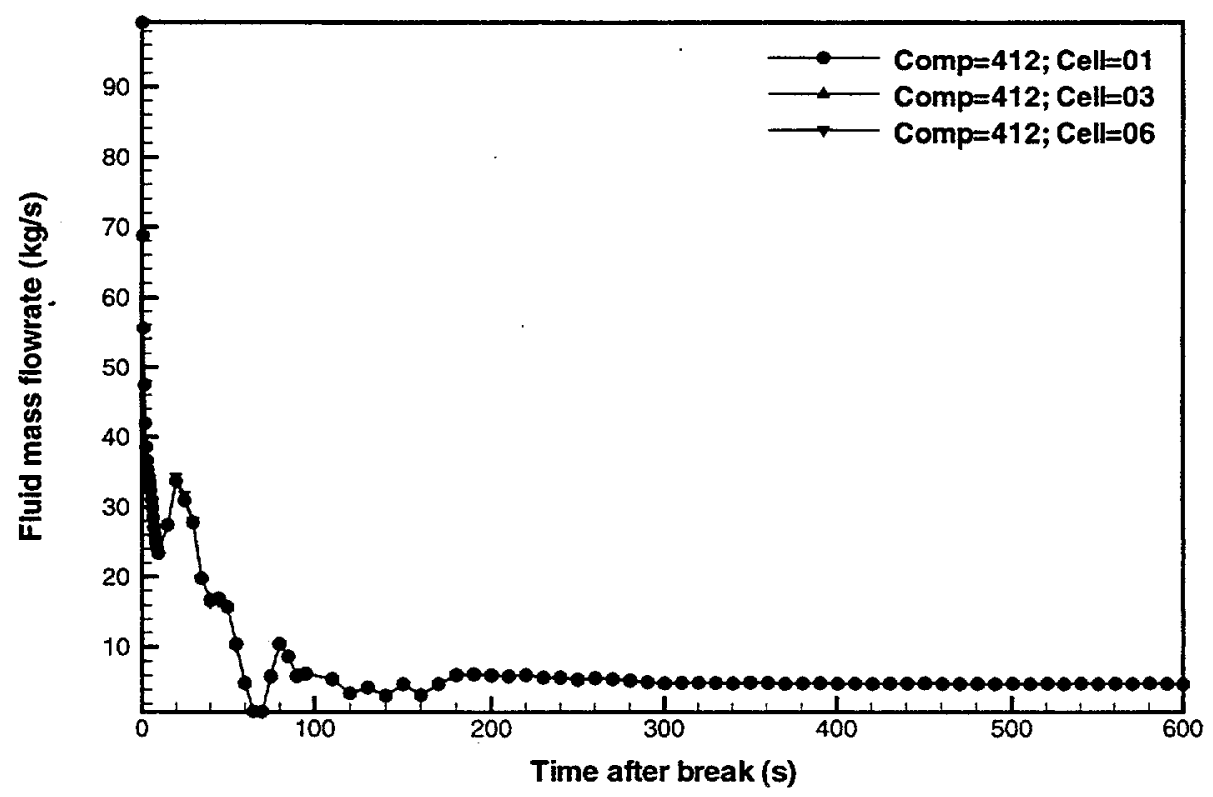

Figure B-21d Module 4 channel liquid mass flowrates for a LOCA (Case 1: external HR break near inlet header). 


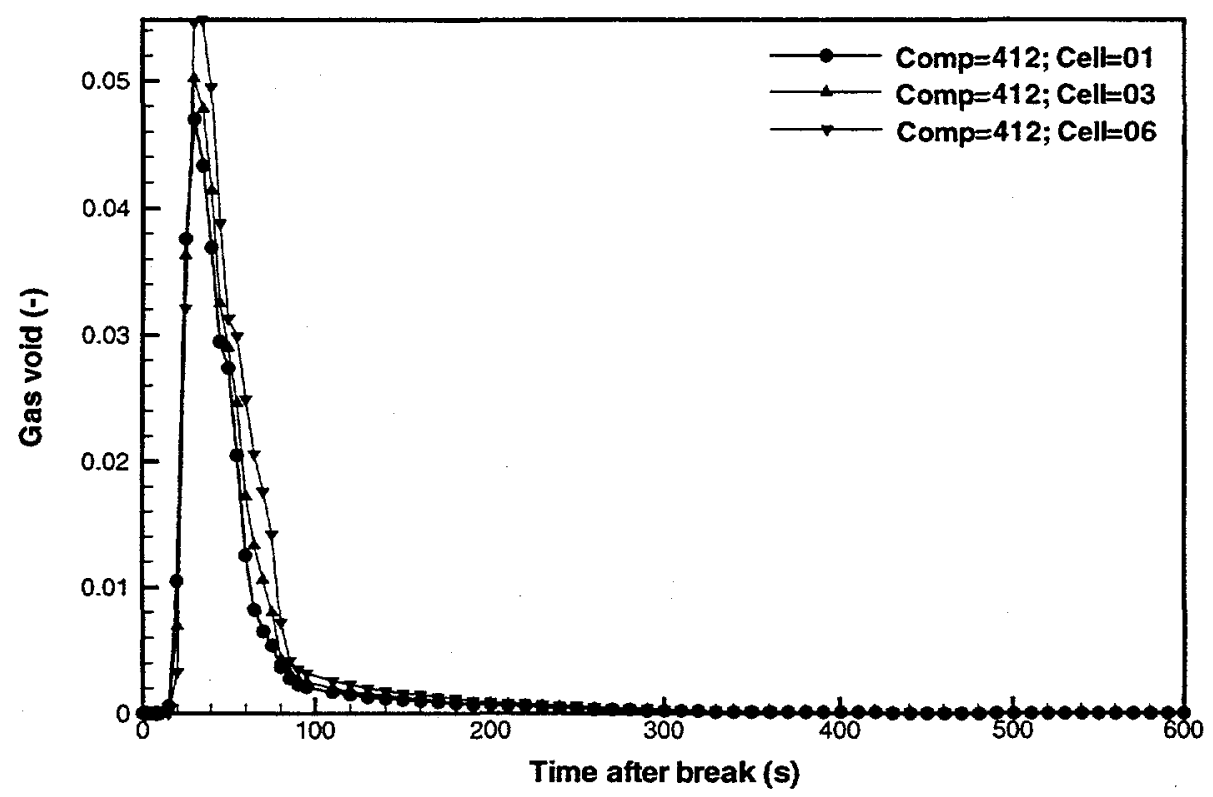

Figure B-21e Module 4 channel void fractions for a LOCA (Case 1: external HR break near inlet header).

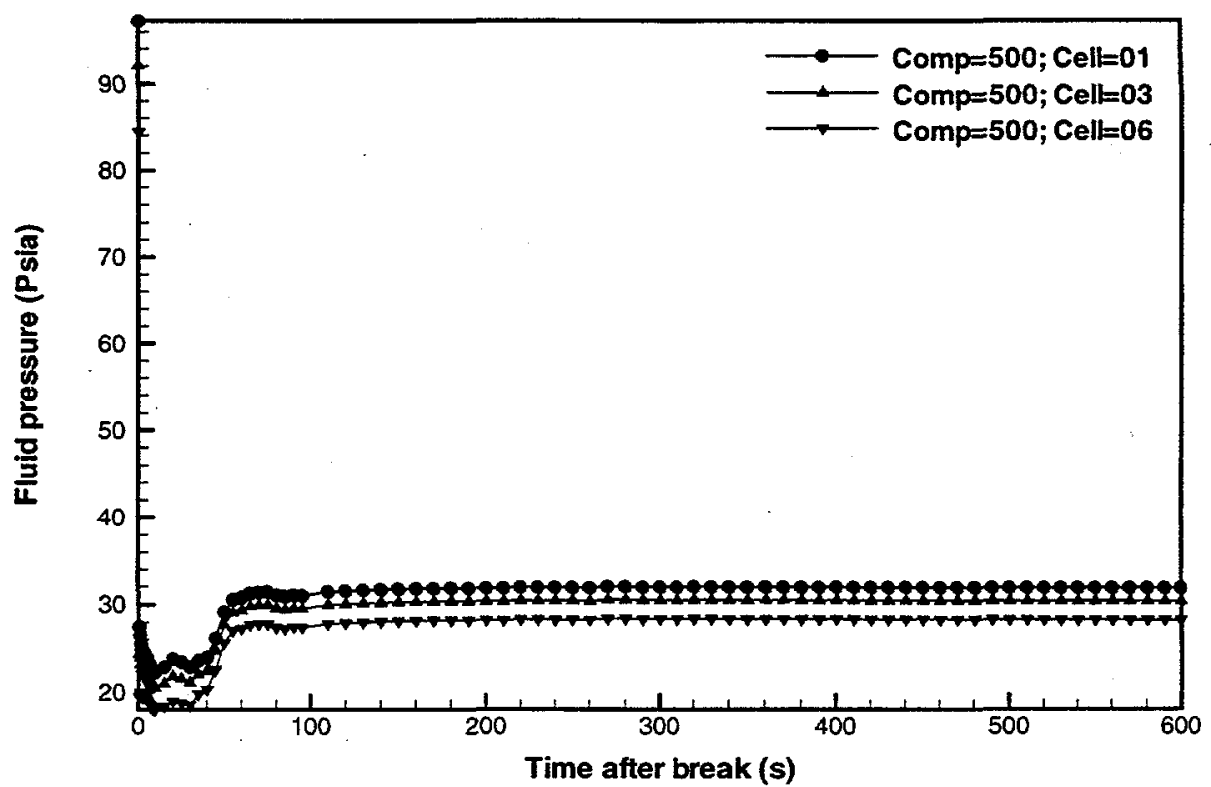

Figure B-22a Module 5 channel fluid pressures for a LOCA (Case 1: external HR break near inlet header). 


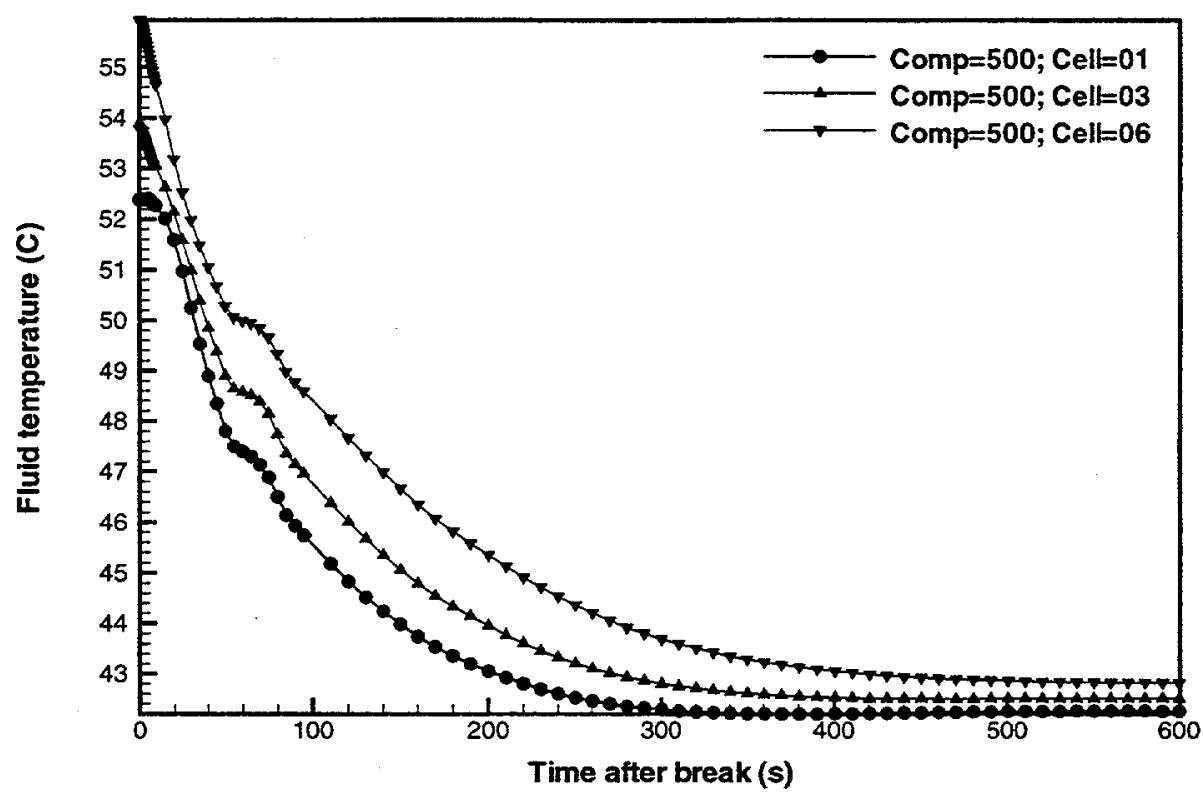

Figure B-22b Module 5 channel fluid temperatures for a LOCA (Case 1: external HR break near inlet header).

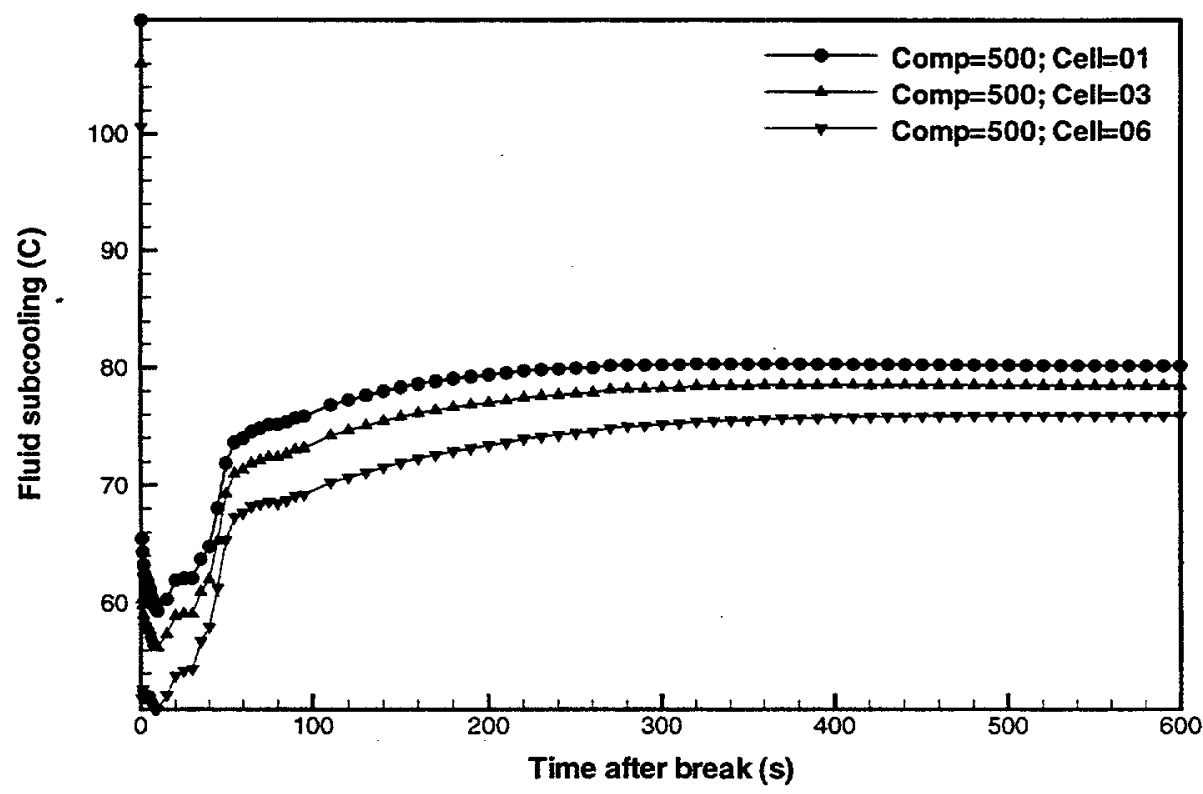

Figure B-22c Module 5 channel fluid subcoolings for a LOCA (Case 1: external HR break near inlet header). 


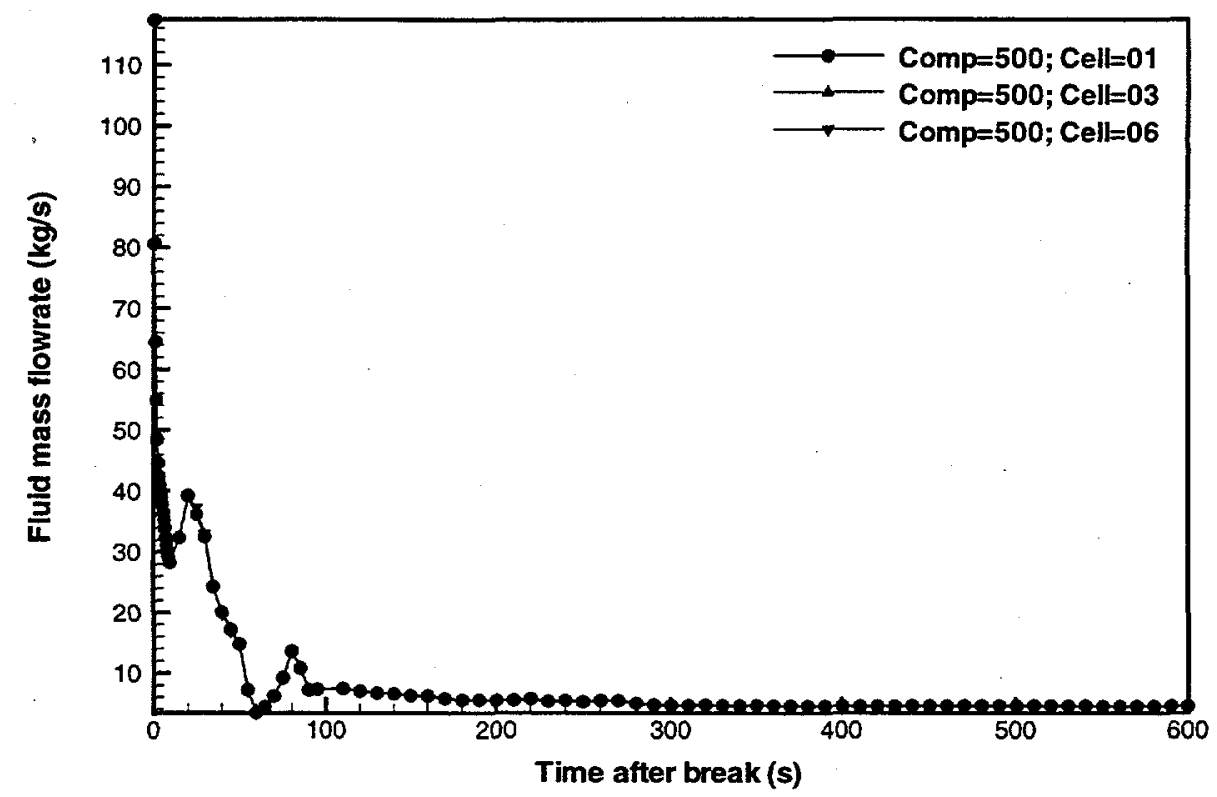

Figure B-22d Module 5 channel liquid mass flowrates for a LOCA (Case 1: external HR break near inlet header).

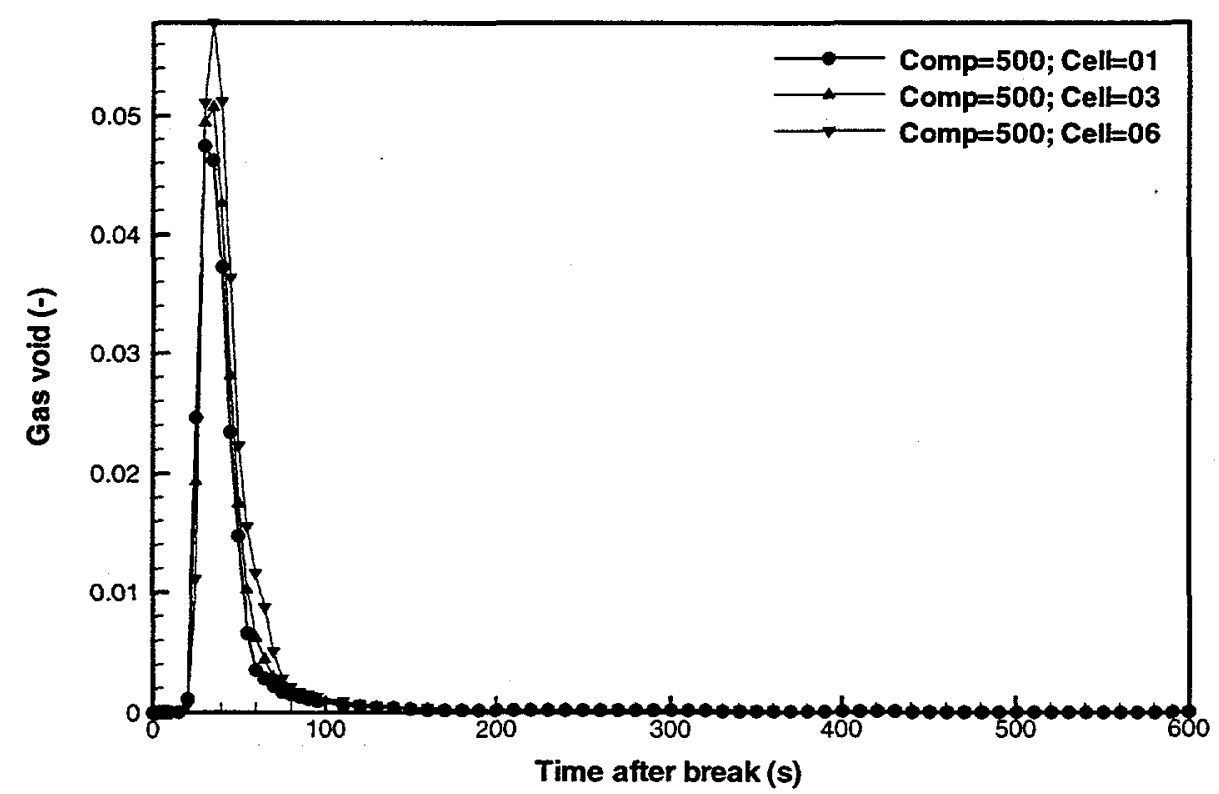

Figure B-22e Module 5 channel void fractions for a LOCA (Case 1: external HR break near inlet header). 


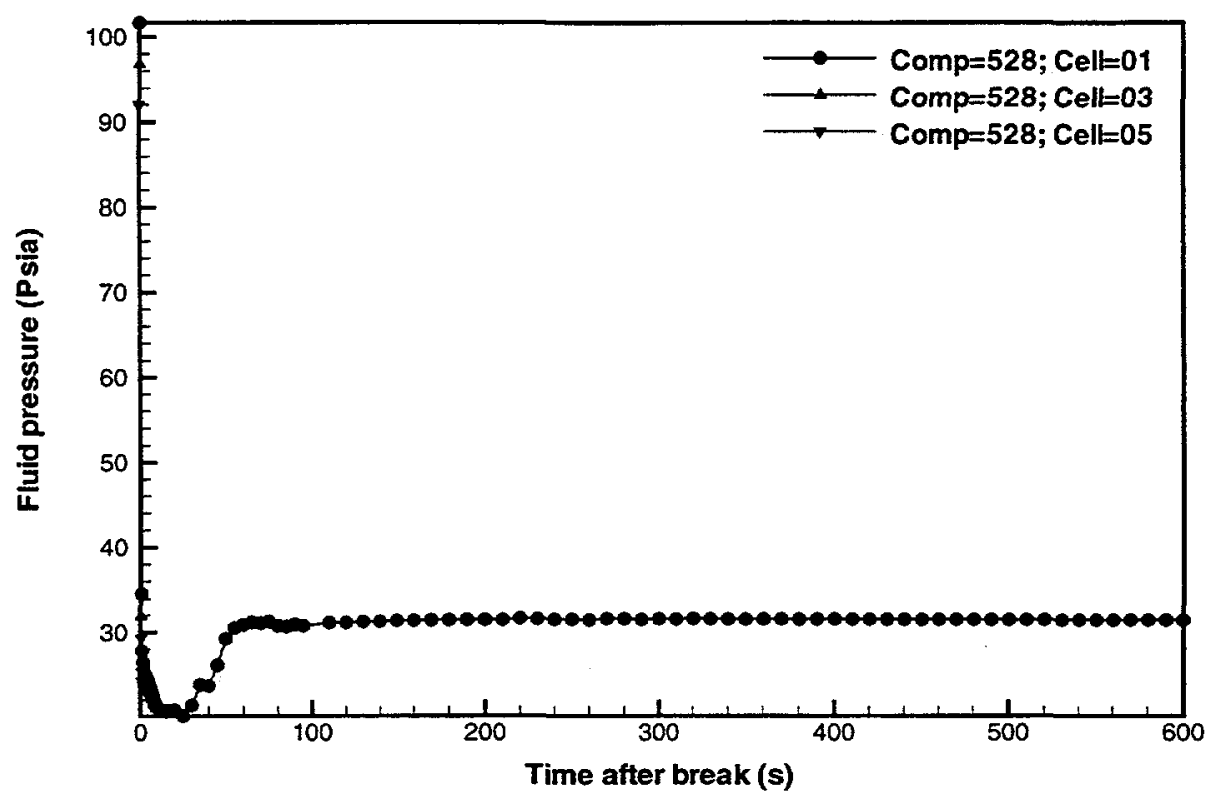

Figure B-23a Module 6 channel fluid pressures for a LOCA (Case 1: external HR break near inlet header).

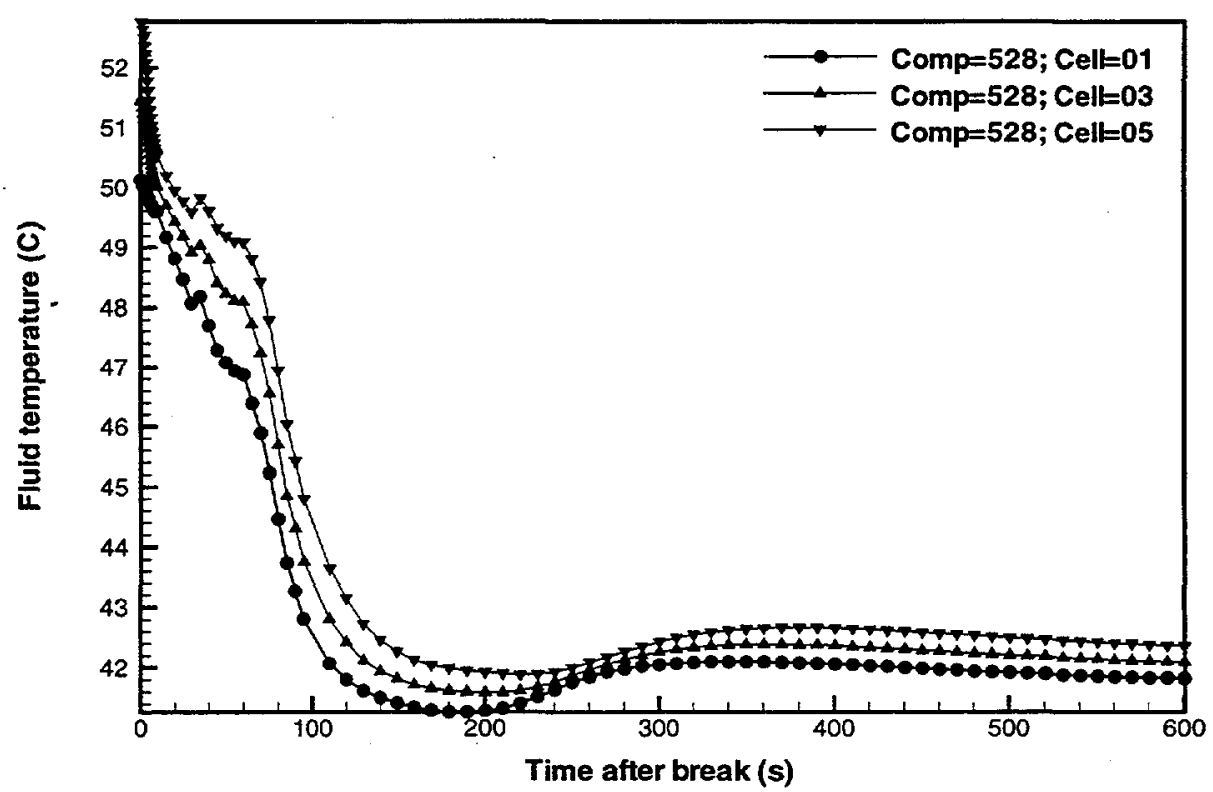

Figure B-23b Module 6 channel fluid temperatures for a LOCA (Case 1: external HR break near inlet header). 


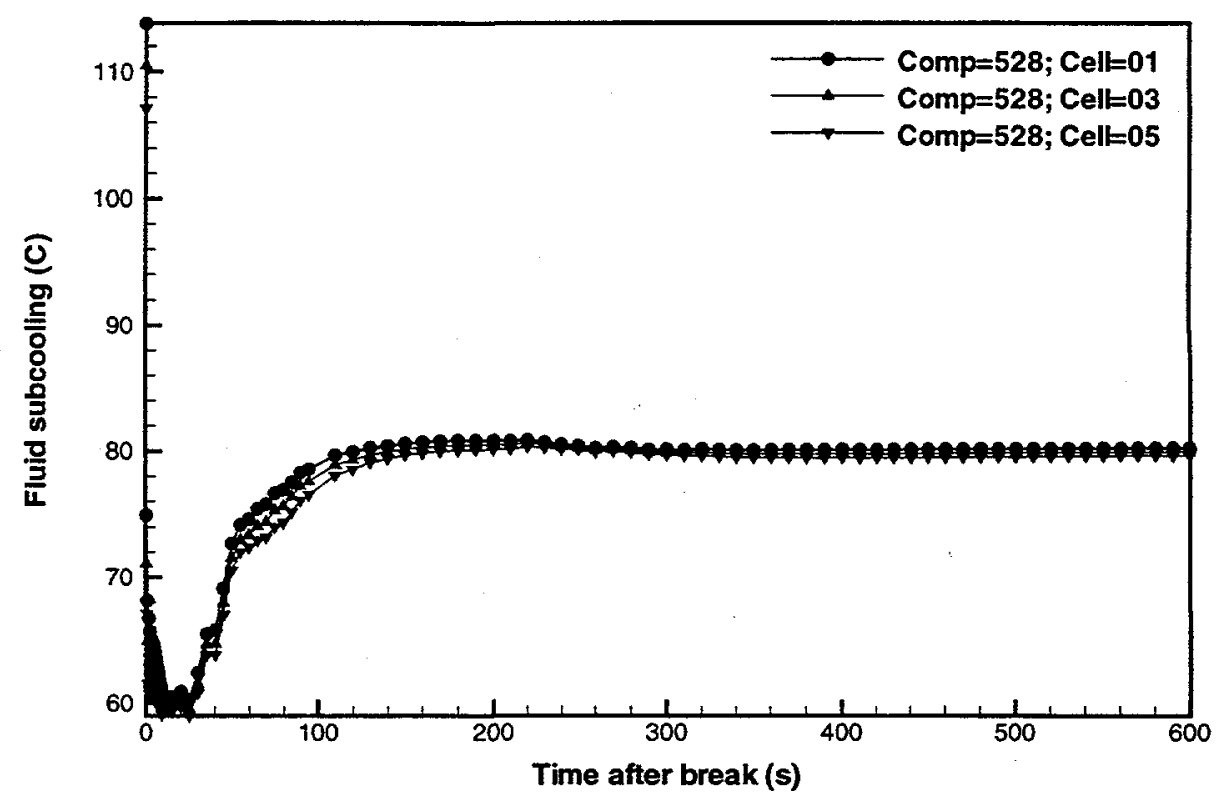

Figure B-23c Module 6 channel fluid subcoolings for a LOCA (Case 1: external HR break near inlet header).

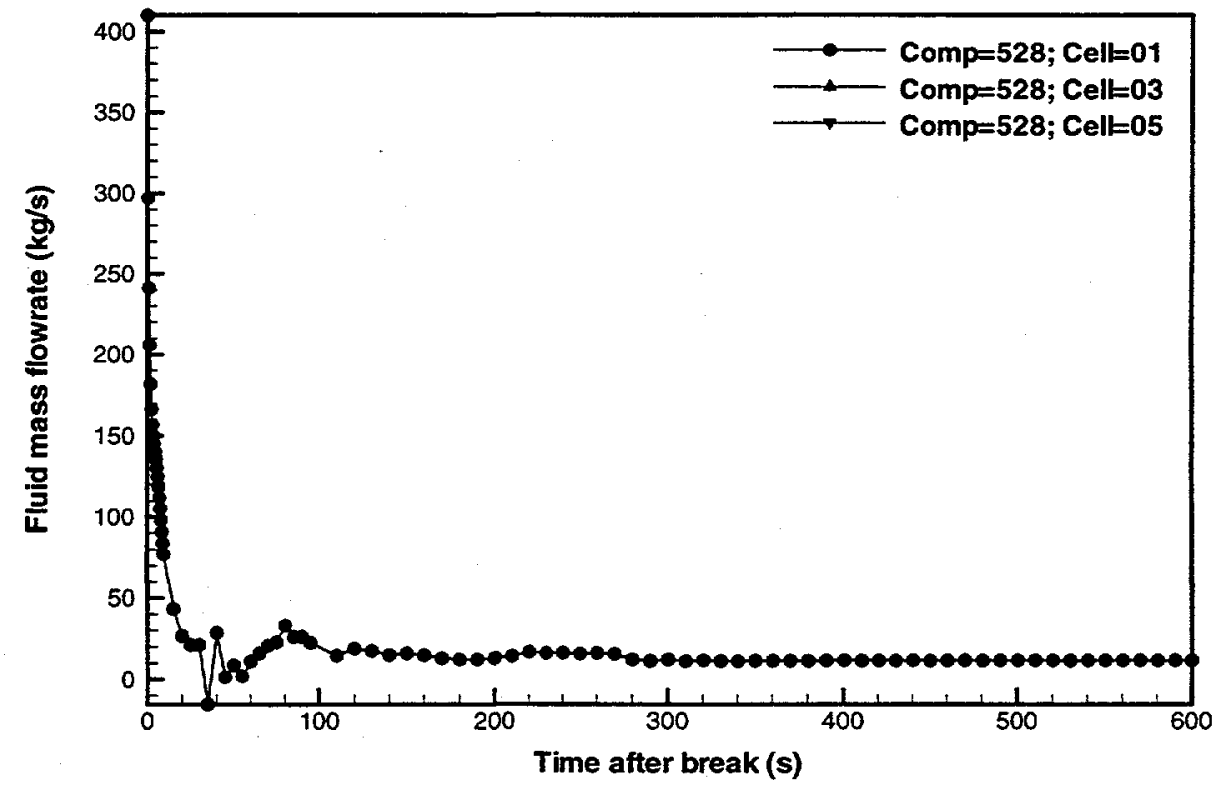

Figure B-23d Module 6 channel liquid mass flowrates for a LOCA (Case 1: external HR break near inlet header). 


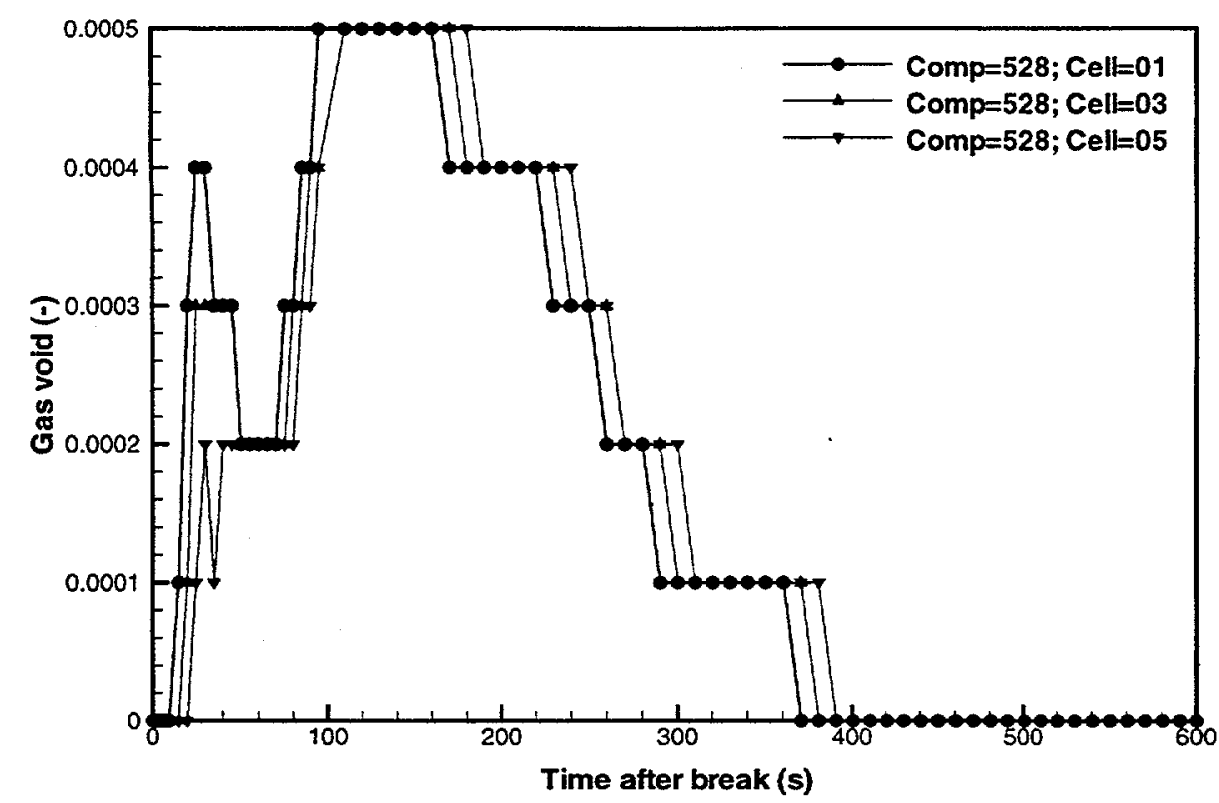

Figure B-23e Module 6 channel void fractions for a LOCA (Case 1: external HR break near inlet header).

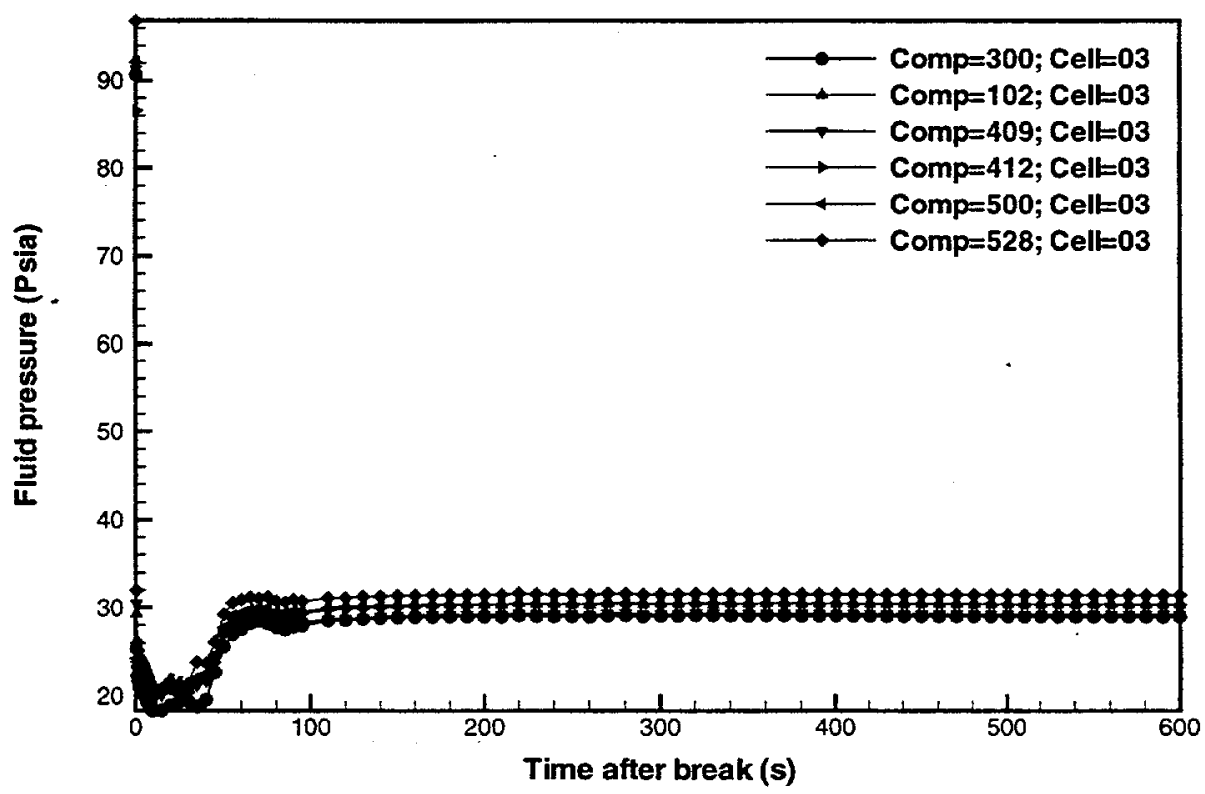

Figure B-24a Mid-plane module fluid pressures for a LOCA (Case 1: external HR break near inlet header). 


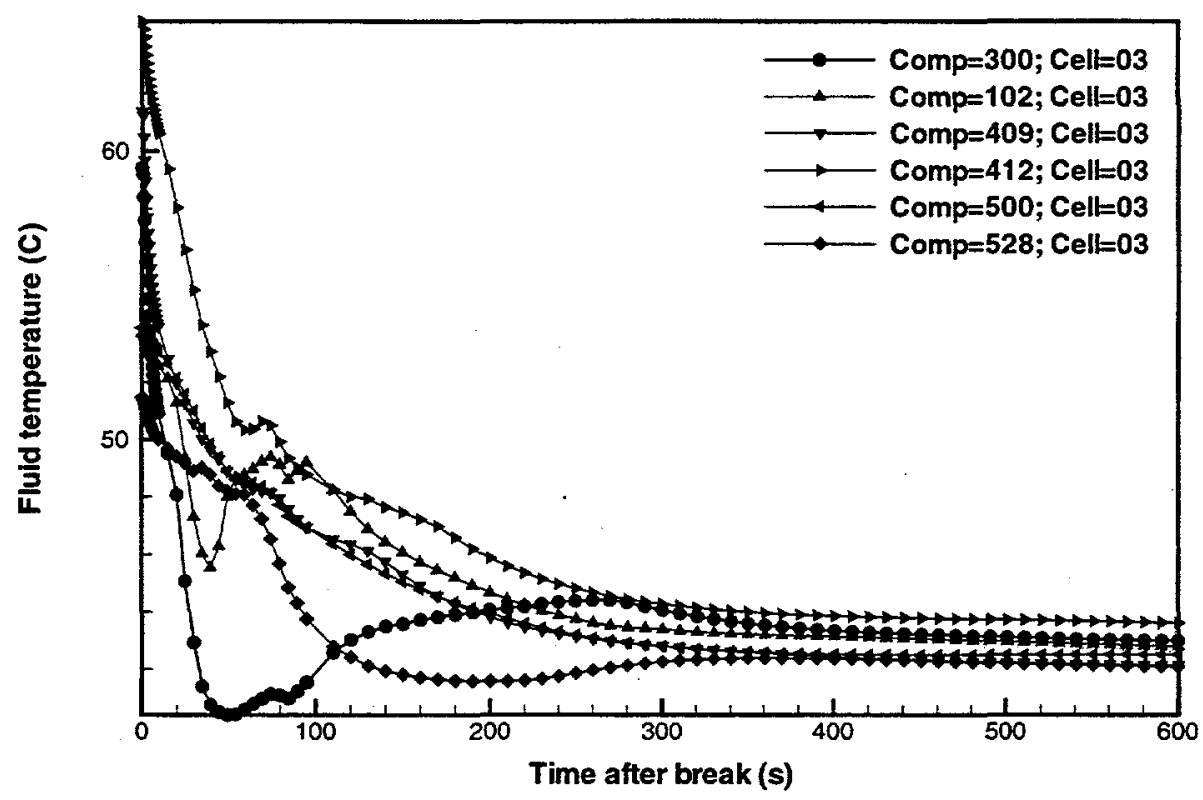

Figure B-24b Mid-plane module fluid temperatures for a LOCA (Case 1: external HR break near inlet header).

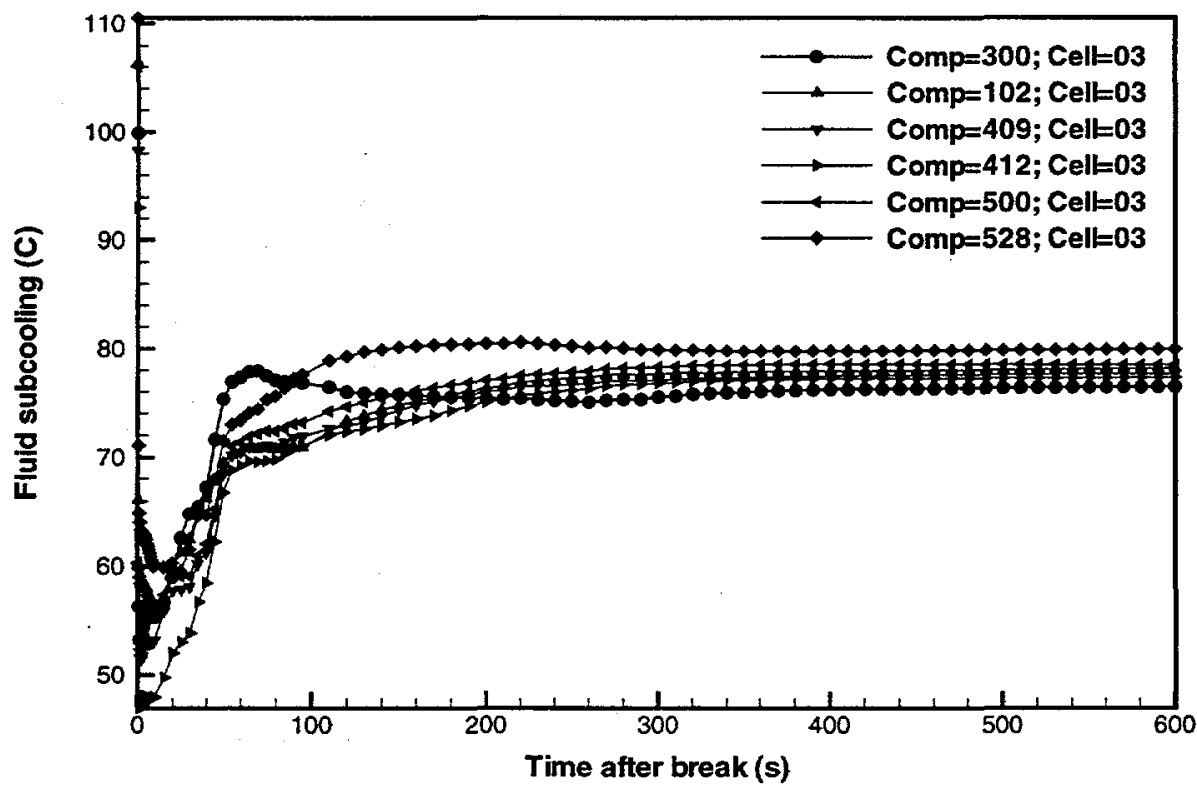

Figure B-24c Mid-plane module fluid subcoolings for a LOCA (Case 1: external HR break near inlet header). 


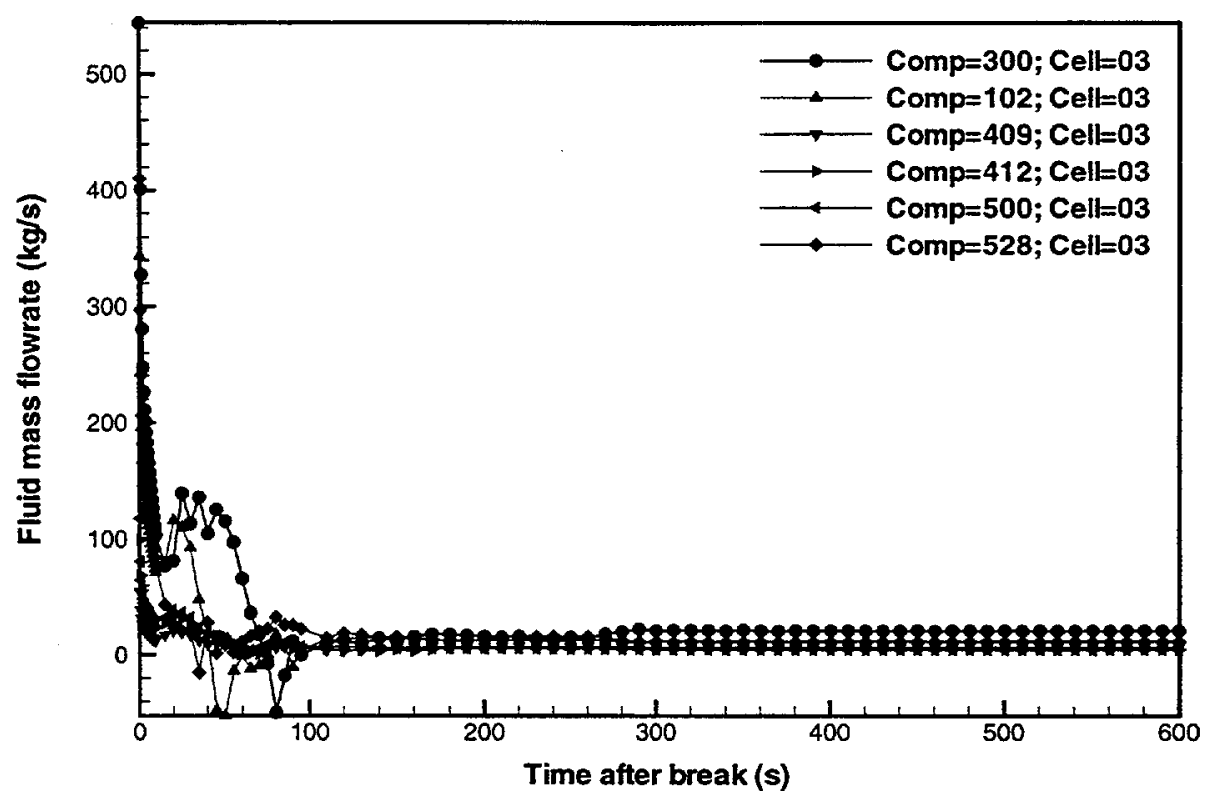

Figure B-24d Mid-plane module liquid mass flowrates for a LOCA (Case 1: external HR break near inlet header).

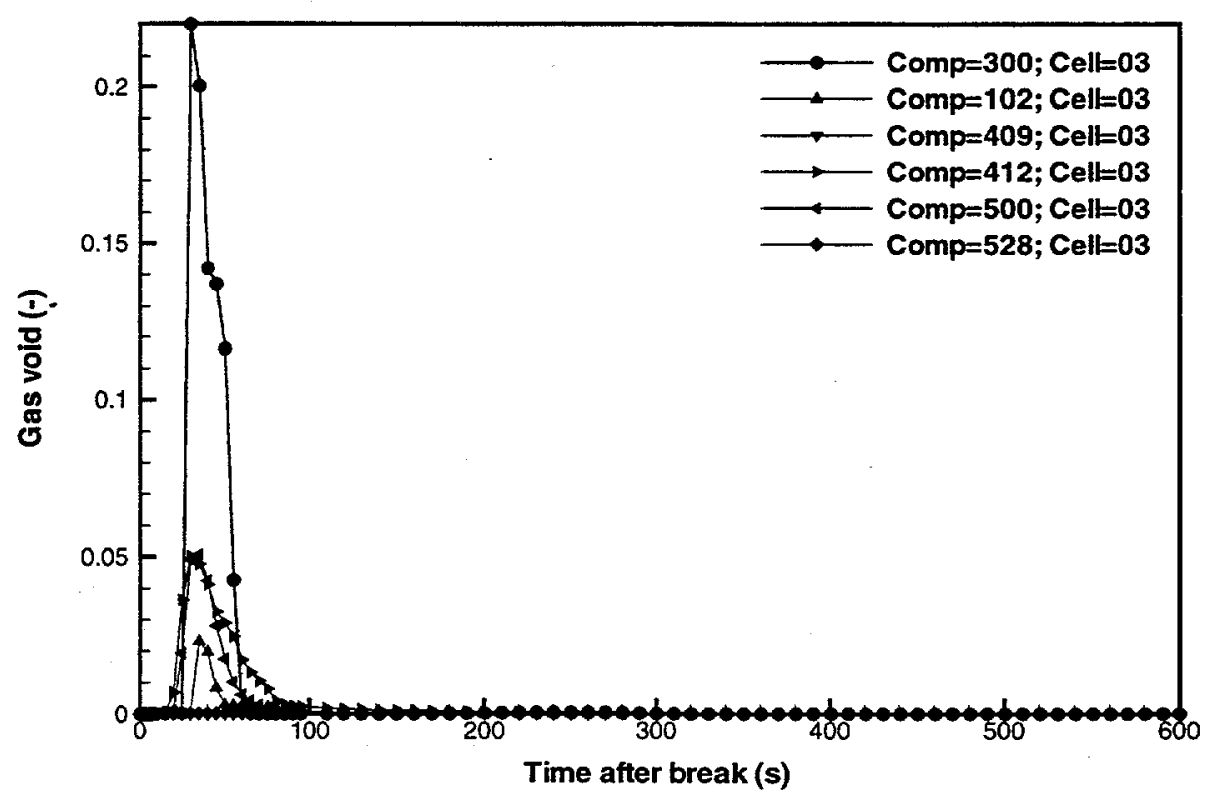

Figure B-24e Mid-plane module void fractions for a LOCA (Case 1: external HR break near inlet header). 


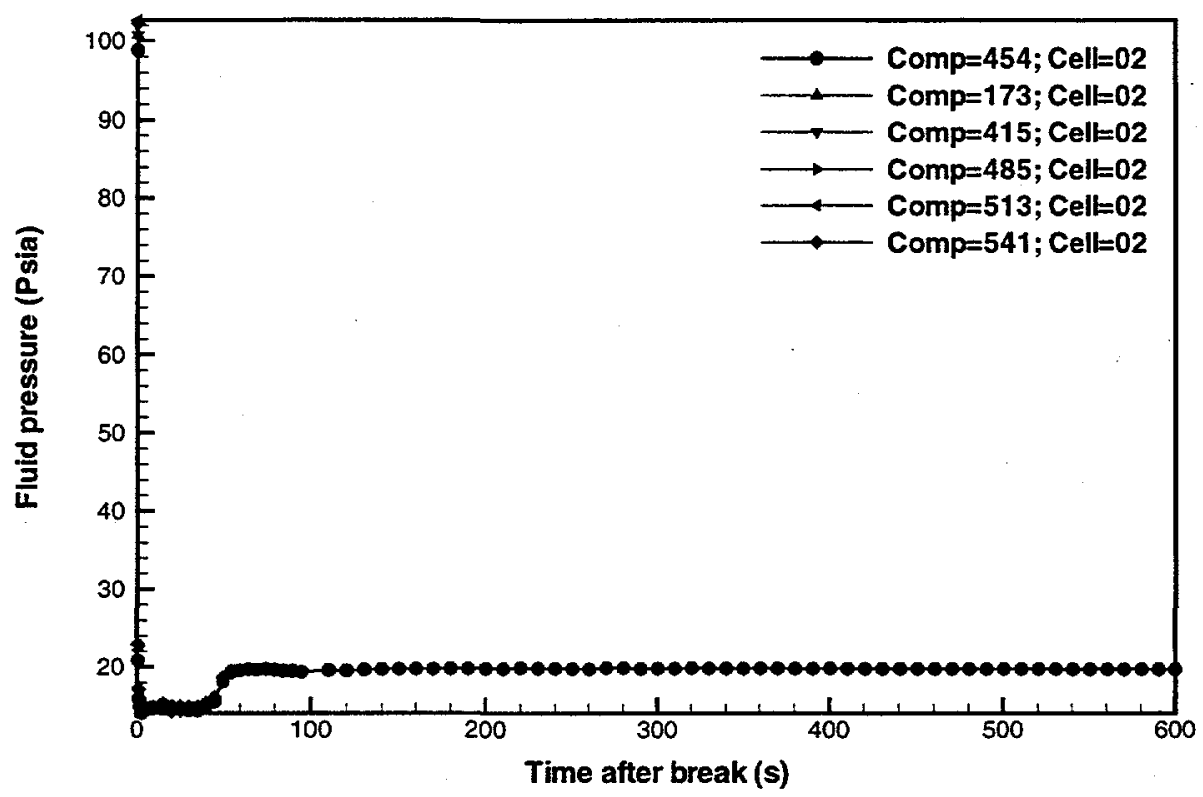

Figure B-25a Module inlet fluid pressures for a LOCA (Case 1: external HR break near inlet header).

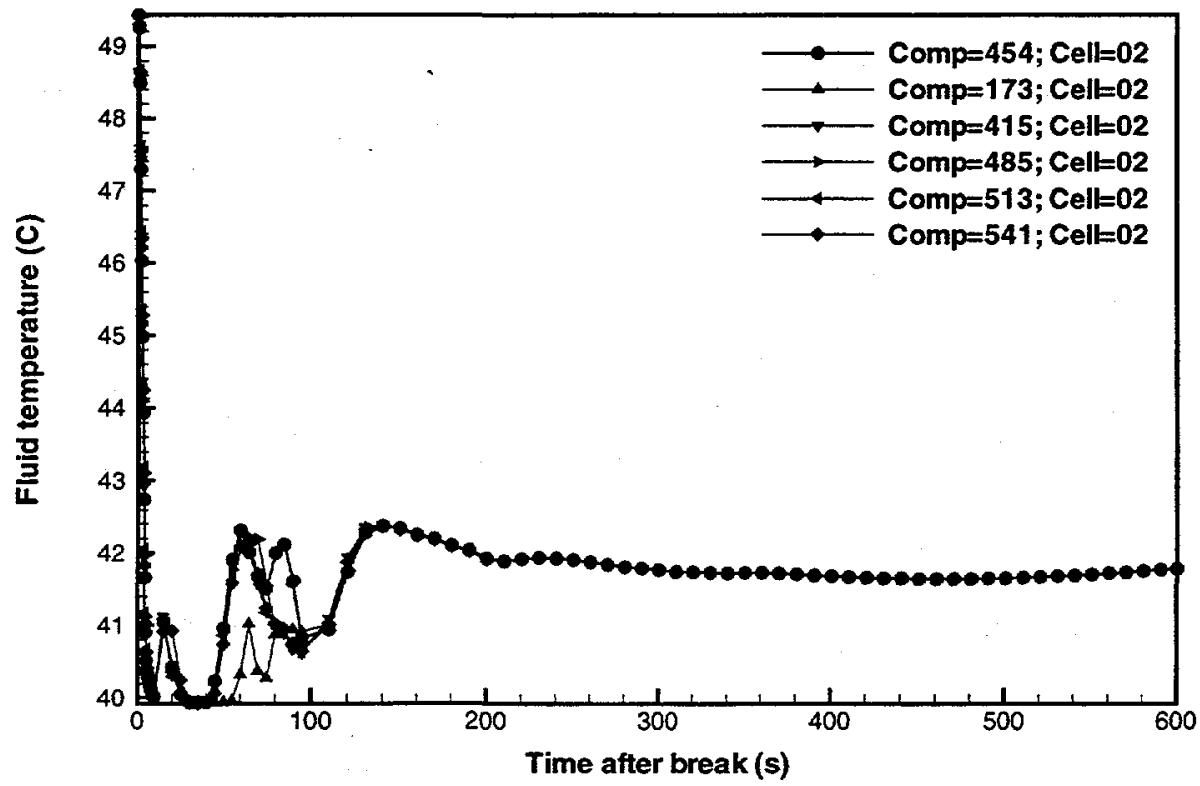

Figure B-25b Module inlet fluid temperatures for a LOCA (Case 1: external HR break near inlet header). 


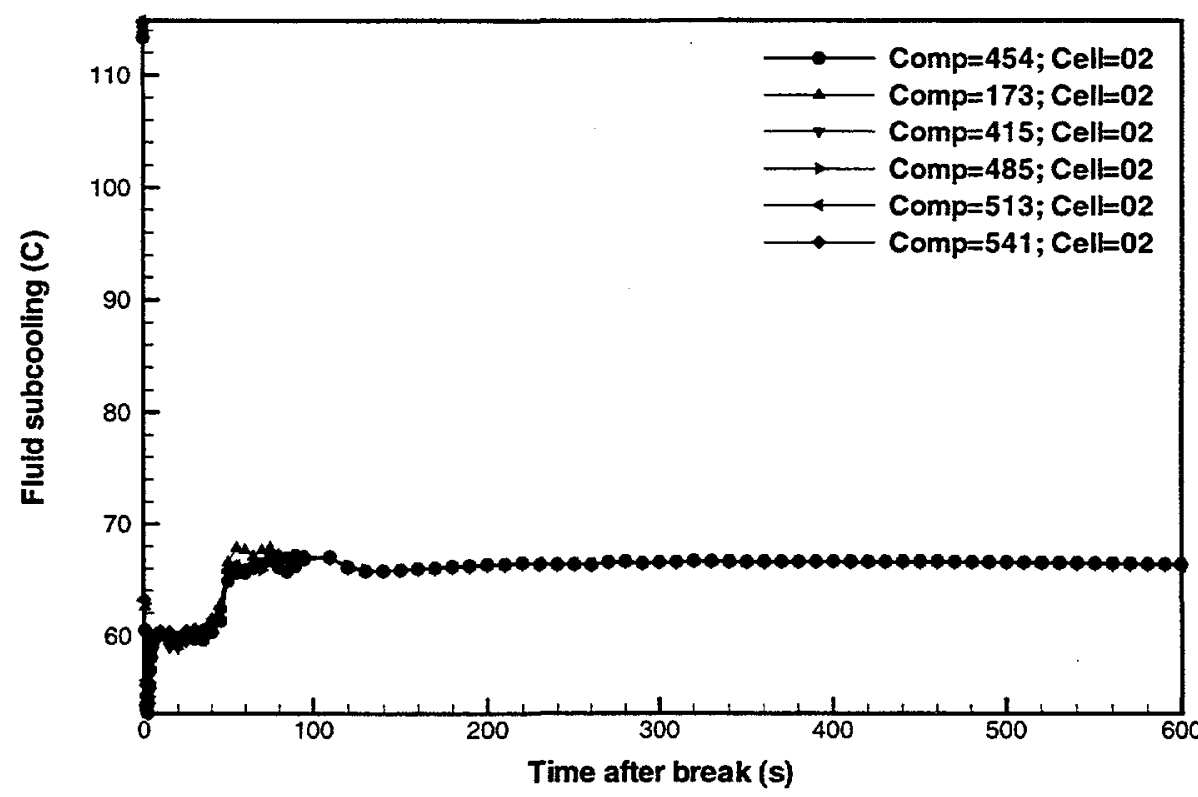

Figure B-25c Module inlet fluid subcoolings for a LOCA (Case 1: external HR break near inlet header).

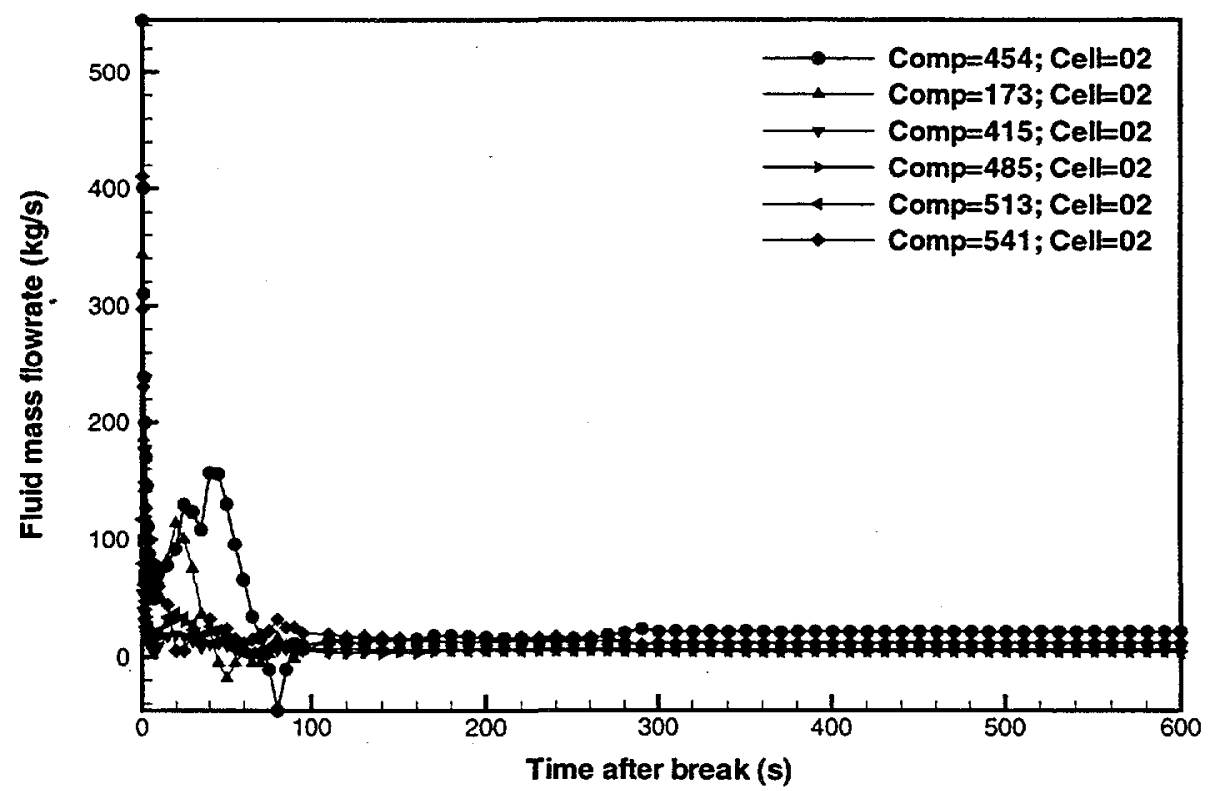

Figure B-25d Module inlet liquid mass flowrates for a LOCA (Case 1: external HR break near inlet header). 
Report:

Section:

BLANKET SAFETY ANALYSES FOR LOCA

(CASE 1: EXTERNAL HR BREAK NEAR INLET HEADER)
Date:

Page:
WSRC-TR-98-0059

Appendix B

$07 / 13 / 98$

61 of 72

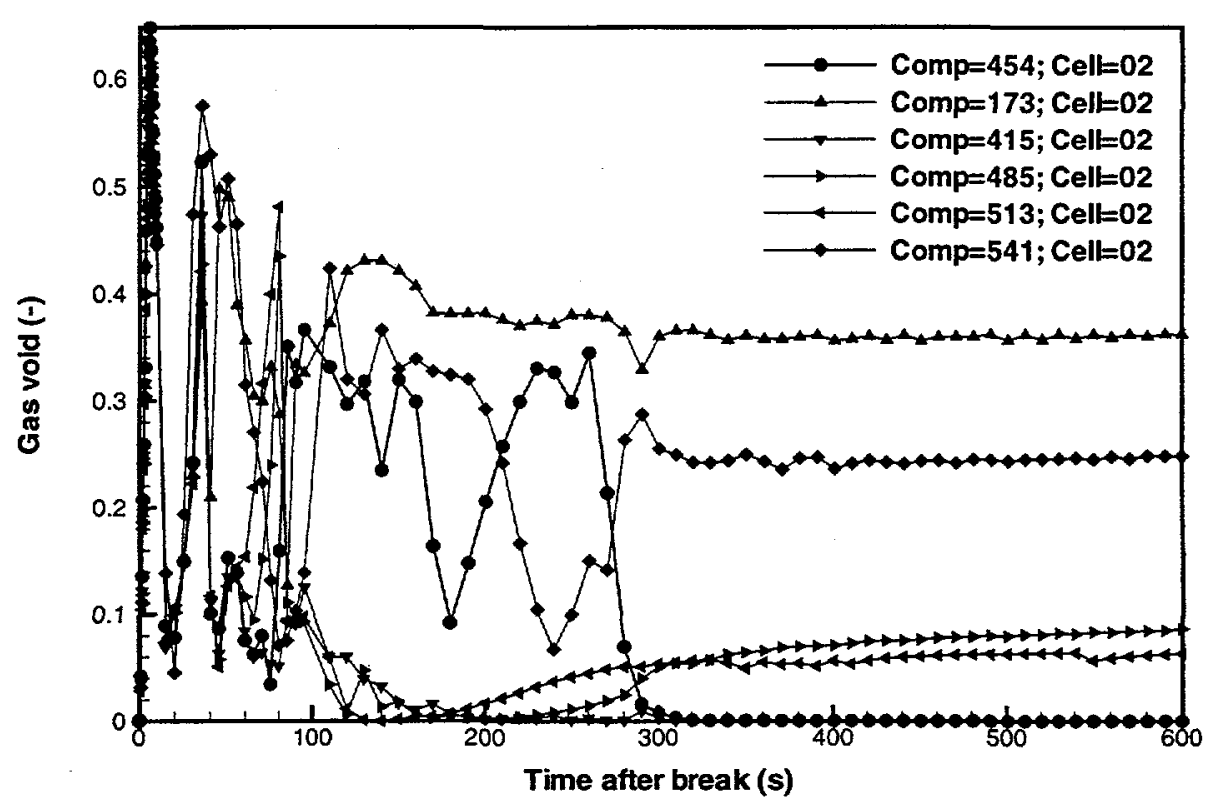

Figure B-25e Module inlet void fractions for a LOCA (Case 1:- external HR break near inlet header). 


\section{Appendix B3 LOCA (Case 1) TRAC Heat Structure Component Figures}

The following figures are from a TRAC simulation for Case 1 of a LOCA (external HR break near inlet header):

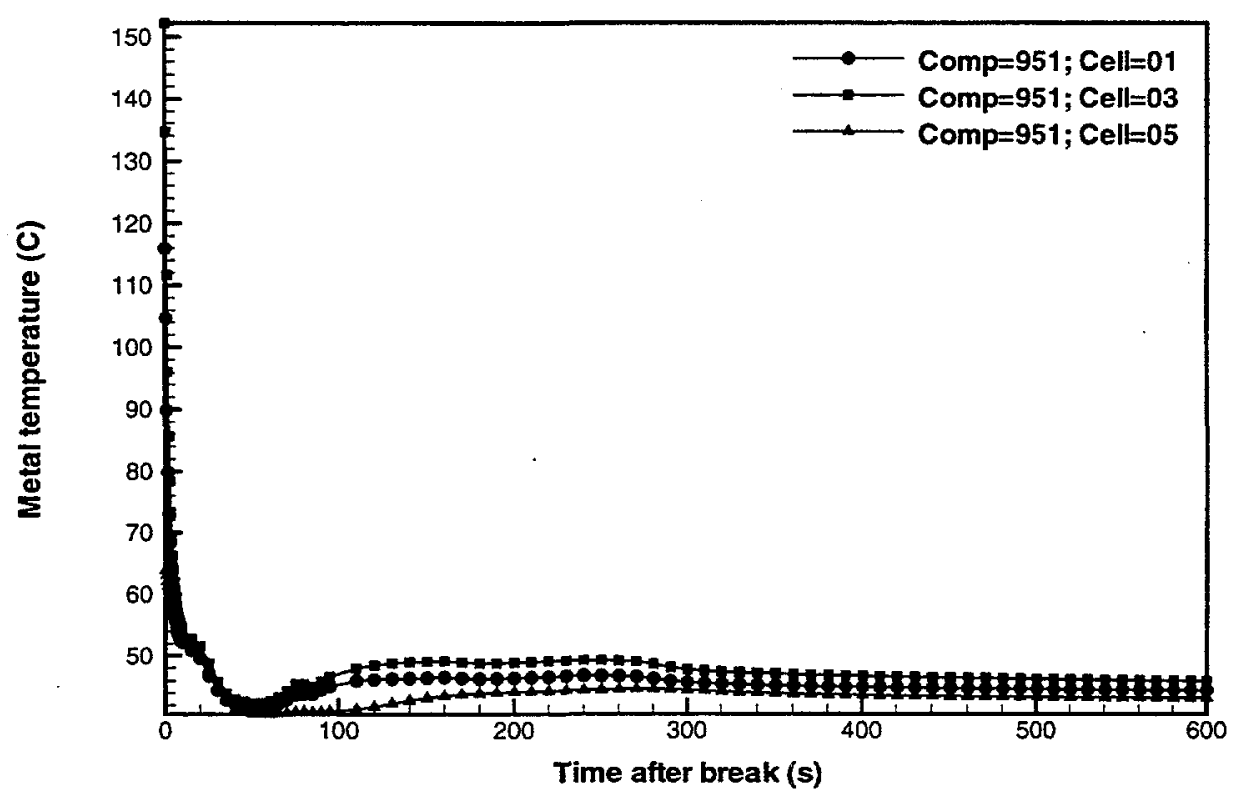

Figure B-26 Module 1 upflow section bottom, mid-plane, and top maximum lead metal temperatures for a LOCA (Case 1: external HR break near inlet header). 


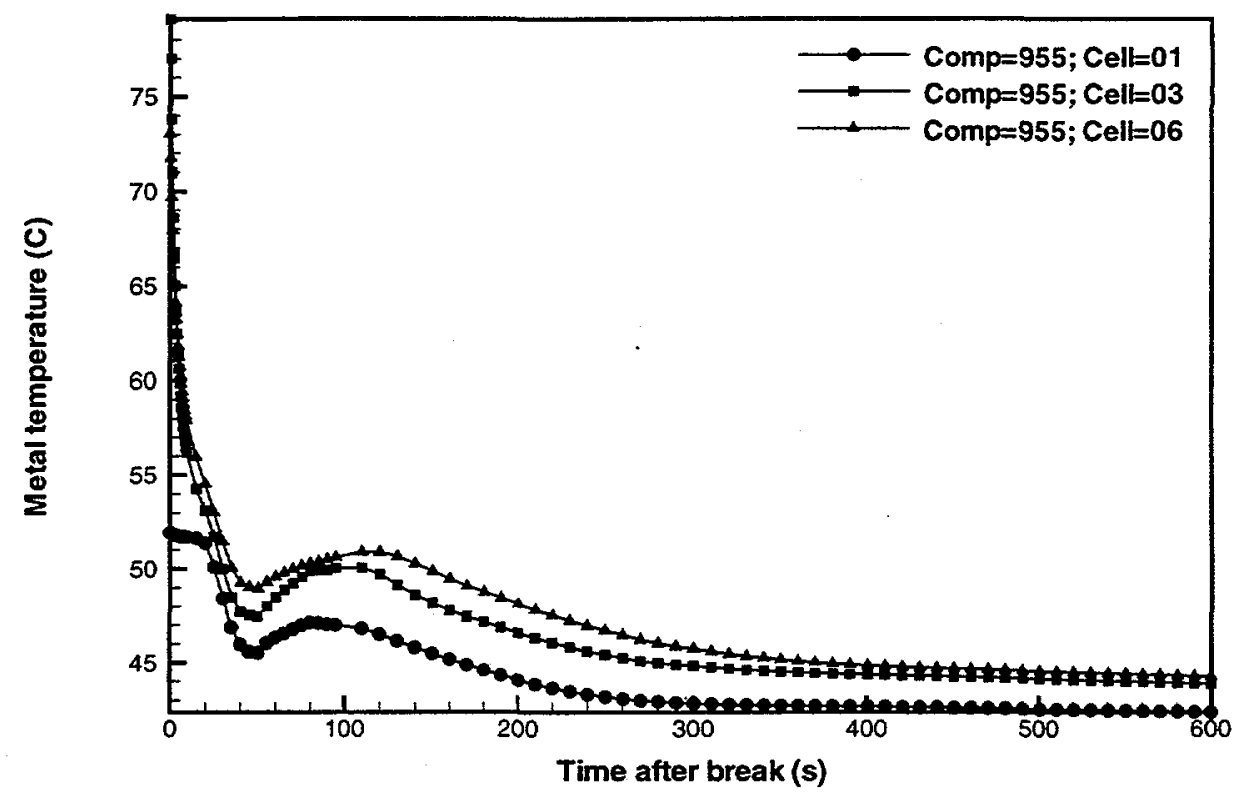

Figure B-27 Module 2 upflow section bottom, mid-plane, and top maximum lead metal temperatures for a LOCA (Case 1: external HR break near inlet header).

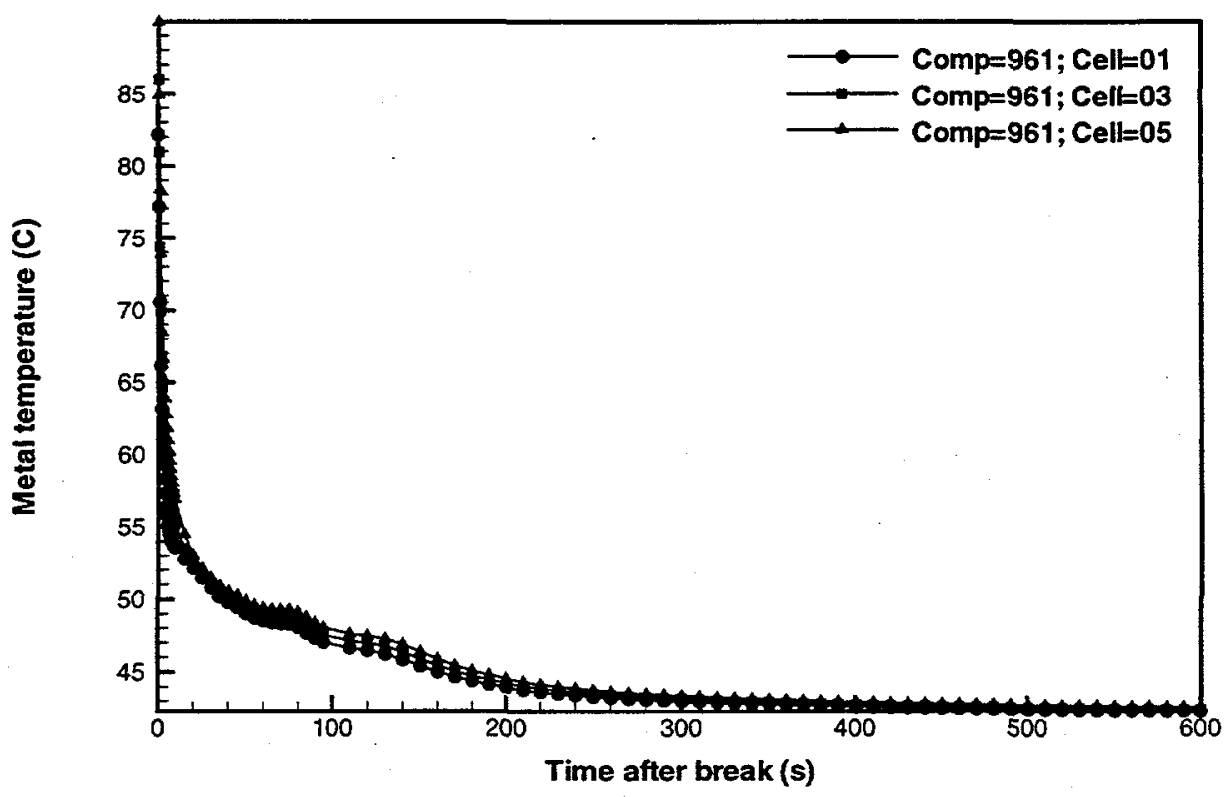

Figure B-28 Module 3 upflow section bottom, mid-plane, and top maximum lead metal temperatures for a LOCA (Case 1: external HR break near inlet header). 


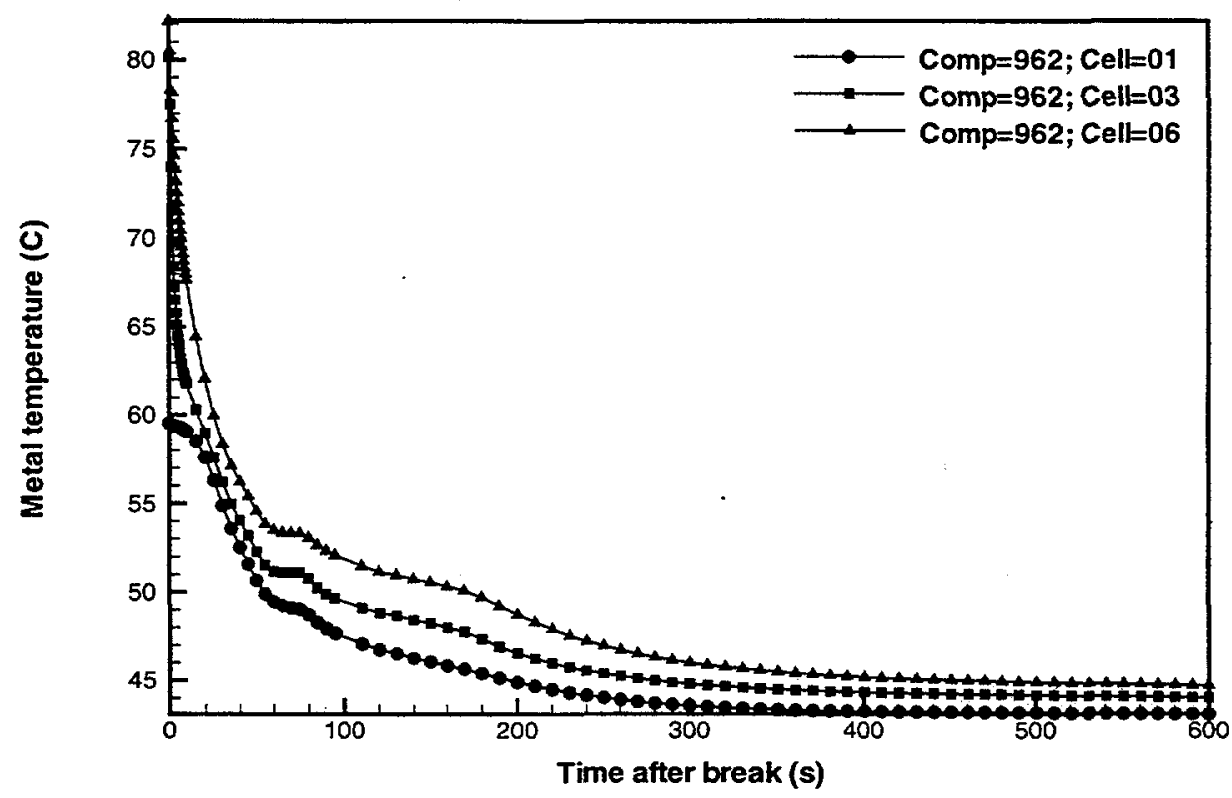

Figure B-29 Module 4 upflow section bottom, mid-plane, and top maximum lead metal temperatures for a LOCA (Case 1: external HR break near inlet header).

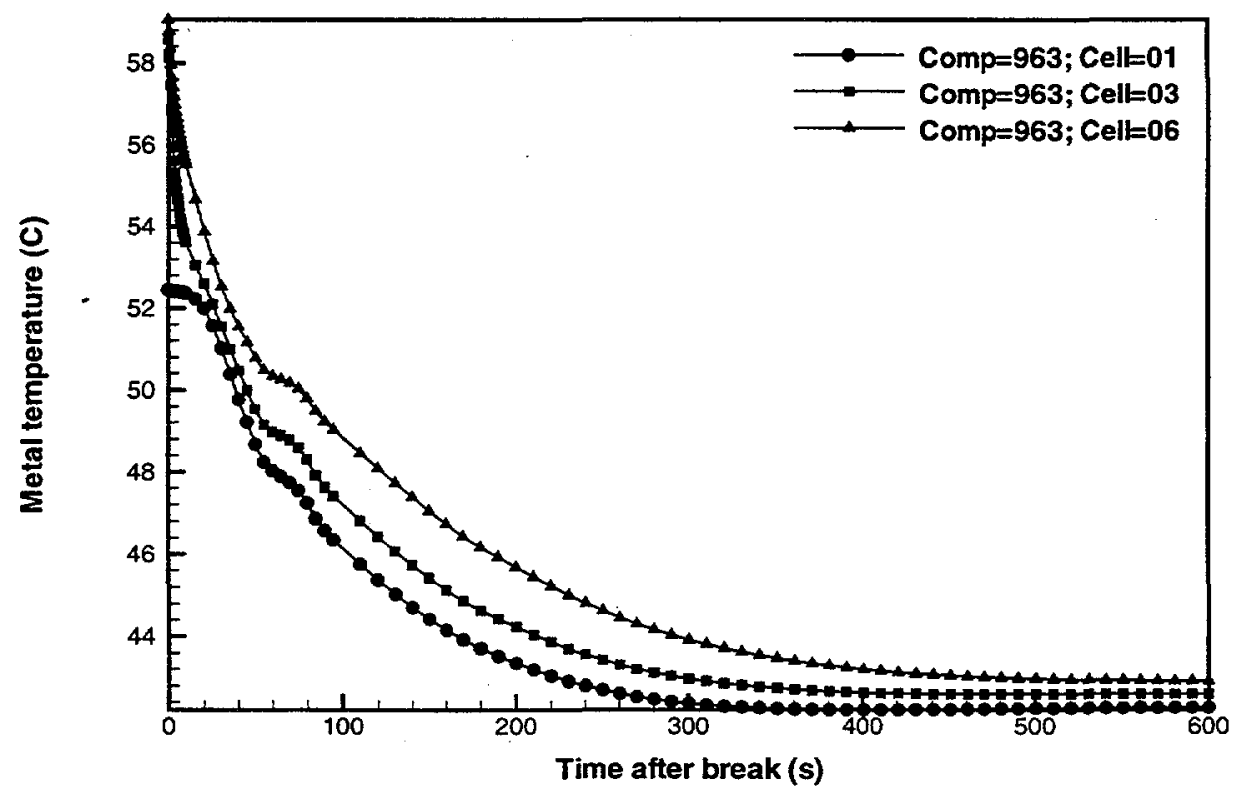

Figure B-30 Module 5 upflow section bottom, mid-plane, and top maximum lead metal temperatures for a LOCA (Case 1: external HR break near inlet header). 


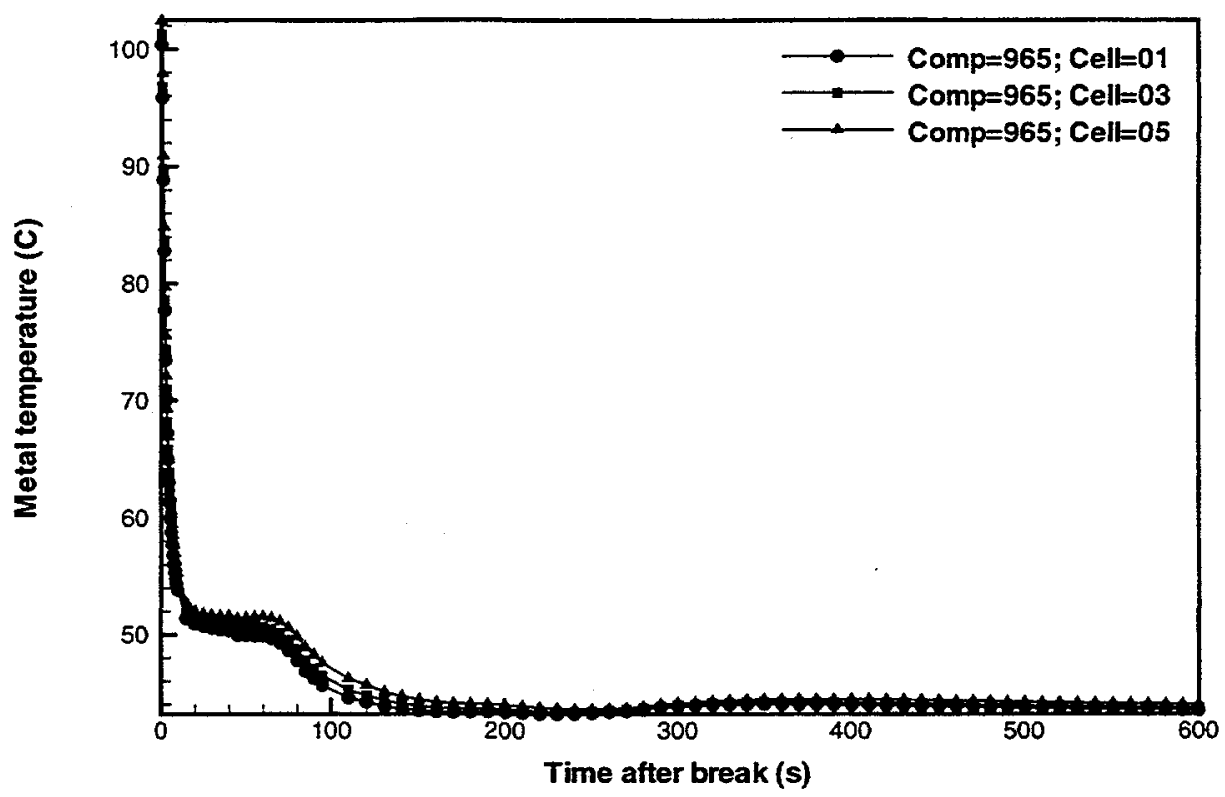

Figure B-31 Module 6 down-stream section bottom, mid-plane, and top maximum lead metal temperatures for a LOCA (Case 1: external HR break near inlet header).

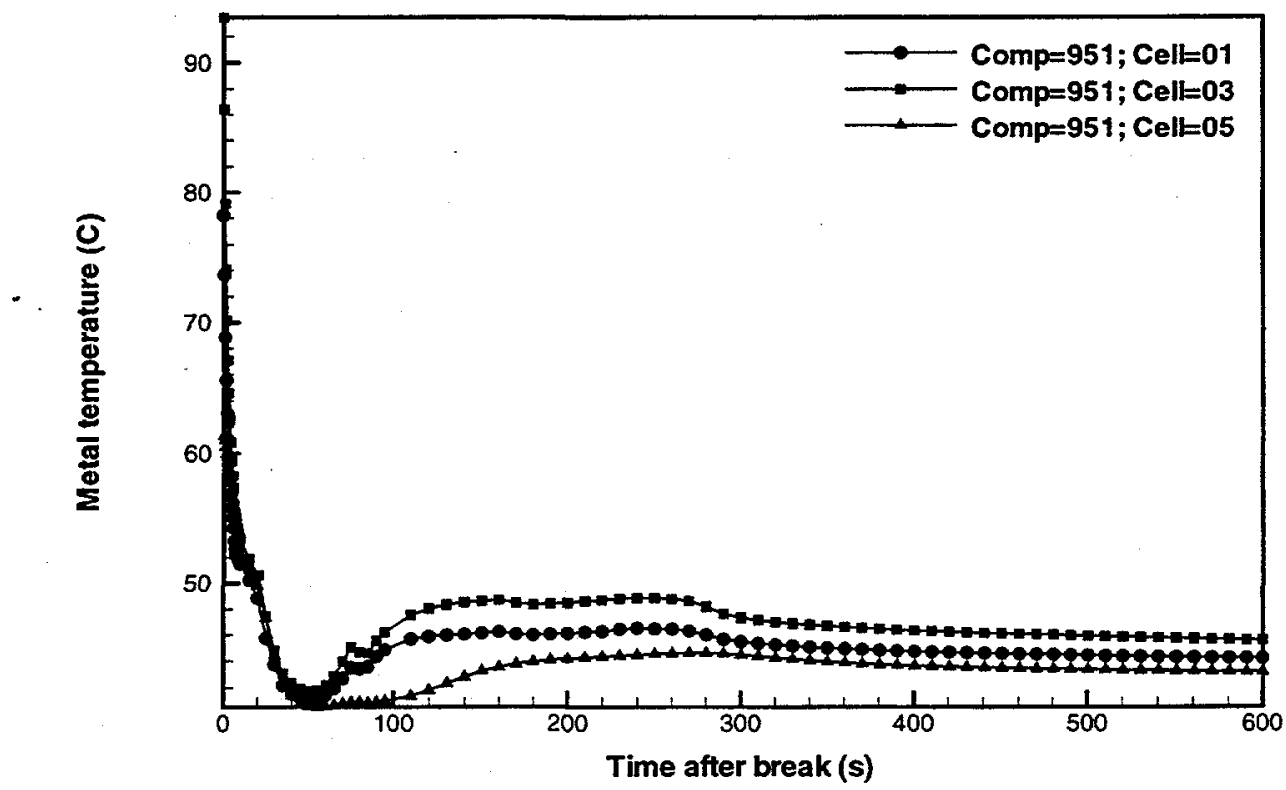

Figure B-32 Module 1 upflow section bottom, mid-plane, and top maximum aluminum metal temperatures for a LOCA (Case 1: external HR break near inlet header). 


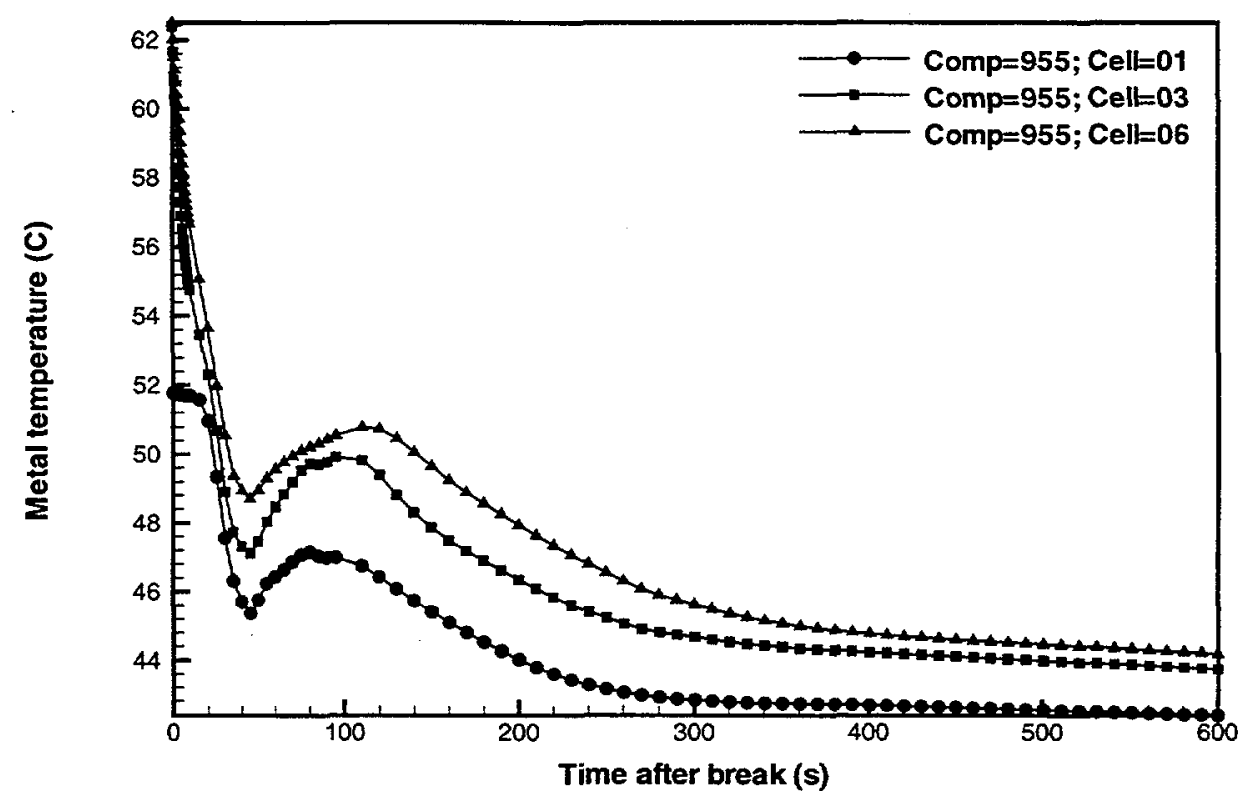

Figure B-33 Module 2 upflow section bottom, mid-plane, and top maximum aluminum metal temperatures for a LOCA (Case 1: external HR break near inlet header).

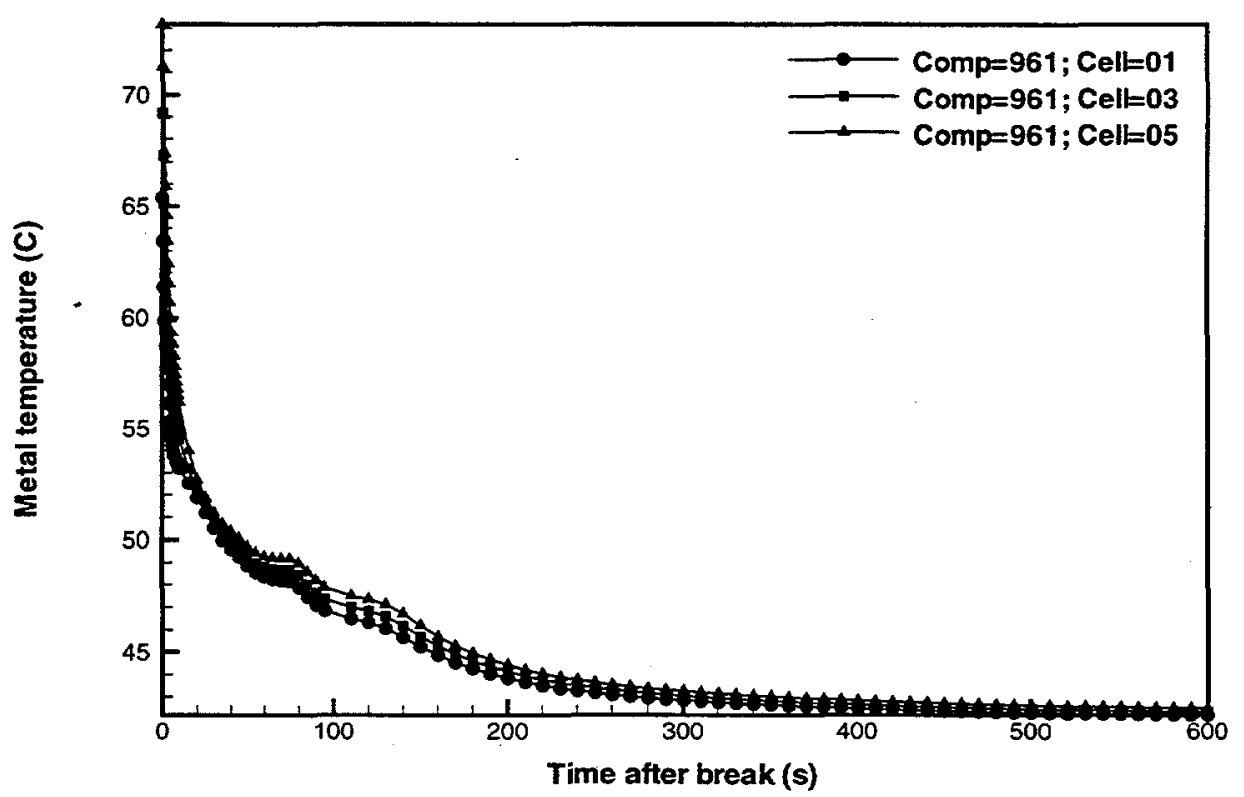

Figure B-34 Module 3 upflow section bottom, mid-plane, and top maximum aluminum metal temperatures for a LOCA (Case 1: external HR break near inlet header). 


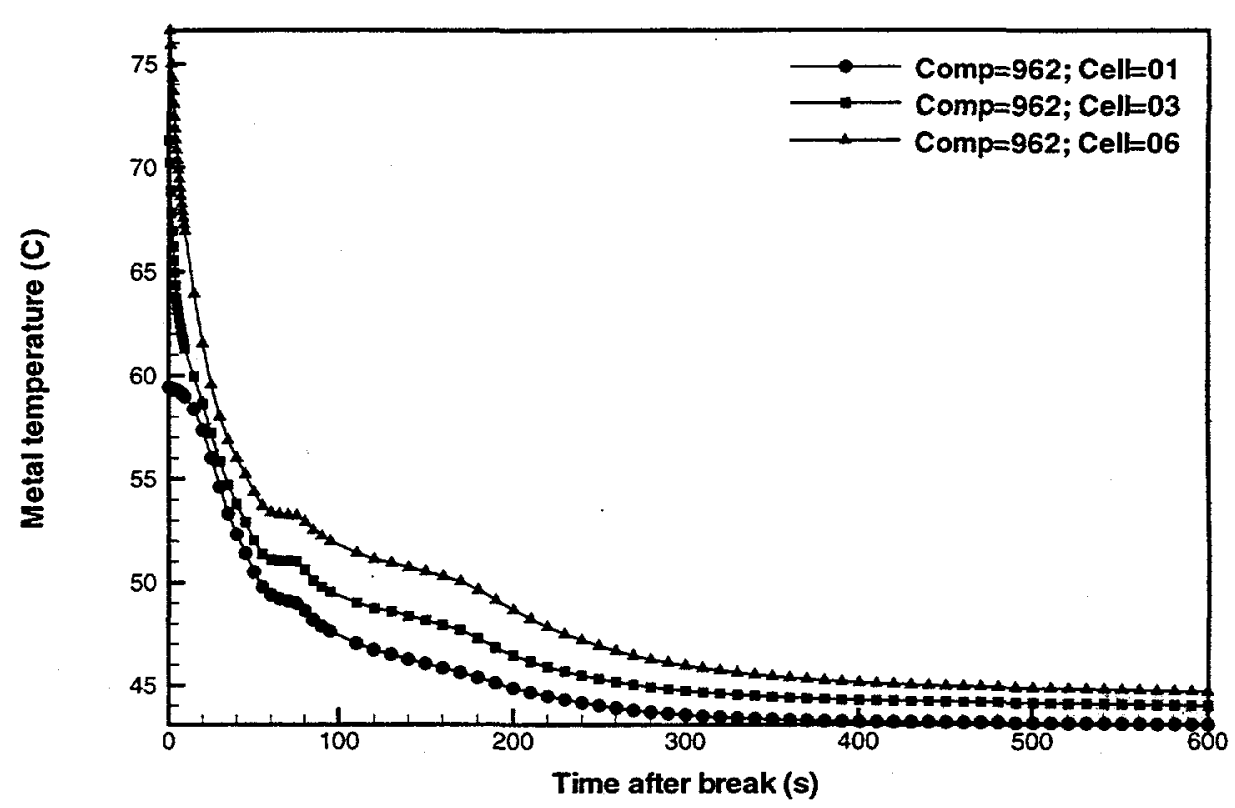

Figure B-35 Module 4 upflow section bottom, mid-plane, and top maximum aluminum metal temperatures for a LOCA (Case 1: external HR break near inlet header).

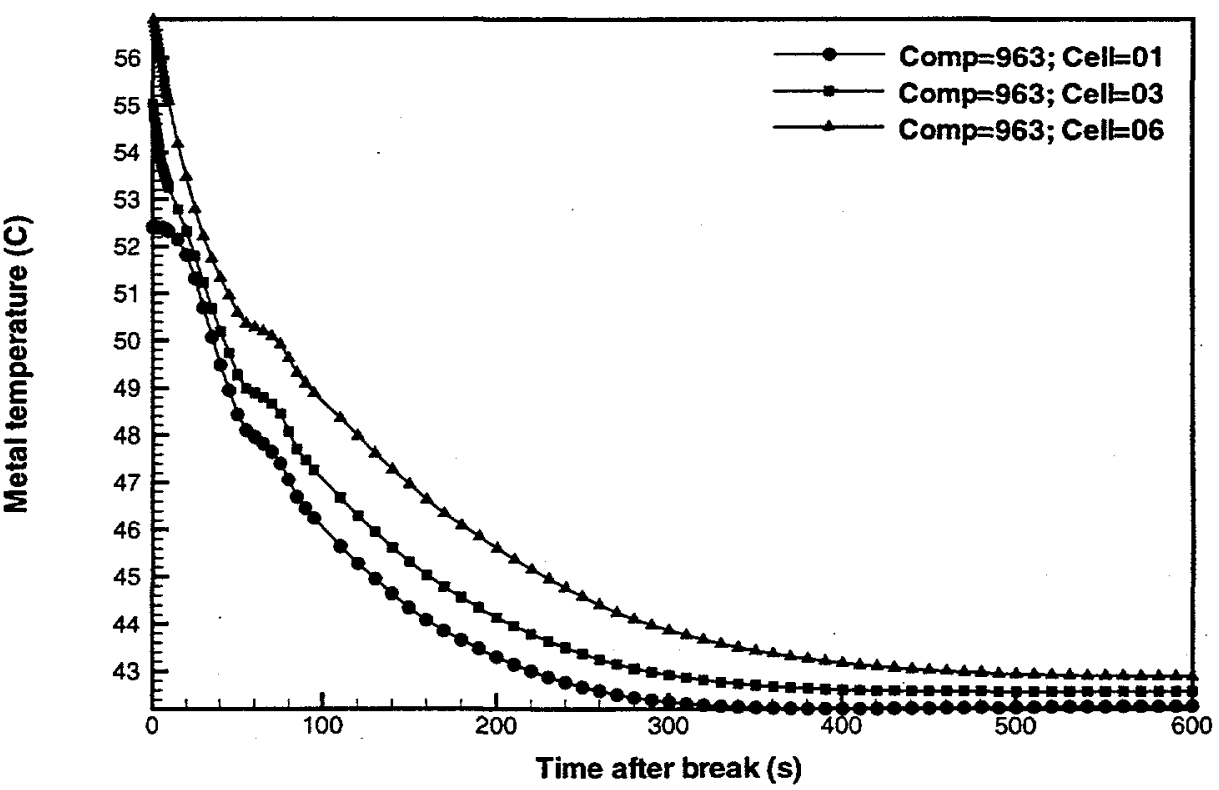

Figure B-36 Module 5 upflow section bottom, mid-plane, and top maximum aluminum metal temperatures for a LOCA (Case 1: external HR break near inlet header). 


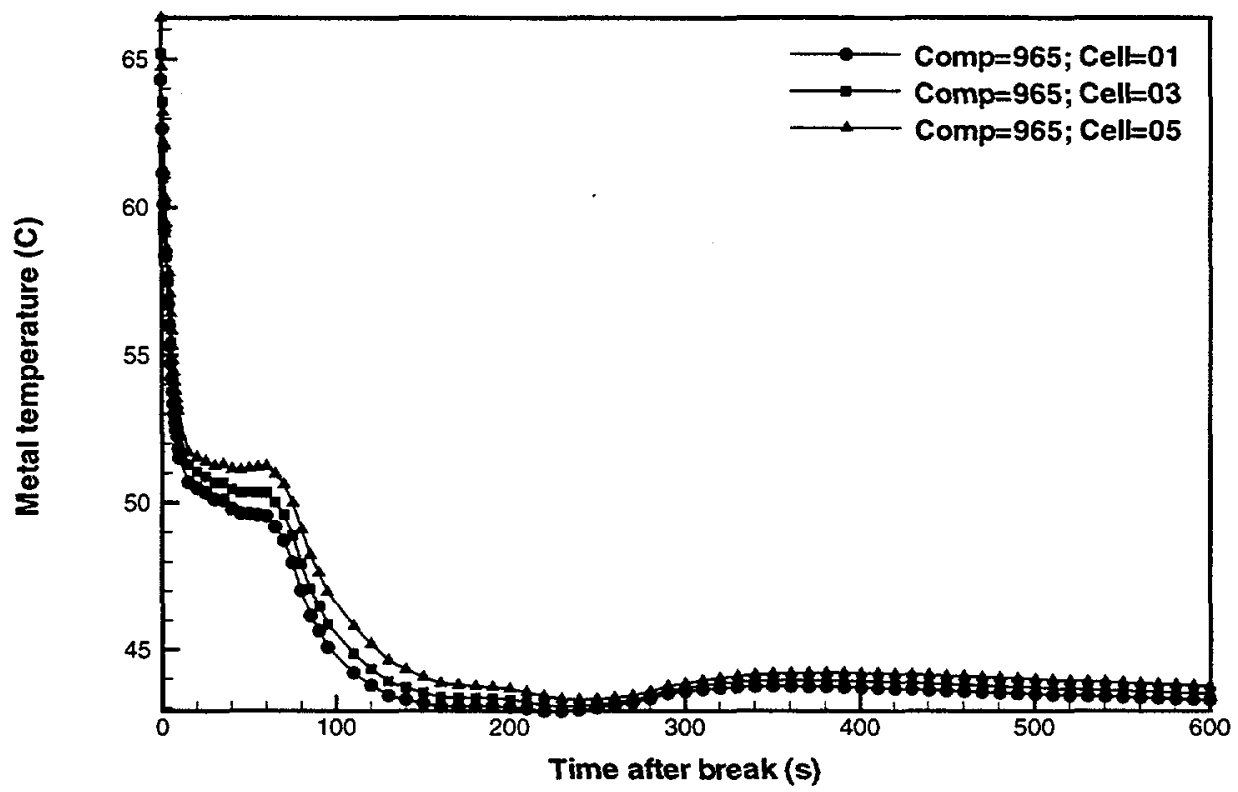

Figure B-37 Module 6 down-stream section bottom, mid-plane, and top maximum aluminum metal temperatures for a LOCA (Case 1: external HR break near inlet header).

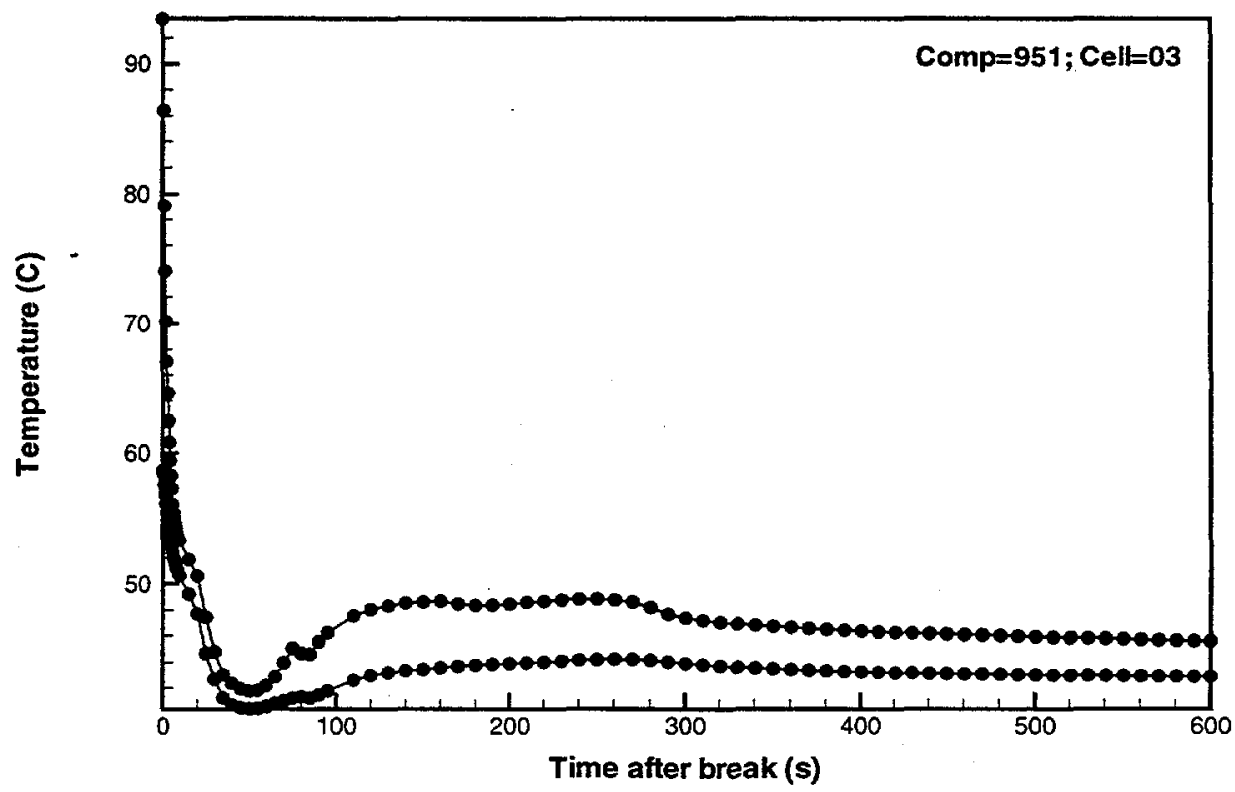

Figure B-38 Module 1 upflow section mid-plane surface and fluid temperatures for a LOCA (Case 1: external HR break near inlet header). 


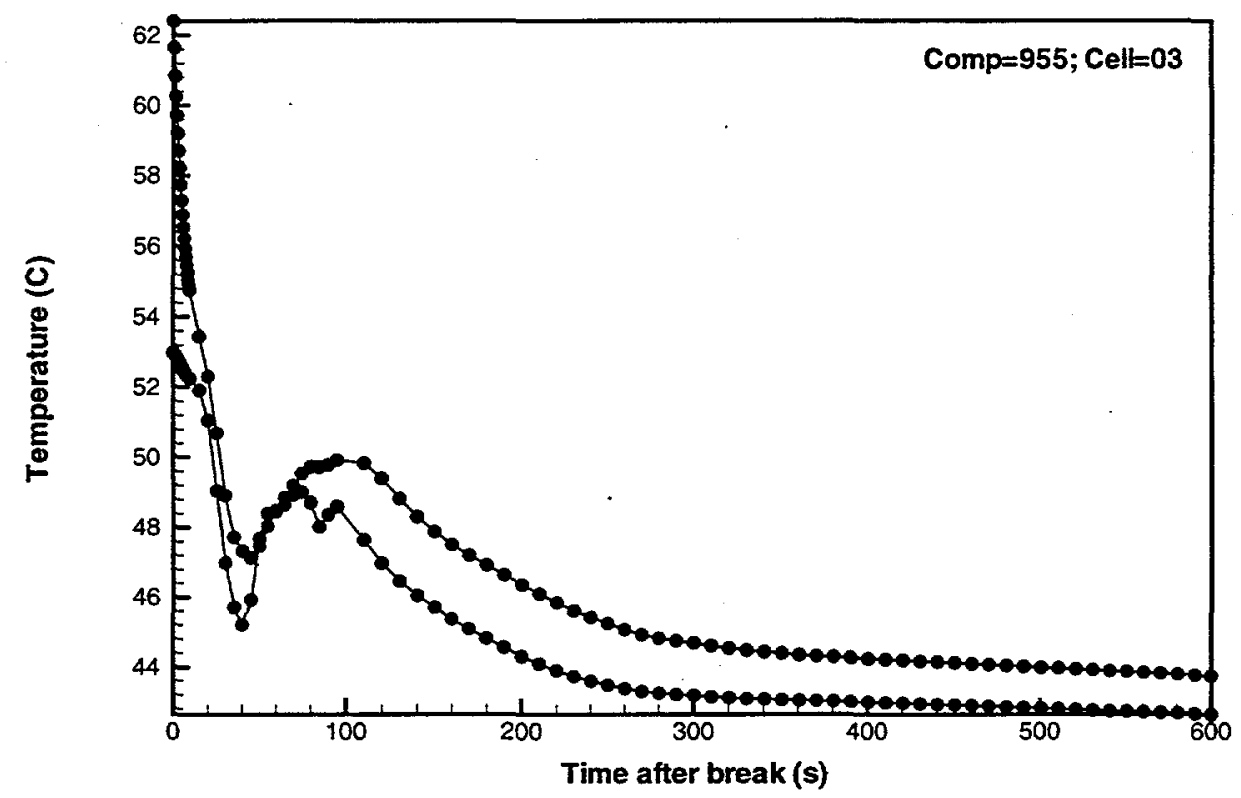

Figure B-39 Module 2 upflow section mid-plane surface and fluid temperatures for a LOCA (Case 1: external HR break near inlet header).

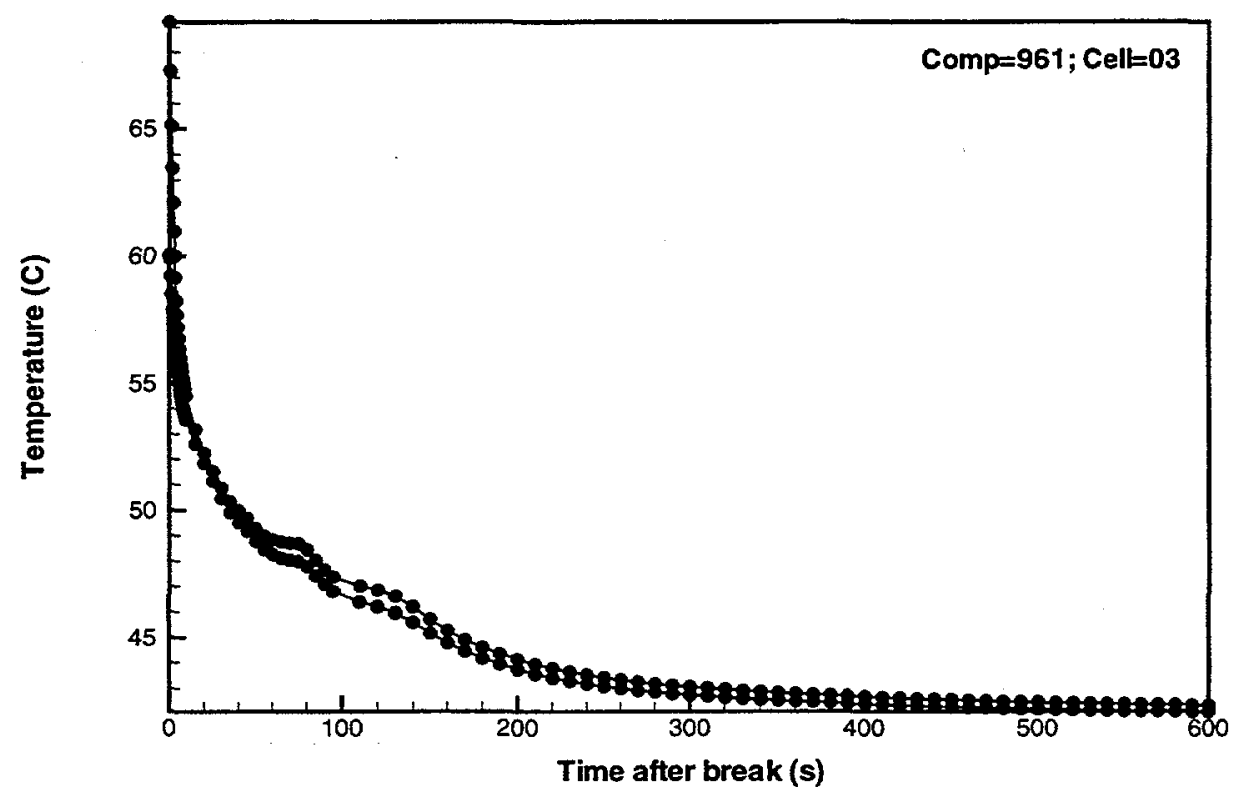

Figure B-40 Module 3 upflow section mid-plane surface and fluid temperatures for a LOCA (Case 1: external HR break near inlet header). 


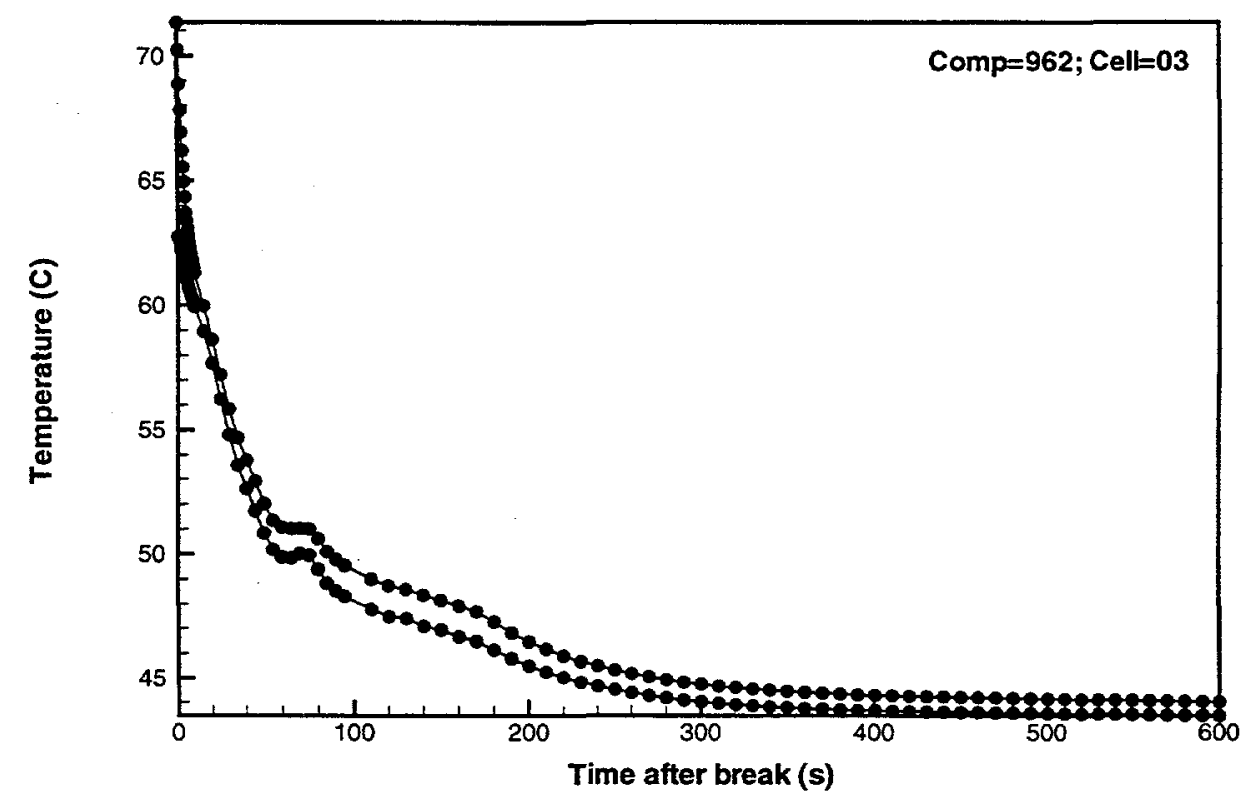

Figure B-41 Module 4 upflow section mid-plane surface and fluid temperatures for a LOCA (Case 1: external HR break near inlet header).

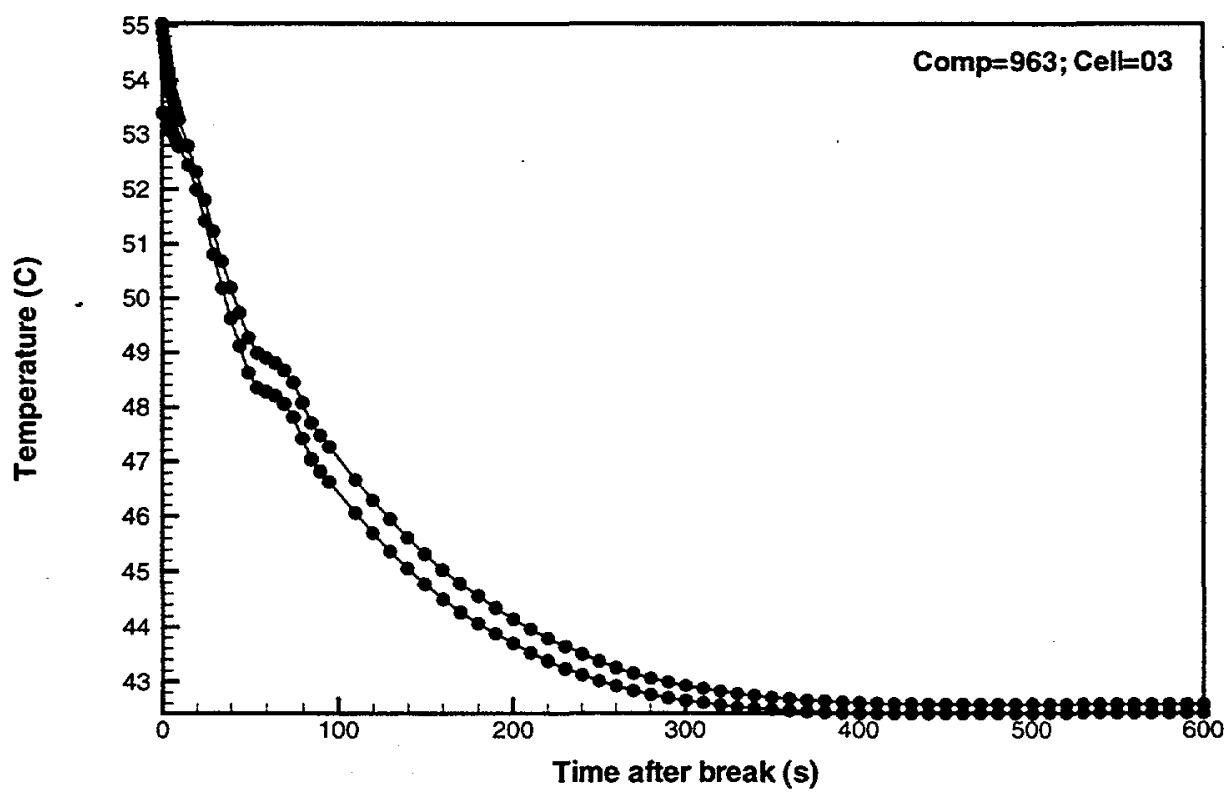

Figure B-42 Module 5 upflow section mid-plane surface and fluid temperatures for a LOCA (Case 1: external HR break near inlet header). 


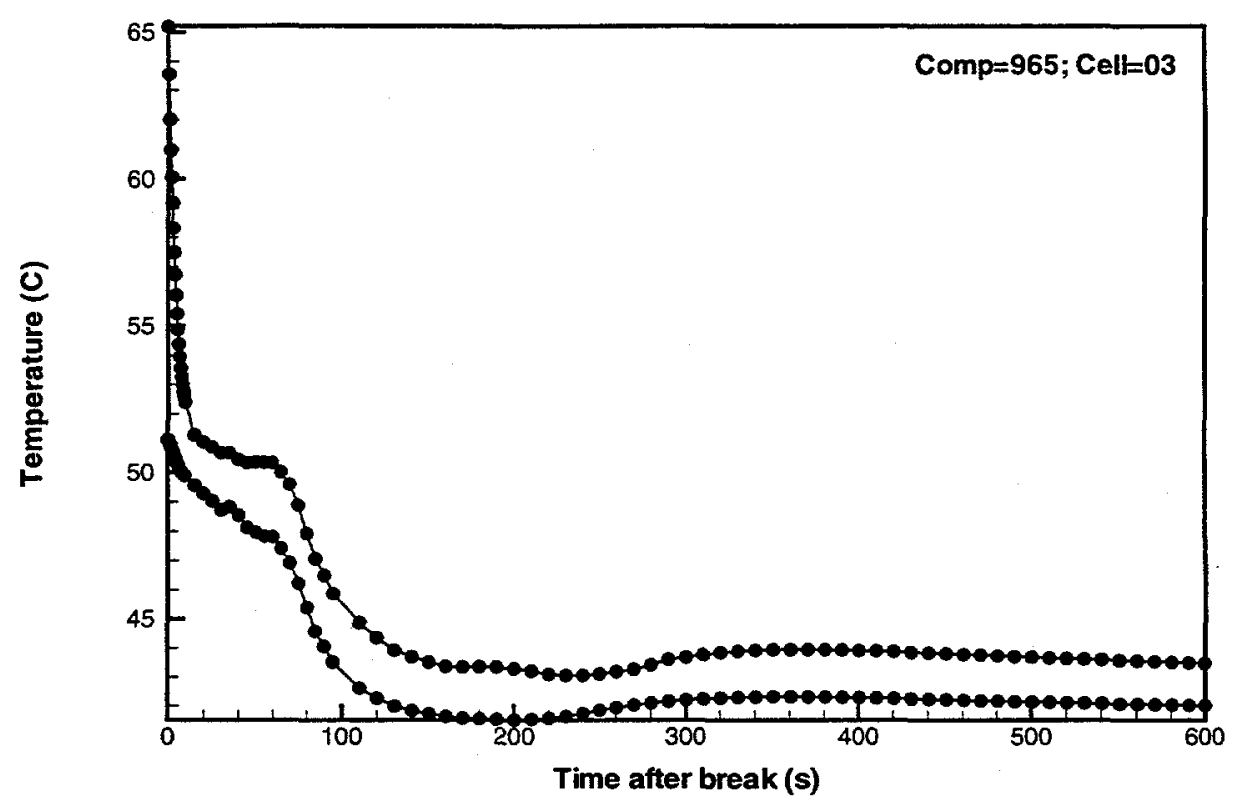

Figure B-43 Module 6 upflow section mid-plane surface and fluid temperatures for a LOCA (Case 1: external HR break near inlet header).

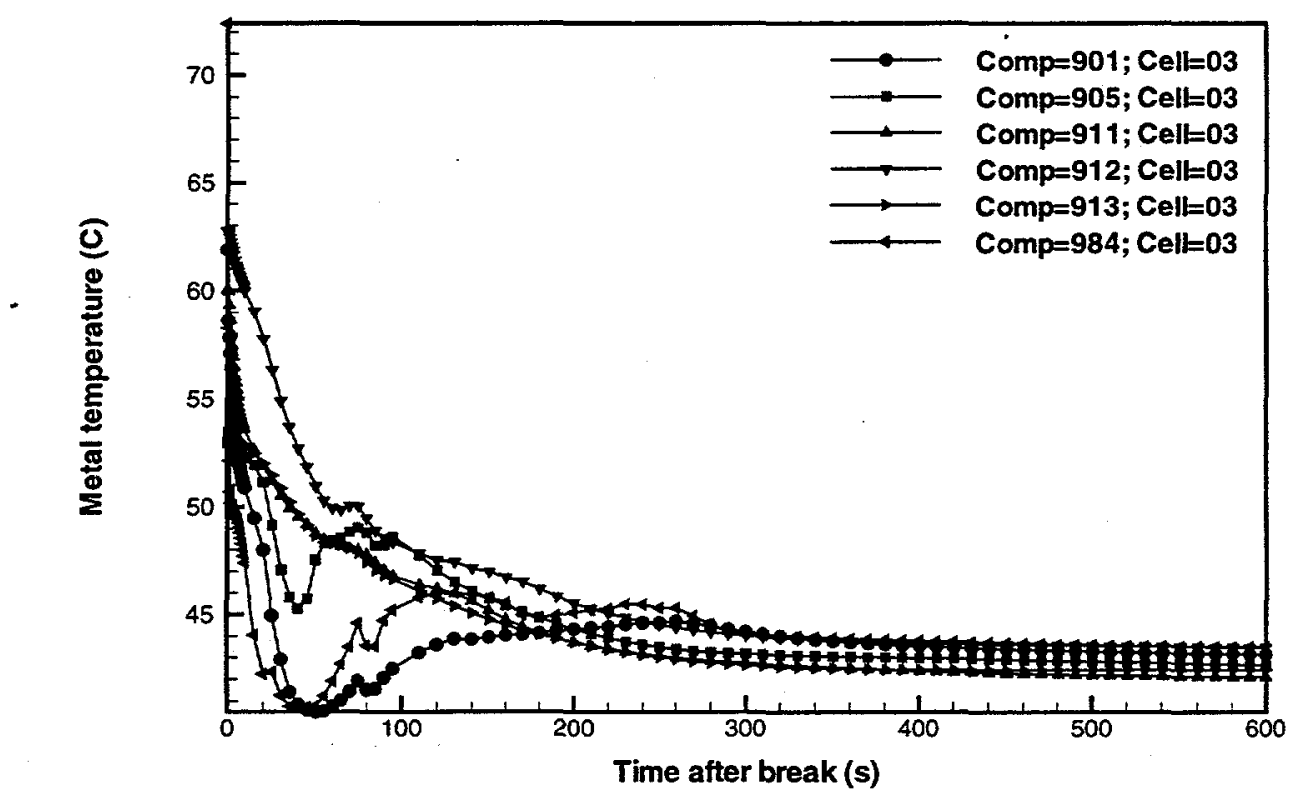

Figure B-44a Metal temperatures for various module outer aluminum surfaces at their mid-plane for a LOCA (Case 1: external HR break near inlet header). 


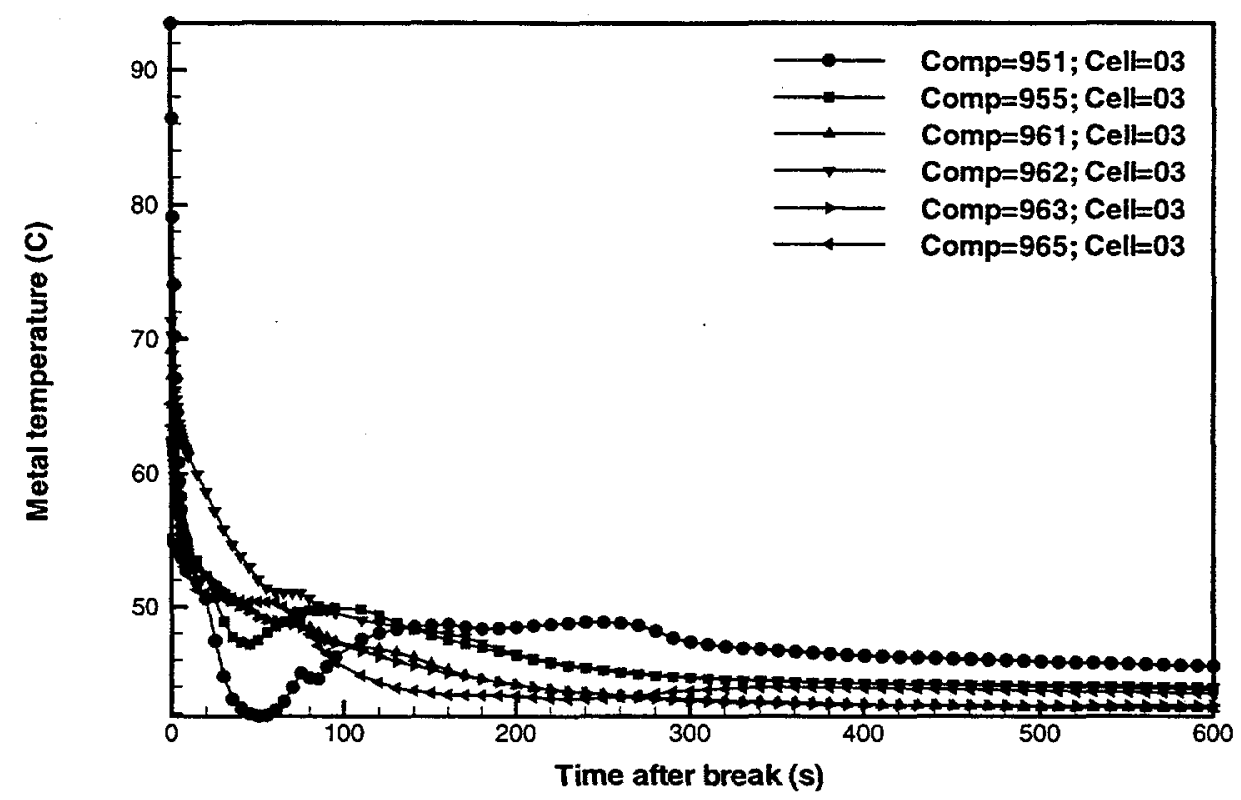

Figure B-44b Metal temperatures for various module outer aluminum surfaces at their mid-plane for a LOCA (Case 1: external HR break near inlet header). 


\section{Appendix C: TRAC Standard Input File for LOCA Case 1 (with Beam Shutdown and Active RHR)}

The file listed below represents the TRAC code "tracin" file that corresponds to the LOCA Case 1 (with beam shutdown and active RHR) for the blanket system. This input deck assumes that a TRAC restart file ("trcrst") exists based on normal operation (NO).

\section{Input file tracin:}

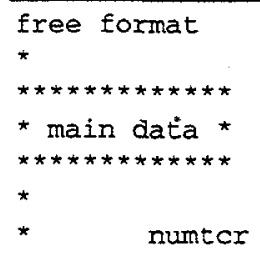

37 ieos

0 inopt

1 nmat

2 id20

0

* APT Lumped Blanket Model **** Component 65 Break ****

6 Module Lumped Model with Primary Coolant Loop and RHR Loop

6 Modules - Lateral (RI/Dec) Module, R2/R3 Module,

3 Backstop Modules, Low Power Module (12/18/1997)

Hydraulic RHR Loop added as of $12 / 22 / 1997$

- This is based on check valve with flow reversal control logic.

Number of material $=2$ ( $\mathrm{Al}$ and $\mathrm{Pb}$ )

- This is single combined mod model without He comp (12/12/1997)

- Aluminum, lead material table got from Ref. (3/5, 1997)

- This is 1 module loop model without prmary coolant and RHR loops

- adding two upper modules (L14B-back / L14F-front) as of 7/18/1997.

- Row2/3 power updated (4/23/1997).

- R2/R3 axial power distribution has been upaated as of $4 / 25 / 1997$.

- Al and lead material properties updated already.

- Unit cell cal. should be checked.

- K-loss values for each comp and elevation levels need be checked.

- Control signal variable was added (4/25/1997).

- Module 5678 connection to fixed header was updated $(5 / 28 / 97)$.

- Blanket primary loop pipe size (14 inch) was updated (5/28/1997).

- Lower modules (module 151517 18) were added/updated (5/29/1997).

- Backstop 1st module was updated (5/29/1997).

- Backstop 2nd and 3rd modules were updated (5/30/1997).

- R2/R3 lateral modules were updated from 9 to 11 bins $(6 / 3 / 1997)$.

- Lateral module 1 to 4 decay powers were updated (6/23/1997).

- Power for each module was updated from the 6/9/97 e-mail except for snout and top modules $(6 / 26 / 97)$.

- Decay power fraction for each module was updated from the $6 / 9 / 97$ e-mail except for snout and top modules $(6 / 26 / 97)$.

- Power for each module was updated from the 6/9/97 e-mail for snout module $(7 / 8 / 97)$.

- Decay power fraction for each module was updated from the 6/9/97 e-mail for snout module $(7 / 8 / 97)$.

- Single loop to connect two front lateral modules was updated (7/16/97).

- Single loop to connect two back lateral modules was updated $(7 / 16 / 97)$. 


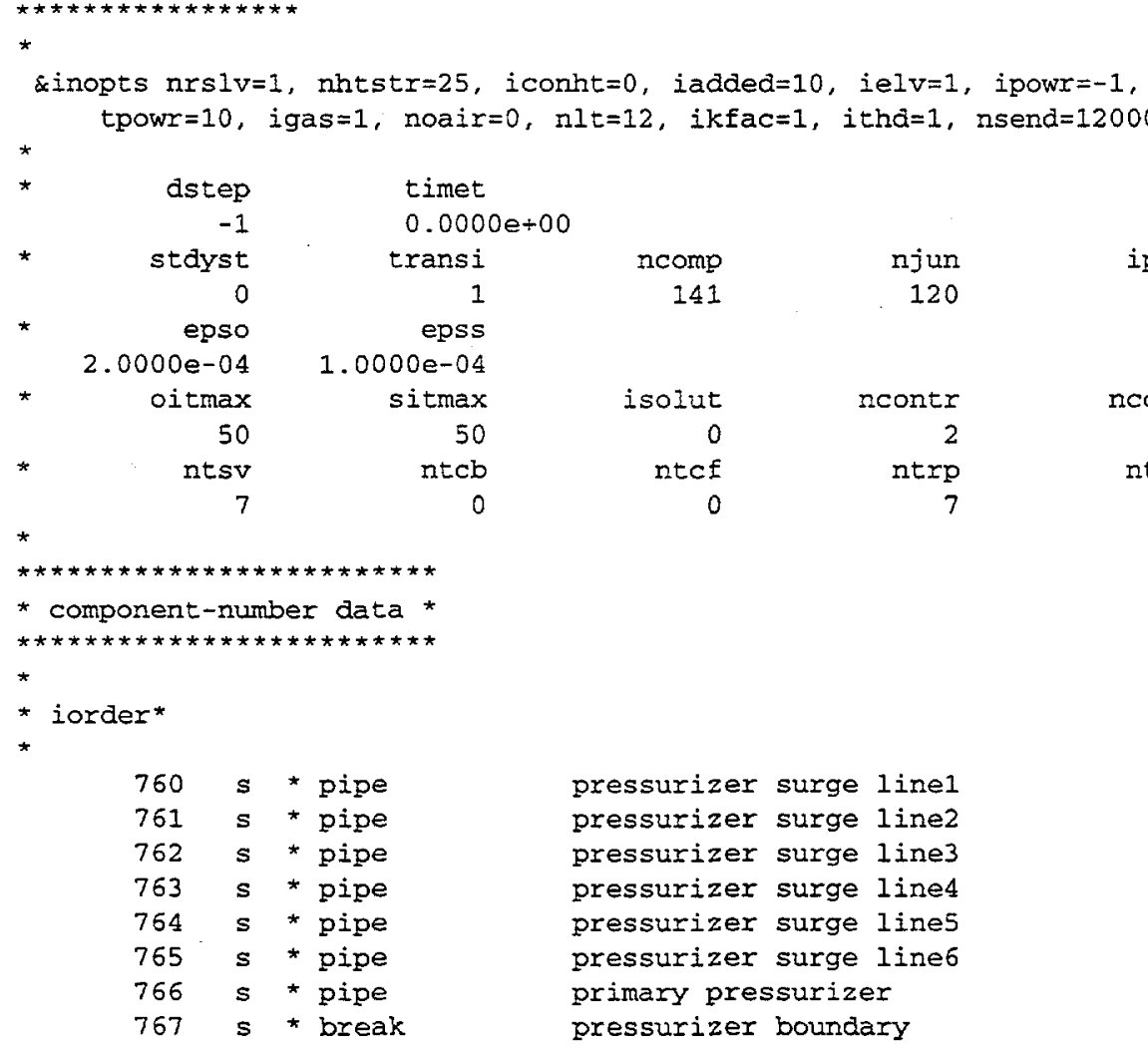

\begin{tabular}{|c|c|c|}
\hline 760 & $\mathbf{s}$ & * \\
\hline 761 & $\mathbf{s}$ & * \\
\hline 762 & $s$ & * \\
\hline 763 & $\mathbf{s}$ & * \\
\hline 754 & $\mathbf{s}$ & * \\
\hline 765 & $\mathbf{s}$ & * \\
\hline 766 & $\mathbf{s}$ & * \\
\hline 767 & $s$ & - \\
\hline
\end{tabular}

pxessurizer surge linel pressurizer surge line2 pressurizer surge line3 pressurizer surge line4 pressurizer surge lines pressurizer surge line6 primary pressurizer pressurizer boundary

$\operatorname{necfi}$

* HR hot leg

$$
\begin{aligned}
& 20 \text { s * pipe } \\
& 21 \text { s * plenum } \\
& 22 \text { s * pipe } \\
& 23 \text { s * pipe } \\
& 24 \text { s * pipe } \\
& 25 \text { s * pipe } \\
& \text { s * pipe } \\
& 27 \text {.s * plenum } \\
& 28 \text { s * pipe } \\
& 30 \mathrm{~s} \text { * pump } \\
& 32 \mathrm{~s} \text { * pipe } \\
& 29 \text { s * pipe } \\
& 31 \mathrm{~s} \text { * pump } \\
& 33 \text { s * pipe }
\end{aligned}
$$

* HR pumps

* HR pump-to-hx piping

$$
\begin{array}{ll}
36 & \mathbf{s} \text { * pipe } \\
37 & \mathbf{s} \text { * pipe } \\
38 & \mathbf{s} \text { * pipe }
\end{array}
$$$$
\text { * HR hx's }
$$

$\begin{array}{ll}40 & \mathrm{~s} \text { * plenum } \\ 48 & \mathrm{~s} \text { * pipe } \\ 50 & \mathrm{~s} \text { * pipe } \\ 52 & \mathrm{~s} \text { * pipe } \\ 54 & \mathrm{~s} \text { * pipe } \\ 56 & \mathrm{~s} \text { * pipe } \\ 49 & \mathrm{~s} \text { * pipe } \\ 51 & \mathrm{~s} \text { * pipe } \\ 53 & \mathrm{~s} \text { * pipe }\end{array}$

IRR pump suction pipe HR pump suction pipe (bic) HR pump suction pipe IR pump suction pipe (bk) HR pump suction pipe HR pump suction pipe (bk) HR pump suction pipe

HR pump suction plenum HR pump \#1 inlet pipe HR pump \#1

HR pump \#1 outlet pipe HR pump \#2 inlet pipe HR pump \#2

HR pump \#2 outlet pipe HR pump discharge plenum

HR pump dicharge pipe HR pump dicharge pipe (bk) HR pump dicharge pipe

$\mathrm{HR}$ hx inlet plenum $\mathrm{HR}$ hx 1 inlet pipe HR $h \times 1$ tubes 1 st pass HR hx 1 mid-header HR $h x 1$ tubes 2 nd pass HR hx 1 outlet pipe HR hx 2 inlet pipe HR hx 2 tubes 1st pass $\mathrm{HR}$ hx 2 mid-header 


\begin{tabular}{|c|c|c|c|}
\hline & 55 & $s$ & * pipe \\
\hline & 57 & s & * pipe \\
\hline & 60 & s & * ple \\
\hline $\mathrm{HR}$ & $\operatorname{cold} I$ & & \\
\hline & 62 & $s$ & * pipe \\
\hline & 63 & $s$ & * pipe \\
\hline & 64 & s & * pipe \\
\hline Com & ponent & $65:$ & is \\
\hline & 515 & $s$ & $\star 1$ \\
\hline & 516 & $\mathbf{s}$ & * \\
\hline & & & \\
\hline & 66 & $s$ & * pipe \\
\hline & 67 & $s$ & * pl \\
\hline & 68 & $s$ & * pipe \\
\hline * HR & hx Sec & ndar & ary side \\
\hline & 710 & $\mathbf{s}$ & * fill \\
\hline & 711 & s & * pipe \\
\hline & 712 & s & * pipe \\
\hline & 713 & $s$ & * pipe \\
\hline & 714 & $\mathbf{s}$ & * brea \\
\hline & 730 & s & * fill \\
\hline & 731 & $s$ & * pipe \\
\hline & 732 & s & * pipe \\
\hline & 733 & $\mathbf{s}$ & * pipe \\
\hline & 734 & s & $*$ \\
\hline 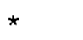 & & & \\
\hline & 621 & s & * pipe \\
\hline & 623 & $\mathbf{s}$ & * pipe \\
\hline & 624 & $s$ & * pipe \\
\hline & 625 & $s$ & * pipe \\
\hline & 630 & $s$ & * pump \\
\hline & 640 & $s$ & al \\
\hline & 652 & $s$ & $\star$ \\
\hline & 660 & $\mathbf{s}$ & * pipe \\
\hline & 661 & $s$ & $*$ \\
\hline & 662 & s & 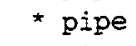 \\
\hline & & s & \\
\hline
\end{tabular}

* RHR hx Secondary Side $6725 *$ t $5 i 13$

671 s * pipe $673 \mathrm{~s}$ * break

$300 s$ * pipe

330 s * plenum

$335 \mathrm{~s}$ * pipe

$340 \mathrm{~s} *$ plenum

$350 \mathrm{~s}$ * plenum

$360 s$ * pipe

$370 \mathrm{~s} *$ plenum

375 s * pipe

$380 \mathrm{~s} *$ plenum

429 s * pipe

$454 \mathrm{~s}$ * pipe

173 s * pipe

$172 \mathrm{~s} *$ plenum

158 s * pipe

$147 \mathrm{~s} *$ plenum

$102 s$ * pipe

$133 \mathrm{~s}$ * pienum

136 s * pipe
$H R$ hx 2 tubes 2nd pass

HR hx 2 outlet pipe

HR hx outlet plenum

HR $h x$ discharge pipe

HR hx discharge pipe (bk)

HR hx discharge pipe

HX-1 sec. break

$\mathrm{EX}-1$ sec. break

HR hx discharge pipe

HR $h x$ discharge pipe (bk)

HR hx discharge pipe

HR hx Secondary Side-I

HR hx Secondary side-1

HR hx Secondary Side-1

HR $h x$ Secondary Side-1

HR hx Secondary Side-1

HR hx Secondary Side-2

HR hx secondary Side-2

HR hx Secondary Side-2

HR $h x$ Secondary side-2

HR hx Secondary Side-2

RHR hot leg sect 1 (bk)

RHR hot leg sect 2

RHR hot leg sect 3 (bk)

RHR hot leg sect 4

RHR primary pump

RHR pump discharge valve

RHR primary heat exchanger tubes

RHR cold leg sect 1

RHR cold leg sect 2 (bk)

RHR cold leg sect 3

RHR cold leg sect 4 (bk)

RHR $h x$ Secondary side

RHR $h x$ secondary side

RHR hx Secondary side

I1 Blanket Row1

L1 Blanket Row1 Plenum

I1 pipe conn. $330-340$

Il outlet header

Il lower plenum

II decouplex

L1 decoupler upper plenum

L1 pipe conn. $370-380$

L1 inlet header

L1 connect hot header-tee

L1 connect cold header-tee

L1 Blanket Row1

L1 Blanket Row1 Plenum

L1 pipe conn. $330-340$

I1 outlet header

Il lower plenum

Il decoupler

Il decoupler upper plenum 


\begin{tabular}{|c|c|c|c|}
\hline 541 & $s$ & $\star$ & pipe \\
\hline 538 & $\mathbf{s}$ & & plenum \\
\hline 535 & $\mathbf{s}$ & ^ & pipe \\
\hline 531 & s & $x$ & plenum \\
\hline 528 & $s$ & * & pipe \\
\hline 536 & $s$ & $\star$ & plenum \\
\hline 539 & s & * & pipe \\
\hline 15 & $\mathbf{s}$ & * & pipe \\
\hline 479 & $s$ & * & plenum \\
\hline 478 & $s$ & ๘ & pipe \\
\hline 418 & $\mathbf{s}$ & $\star$ & plenum \\
\hline 409 & s & * & pipe \\
\hline 423 & $\mathbf{s}$ & $\star$ & plenum \\
\hline 417 & $s$ & * & pipe \\
\hline 485 & $\mathbf{s}$ & t & pipe \\
\hline 489 & $\mathbf{s}$ & * & plenum \\
\hline 480 & $\mathbf{s}$ & * & pipe \\
\hline 419 & $\mathbf{s}$ & * & plenum \\
\hline 412 & $\mathbf{s}$ & * & pipe \\
\hline 483 & $\mathbf{s}$ & ^ & plenum \\
\hline 484 & $\mathbf{s}$ & ఓ & pipe \\
\hline 513 & $s$ & & pipe \\
\hline 510 & s & & plenum \\
\hline 507 & $s$ & & pipe \\
\hline 503 & $\mathbf{s}$ & * & plenum \\
\hline 500 & $s$ & & pipe \\
\hline 508 & $s$ & & plenum \\
\hline 511 & $s$ & * & pipe \\
\hline
\end{tabular}

$901 s *$ rod

$951 \mathrm{~s}$ * rod

984 s * roo

$905 s *$ rod

$955 \mathrm{~s}$ * rod

$916 \mathrm{~s}$ * $\operatorname{rod}$

$966 \mathrm{~s}$ * rod

$915 \mathrm{~s} * \operatorname{rod}$

$965 \mathrm{~s} * \operatorname{rod}$

$911 \mathrm{~s}$ * $\operatorname{rod}$

$961 \mathrm{~s}$ * rod

$988 \mathrm{~s}$ * rod

$912 \mathrm{~s}$ * $\operatorname{rod}$

$962 \mathrm{~s}$ * rod

931 s * rod

978 s * rod

$913 \mathrm{~s} * \operatorname{rod}$

$963 \mathrm{~s}$ * rod

$932 \mathrm{~s} * \operatorname{rod}$

979 s * rod

$919 s * \operatorname{rod}$

$920 \mathrm{~s}$ * rod

$921 \mathrm{~s} * \operatorname{rod}$

$922 \mathrm{~s}$ * rod
L1 Blanket Row1

Il Blanket Row1 Plenum

L1 pipe conn. $330-340$

L1 outlet header

Ll lower plenum

il decoupler

L1 decoupler upper plenum

L1 Blanket Row1

L1 Blanket Rowl Plenum

L1 pipe conn. $330-340$

L1 outlet header

L1 lower plenum

L1 decoupler

L1 decoupler upper plenum

2nd DNS Blanket Row1

2nd DNS Blanket Row1 Plenum

2nd DNS pipe conn. 330 - 340

2nd DNS outlet header

2nd DNS lower plenum

2nd DNS decoupler

2nd DNS dec upper plenum

Third DNS Blanket Rowl

Third DNS Rowl Plenum

Third DNS pipe conn. 330-340

Third DNS outlet header

Third DNS lower plenum

Third DNS decoupler

Third DNS dec upper plenum

annular aluminum rod cylindrical lead rod cylindrical lead rod

annular aluminum rod cylinarical lead rod cylinarical lead rod cylindrical lead rod

annular aluminum rod cylindrical lead rod

annular aluminum rod cylindrical lead rod cylindrical lead rod

annular aluminum rod cylindrical lead rod cylindrical lead rod cylinarical lead rod

annular aluminum rod cylindrical lead rod cylindrical lead rod cylindrical lead rod

annular ss rod annular ss rod annular ss rod annular ss rod 
$971 e * \operatorname{rod}$

*

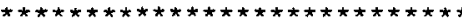

* material-properties data *

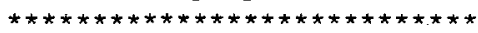

*

* matb *

* ptoln *

51

2

* lead material

*

* $\quad \operatorname{prptb}(1, i) \quad \operatorname{prptb}(2, i)$

$2.7300 e+02 \quad 1.1374 e+04$

$1.0000 e+10 \quad 1.1374 e+04$

e

*

* aluminum material

* $\operatorname{prptb}(1, i)$

$2.7300 \mathrm{e}+02$

$3.0000 e+02$

$\operatorname{prptb}(2, i)$

$2.6990 e+03$

$2.6990 e+03$

$3.7300 e+02$

$4.7300 e+02$

$2.6990 e+03$

$6.7300 e+02$

1. $0000 e+10$

$2.6990 e+03$

$2.6990 e+03$

$2.6990 e+03$

e

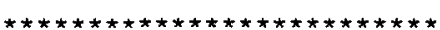

;

* CSS data

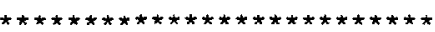

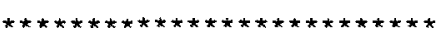

* control-parameter data *

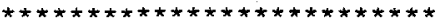

*

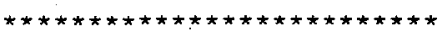

* signal variables

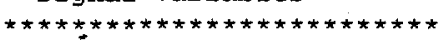

*

* time

idsv isva

1

isvn

ilcn

0

* pressure difference across RHR check valve

* idsv isvn ilcn

$2 \quad-21 \quad 640$

* Elapse.time since RHR pump activated * iasv

isvn

ilcn

3

0

0

* Elapse time since HR pumps activated

* idsv

isvm

ilcn

4

0

0

* pressure difference across HR check valve

* idsv isvm ilcn 5

$-21$

ilen
32 prptb $(4, i)$

$3.4592 e+01$

$3.3382 e+01$

prptb (5, i)

2. $8000 e-01$

$2.8000 e-01$ $\operatorname{prptb}(4, i)$

$2.1046 e+02$

$2.1046 e+02$

$2.1046 e+02$

$2.2175 e+02$

$2.2845 e+02$

$2.3000 \mathrm{e}+02$ prptb $(5, i)$

5.0000e-02

5.0000 e- 02

5.0000e-02

$5.0000 e-02$

$5.0000 e-02$

5. 0000 e- 02

icn 1

icn2

0

0

icnl

icn2

2

icn 1

icn2

0

0

icn 1

icn2

0

0

icn 1

icn2

1 
* pressure difference across HR check valve

* idsv isvn ilcn

Page:

* pressure, cold leg at plenum, component 761

$\begin{array}{cccrr}\text { * } & & & \\ \text { idsv } & \text { isvn } & \text { ilcn } & \text { icnl } & \text { icn2 } \\ 7 & 21 & 761 & 1 & 1\end{array}$

* control-block data *

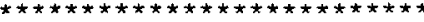

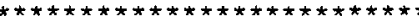

* trips

$* * * * * * * * * * * * * * * * * * * * * * * * * *$

* trips from off to on at time given by setp $(2)$, fill BC ntse ntct ntsf ntap isrt iatp 101

setp (1)

$$
\text { setp (2) }
$$

$0.0000 e+00$

setp (2)

atsp (1)

1. $0000 e-04$

dtsp (2)

$0.0000 e+00$

$0.0000 e+00$

ifsp (1)

ifsp (2)

* trips from on to off at time given by setp (2)

* idt

102

setp $(1)$

$0.0000 e+00$

$\operatorname{dtsp}(1)$

$0.0000 e+00$

ifsp (1)

iste

iset

iset

itst

ntsd

0

idsg$$
\operatorname{setp}(2)
$$

$1.0000 \mathrm{e}+04$

atsp (2)

$0.0000 e+00$

ifsp (2)

* trips from off to on at time given by setp(2), trips RHR check valve

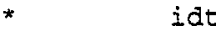
idtp

$\operatorname{setp}(1)$

$0.0000 e+00$

$\operatorname{atsp}(1)$

$0.0000 e+00$

* ifsp (1)

isrt

iset

itst

idsg

setp (2)

$1.0000 e-04$

dtsp (2)

$0.0000 e+00$

ifsp (2)

* trips from off to on when the cold leg 1 press. drops below setp(1)

* trips power in bundles, heat structures

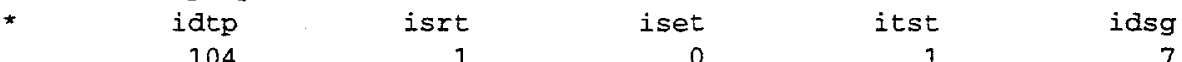

1

0

1

7

* $\operatorname{setp}(1)$

$6.8745 e+05$

$\operatorname{atsp}(1)$

2. 0000 e-01

ifsp (1)

setp (2)

$6.8745 e+05$

atsp (2)

2. 0000 e-01

ifsp (2)

*

* trips from off to on at setp(2), starts RHR pump.

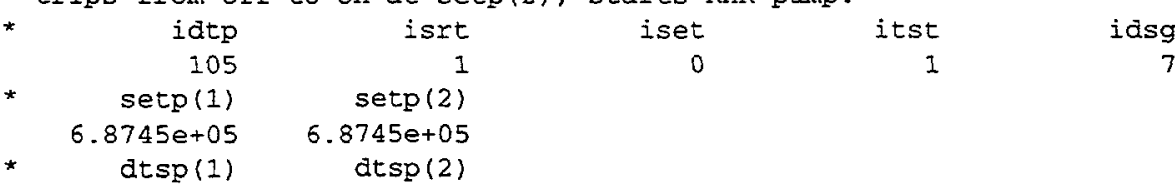




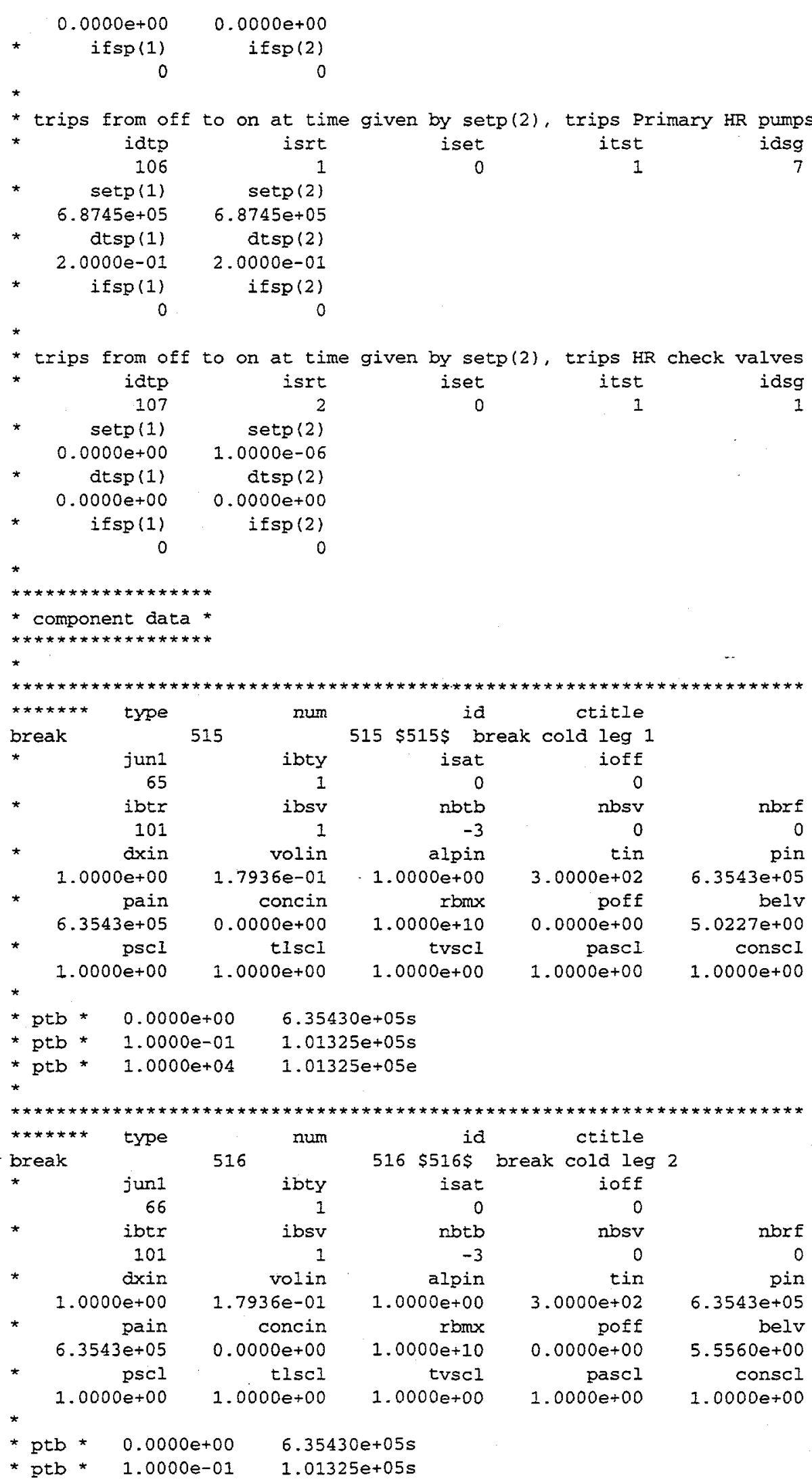


* ptb* $1.0000 e+04 \quad 1.01325 e+05 e$

*

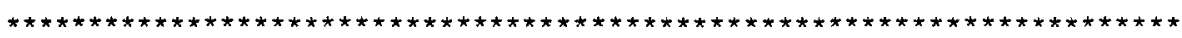

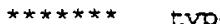

fil

* $\quad \begin{array}{r}\text { jun } 1 \\ 767\end{array}$

num

id

ctitle

767

$767 \$ 767 \$$ pressurizer boundary

* twtola

ifty

ioff

2

$0.0000 e+00$

$r f m x$

* dxin

1. $0000 e+20$

volin

1. $0000 e+00$

1. $8639 e-02$

pin

pain

$6.6679 e+05$

$6.6679 e+05$

concin

$0.0000 e+00$

alpin

1. $0000 \mathrm{e}+00$

Elowin

$0.0000 e+00$

I. felv

1. $1100 e+01$

vlin

$0.0000 e+00$

vrin

$0.0000 e+00$

$3.1315 e+02$

tvin

*

end

*

$\star * \star \star * * * * * \star * \star * * * * * * *$

* time-step data *

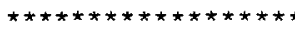

* atmin

1. 0000 e-07

dtmax

1. $0000 \mathrm{e}-03$

gfint

tend

edint

$5.0000 e+00$

$2.0000 e-02$

dmpint

1. $0000 e^{-01}$

1. $0000 e+06$

1.000

rtwfp

$3.1315 e+02$

* dtmin

atmax

1. $0000 e-07$

5. $0000 e-03$

gfint

$5.0000 e-01$

$5.0000 e+00$

1. $0000 \mathrm{e}+01$

dmpint

1. $0000 e+06$

* dtmi

1.0000e-07

atmax

* edint

1. 0000 e-02

gfint

$5.0000 e+00$

$5.0000 e+00$

1. $0000 e+02$

dmpint

$1.0000 e+06$

* dtmin

1.0000e- 07

* edint

dtmax

$5.0000 e-02$

gfint

$6.0000 e+02$

ampint

5. $0000 e+00$

$1.0000 e+06$

$00 e+06$

$\star$

endflag

$-1.0000 \mathrm{e}+00$ 


\section{Appendix D: TRAC Graphics Input File for LOCA Case 1 (with Beam Shutdown and Active RHR)}

The file listed below represents the TRAC code "graphin" file that corresponds to the LOCA Case 1 (with beam shutdown and active RHR) for the blanket system. This input deck contains the various graphics points selected for output to the "tecsum.grf" file.

Input file graphin:

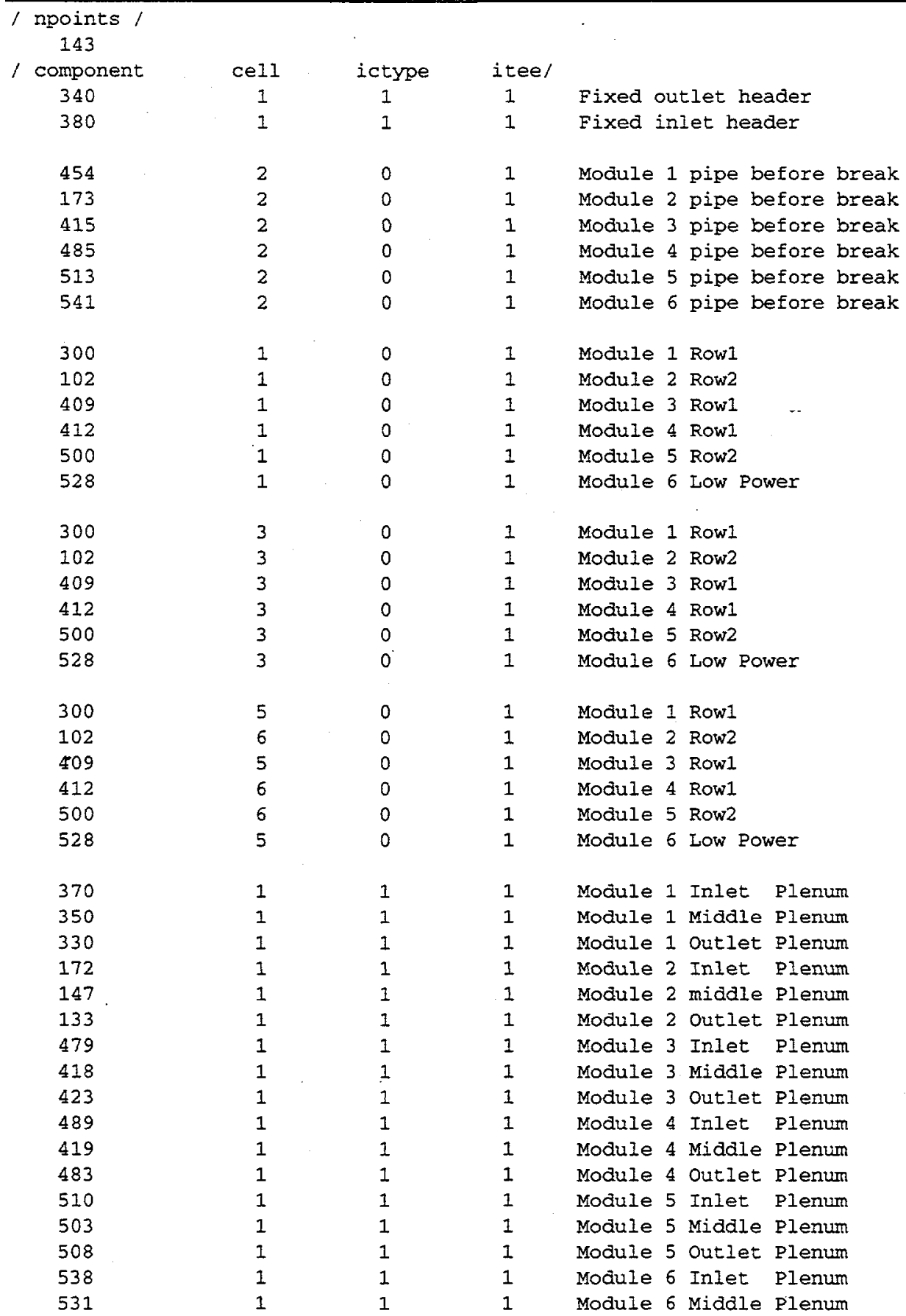




$$
536
$$$$
26
$$$$
22
$$$$
20
$$

\section{1}

1

7

1

1

2

1

2

2

2

1

3

2

1

2

3.

$\leq$

1

$\begin{array}{ll}1 & 1\end{array}$

Module 6 outlet Plenum

Hot leg pump suction line

Hot leg pump suction line near break Hot leg pump suction line near break

PCL Pump 1 Suction

PCL Pump 1 Discharge

PCL Pump 2 Suction

PCL Pump 2 Discharge

PCL Pump 1 check valve

PCL Pump 2 check valve

PCL Pump to $\mathrm{HX}$

PCI Ex 1 inlet

PCL HX 1 midale

PCL Hx 1 outlet

PCL Hix 2 inlet

PCL Hx 2 middle

PCL Hx 2 outlet

PCL Hx 1 secondary side outlet

PCL HX 1 secondary side inlet fill

PCL Hx 2 secondary side outlet

PCL HX 2 secondary side inlet fill

Cold leg $\mathrm{Hx}$ discharge line

Cold leg $\mathrm{Hx}$ discharge line near break

Cold leg Hx discharge line near break

RHR Pump Suction

RHR Pump Discharge

RHR Hx inlet

RHR HX outlet

RHR Hx secondary side outlet

RHR HX secondary side inlet fill

Pzr Pressure Signal

Pzr Bottom Pressure

Pzr Bottom Pressure

Pzr Bottom Pressure

Hot Module (1) upflow inside Hot Module (1) upflow inside Hot Module (1) upflow inside Hot Module (1) upflow outside Hot Module (1) upflow outside Hot Module (1) upflow outside Hot Module (2) upflow inside Hot Module (2) upflow inside Hot Module (2) upflow inside Hot Module (2) upflow outside Hot Madule (2) upflow outside Hot Module (2) upflow outside Hot Module (3) upflow inside Hot Module (3) upflow inside Hot Module (3) upflow outside Hot Module (3) upflow outside Hot Module (3) upflow outside Hot Module (3) upflow outside 


$\begin{array}{llll}962 & 1 & 3 & 1 \\ 962 & 3 & 3 & 1 \\ 962 & 6 & 3 & 2 \\ 962 & 1 & 3 & 2 \\ 962 & 3 & 3 & 2 \\ 962 & 6 & 3 & 1 \\ 963 & 1 & 3 & 1 \\ 963 & 3 & 3 & 2 \\ 963 & 6 & 3 & 1 \\ 963 & 1 & 3 & 1 \\ 963 & 3 & 3 & 1 \\ 963 & 6 & 3 & 2 \\ 965 & 1 & 3 & 2 \\ 965 & 3 & 3 & 2 \\ 965 & 5 & 3 & \end{array}$
Hot Module (4) upflow inside Hot Module (4) upflow inside Hot Module (4) upflow outside Hot Module (4) upflow outside Hot Module (4) upflow outside Hot Module (5) upflow inside Hot Module (5) upflow inside Hot Module (5) upflow inside Hot Module (5) upflow outside Hot Module (5) upflow outside Hot Module (5) upflow outside Hot Module (6) upflow inside Hot Module (6) upflow inside Hot Module (6) upflow inside Hot Module (6) upflow outside Hot Module (6) upflow outside Hot Module (6) upflow outside

984

984

984

901

901

901

916

916

916

905

905

905

988

988

988

911

911

911

931

931

931

912

912

912

932

932

932

913

913

913

\begin{abstract}
Module 1 downflow AI 1 Module 1 downflow AI 3 Module I downflow AI 5 Module 1 upflow Al 1 Module 1 upflow AI 3 Module 1 upflow Al 5 Module 2 downflow Al 1 Module 2 downflow A1 3 Module 2 downflow AI 6 Module 2 upflow AI 1 Module 2 upflow Al 3 Module 2 upflow Al 6 Module 3 downflow Al 1 Module 3 downflow Al 3 Module 3 downflow AI 5 Module 3 upflow AI 1 Module 3 upflow Al 3 Module 3 upflow Al 5 Module 4 downflow AI 1 Module 4 downflow Al 3 Module 4 downflow AI 6 Module 4 upflow Al 1 Module 4 upflow Al 3 Module 4 upflow Al 6 Module 5 downflow Al 1 Module 5 downflow Al 3 Module 5 downflow Al 6 Module 5 upflow Al 1 Module 5 upflow Al 3 Module 5 upflow Al 6
\end{abstract}

INPUT NOTES :

npoints - number of locations (points) within TRAC model graphics requested component - component id number containing specified graph point cell - cell number with in component where graphics requested ictype - type of component:

10 for fill, pipe, pressurizer, pump, tee, turb, value) (1 for plenum)

OUTPUT NOTES: 
WESTINGHOUSE SAVANNAH RIVER COMPANY

BLANKET SAFETY ANALYSES FOR LOCA

(CASE 1: EXTERNAL HR BREAK NEAR INLET HEADER)
Report:

Section:

Date:

Page:
WSRC-TR-98-0059

Appendix D

$07 / 13 / 98$

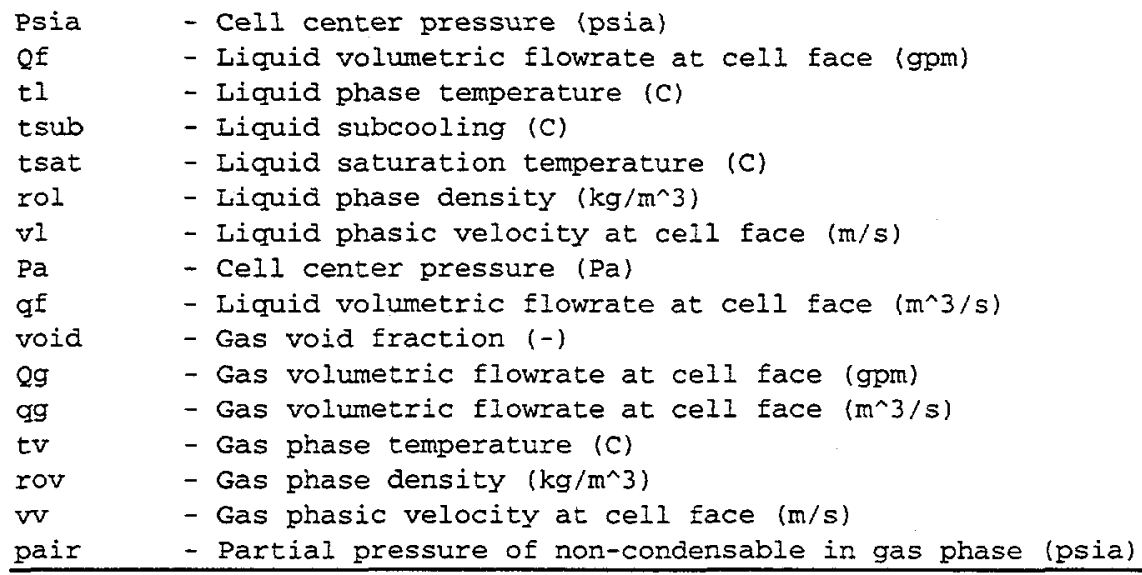




\section{Appendix E: FLOWTRAN-TF Input File for LOCA Case 1 (with Beam Shutdown and Active RHR)}

Below is an abridged listing of the FLOWTRAN-TF input deck for LOCA Case 1. The finite element input of the solid geometric parameters used in the heat conduction calculations and the fluid geometry input are identical to the values given in Ref. [6] and have been edited from this listing to save space.

\section{Input file apt.in:}

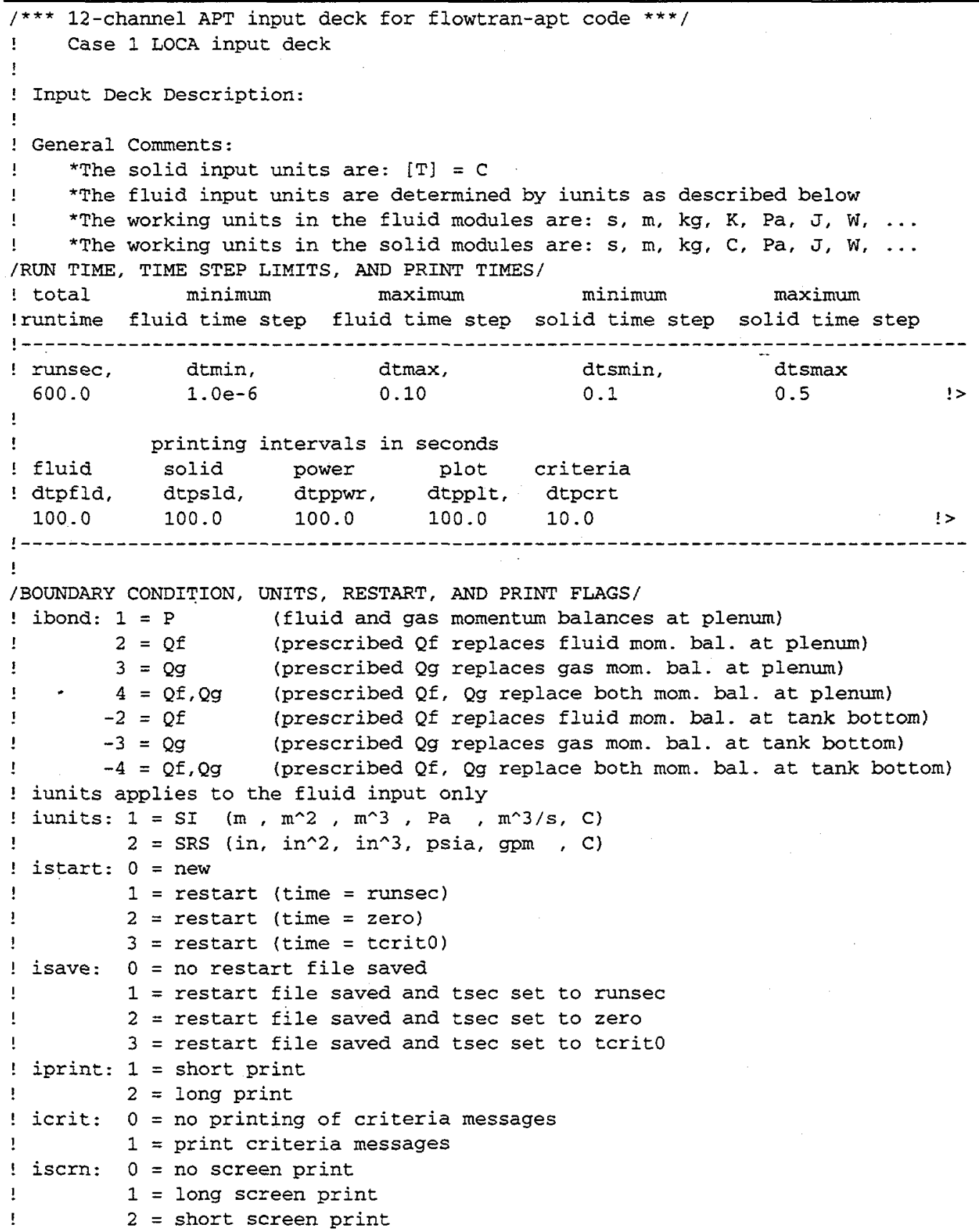




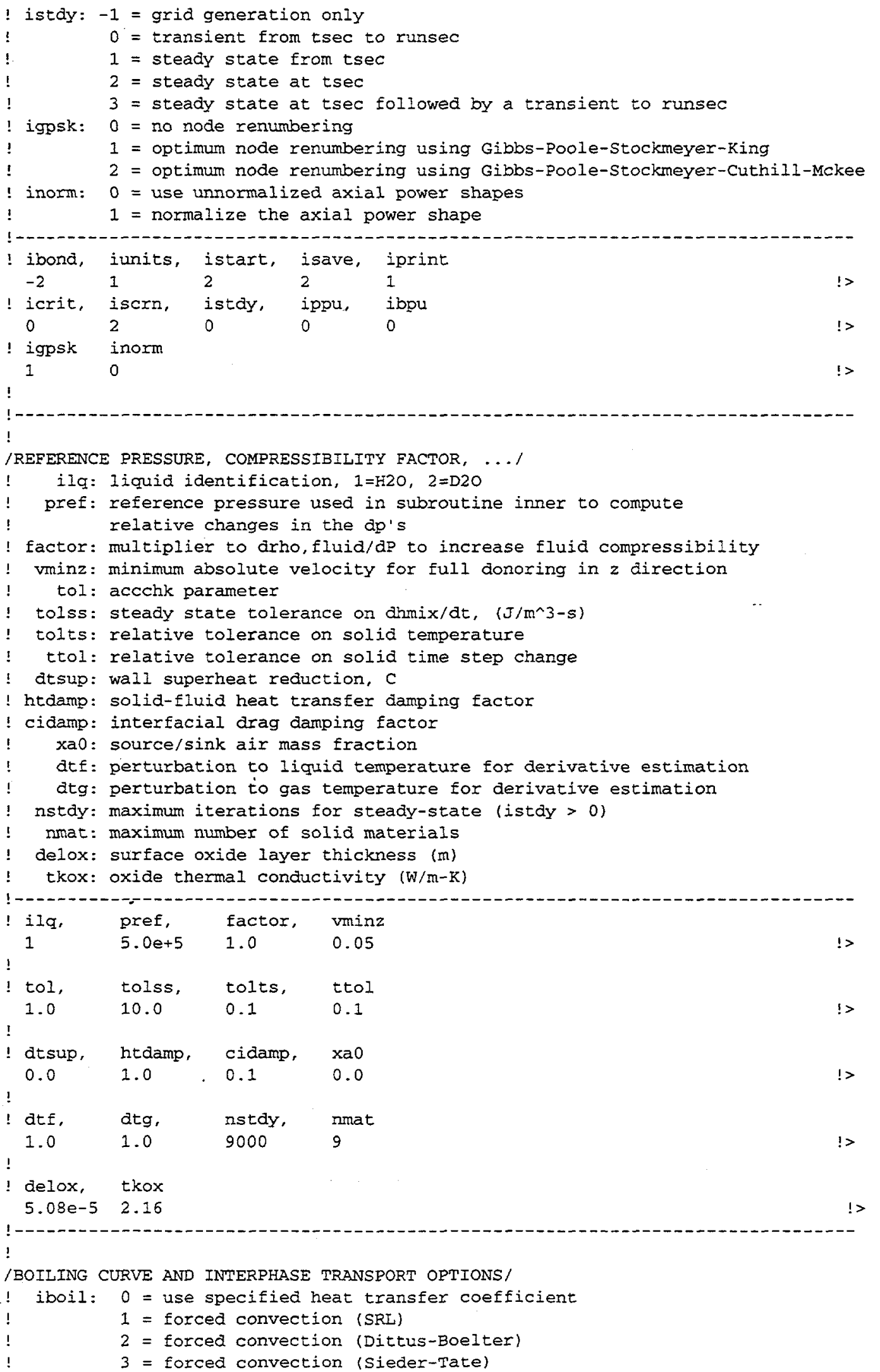




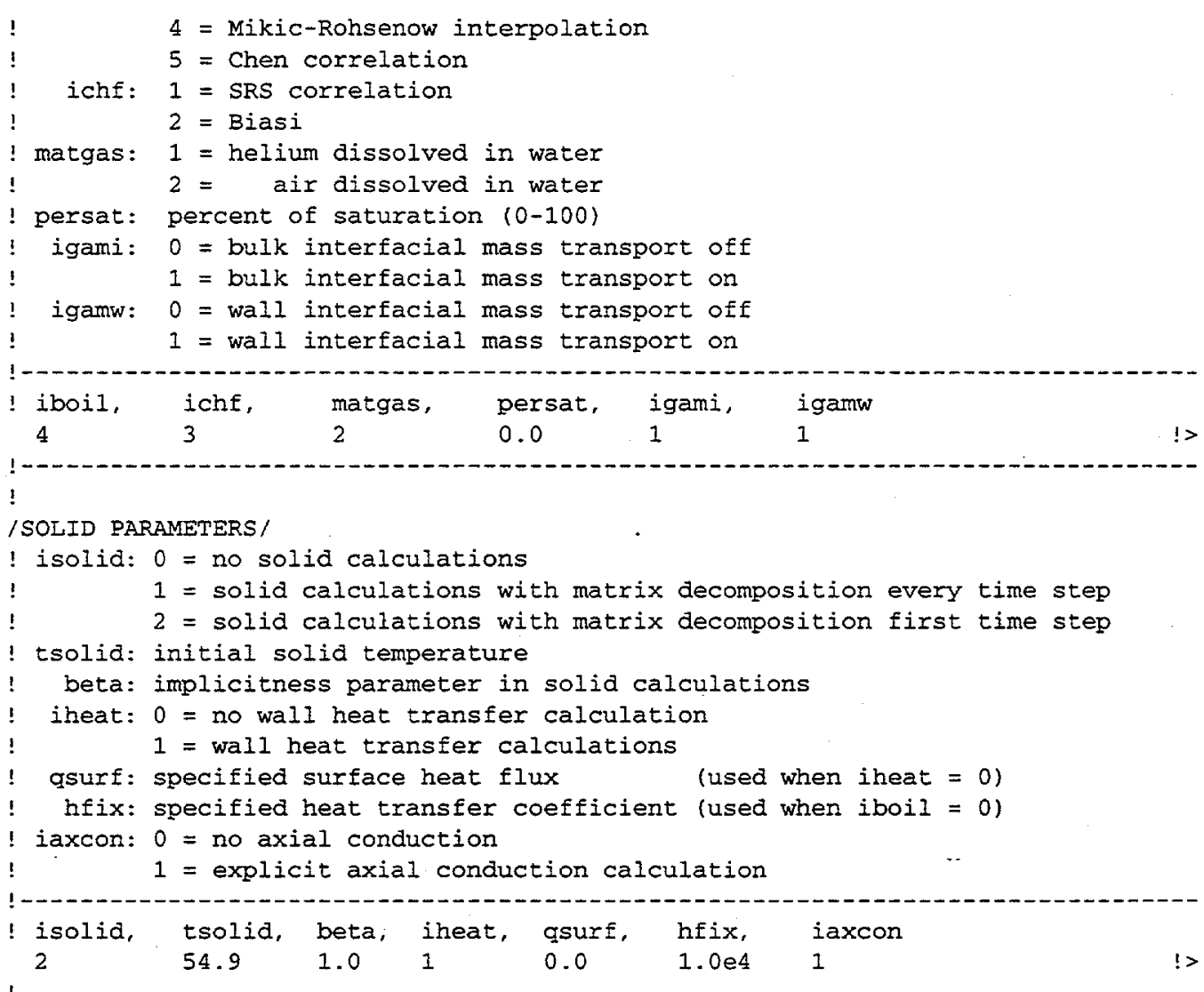

/INNER ITERATION OPTIONS \& NEWTON ITERATION PARAMETERS/

! irebal: $0=$ no coarse mesh rebalance

$1=$ coarse mesh rebalance on first pass

2 = coarse mesh rebalance on each pass

ncmr: number of coarse mesh rebalances when irebal $=1$ or 2

epsin: inner iteration convergence criterion for relative dp error

initmx: max. number of inner iterations allowed

epsp: newton iteration convergence criterion for absolute $p$ error in $\mathrm{Pa}$

epsalp: newton iteration convergence criterion for absolute alp error

epstg: newton iteration convergence criterion for absolute tg error in $\mathrm{K}$

epstf: newton iteration convergence criterion for absolute tf error in $\mathrm{k}$

epsxa: newton iteration convergence criterion for absolute xa error

nitmax: $\mid$ nitmax $\mid=\max$. number of newton iterations allowed

If nitmax is positive and |nitmax| iterations are reached, then

then computations continue using the mth iterate values from the

|nitmax| iteration.

If nitmax is negative and |nitmax| iterations are reached, then

a new time step with a time step reduction is requested.

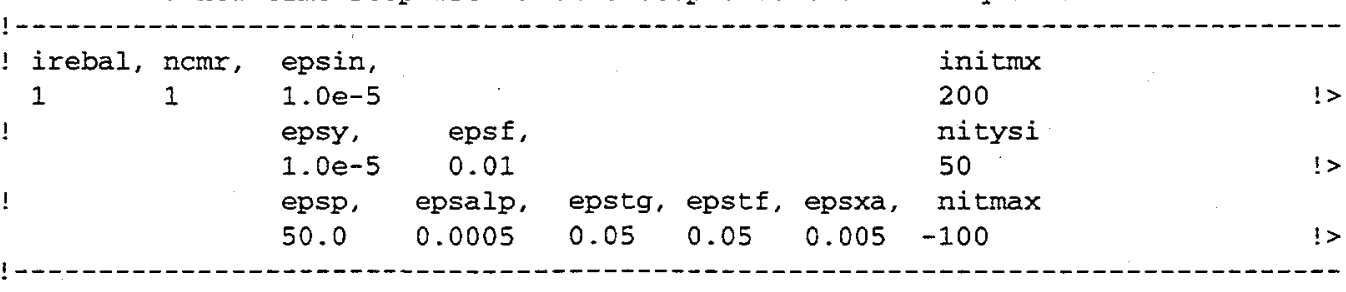

!

/NUMBER OF SPLINE PROFILES AND DATA POINTS/

! ndata: number of data groups 


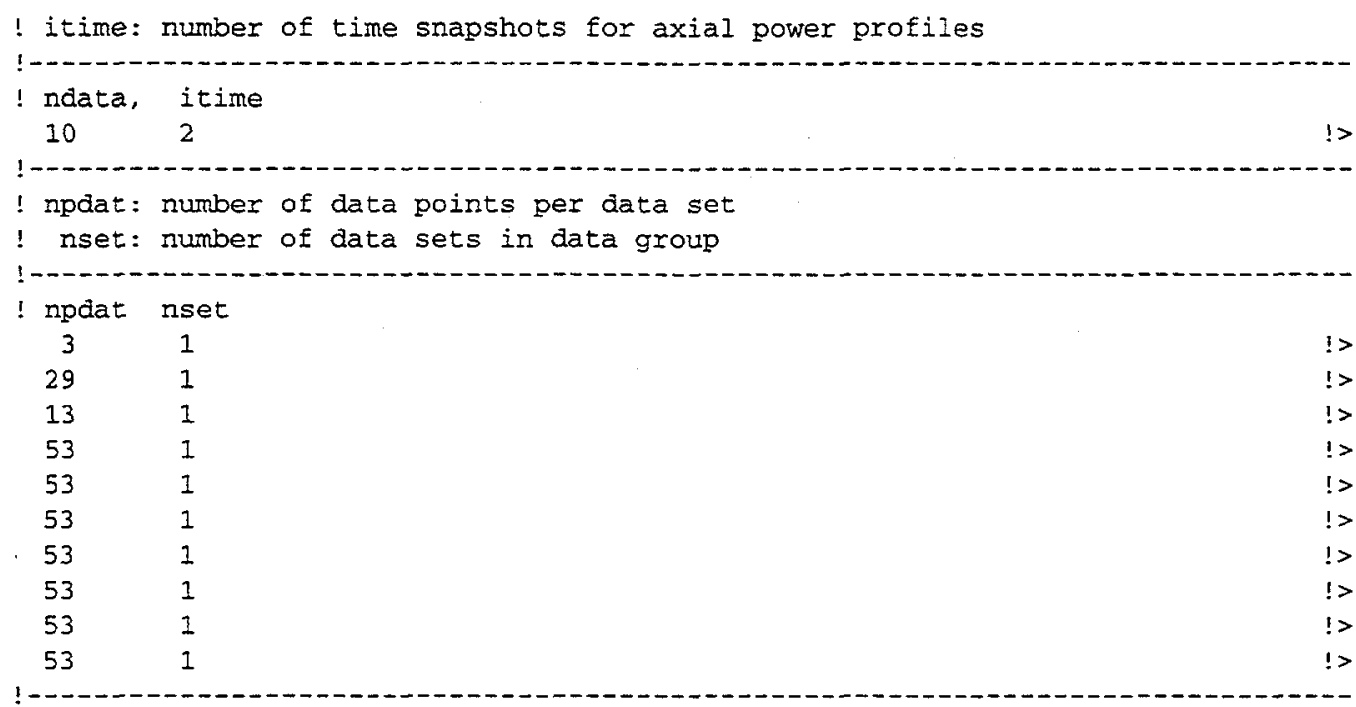

/GEOMETRIC DIMENSIONS:/

nchn: number of flow channels

nzt: number of top section axial cells $(>=2)$

$\mathrm{nz}$ : number of middle section axial cell layers $(>=3)$

$\mathrm{nzb}$ : number of bottom section axial cells $(>=2)$

nchn, nzt, nz, nzb

$12 \quad 2 \quad 20 \quad 2$

/POWER ITERATION INPUT/

power: initial power in $\mathrm{kW}$

maxpi: maximum number of power iterations

! tolpow: tolerance on power limit

! ncrit: number of criteria used to check for power limit

!--

! power, maxpi, tolpow, ncrit

$\begin{array}{lllll}61.5 & 1 & 0.005 & 8 & \text { !> }\end{array}$

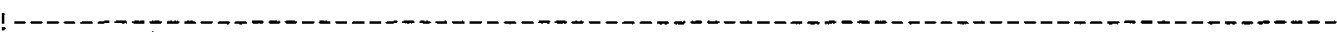

$!$

SENSITIVITY VARIABLES INPUT SECTION

/SENSITIVITY PARAMETERS/

! cizfac: axial interfacial drag multiplying factor

! xcofh, xreh, xcofl, xrel, xkmet, xcunet

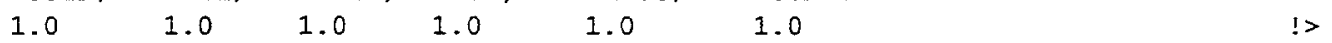

xhfi, xhgi, xkgi, xphi

$1.0 \quad 1.0 \quad 1.0-1.0$

! cizfac xfric, plnht, cipln, formhs, alphs

$\begin{array}{lllllll}1.0 & 1.0 & 8.75 & 1.0 & 5.382 & 0.05 & !>\end{array}$

! alb2, als2, ala2, expbs, expsa

$\begin{array}{llllll}0.25 & 0.52 & 0.75 & 4.0 & 4.0 & \text { 1> }\end{array}$

! INPUT FOR SOLID FINITE ELEMENT CALCULATIONS 
Solid mesh input for finite element regions, nodes and side boundary conditions is identical to that shown in reference [6].

FLUID GEOMETRY AND MOMENTUM CLOSURE INPUT SECTION

Fluid geometry input is identical to that shown in reference [6].

/BOUNDARY CONDITION INPUT SECTION/

/OUTLET PLENUM (TOP)/

ppl0: multiplier to P transient profile

ippl: $P$ transient identifier

alpplo: multiplier to alpha transient profile

ialpl: alpha transient identifier

tfpl0: multiplier to Tf transient profile

itfpl: Tf transient identifier

tgp 10: multiplier to Tg transient profile

itgp 1: Tg transient identifier

xap10: multiplier to Xa transient profile

ixapl: Xa transient identifier

pplo, ippl

$584133.9 \quad 8 \quad$ !>

! alpplo, ialpl

$1.0 \quad 10 \quad$ !>

! tf010, itfpl

$59.85 \quad 9 \quad$ !>

! tgp10, itgpl

$59.85 \quad 9 \quad$ !>

! xapl0, ixapl

$0.0 \quad 1 \quad !>$

!

/INLET PLENUM (BOTTOM)/

ptbo: multiplier to $P$ transient profile

iptb: $P$ transient identifier

alptbo: multiplier to alpha transient profile

ialtb: alpha transient identifier

tftbo: multiplier to Tf transient profile

itftb: Tf transient identifier

tgtbo: multiplier to Tg transient profile

itgtb: Tg transient identifier

xatbo: multiplier to $x a$ transient profile

ixatb: Xa transient identifier

! ptbo, iptb

685997.155

! alptbo, ialtb

$1.0 \quad 7 \quad$ !> 


$\begin{array}{lll}\text { tftbo, } & \text { itftb } & \\ 53.05 & 6 & \text { !> } \\ \text { !gtbo, } & \text { itgtb } & \\ 53.05 & 6 & \text { !> } \\ \text { xatbo, } & \text { ixatb } & \\ 0.0 & 1 & !>\end{array}$

\section{/INLET FLOW DATA/}

! The following inlet flow data is always used to initialize

! axial velocities and will also be used to define the

! appropriate prescribed flowrate for $t>0$ if ibond $=2$, 3 , or 4 .

! gfino: multiplier to Qf transient profile

! iqfin: Qf transient identifier

! qgino: mültiplier to $\mathrm{gg}$ transient profile

! iqgin: Qg transient identifier

! gfino = Nominal APT total flow 12 half channels, , transient

! qfino, iqfin

$\begin{array}{lll}-1.508 e-3 & 4 \\ \text { ggino, } & \text { iggin } & \end{array}$

! qgino, iqgin

$0.0 \quad 1 \quad$ ! >

!

/INITIAL CONDITION INPUT SECTION/

! If iseto $>0$ then initial conditions are

! input for fluid parameters at each axial level

! iseto

$$
0
$$

/CRITERIA CHECKING FLAGS AND PEAKING FACTORS/

ICRITERIA CHECKING FLAGS AND PEAKING FACTORS/

$\begin{array}{lrrrrrrrrr}\text { ! checking flags for criteria } & \# 1 & \# 2 & \# 3 & \# 4 & \# 5 & \# 6 & \# 7 & \# 8 & \\ & 0 & 0 & 0 & 0 & 0 & 0 & 0 & 0 & 1> \\ \text { ! peaking factors for criteria } & \# 1 & \# 2 & \# 3 & \# 4 & \# 5 & \# 6 & \# 7 & \# 8 & \\ & 1.0 & 1.0 & 1.0 & 1.0 & 1.0 & 1.0 & 1.0 & 1.0 & 1>\end{array}$

/CRITERIA CHECKING TIME/

! time to begin criteria checking, sec

! tcrito

$$
0.0
$$

!>

1

! POWER INPUT

$!$

/POWER PROFILE SPIINE POINTERS/

! DECAY HEAT TRANSIENT

3 !>

!

/AXIAL SPLINE POINTERS AND TIMES/

$$
\begin{array}{llll}
2 & 0.0 & 2 & 600.00
\end{array}
$$

/TRANSIENT DATA SET INPUT SECTION/

$!$

/DATA SET NUMBER $1 /$

! enter data set label below

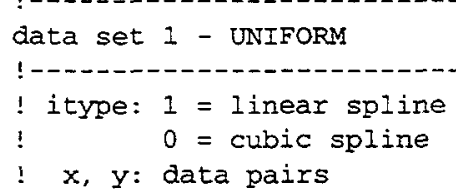




$\begin{array}{rll} & \text { itype } & \\ 1 & !> \\ x(\text { ipt }), & y(\text { ipt }) & \text { ipt=1,npts } \\ 0.0 & 1.0 & !> \\ 60.0 & 1.0 & !> \\ 600.0 & 1.0 & !>\end{array}$

/DATA SET NUMBER 2/

data set 2 - NON-UNIFORM AXIAL POWER PROFILE

! itype

1

! $x$ (ipt), $y(i p t)$

$0.00 \quad 0.032$

$0.10 \quad 0.043$

$0.20 \quad 0.049$

$0.30 \quad 0.074$

$0.40 \quad 0.093$

$0.50 \quad 0.124$

$0.60 \quad 0.165$

$0.70 \quad 0.217$

$0.80 \quad 0.317$

$0.90 \quad 0.508$

$1.00 \quad 0.943$

$1.10 \quad 1.446$

$1.20 \quad 1.658$

$1.30 \quad 1.754$

$1.40 \quad 1.783$

$1.50 \quad 1.827$

$1.60 \quad 1.870$

$1.70 \quad 1.881$

$1.80 \quad 1.915$

$1.90 \quad 1.915$

$2.00 \quad 1.887$

$2.10 \quad 1.864$

$2.20 \quad 1.790$

$2.30 \quad 1.660$

$2.40 \quad 1.423$

$2.50 \quad 0.932$

$2.60 \quad 0.506$

$2.70 \quad 0.313$

$2.80 \quad 0.229$

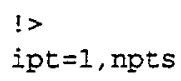

! -

data set 3 - DECAY POWER CURVE $(+1$ second time delay)

! itype

$1 \quad !>$

! $x$ (ipt), $y(i p t) \quad$ ipt $=1$, npts

$0.00 \quad 1.000000000 E+00$

$1.00 \quad 1.000000000 E+00$

$1.01 \quad 1.298500039 \mathrm{E}-02$

$2.00 \quad 9.929999709 E-03$

$3.00 \quad 8.652999997 \mathrm{E}-03$

$6.00 \quad 7.736000232 \mathrm{E}-03$

$11.00 \quad 7.573999930 \mathrm{E}-03$

$21.00 \quad 7.437000051 \mathrm{E}-03$

$61.00 \quad 7.073000073 E-03$

$121.00 \quad 6.672000047 \mathrm{E}-03$ 


$\begin{array}{rr}301.00 & 5.936999805 E-03 \\ 601.00 & 5.392999854 E-03 \\ 1201.00 & 4.968000110 E-03\end{array}$

IDATA SET NUMBER 4 /

data set 4 - COOLANT FLOW TRANSIENT

! itype

$$
1
$$

! $x(i p t)$,

$$
0.00 \quad 1.00000 E+00
$$

$0.52 \quad 7.37075 E-01$

$1.02 \quad 5.72705 E-01$

$1.52 \quad 4.40728 \mathrm{E}-01$

$2.02 \quad 3.63497 \mathrm{E}-01$

$2.52 \quad 3.06184 \mathrm{E}-01$

$3.02 \quad 2.61426 \mathrm{E}-01$

$3.52 \quad 2.03020 E-01$

$4.02 \quad 1.79780 \mathrm{E}-01$

$4.52 \quad 1.59863 \mathrm{E}-01$

$5.02 \quad 1.30665 \mathrm{E}-01$

$5.52 \quad 1.25023 E-01$

$6.02 \quad 1.29952 \mathrm{E}-01$

$6.521 .33560 \mathrm{E}-01$

$7.02 \quad 1.36582 \mathrm{E}-01$

$7.52 \quad 1.37488 \mathrm{E}-01$

$8.02 \quad 1.34386 \mathrm{E}-01$

$8.52 \quad 1.29507 \mathrm{E}-01$

$9.02 \quad 1.31412 \mathrm{E}-01$

$9.53 \quad 1.26434 \mathrm{E}-01$

$20.01 \quad 2.64245 \mathrm{E}-01$

$30.01 \quad 2.86157 E-01$

$40.02 \quad 2.71281 E-01$

$50.02 \quad 1.89285 \mathrm{E}-01$

$60.02 \quad 1.08393 \mathrm{E}-01$

$70.02 \quad 4.13263 \mathrm{E}-02$

$80.02-1.12396 E-01$

$90.03 \quad 1.49038 \mathrm{E}-03$

$120.00 \quad 1.74915 \mathrm{E}-02$

140.04 . $2.20894 \mathrm{E}-02$

$160.06 \quad 1.73916 \mathrm{E}-02$

$180.07 \quad 3.28674 E-02$

$200.09 \quad 3.25850 \mathrm{E}-02$

$220.10 \quad 3.76668 \mathrm{E}-02$

$240.14 \quad 3.70127 \mathrm{E}-02$

$260.14 \quad 3.74400 \mathrm{E}-02$

$280.17 \quad 3.57250 \mathrm{E}-02$

$300.19 \quad 3.34945 \mathrm{E}-02$

$320.23 \quad 3.50223 \mathrm{E}-02$

$340.26 \quad 3.58246 \mathrm{E}-02$

$360.29 \quad 3.80585 \mathrm{E}-02$

$380.31 \quad 3.48329 \mathrm{E}-02$

$400.34 \quad 3.07494 \mathrm{E}-02$

$420.35 \quad 3.13773 \mathrm{E}-02$

$440.36 \quad 3.58999 \mathrm{E}-02$

$460.37 \quad 3.79180 \mathrm{E}-02$

$480.39 .3 .86266 \mathrm{E}-02$

$500.42 \quad 3.91022 \mathrm{E}-02$

$520.46 \quad 3.89507 \mathrm{E}-02$

$540.48 \quad 3.92542 \mathrm{E}-02$

$560.49 \quad 3.69746 \mathrm{E}-02$ 
$580.51 \quad 3.91763 \mathrm{E}-02$

$600.03 \quad 4.03917 \mathrm{E}-02$

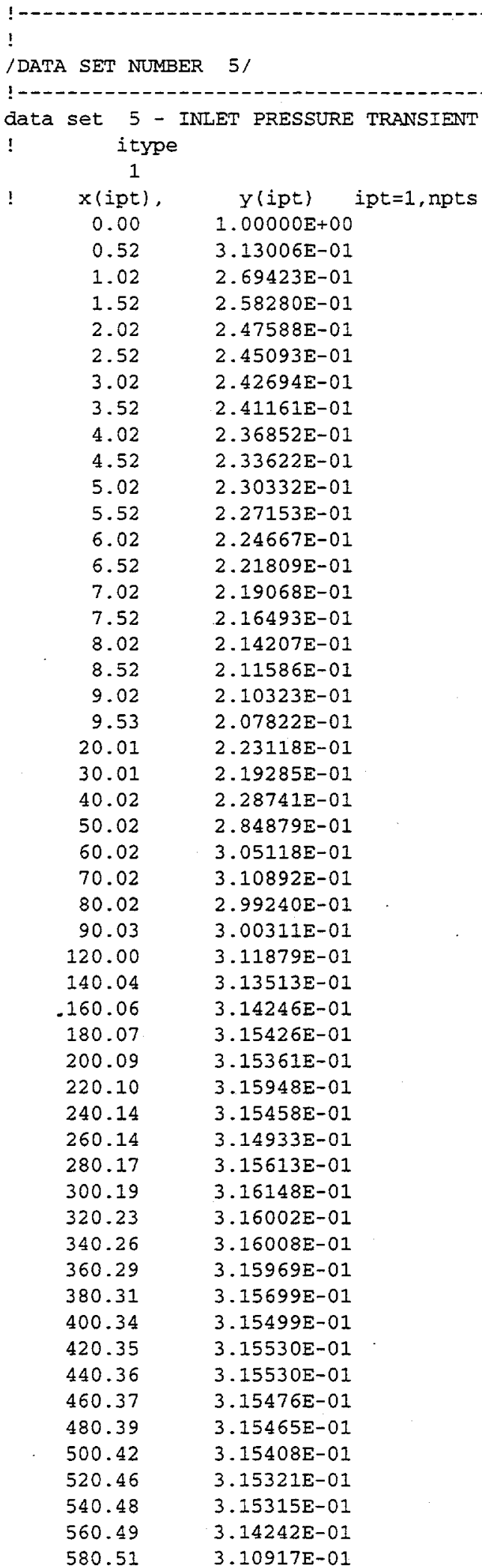


600.03

$3.08995 \mathrm{E}-01$

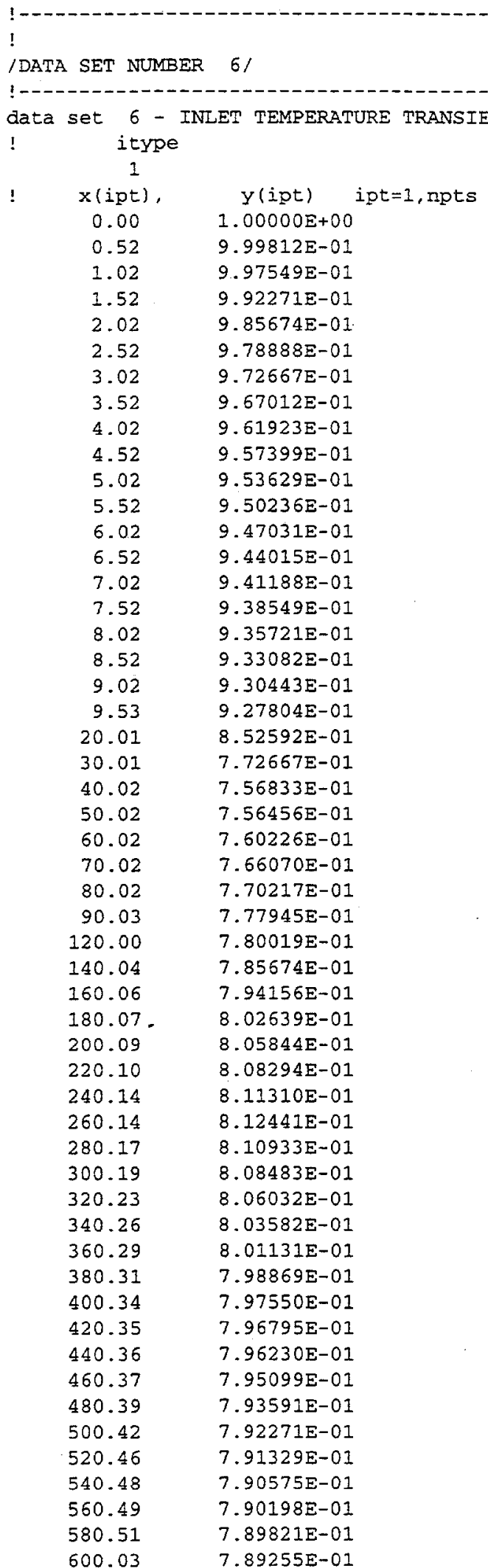




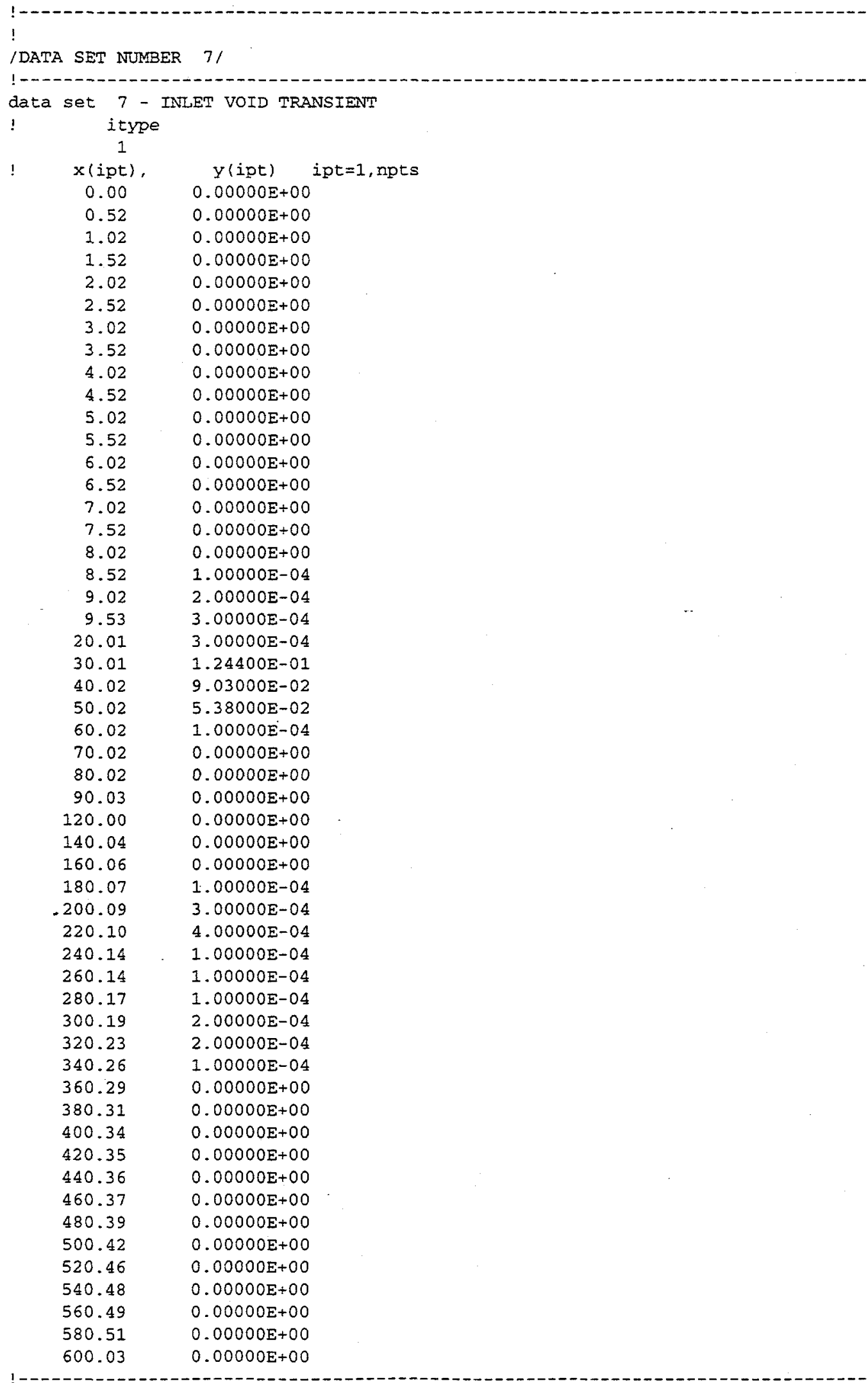


/DATA SET NUMBER $9 /$

data set 9 - OUTLET TEMPERATURE TRANSIENT

! itype

1
$x(i p t)$
0.00

$0.52 \quad 9.99833 E-01$

$1.02 \quad 9.98830 \mathrm{E}-01$

$1.52 \quad 9.95656 \mathrm{E}-01$

$2.02 \quad 9.91145 \mathrm{E}-01$

$2.52 \quad 9.85631 \mathrm{E}-01$

$3.02 \quad 9.79616 \mathrm{E}-01$

$3.52 \quad 9.72932 \mathrm{E}-01$

$4.02 \quad 9.65915 \mathrm{E}-01$

$4.52 \quad 9.58897 \mathrm{E}-01$

$5.02 \quad 9.51880 \mathrm{E}-01$

$5.52 \quad 9.44862 \mathrm{E}-01$

$6.02 \quad 9.38179 \mathrm{E}-01$

$6.529 .31830 \mathrm{E}-01$

$7.02 \quad 9.25815 \mathrm{E}-01$

$7.52 \quad 9.20134 \mathrm{E}-01$

$8.02 \quad 9.15121 \mathrm{E}-01$

$8.529 .10276 \mathrm{E}-01$

$9.02 \quad 9.06099 \mathrm{E}-01$

$9.53 \quad 9.02089 \mathrm{E}-01$

$20.01 \quad 8.45113 \mathrm{E}-01$

$30.01 \quad 7.36174 \mathrm{E}-01$

$40.02 \quad 6.83041 E-01$

$50.02 \quad 6.76692 \mathrm{E}-01$

$60.02 \quad 6.76859 \mathrm{E}-01$

$70.02 \quad 6.78363 \mathrm{E}-01$

$80.02 \quad 6.79198 \mathrm{E}-01$

$90.03 \quad 6.92063 \mathrm{E}-01$

$120.00 \quad 6.91395 \mathrm{E}-01$

$140.04 \quad 6.96909 \mathrm{E}-01$

$160.06 \quad 7.06266 \mathrm{E}-01$

$180.07 \quad 7.18630 \mathrm{E}-01$

$200.09 \quad 7.27151 \mathrm{E}-01$

$220.10 \quad 7.32665 \mathrm{E}-01$

$240.147 .35840 \mathrm{E}-01$

$260.14 \quad 3.37678 \mathrm{E}-01$

$280.17 \quad 7.38847 \mathrm{E}-01$

$300.19 \quad 7.39515 E-01$

$320.23 \quad 7.39348 \mathrm{E}-01$

$340.26 \quad 7.38346 \mathrm{E}-01$

$360.29 \quad 7.36174 \mathrm{E}-01$

$380.31 \quad 7.33667 E-01$

$400.34 \quad 7.31495 \mathrm{E}-01$

$420.35 \quad 7.29992 \mathrm{E}-01$

$440.36 \quad 7.28989 \mathrm{E}-01$

$460.37 \quad 7.27485 \mathrm{E}-01$

$480.39 \quad 7.25480 \mathrm{E}-01$

$500.42 \quad 7.23308 \mathrm{E}-01$

$520.46 \quad 7.21303 \mathrm{E}-01$

$540.48 \quad 7.19465 \mathrm{E}-01$

$560.49 \quad 7.18129 \mathrm{E}-01$

$580.51 \quad 7.17126 \mathrm{E}-01$

$600.03 \quad 7.16291 \mathrm{E}-01$

!

/DATA SET NUMBER 10/ 


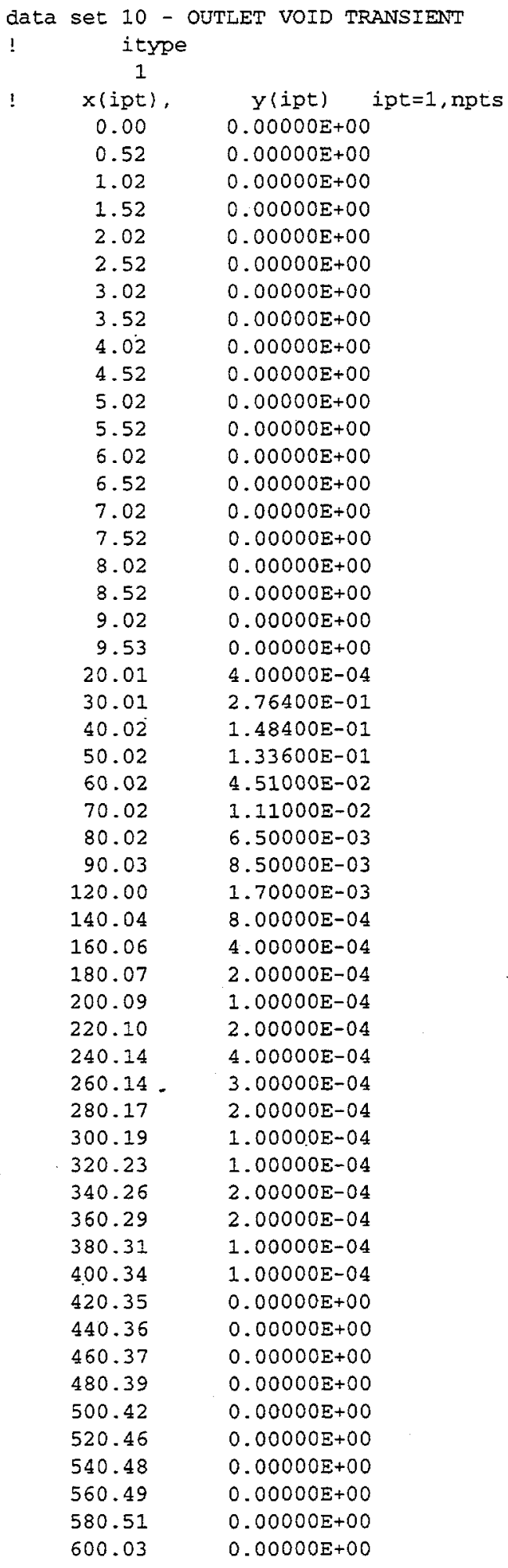

